\title{
O EFEITO DA MODERAÇÃO DA INOVAÇÃO FRUGAL SOBRE A ORIENTAÇÃO ESTRATÉGICA PARA ECO INOVAÇÃO E MANUFATURA VERDE EM PAÍSES EMERGENTES E DESENVOLVIDOS
}

Tese de Doutorado apresentada ao Programa de Mestrado e Doutorado em Administração do Centro Universitário FEI para a obtenção do título de Doutora em Administração.

Orientada pelo Prof. Dr. Roberto Carlos Bernardes 
Tarraço, Elisângela Lazarou.

$\mathrm{O}$ efeito da moderação da inovação frugal sobre a orientação estratégica para ecoinovação e manufatura verde em paises emergentes $\mathrm{e}$ desenvolvidos / Elisângela Lazarou Tarraço. São Paulo, 2020. 205 p. : il.

Tese - Centro Universitário FEI.

Orientador: Prof. Dr. Roberto Carlos Bernardes.

1. Inovação frugal. 2. Ecoinovação. 3. Manufatura verde. 4. Mercados emergentes. I. Bernardes, Roberto Carlos, orient. II. Título.

Elaborada pelo sistema de geração automática de ficha catalográfica da FEI com os dados fornecidos pelo(a) autor(a). 
centre

unimoraitario

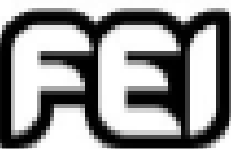

APRESENTACĀO DE TESE

ATA DA BANCA JULGADORA

Programa de Fós-Graduaço Stricto Sensu em Administraço

DOUTORADO FPGA-40

Aluno: Elsangela Lasaru Tarape

Matricula: 711701-3

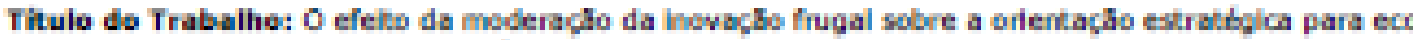

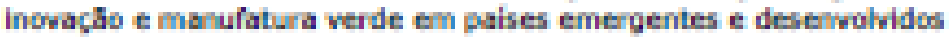

Area de Concentraçios Cestho da Inomaçbo

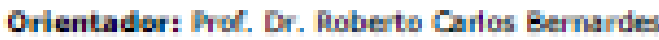

Dula da realiecho da defesa: $63 / 12 / 2020$.

Awaliaglio da Banca Examinadura:

PBIMLELASELEDA.

S.o Palo, $03 / 12 / 2000$.

\section{MEMELOS DA BANCA EXAHINADORA}

Prol. Dr. Boberta Carlos Bernardes

Ass.

Prol. Dr. Henrique Hachado Barres

Asth.:

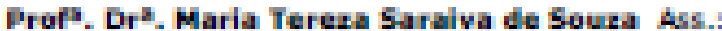

Pruf. Dr. Felipe Hendes Burini

Als.

Pruil. Dr. Glancarlo Gomes

Ahs

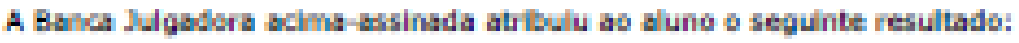

AMOWADO $\square \quad$ REPAONADO $\square$

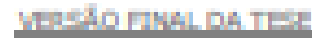

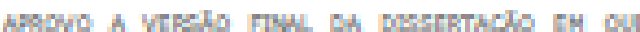

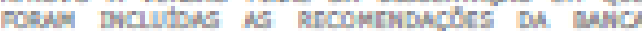
DUMBWESA

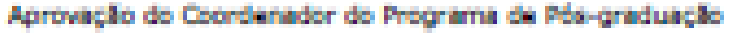

Prof. Di. Hanilue Hachads Barrob 
À minha filha Larissa Lazarou Tarraço, por ser presente, inspirar, compreender e me amar. 


\section{AGRADECIMENTOS}

Em um processo de construção de conhecimento, seja ele científico, seja sobre as nossas próprias limitações, todos os tipos de sentimentos estão presentes. Há paixão, motivação, alegria, curiosidade e satisfação; mas há também frustração, raiva, desânimo, desespero e tristeza. E, se nesse momento, chego à conclusão de uma trajetória, é porque muitas pessoas estiveram comigo, com apoio e palavras de incentivo.

Manifesto, então, a minha gratidão aos meus pais: Semprelina, a mulher mais resiliente e forte que conheço, e Athanassios, que resume todo o meu entendimento de perseverança e de uma vida pautada pelo trabalho justo e honesto.

Ao meu marido Júlio - meu porto seguro, amigo e companheiro de todas as horas -, que aceitou estar ao meu lado, mesmo diante das dificuldades que a minha decisão trouxe à nossa tranquila e confortável vida, para que eu pudesse realizar meu sonho.

À minha filha Larissa, hoje com 14 anos, que passou metade da sua vida aprendendo a lidar com o meu tempo dividido entre os livros, as orientações, as aulas e a escrita. Espero que, um dia, ela entenda o quanto tudo isso significou para nós.

Aos meus irmãos Stefanos, Helene, Elisabeth e Bruno, e ao meu sobrinho Giuseppe, por entenderem as minhas ausências e torcerem, cada um do seu jeito, para que eu vivesse essa experiência.

Agradeço ao meu orientador, Prof. Dr. Roberto Carlos Bernardes, pelas lições aprendidas, que ultrapassam o campo acadêmico. Ao longo do nosso convívio de sete anos, entendi um pouco mais sobre integridade, respeito, amizade, humildade e confiança. Sou grata pelas oportunidades, pelos conselhos e pelo tratamento humano e carinhoso a mim dispensado, sobretudo no que diz respeito às minhas limitações e dúvidas.

Ao meu coorientador, Prof. Dr. Felipe Borini, que, durante toda a caminhada, confiou em minha capacidade, dando lições únicas sobre a vida acadêmica e o amadurecimento do pesquisador. Espero um dia poder retribuir a generosidade e a disponibilidade a mim dedicadas.

Meu agradecimento ao Prof. Dr. Henrique Barros, coordenador do curso de PósGraduação do Centro Universitário da FEI, e um dos profissionais mais íntegros, transparentes e humanos que já conheci. Obrigada por me apoiar sempre, da forma como só os melhores amigos fazem.

Aos professores do Programa de Mestrado e Doutorado em Administração da FEI, pelo profissionalismo, por tamanha dedicação e pelo exemplo de como um bom pesquisador deve ser. 
À Carmem, por todo suporte administrativo na secretaria da FEI e, principalmente, pela amizade construída nas conversas em sua mesa.

À amiga Sabrina Della Santa Navarrete, pela companhia nos cafés, em manhãs, tardes, noites e finais de semana compartilhados para a discussão acerca da coleta dos dados e de estatísticas. Nossas conversas e a amizade construída fazem parte dos melhores momentos do doutorado. Espero que sejam muitos e bem-sucedidos os nossos artigos!

Aos amigos de doutorado: Marcio Lui, Annaysa Salvador, Daiane Ribeiro, Tarso Ramalho, Monica Sordi, e Suzi Ferreira Dias, obrigada pelas animadas conversas, por tantas trocas de conhecimento e inúmeras palavras de incentivo. Vocês fizeram toda a diferença entre avançar ou desistir frente a esse desafio, que agora está sendo vencido.

Minha gratidão e amor a dois amigos que, infelizmente, não estão mais neste plano terreno para comemorarmos: a colega de doutorado Melissa Galdino e o amigo advogado João Batista Bara. Melissa deixou sua tese por concluir e era exemplo de amor à docência; e meu caro João Bara, que fazia questão de ser chamado de "doutor", aguardava, ansioso, o momento de me também me chamar de "doutora".

Agradeço à Capes, pela concessão da bolsa de estudos, em parte para o mestrado e, no período integral, no doutorado. Tomara que outros possam ter as mesmas ou até melhores oportunidades de estudar e de realizar seus projetos de pesquisa.

Sou grata sempre a Deus, pela vida extraordinária e pela família amorosa e paciente que tenho. Por suas mãos, vieram amigos, professores, lições, alunos, instituições de ensino e oportunidades de conhecimento. 
"Alguns homens triunfam apenas enquanto dura o estímulo alheio. Outros triunfam apesar de tudo. Escolha." 


\section{RESUMO}

No contexto das estratégias de mobilização das capacidades das empresas e de governos para alcançar o crescimento econômico, diante da escassez de recursos e das pressões do ambiente institucional por produtos e processos ambientalmente conscientes, tem-se elevado a importância da inovação frugal - uma das soluções potenciais para o desenvolvimento sustentável. Estratégias empresariais orientadas para a inovação frugal, com a aplicação em processos produtivos, para resultados ambientais mais sustentáveis, necessitam de compreensão. Nesse sentido, este estudo objetiva validar o efeito da moderação da inovação frugal nas seguintes dimensões: (a) quanto maior a presença de inovações frugais nas organizações, maior a relação existente entre a orientação estratégica para a ecoinovação e a manufatura verde; e (b) se existem evidências de diferenças comportamentais entre países emergentes e desenvolvidos. Como objetivos específicos, busca-se verificar a influência: (a) das pressões institucionais de mercado e regulatórias, e da orientação estratégica para a ecoinovação, quanto maior a estratégia de inovação frugal na organização; (b) da relação entre a manufatura verde e o desempenho da organização, quanto maior a estratégia de inovação frugal; e (c) comparar os resultados das relações entre as pressões do ambiente institucional e a orientação estratégica para a ecoinovação, e entre a manufatura verde e o desempenho organizacional, nos mercados desenvolvidos e emergentes, quanto maior o efeito de moderação da inovação frugal. Para tanto, utilizou-se uma abordagem quantitativa, por meio do modelo de equações estruturais (PLS-SEM), para analisar 303 organizações do setor de manufatura, sendo 173, em países emergentes (Brasil e Índia), e 130 de países desenvolvidos (Alemanha e Estados Unidos da América). Como resultado, as organizações mais frugais têm maior relevância na relação entre a orientação estratégica para a ecoinovação e a manufatura verde, do que as menos frugais. Tal inovação, portanto, estabelece-se como um potencial alavanca para o desenvolvimento sustentável. Esse resultado também é encontrado na análise das organizações em países emergentes, nos quais a inovação frugal, mesmo sob um cenário de restrições, pode impulsionar os esforços voltados aos objetivos ambientais. Nos países desenvolvidos, em contrapartida, não há evidência de que esse efeito seja significativo para as organizações mais frugais. Este trabalho contribui, então, com a teoria acadêmica sobre o papel da estratégia de inovação frugal para o fortalecimento da relação entre a orientação estratégica, a ecoinovação e a manufatura verde, e confirma os estudos sobre a importância da inovação frugal para os mercados emergentes, como solução às limitações de recursos destinados às estratégias de sustentabilidade.

Palavras-chave: Inovação frugal. Ecoinovação. Manufatura verde. Mercados emergentes. 


\begin{abstract}
In the context of strategies to mobilize the capacities of companies and governments to achieve economic growth, given the scarcity of resources and the pressures of the institutional environment for environmentally conscious products and processes, the importance of frugal innovation has increased - one of the solutions potentials for sustainable development. Business strategies oriented towards frugal innovation, with application in production processes, for more sustainable environmental results, need understanding. In this sense, this study aims to validate the effect of moderating frugal innovation in the following dimensions: (a) the greater the presence of frugal innovations in organizations, the greater the relationship between the strategic orientation for eco-innovation and green manufacturing; and (b) whether there is evidence of behavioral differences between emerging and developed countries. As specific objectives, we seek to verify the influence: (a) institutional market and regulatory pressures, and the strategic orientation for eco-innovation, the greater the frugal innovation strategy in the organization; (b) the relationship between green manufacturing and the organization's performance, the greater the frugal innovation strategy; and (c) comparing the results of the relationships between the pressures of the institutional environment and the strategic orientation for eco-innovation, and between green manufacturing and organizational performance, in developed and emerging markets, the greater the moderating effect of frugal innovation. To do so, a quantitative approach was used, using the structural equation model (PLS-SEM), to analyze 303 organizations in the manufacturing sector, 173 in emerging countries (Brazil and India), and 130 in developed countries (Germany and the United States of America). As a result, the most frugal organizations have more relevance in the relationship between the strategic orientation for eco-innovation and green manufacturing, than the less frugal ones. Such innovation, therefore, establishes itself as a potential lever for sustainable development. This result is also found in the analysis of organizations in emerging countries, in which frugal innovation, even under a scenario of restrictions, can boost efforts aimed at environmental objectives. In developed countries, on the other hand, there is no evidence that this effect is significant for the most frugal organizations. This work, then, contributes with academic theory on the role of frugal innovation strategy for strengthening the relationship between strategic orientation, eco-innovation and green manufacturing, and confirms studies on the importance of frugal innovation for emerging markets, as a solution to the limitations of resources allocated to sustainability strategies.
\end{abstract}

Keywords: Frugal innovation. Eco innovation. Green manufaturing. Emerging markets. 


\section{LISTA DE FIGURAS}

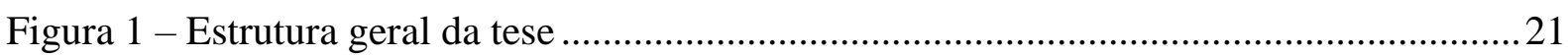

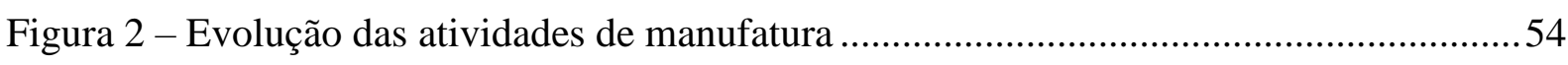

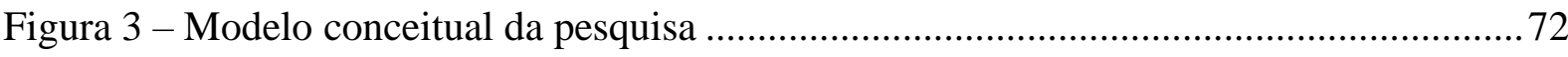

Figura 4 - Cronologia de publicações das referências utilizadas ........................................... 74

Figura 5 - Fonte de origem das referências bibliográficas.................................................. 75

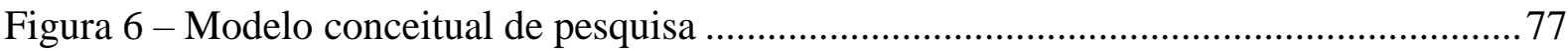

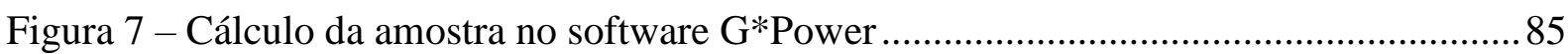

Figura 8 - Modelo final da amostra, desenvolvido com o efeito da moderação mais frugal.110

Figura 9 - Modelo final da amostra, desenvolvido com o efeito da moderação menos frugal 110

Figura 10 - Modelo final da amostra emergente, com o efeito da moderação mais frugal ...110 Figura 11 - Modelo final da amostra emergente, com o efeito da moderação menos frugal.111 Figura 12 - Modelo final da amostra total, com o efeito da moderação mais frugal .............111

Figura 13 - Modelo final da amostra total, com o efeito da moderação menos frugal ..........111 


\section{LISTA DE QUADROS}

Quadro 1 - Agenda de pesquisa da ecoinovação ................................................................ 31

Quadro 2 - Inovação frugal e ecoinovaçãa .................................................................... 45

Quadro 3 - Ecoinovação e dimensões da inovação frugal .................................................... 49

Quadro 4 - Relação entre manufatura verde e desempenho ..................................................57

Quadro 5 - Hipóteses do modelo teórico proposto …….......................................................... 70

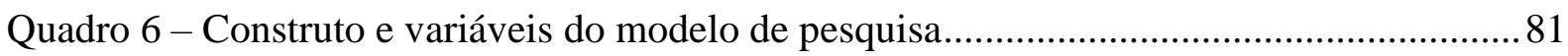

Quadro 7 - Resumo dos resultados das hipóteses ........................................................... 113

Quadro 8 - Resumo do resultado da hipótese H1a...........................................................116

Quadro 9 - Resumo dos resultados das hipóteses H2a, H3a............................................. 121

Quadro 10 - Resumo do resultado da hipótese H4a......................................................... 124

Quadro 11 - Resumo dos resultados das hipóteses H1b e H1c .......................................... 125

Quadro 12 - Resumo dos resultados das hipóteses H2b e H2c, H3b e H3c ......................... 129

Quadro 13 - Resumo dos resultados das hipóteses H4b e H4c ........................................... 132 


\section{LISTA DE TABELAS}

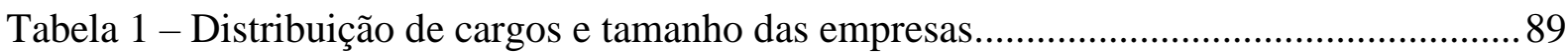

Tabela 2 - Análise descritiva das variáveis latentes por país ................................................90

Tabela 3 - Análise descritiva das variáveis latentes em países emergentes, desenvolvidos e na

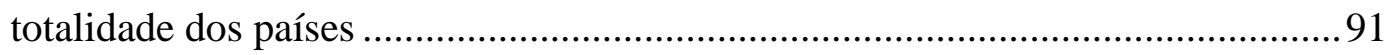

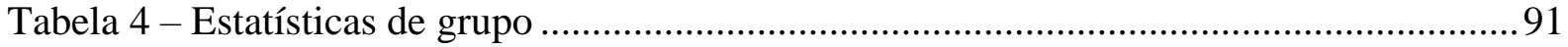

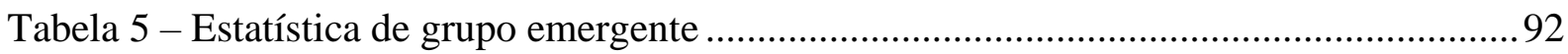

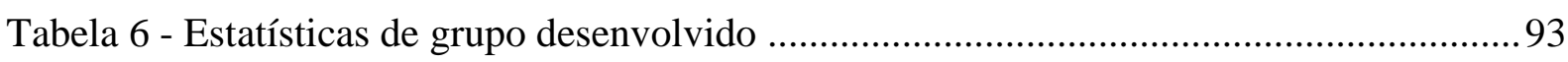

Tabela 7 - Média e desvio-padrão das variáveis dos construtos ........................................... 95

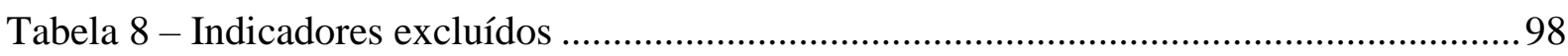

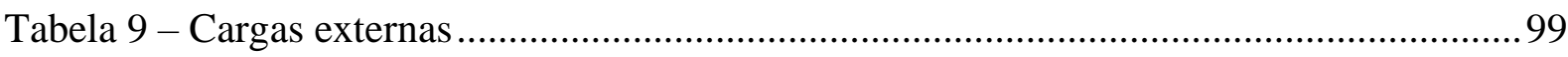

Tabela 10 - Colinearidade estatística - VIF externo........................................................ 100

Tabela 11 - Validade convergente e confiabilidade de $1^{\text {a }}$ ordem ....................................... 101

Tabela 12 - Validade convergente e confiabilidade estrutural............................................. 102

Tabela 13 - Validade discriminante de $1^{\mathrm{a}}$ e $2^{\mathrm{a}}$ ordem ou estrutural ...................................... 102

Tabela 14 - Teste de significância (Bootstrapping) - Desenvolvidos e emergentes ............. 104

Tabela 15 - Teste de significância (Bootstrapping) - Total ................................................ 104

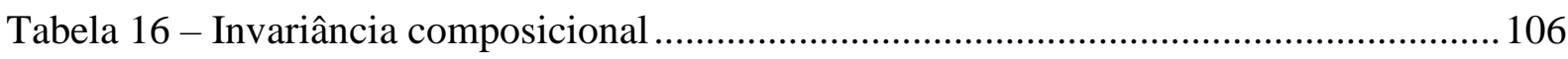

Tabela 17 - Coeficientes de caminho (Permutação) - Desenvolvidos e emergentes ............. 107

Tabela 18 - Coeficientes de caminho (Permutação) - Total................................................... 107

Tabela 19 - Testes paramétricos e não paramétricos - Desenvolvidos e emergentes ............ 108

Tabela 20 - Testes paramétrico e não paramétrico - Total .................................................... 108

Tabela 21-Teste de hipótese da análise multigrupo (Bootstrapping) - Desenvolvidos e

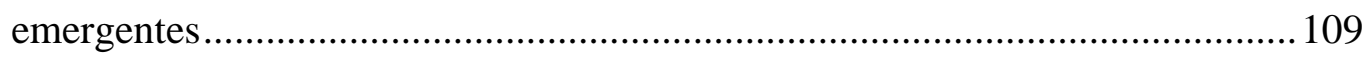

Tabela 22 - Teste de hipótese da análise multigrupo (Bootstrapping) - Total ...................... 109 


\section{SUMÁRIO}

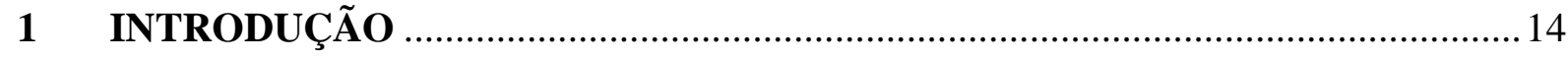

1.1 SITUAÇÃO-PROBLEMA E JUSTIFICATIVA DE PESQUISA ................................. 16

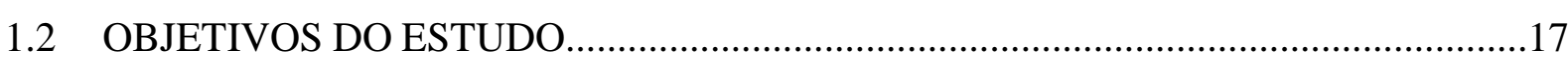

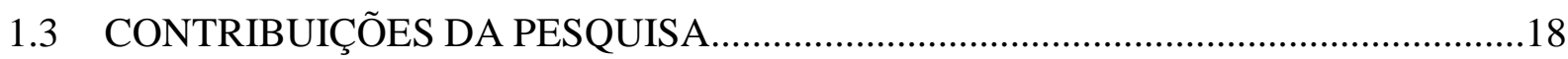

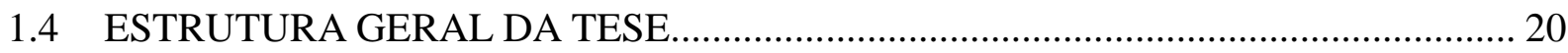

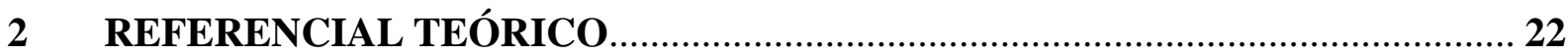

2.1 AMBIENTE INSTITUCIONAL E COMPORTAMENTO DA INOVAÇÃO ...............22

2.2 ORIENTAÇÃO ESTRATÉGICA PARA ECOINOVAÇÃO .......................................27

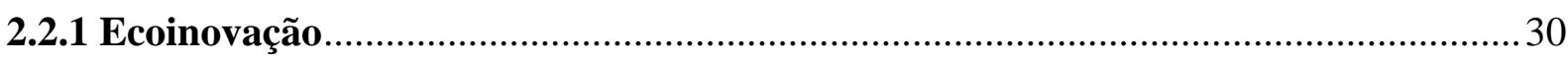

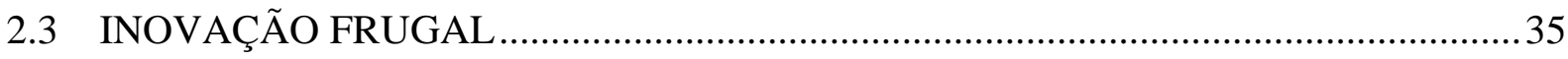

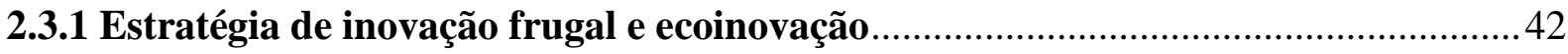

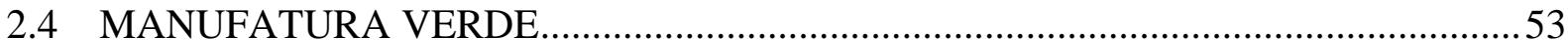

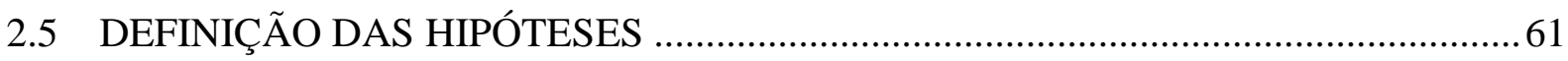

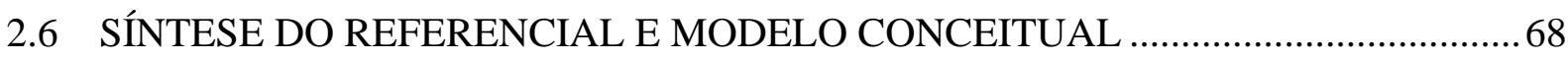

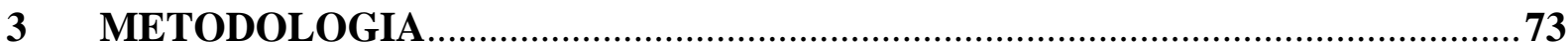

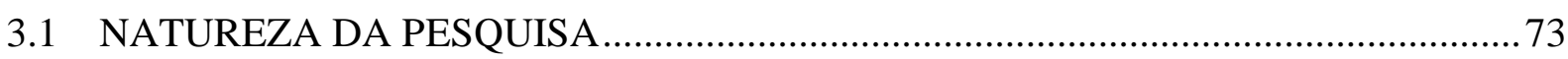

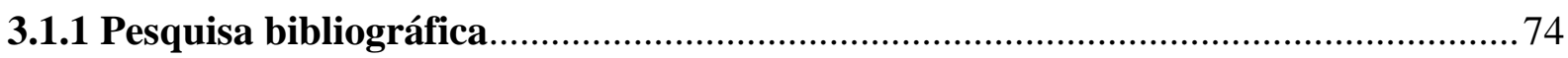

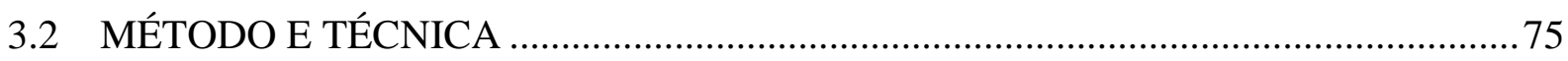

3.3 DEFINIÇÃO DAS VARIÁVEIS E INDICADORES …............................................. 76

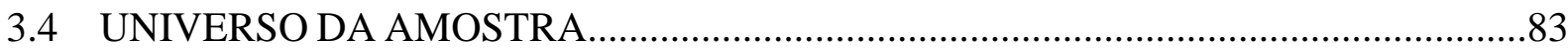

3.5 INSTRUMENTAL DE PESQUISA E PROCEDIMENTOS DE CAMPO....................85

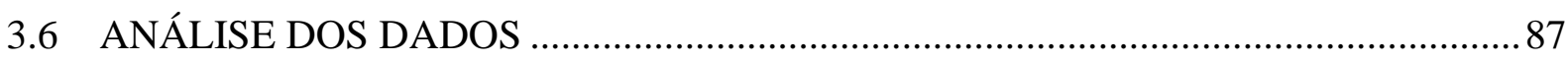

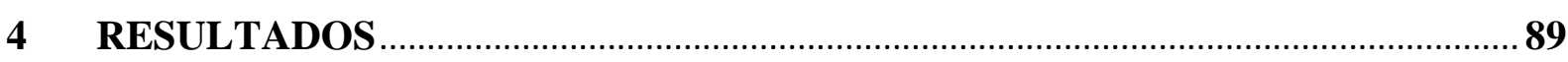

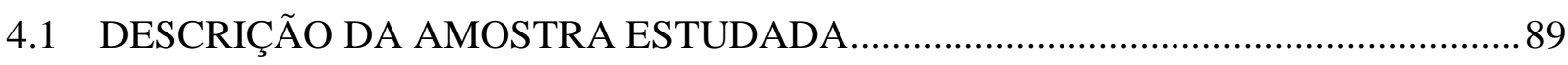

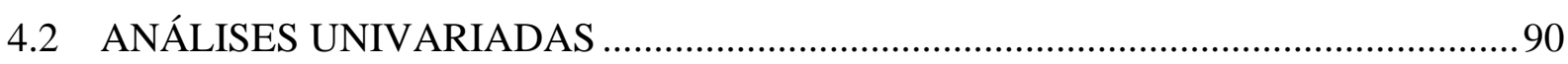

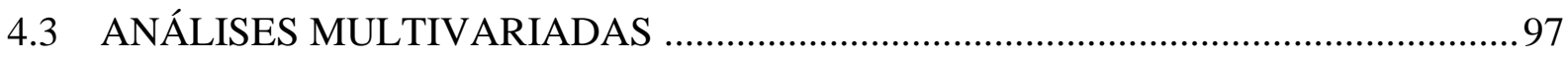

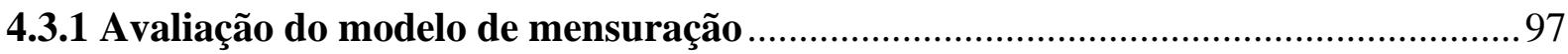

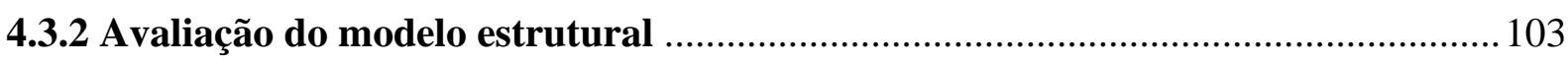

4.3.3 Avaliação da moderação no modelo estrutural .................................................... 105

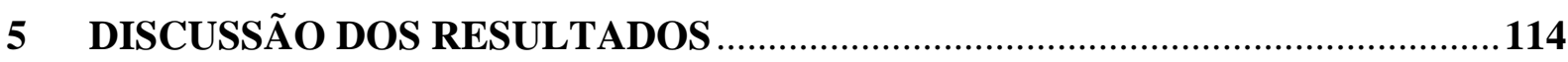

5.1 A INCIDÊNCIA DA INOVAÇÃO FRUGAL NA RELAÇÃO ENTRE A ORIENTAÇÃO ESTRATÉGICA PARA A ECOINOVAÇÃO E A MANUFATURA VERDE 
5.2 A INOVAÇÃO FRUGAL PARA A ECOINOVAÇÃO E AS RELAÇÕES ENTRE O AMBIENTE INSTITUCIONAL, A ORIENTAÇÃO ESTRATÉGICA PARA A ECOINOVAÇÃO, A MANUFATURA VERDE E O DESEMPENHO..........................120

5.3 ANÁLISE E IMPLICAÇÕES ENTRE MERCADOS EMERGENTES E

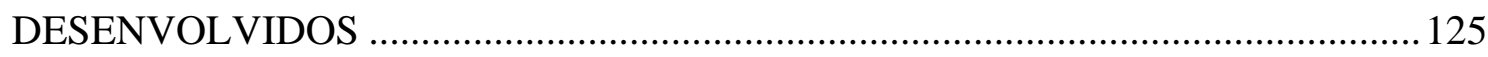

6 CONCLUSÕES E CONSIDERAÇÕES FINAIS..................................................134

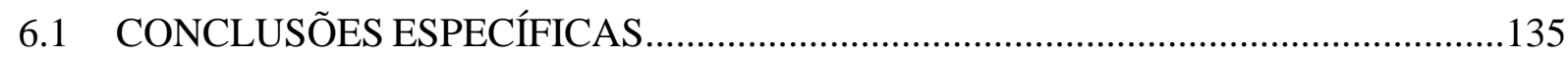

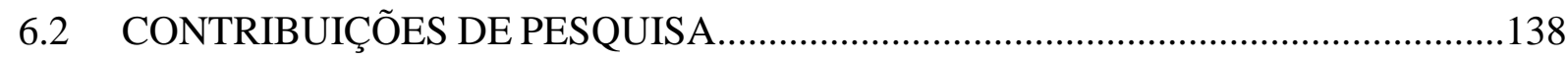

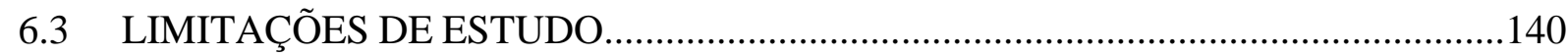

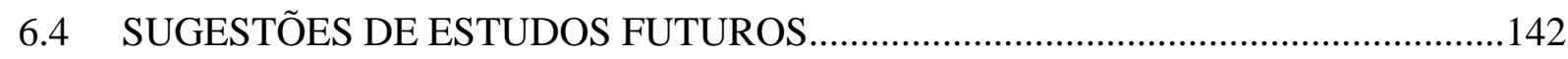

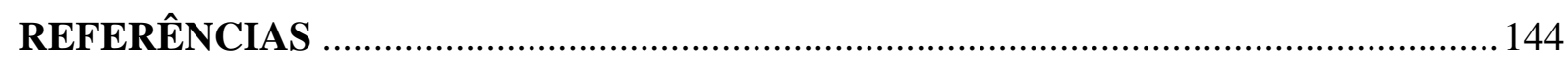

APÊNDICE A - QUESTIONÁRIO EM INGLÊS ………..............................................177

APÊNDICE B - QUESTIONÁRIO EM PORTUGUÊS..................................................... 180

APÊNDICE C - CONCEITOS DE ECOINOVAÇÃO ..................................................183

APÊNDICE D - RELAÇÃo DAS PRÁTICAS DE MANUFATURA E DESEMPENHO ORGANIZACIONAL/OPERACIONAL ...............................................185

APÊNDICE E - ECOINOVAÇÃO E DIMENSÕES DA INOVAÇÃO FRUGAL .........187

APÊNDICE F - INOVAÇÃO FRUGAL E ECOINOVAÇÃO ………………………....196

APÊNDICE G - SOLUÇÕES ECOINOVADORAS E INOVAÇÃO FRUGAL ...........204 


\section{INTRODUÇÃO}

É crescente o interesse acadêmico e da indústria no estudo interdisciplinar dos impactos das estratégias organizacionais de ecoinovação e da manufatura verde, sob o ponto de vista do desenvolvimento sustentável e da inovação tecnológica (DEL RÍO; PEÑASCO; ROMEROJORDÁN, 2016).

Para os mercados desenvolvidos, a atenção se concentra na relação entre a orientação estratégica para a ecoinovação e a manufatura verde nas organizações (CAINELLI; DE MARCHI; GRANDINETTI, 2015; DANGELICO; PUJARI, 2010; GONZÁLEZ-MORENO; SÁEZ-MARTÍNEZ; DÍAZ-GARCÍA， 2013; SEGARRA-OÑA; PEIRÓ-SIGNES; MONDÉJAR-JIMÉNEZ, 2016); já para os mercados emergentes, a literatura apresenta a discussão acerca do desenvolvimento de produtos e da evolução na cadeia de produção, diante de rigorosos requisitos regulatórios (GANAPATHY et al., 2014; HSU; TAN; ZAILANI, 2016; REHMAN; SETH; SHRIVASTAVA, 2016; SANNI, 2018).

Independentemente do padrão de desenvolvimento do mercado em que atuam, as organizações são desafiadas a considerar outros fatores para se tornarem ambientalmente conscientes e mais atuantes. Sob pressões regulatórias institucionais mais severas e condições ambientais adversas, tais como a expansão das desigualdades sociais, o desemprego estrutural, a fragmentação, o declínio de renda e o envelhecimento da população, são necessárias novas soluções, bem como estratégias empresariais mais inovadoras, em termos ambientais, e inclusivas, no âmbito social (BOUND; THORNTON, 2012; HOSSAIN; SIMULA; HALME, 2016).

Nesse contexto, a discussão sobre as capacidades de inovação, para negócios direcionados a soluções frugais, tem recebido grande interesse das empresas, sendo ela considerada para a aplicação em mercados emergentes e desenvolvidos (ANGOT; PLÉ, 2015; GOVINDARAJAN; TRIMBLE, 2014; KHAN, 2016; TIWARI; FISCHER; KALOGERAKIS, 2016).

A partir da compreensão conceitual embasada em critérios, como funcionalidades centrais e soluções de baixo custo, desenvolvidas a partir da interação com ecossistemas de inovação (PISONI; MICHELINI; MARTIGNONI, 2018), a inovação frugal tem sido apresentada, na literatura, como um estágio inicial para que as organizações se capacitem no desenvolvimento de inovações sustentáveis (BAS, 2016; BASU; BANERJEE; SWEENY, 2013), e nas atividades de redução do uso de recursos, aplicadas ao fluxo global da cadeia de produção (SCHIEDERIG; TIETZE; HERSTATT, 2012). 
Diante da necessidade de discussão e de reflexão sobre os impactos da inovação frugal para a sustentabilidade (LEVÄNEN; LINDEMAN, 2016), o objetivo deste estudo é aprofundar o debate do efeito que essa inovação exerce sobre a relação entre a orientação estratégica para a ecoinovação e a manufatura verde, de forma a contribuir com o desenvolvimento sustentável das organizações.

Dessa forma, expande-se a visão mais restrita da inovação frugal, ampliando o foco dos processos das inovações realizados por meio da replicação de tecnologias de baixo custo para uma nova mentalidade de solução estratégica, voltada à eficiência de recursos em regimes de escassez (BREM, 2017), o que envolve tecnologias avançadas, frugais e sustentáveis na manufatura. (HOSSAIN, 2018; LEACH et al., 2012). Como estratégia, a inovação frugal aborda a melhoria econômica da organização, e o atendimento às questões sociais e ambientais da sociedade (SANTOS; BORINI; OLIVEIRA JÚNIOR, 2020).

Nesse sentido, esta pesquisa contribui com a literatura por propor a análise do efeito da inovação frugal como forma de melhorar a relação entre a orientação estratégica para a ecoinovação e as práticas de manufatura verde, tanto em mercados emergentes quanto desenvolvidos, e discutir as diferenças entre esses países.

Assim, a tese defendida nesta pesquisa é que, quanto maior a incidência da inovação frugal em uma empresa, mais forte é o seu efeito de moderação entre a orientação estratégica para a ecoinovação e a implementação de práticas de manufatura verde.

A discussão sobre a evolução da inovação frugal e o posicionamento reativo para desenvolver a proatividade em novas abordagens, voltadas às práticas sustentáveis (DE OLIVEIRA et al., 2018), precisam considerar a influência do ambiente institucional, haja vista a teoria evidenciar que as organizações não estão limitadas a atender apenas aos propósitos de produção de bens e de serviços, já que dependem, conjuntamente, da adaptação dos fornecedores, dos clientes e dos concorrentes, bem como dos atores críticos de campo, como os reguladores, as associações, os profissionais e a mídia (HININGS; GEGENHUBER; GREENWOOD, 2018).

Nesse ambiente institucional, as inovações se estabelecem como práticas necessárias à adaptação a esses processos, como o desenvolvimento de novos produtos (ERNST et al., 2015), e de processos que integrem as tecnologias desses múltiplos atores, e que tenham foco em novas proposições de valor (FUENFSCHILLING; TRUFFER, 2014; VARGO; WIELAND; AKAKA, 2015). Para as ecoinovações, nas instituições formais e informais, as regulamentações e a pressão dos clientes são identificadas como os principais fatores direcionadores de 
estratégias e de práticas de manufatura (BOONS et al., 2013; MONTALVO, 2008; PORTER; LINDE, 1995; REHFELD; RENNINGS; ZIEGLER, 2007).

Como consequência da orientação estratégica e da implementação de atividades de manufatura verde, como método de retenção do desperdício e da poluição, integrando design de produtos e processos (HSU; TAN; ZAILANI, 2016; SHRIVASTAVA; SHRIVASTAVA, 2017), são percebidas alterações no desempenho financeiro, por meio do aumento da produtividade (BURGOS-JIMÉNEZ et al., 2013), e na participação de mercado, pelo reconhecimento das práticas ambientais (BURGOS-JIMÉNEZ et al., 2013; CHEN; TSOU; HUANG, 2009; CHEN; LAI; WEN, 2006).

\subsection{SITUAÇÃO-PROBLEMA E JUSTIFICATIVA DE PESQUISA}

Diante do cenário de discussão sobre a capacidade das organizações e dos governos de alcançar crescimento econômico, enquanto lidam com a escassez (DRESSLER; BUCHER, 2018), aumenta a importância de investigar em profundidade se, e como, as inovações frugais podem instigar o desenvolvimento sustentável (ROSCA; REEDY; BENDUL, 2018), considerando o crescimento da consciência global sobre o tema e as regulações ambientais existentes (TIWARI; FISCHER; KALOGERAKIS, 2016; TIWARI; KALOGERAKIS, 2016).

Quanto ao papel da inovação frugal, as pesquisas abordam o seu potencial para: (a) possibilitar o desenvolvimento sustentável (BHATTACHARYYA et al., 2017; HYVÄRINEN; KESKINEN; VARIS, 2016; KHAN, 2016; KNORRINGA et al., 2016); (b) implementar a ecoinovação frugal em produtos, processos e na cadeia de suprimentos (HYVÄRINEN; KESKINEN; VARIS, 2016; SHARMA; IYER, 2012); e (c) ser utilizada como estratégia para alcançar as questões sociais e ambientais (MOURTZIS et al., 2016; RAO, 2017a).

Apesar de as atividades de inovação frugal estarem presentes nas organizações, as discussões sobre a difusão da orientação estratégica e da sua relação com as práticas organizacionais de manufatura verde ainda estão no início de sua construção (ROSCA; REEDY; BENDUL, 2018), havendo escassez de estudos acerca do potencial de sustentabilidade ecológica objetivado por essa inovação, tanto em países desenvolvidos como naqueles em desenvolvimento (ALBERT, 2019).

Face aos argumentos elaborados nesta introdução, este trabalho tem como perguntas de pesquisa duas questões que se entrelaçam: (1) As organizações com maior incidência de inovação frugal têm melhor resultado na relação entre a orientação estratégica para a ecoinovação e a manufatura verde?; (2) Há diferença entre países emergentes e desenvolvidos, 
nas relações entre as pressões do ambiente institucional, a orientação estratégica, a manufatura verde e o desempenho?

Diante dessa proposta, este estudo utilizou a pesquisa quantitativa, envolvendo executivos de organizações do setor de manufatura, que têm atividades de manufatura verde e de ecoinovação, sendo 173, de países emergentes (Brasil e Índia), e 130, de países desenvolvidos (Alemanha e Estados Unidos da América), totalizando 303 respostas.

Os dados, coletados entre setembro e agosto de 2019, foram analisados a partir do modelo de equações estruturais, com o auxílio do software SmartPLS v3.0. Para verificar o impacto da estratégia de inovação frugal na relação entre a orientação estratégica para a ecoinovação e a manufatura verde, as organizações respondentes foram segmentadas em estratégias mais e menos frugais, como uma variável moderadora categórica para a análise de multigrupo, de acordo com as respostas ao questionário da escala proposta. E, para o exame segmentado dos países participantes da pesquisa, com fins de atender aos objetivos ora propostos, eles foram divididos em dois grupos - o de países emergentes (Brasil e Índia), e o de países desenvolvidos (EUA e Alemanha).

Considerando que os esforços e os benefícios da orientação estratégica para a ecoinovação e a inovação frugal são aplicáveis tanto em mercados emergentes quanto nos já desenvolvidos (BOUND; THORNTON, 2012; SANTOS; BORINI; OLIVEIRA JÚNIOR, 2020; ZESCHKY; WIDENMAYER; GASSMANN, 2011), esta pesquisa analisou as relações propostas por um país reconhecido nas áreas de ecoinovação e de manufatura (Alemanha) (HORBACH, 2014; TRIEBSWETTER; WACKERBAUER, 2008), e por países com destaque no desenvolvimento de inovações frugais (Estados Unidos da América e Índia - epicentro desse tipo de inovação) (HOSSAIN, 2017). Ademais, os outros quatro países escolhidos, incluindo o Brasil, constam na lista dos dez com maior publicação na área de gestão da cadeia de manufatura verde (DE OLIVEIRA et al., 2018).

\subsection{OBJETIVOS DE ESTUDO}

Diante da literatura existente, esta pesquisa se propõe a: (a) validar que, quanto maior a estratégia de inovações frugais nas organizações, maior a relação existente entre a orientação estratégica para a ecoinovação e a manufatura verde; e (b) evidenciar que há diferença nessas relações, quando analisados países emergentes e desenvolvidos. Sendo assim, o objetivo central é analisar o efeito da moderação da inovação frugal sobre a orientação estratégica para a ecoinovação e a manufatura verde. 
E, como objetivos específicos, esta pesquisa tem o propósito de verificar a influência: (a) das pressões institucionais de mercado, das regulatórias e da orientação estratégica, quanto maior a estratégia de inovação frugal na organização; (b) da relação entre a manufatura verde e o desempenho da organização, quanto maior a estratégia de inovação frugal na organização; e de (c) comparar os resultados das relações entre as pressões do ambiente institucional e a orientação estratégica para a ecoinovação, e entre a manufatura verde e o desempenho organizacional, nos mercados desenvolvidos e emergentes, quanto maior o efeito de moderação da inovação frugal.

\subsection{CONTRIBUIÇÕES DE PESQUISA}

Esta tese contribui com a teoria, pois preenche a lacuna sobre o papel da estratégia de inovação frugal no fortalecimento da orientação estratégica para a ecoinovação e a manufatura verde. Ou seja, verificou-se que, quando as organizações adotam atividades de inovação frugal, há maior impacto das estratégias orientadas à diminuição e à preservação de recursos ambientais sobre as práticas da manufatura verde (BREM, 2017; ROSCA; REEDY; BENDUL, 2018).

Alinhada a esse propósito, ao envolver países emergentes e desenvolvidos na análise, esta pesquisa demonstra o potencial do conceito para além das fronteiras geográficas, isto é, não apenas como forma de suprir necessidades financeiras e sociais, mas também de se projetar como uma solução para impulsionar o crescimento sustentável nesses países (AGARWAL; BREM; DWIVEDI, 2019; BREM, 2017).

A utilização integrada de diferentes países na análise das práticas de manufatura verde (DE OLIVEIRA et al., 2018); e o estudo de fatores capazes de influenciar na implementação dessas práticas, na reutilização e na preservação de recursos naturais (JABBOUR et al., 2014), são duas outras lacunas teóricas preenchidas por esta pesquisa, que contribui, mais uma vez, para expandir a literatura sobre o assunto.

Sob outra perspectiva de análise, esta pesquisa corrobora os estudos que atestam a importância da inovação frugal para os mercados emergentes, como solução às limitações de recursos e de mercado para alcançar as estratégias voltadas à sustentabilidade. Assim, nos países em desenvolvimento, a orientação estratégica para a ecoinovação tem maior impacto sobre as práticas de manufatura verde, em organizações com maior incidência de inovação frugal (se comparadas àquelas menos frugais). Essa relação, então, é potencializada pelo papel que a inovação frugal exerce em tais empresas. Em contrapartida, nas organizações inseridas 
em mercados desenvolvidos, a intensidade da interação das estratégias de inovação frugal não é tida como significativa nessa relação.

As consequências esperadas da interação da inovação frugal em tais relações são: a possibilidade de aumento da eficiência energética dos países envolvidos (AGARWAL et al., 2016; BHATTI, 2012; BHATTI; VENTRESCA, 2013); meio de recuperação econômica para os mercados emergentes (BHATTI, 2012); e forma de atender à ascensão e às pressões regulatórias e sociais por produtos ecologicamente amigáveis (CUNHA et al., 2014).

Portanto, este estudo complementa a literatura da teoria institucional (LAWRENCE; SIMON, 2008; SHU et al., 2016; SMINK; HEKKERT; NEGRO, 2015; VARGO; WIELAND; AKAKA, 2015), ao mostrar que o impacto da interação das dimensões da inovação frugal, para atender aos propósitos da organização de alcançar objetivos ambientais, pode ter diferentes níveis de estratégia, a depender do grau de desenvolvimento do país.

Gerencialmente, perante as dificuldades de implementar modelos de negócio de inovação sustentável em países emergentes (BIRKIN et al., 2009; SHRIMALI et al., 2011), esta pesquisa contribui por apresentar como a inovação frugal, originalmente desenvolvida como resposta às lacunas institucionais (KHANNA; PALEPU; BULLOCK, 2010; TAAL et al., 2012), pode ser utilizada como alavanca, pela qual as organizações podem alcançar seus objetivos locais e globais de sustentabilidade e de competitividade.

Quanto aos resultados relativos às diferenças de ambiente institucional entre países de níveis de desenvolvimento distintos, esta pesquisa apresenta a respostas das organizações frente aos direcionadores regulatórios e de mercado do ambiente institucional e, consequentemente, como devem ser adequadas as estratégias gerenciais voltadas à ecoinovação e à manufatura verde.

Ao considerar o ambiente institucional como fator predecessor da adoção da orientação estratégica para a ecoinovação, sob a perspectiva das pressões regulatórias e de mercado de consumo, esta pesquisa pode contribuir para a criação de políticas públicas de incentivo às ecoinovações, com foco no design e nos aspectos ecológicos (DORAN; RYAN, 2016; FRANCESCHINI; PANSERA, 2015), e fomentar a reflexão de como isso pode influenciar positivamente a implementação de práticas de manufatura verde e o desempenho operacional e organizacional das firmas.

Embora haja um crescente interesse no conceito de inovação frugal, bem como uma quantidade significativa de publicações que o aplicam (PISONI; MICHELINI; MARTIGNONI, 2018), o tema é recente; e a escala de dimensões (custo, funcionalidade e ecossistema de inovação), como estratégia de inovação frugal, ainda não foi utilizada em 
modelos que abarcam sua relação com a orientação estratégica de ecoinovação e a manufatura verde. Ademais, o conhecimento existente sobre os aspectos ecológicos das inovações frugais está baseado em pesquisas conceituais, o que implica a necessidade de estudos com abordagem quantitativa (HOSSAIN, 2017).

\subsection{ESTRUTURA GERAL DA TESE}

Além desta introdução (Seção 1), este trabalho apresenta a literatura sobre o ambiente institucional para a inovação, a orientação estratégica para a ecoinovação, a inovação frugal, e a estratégia de inovação frugal para a sustentabilidade e a manufatura verde (Seção 2); a metodologia do estudo (Seção 3); os resultados da análise estatística (Seção 4); a discussão e as implicações teóricas dos resultados (Seção 5); e, por fim, a conclusão, as limitações do estudo e as sugestões para futuras pesquisas (Seção 6). A estrutura final da tese e os pontos abordados em sua defesa estão representados a seguir (Figura 1). 
Figura 1 - Estrutura geral da tese
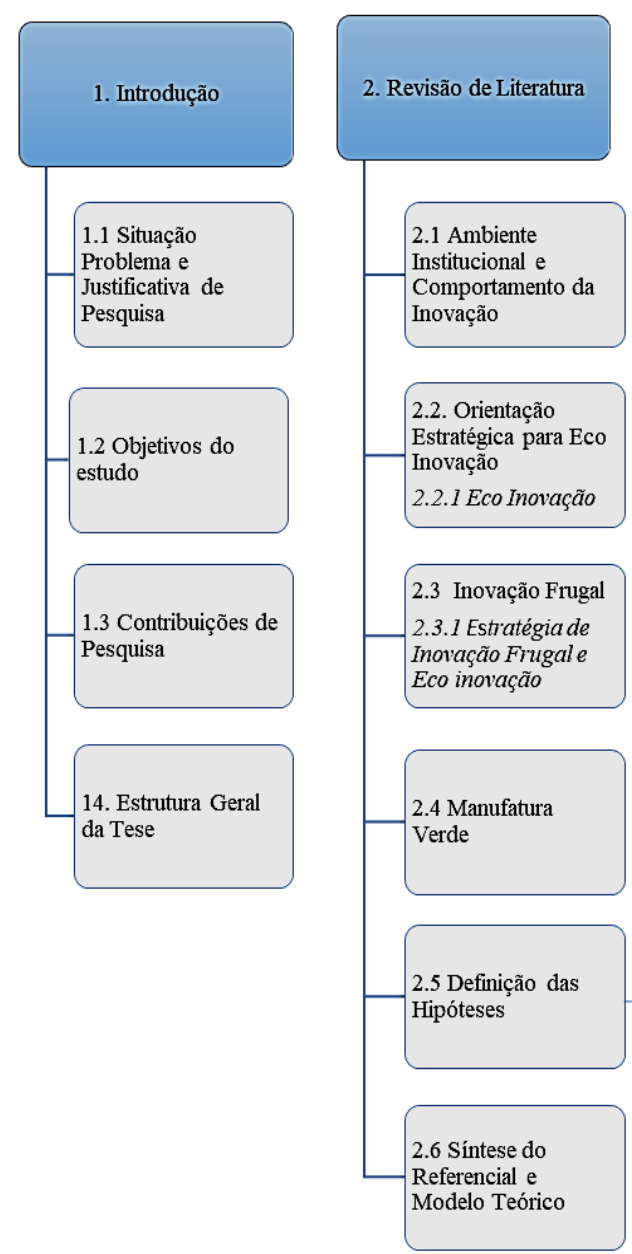

H1a: Quanto maior o efeito da moderação do inovação frugal, maior é a relação entre orientação estratégica para eco inovação e manufatura verde.

H1b/c: Quanto maior o efeito da moderação da inovação frugal, maior é a relação entre

orientação estratégica para eco inovaçãoe manufatura verde em organizações de paises emergentes/desenvolvidos.

H2a: Quanto maior o efeito da moderação da inovação frugal, maior e a relação entre a pressão regulatória e a orientação estratégica para eco inovação.

H2b/c: Quanto maior o efeito da moderação da inovação frugal, maior é a relação entre a pressáo regulatoria e a orientação estratégica para eco inovação em organizações de paises emergentes/desenvolvidos.

H3a: Quanto maior o efeito da moderação do inovação frugal, maior é a relação entre a pressão do mercado consumidor e a orientação estratégica para eco inovação.

H3b/c: Quanto maior o efeito da moderação da inovação frugal, maior e a relação entre a

pressão do mercado consumidor e a orientação estratégica para eco inovação em organizaçôes de paises emergentes/desenvolvidos.

H4a: Quanto maior o efeito da moderação do inovação frugal, maior e a relação entre a manufatura verde e o desempenho das organizações.

H4b/c: Quanto maior o efeito da moderação da inovaçãofrugal, maior é a relação entre a

manufatura verde e o desempenho em

organizações de paises

emergentes/desenvolvidos

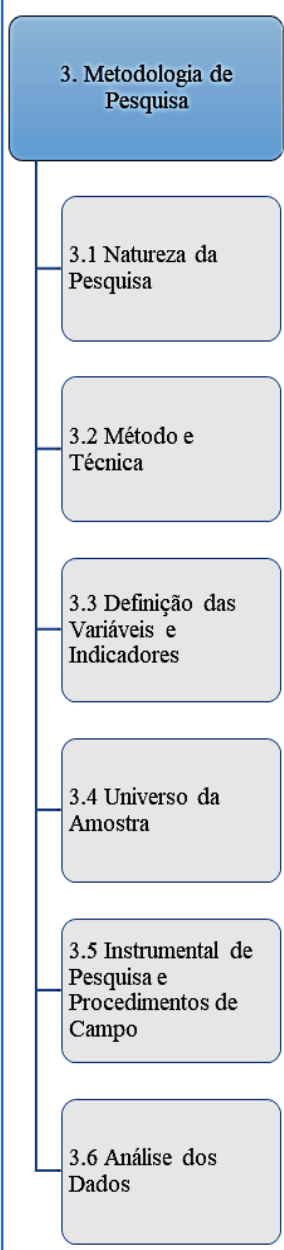

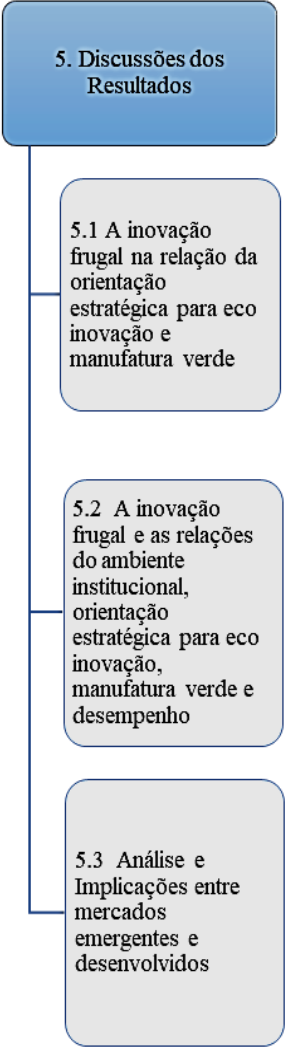

6. Conclusão e Considerações Finais

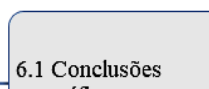

específicas

4.1 Descrição da

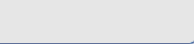

4.2 Análise

Univariada

4.3 Análise

Multivariada

4.3.1 Avaliação do

Modelo de
Mensuração

4.3.2Avaliaşão do

4.3.3. tvaliacro da

moderaç̃o no

modelo estrutural

5.3 Análise

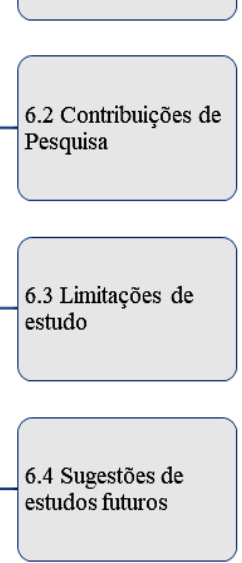




\section{REFERENCIAL TEÓRICO}

A revisão da literatura abre este capítulo, evidenciando: o ambiente institucional para a inovação, representado pelas pressões regulatória ambiental e do mercado consumidor (Seção 2.1); as características da orientação estratégica para a ecoinovação e o conceito de ecoinovação, na literatura de inovações voltadas à redução e à preservação dos recursos naturais (Seção 2.2); a inovação frugal, em seu conceito e dimensões; e a incidência da inovação frugal como fator relevante da relação entre as estratégias de orientação de ecoinovação e as práticas de manufatura verde (Seção 2.3); e a relação entre a manufatura verde e o seu impacto no desempenho das organizações (Seção 2.4). As hipóteses levantadas por esta pesquisa (Seção 2.5); a síntese do referencial teórico utilizado e o modelo conceitual construído (Seção 2.6) encerram o capítulo.

\subsection{AMBIENTE INSTITUCIONAL E COMPORTAMENTO DA INOVAÇÃO}

A teoria institucional tem como proposição analítica a abordagem dos fenômenos sociais, em particular, os organizacionais, concebendo o mundo social como sendo constituído de forma significativa pelas instituições, a partir de regras, práticas e estruturas duradouras, que estabelecem as suas condições de ação (LAWRENCE; SIMON, 2008). Dessa forma, segundo essa teoria, as operações da organização são afetadas e direcionadas pelas instituições presentes em seu ambiente de atuação, com ênfase nas interações entre as instituições formais e informais (SHU et al., 2016).

Nessa mesma linha conceitual, está a teoria neoinstitucional de DiMaggio e Power (1983), fundamentada em três processos isomórficos: (1) o coercitivo ou regulatório, formado pelas regras de natureza coercitiva ou de regulamentação, criadas pelo governo ou por instituições de controle. Por estar relacionado às estruturas formais de leis codificadas, decretadas e utilizadas por uma nação, sociedade ou comunidade (MANOLOVA; EUNNI; GYOSHEV, 2008), o governo representa uma das principais instituições formais (SHU et al., 2016) presentes nesses processos; (2) o normativo, relacionado aos aspectos culturais e morais, aplicados às organizações e aos indivíduos, e amplamente inseridos nas interações sociais e sustentados pelas comunidades públicas e sociais (MEYER; ROWAN, 1977; SHU et al., 2016); e, por fim, (3) o mimético ou cognitivo, que se refere à percepção dos indivíduos do ambiente e da relação por eles estabelecida com os aspectos organizacionais. Tal processo envolve a 
reação desses indivíduos perante o ambiente, refletindo suas crenças, vivências e expectativas de interação em sociedade (MANOLOVA; EUNNI; GYOSHEV, 2008).

No que diz respeito às instituições formais e informais, as pressões específicas do ambiente institucional impactam a relação entre a orientação estratégica para a ecoinovação e a manufatura verde, haja vista a influência dos interessados regulatórios no papel do governo, redes informais, associações e concorrentes, consumidores, fornecedores, funcionários, grupos comunitários, associações ambientais e meios de comunicação (HENRIQUES; SADORSKY, 1996).

Entre os fatores de pressão institucional, os regulatórios e os do mercado consumidor influenciam significativamente a adoção de práticas que favorecem a ecoinovação dentro das organizações e, por extensão, o desempenho ambiental (CHEN; LAI; WEN, 2006; HUANG et al., 2016; TRIEBSWETTER; WACKERBAUER, 2008), sendo, desse modo, constantemente relatados como impulsionadores da ecoinovação (HOJNIK; RUZZIER, 2016).

A análise das pressões institucionais demonstra que o atendimento às regulamentações e a preferência dos consumidores por produtos com atributos de menor impacto ambiental (chamados de "verdes"), seja em sua fabricação, seja no seu descarte, ou por aqueles com o caráter sustentável, como a redução de energia no seu uso (KAMMERER, 2009), têm influenciado o crescimento de inovações voltadas às questões ambientais (CLEFF; RENNINGS, 1999; REHFELD; RENNINGS; ZIEGLER, 2007).

Os instrumentos de regulamentação ambiental; os subsídios ambientais; as abordagens regulatórias de conformidade ambiental, da saúde e de segurança (DEL RÍO; PEÑASCO; ROMERO-JORDÁN, 2015; HORBACH, 2008; HORBACH; RAMMER; RENNINGS, 2012); e os incentivos de regulação e de fiscalização ambiental, levam a organização a adquirir tecnologias ambientalmente amigáveis de controle e de prevenção ambiental (SHARMA, 2000; SHARMA; PABLO; VREDENBURG, 1999; VERBEKE; BUYSSE, 2003), direcionando, desse modo, a implementação de estratégias de ecoinovação de produtos, de processos, organizacional e de pesquisa e desenvolvimento (P\&D) (HOJNIK; RUZZIER, 2016; TRIGUERO; MORENO-MONDÉJAR; DAVIA, 2015).

Quanto à pressão do mercado consumidor, a evolução da consciência ambiental dos indivíduos apresenta às organizações um cenário competitivo, em que a preferência e a disposição em escolher e adquirir produtos estão pautadas na sua condição de sustentáveis ou de ambientalmente amigáveis (BERRY; RANDINELLI, 1998; HENRIQUES; SADORSKY, 1996). Vale ressaltar que os consumidores ambientalmente conscientes estão dispostos a pagar mais por esses produtos (JANSSON, 2011; SAMMER; WÜSTENHAGEN, 2006), desde que 
eles tenham sido manufaturados em processos com flexibilidade e maior capacidade de reduzir custos e de conter o consumo de energia por unidade, e orientados pela ecoinovação (SEGARRA-ONA; PEIRO-SIGNES; PAYA-MARTINEZ, 2014).

Embora ambas as pressões institucionais aqui mencionadas tenham significativo impacto na escolha de estratégias (CHEN; LAI; WEN, 2006), elas exercem papéis diferentes na promoção do direcionamento ambiental das organizações, e têm efeitos distintos, quando analisadas em mercados emergentes e desenvolvidos (HORBACH, 2016; HORBACH; RAMMER; RENNINGS, 2012; HUANG et al., 2016).

Quanto ao efeito das pressões regulatórias, dos subsídios e das atividades reguladoras, eles se distinguem pelo estágio do padrão tecnológico dos países, influenciando distintamente os domínios de ecoinovação (HORBACH, 2016).

Sendo assim, nos países desenvolvidos, as regulamentações motivam inovações com economia de custos, em campos emergentes da ecoinovação, como a redução do uso de materiais e de energia (HORBACH, 2016; HORBACH; RAMMER; RENNINGS, 2012), impulsionando a adoção de tecnologias mais limpas (ARIMURA et al., 2016; DEL RÍO GONZÁLEZ, 2009), ou aplicadas no final da cadeia de produção, em sistemas de gerenciamento ambiental (FRONDEL; HORBACH; RENNINGS, 2008). Além disso, para atender à lei de energia renovável, países de tecnologia intensiva, como a Alemanha, adaptam suas tecnologias para a atenuação energética em novos campos, reduzindo o uso de matériaprima.

Já, nos mercados emergentes, esse tipo de regulamentação é quase inexistente, implicando em custos mais elevados para a produção (HORBACH, 2016), sendo a conformidade regulamentar motivada pela redução dos custos das penalidades dos danos ambientais (HORBACH; RAMMER; RENNINGS, 2012; YUAN; XIANG, 2018), e focada em inovações, nos campos tecnológicos tradicionais, como o tratamento e o controle de resíduos, no final do processo produtivo, com fins de diminuir a poluição da água, do ar, do solo e de ruído (HORBACH, 2016).

Atender às pressões normativas e coercitivas tem sido uma forma de os mercados emergentes atraírem investimentos em inovação. Yang, Tseng e Chen (2012), em pesquisa sobre a China, por exemplo, apontam a relação positiva entre a conformidade às regulamentações e o crescimento dos investimentos em P\&D. Chakraborty e Chatterjee (2017), por sua vez, ao tratarem do uso de corantes na Índia, afirmam que a pressão das regulamentações ambientais não só proporcionam maior investimento em $\mathrm{P} \& \mathrm{D}$, como 
possibilitam maior transferência de tecnologia e o desenvolvimento de práticas de produção, nas organizações locais.

Nesse sentido, Huang et al. (2016) observam que a pressão do consumidor, em mercados emergentes, tem impacto positivo nos investimentos de $\mathrm{P} \& \mathrm{D}$, nas redes de colaboração, e efeito indireto no desempenho ambiental da organização. Diante da pressão regulatória, contudo, esse efeito é direto, revertido na construção de uma cultura gerencial de ecoinovação (HUANG et al., 2016).

Tais resultados de investimentos, específicos para P\&D ambiental, motivados pelas pressões normativas, não são encontrados, todavia, em mercados desenvolvidos (BRUNNERMEIER; COHEN, 2003; KNELLER; MANDERSON, 2012). Sendo assim, a intensidade da pressão do mercado consumidor, exercida sobre as estratégias de orientação para a ecoinovação, difere nos mercados emergentes e nos desenvolvidos.

Apesar de a pressão do consumidor e a pressão institucional terem efeito indireto no desempenho da ecoinovação, em países emergentes, a demanda dos clientes por produtos e por serviços ambientais, segundo Huang et al. (2016), não impacta as decisões estratégicas da organização. Em contrapartida, de acordo com Choi et al. (2019), a pressão do consumidor, em países como a China, ativa os fatores de responsabilidade social corporativa e, por consequência, impacta as estratégias organizacionais.

Vale informar que a ausência de pressão do mercado consumidor nos países emergentes é creditada, em grande parte, à deficiência de desenvolvimento da consciência ambiental dos consumidores, e, ainda, aos baixos padrões de vida e de renda, que os impede de pagar os altos preços de produtos ecológicos (LI, 2014; MATHIYAZHAGAN; SENGUPTA; MATHIVATHANAN, 2019).

Comparativamente, a tomada de decisão pela compra de produtos ambientalmente amigáveis, nos países desenvolvidos, como os Estados Unidos, por exemplo, é direcionada pela reputação ambiental da organização e pela disposição (e condições) dos consumidores (cerca de 75\% dos americanos) em pagar mais por eles (CARTER; KALE; GRIMM, 2000).

Sendo assim, Hojnik e Ruzzier (2016) apontam que as estratégias de ecoinovação são direcionadas pelas oportunidades de criação de novos mercados, e pela mudança ou desenvolvimento da reputação positiva ambiental da organização, que promovem a adoção e a difusão das ecoinovações entre os consumidores.

Nesse sentido, Florida (1996), em pesquisa sobre o mercado norte-americano, demonstrou a importância da pressão do consumidor para a criação de estratégias ambientais e a evolução de uma manufatura mais limpa. Atender a essas pressões é elemento central para a 
aproximação entre a empresa e seus clientes, fortalecendo o relacionamento, o desempenho financeiro e ambiental, e, por extensão, a competitividade (IRANMANESH et al., 2019).

Nos mercados desenvolvidos, a consciência do consumidor sobre os riscos ambientais e os danos do uso inadequado de recursos naturais está aumentando, descortinando um novo cenário de comportamento, de expectativas, e da disposição financeira em adquirir produtos que não agridam o meio ambiente (HART, 1996; HENRIQUES; SADORSKY, 1996; JANSSON, 2011; SAMMER; WÜSTENHAGEN, 2006).

A pressão institucional, em tais organizações, é de um consumidor consciente dos danos ambientais, causados por produtos e serviços em toda a cadeia de valor, das atividades de produção ao uso. Na Holanda, por exemplo, o uso de eletricidade proveniente de fontes renováveis, como a eólica, desperta orgulho (MATHIYAZHAGAN; SENGUPTA; MATHIVATHANAN, 2019). E na Espanha, a pressão exercida sobre a indústria automobilística, para conter os impactos negativos gerados pelos bens produzidos, tem orientado processos mais flexíveis, aumentando a capacidade de produção ereduzindo os custos e o consumo de energia por unidade produzida, sendo os produtos também ambientalmente orientados (SEGARRA-ONA; PEIRO-SIGNES; PAYA-MARTINEZ, 2014).

A percepção do mercado consumidor sobre o uso reduzido de energia e de matériaprima, assim como as práticas de reciclagem, a atenuação da poluição e a substituição de insumos por materiais menos poluentes ou perigosos para o meio ambiente, têm surtido efeito positivo nas estratégias e na atividade de inovação, em organizações de vários países da Europa (DORAN; RYAN, 2016; KESIDOU; DEMIREL, 2012; REHFELD; RENNINGS; ZIEGLER, 2007).

Sendo assim, para manter a competitividade, em um mercado local e global, sob a pressão de consumidores com maior conscientização, e envolver outras partes interessadas, como comunidades, associações e influenciadores, as organizações tiveram que repensar e reestruturar suas operações produtivas, investindo em ecoinovação e na difusão de práticas de manufatura verde (AHMAD; KHAN; MITTAL, 2015; VACHON; KLASSEN, 2006).

Nesse mesmo contexto, do ambiente institucional para a inovação, a seção seguinte trata da dimensão formal da orientação estratégica para a ecoinovação nas organizações, como resposta efetiva às pressões regulatórias e do mercado consumidor. 


\subsection{ORIENTAÇÃO ESTRATÉGICA PARA ECOINOVAÇÃO}

A estratégia de inovação das empresas pode ser explicada pela lente da teoria institucional, considerada, atualmente, uma das abordagens mais influentes na ciência organizacional (FUENFSCHILLING; TRUFFER, 2014). Fundamentada na análise dos fenômenos sociais, constituídos por regras, práticas e estruturas, que definem as condições de atuação das empresas (LAWRENCE; SIMON, 2008), a centralidade de seu conceito está no destaque à maneira pela qual procedimentos, estruturas ou ideias são adotados, com base nas definições externas de legitimidade, e não somente com fins de eficiência (DIMAGGIO; POWELL, 1983; MEYER; ROWAN, 1977).

O ambiente institucional é caracterizado pelo conceito de campos organizacionais, que engloba as empresas, em conjunto com fornecedores, consumidores de recursos e de produtos, agências reguladoras e concorrentes (DIMAGGIO; POWELL, 1983). Como esses são componentes integrados e inter-relacionados ao ambiente institucional, qualquer mudança em seu equilíbrio exerce pressão sobre o todo, pedindo por adaptações, estruturadas em estratégias para a geração de novos arranjos, seja para solucionar um problema específico, seja para tratar de um conjunto de problemas, a fim de garantir a sobrevivência da organização (LAWRENCE, 1999; LAWRENCE; SIMON, 2008; TOLBERT; ZUCKER, 1996).

Nesse sentido, a estratégia das empresas é a resposta às pressões institucionais; e as inovações se estabelecem como práticas necessárias à adaptação, tanto a esses processos de diferenciação e de competitividade, como no desenvolvimento de novos produtos (ERNST et $a l ., 2015)$. Isto é, o desenvolvimento de novas tecnologias e de inovação inclui um processo de institucionalização (habitualização, objetivação e sedimentação), que integra as tecnologias existentes e os múltiplos atores do ambiente institucional, com foco em novas proposições de valor (FUENFSCHILLING; TRUFFER, 2014; VARGO; WIELAND; AKAKA, 2015).

Para DiMaggio e Powell (1983), os processos coercitivos advêm de pressões formais e informais, exercidas pelo governo, por outras organizações e pela cultura do meio ambiente da organização. Os processos miméticos, por sua vez, estão associados a incertezas, inerentes à tecnologia e à dinâmica do mercado, fatores responsáveis por direcionar as práticas das organizações que lideram em seu campo de atuação. O isomorfismo normativo, por sua vez, é resultado das estruturas e de padrões cognitivos, controlados e criados pelos órgãos reguladores (DIMAGGIO; POWELL, 1983; LAWRENCE; SIMON, 2008).

O sucesso organizacional, no entanto, não está limitado apenas à conformidade a esses processos, pois resulta, também, de estratégias de adesão, compromisso, prevenção, desafio e, 
inclusive, da manipulação das pressões às quais as empresas estão sujeitas (MITEREV; ENGWALL; JERBRANT, 2017; OLIVER, 1991).

O estudo dos impactos das pressões institucionais sobre as estratégias das organizações foi amplamente desenvolvido na literatura de operações, negócios e projetos (CAO; LI; WANG, 2014; DADDI et al., 2016; DUBEY; GUNASEKARAN; SAMAR ALI, 2015; HE et al., 2016; LIU et al., 2010; YE et al., 2013; ZHU; SARKIS; LAI, 2013), sendo também encontrado em trabalhos de responsabilidade social corporativa e de sustentabilidade (CLEMENS; BAMFORD; DOUGLAS, 2008; WIJETHILAKE; MUNIR; APPUHAMI, 2017); de gerenciamento da cadeia de suprimentos (MCFARLAND; BLOODGOOD; PAYAN, 2008); de negócios internacionais (PENG, 2003; PENG et al., 2009); e acerca de estratégias de internacionalização (ANG; BENISCHKE; DOH, 2015; SANTANGELO; MEYER, 2011).

Sendo assim, o ambiente institucional impacta a estratégia da organização, tanto em sua orientação como em sua execução. A orientação estratégica de uma organização é composta por princípios, que: guiam as suas atividades de marketing e a própria elaboração das estratégias, representam os elementos da sua cultura, e direcionam as interações com o mercado, os consumidores e os competidores (M'ZUNGU; MERRILEES; MILLER, 2017; NOBLE; SINHA; KUMAR, 2002).

Por meio da orientação estratégica, a organização cria comportamentos adequados à continuidade do seu desempenho superior, alinhando-os aos consumidores, à competitividade, e ao desenvolvimento tecnológico (NARVER; SLATER, 1990). No que diz respeito à inovação, essa orientação deve ser contínua, estando relacionada ao desenvolvimento e à introdução de produtos e de serviços inovadores no mercado, antes de seus concorrentes (KERIN; VARADARAJAN; PETERSON, 1992). Isso permite às organizações prever riscos; tomar ações preventivas quanto aos concorrentes; atualizar-se, no que tange aos avanços tecnológicos; responder às mudanças ambientais; e atender às expectativas de seus consumidores, de modo a reconfigurar capacidades e processos organizacionais voltados à competitividade (CARAYANNIS et al., 2014).

A proposta de definição do construto de execução estratégica, de De Oliveira, Carneiro e Esteves (2019), considera que o conceito envolve os processos e os procedimentos necessários ao fluxo de comunicação organizacional interna sobre os desafios, bem como a tradução do plano estratégico em ações específicas, estabelecendo, com isso, consistência entre os esforços distribuídos pela organização e as decisões de uso de recursos.

Assim, entre a soma de atividades e as escolhas necessárias à execução do plano estratégico (HREBINIAK, 2006), a orientação estratégica deve ser disseminada para as 
atividades de produção, no fluxo de informações, e para utilizar esforços disciplinados, a partir de um roteiro de operacionalização. Logo, o ambiente institucional pode impactar tanto a orientação das estratégias quanto a execução das práticas da produção.

No âmbito do contexto institucional, com clientes e sociedade interessados em atitudes empresariais social e ecologicamente representativas (BASU; PALAZZO, 2008), a orientação estratégica ambiental das organizações reflete o quanto elas estão comprometidas com a proteção do meio ambiente, quais os seus limites ao respeitá-lo e ao cuidar dele, e como elas respondem às partes externas sobre as suas atitudes (BANERJEE, 2001).

Nesse sentido, as ameaças naturais de escassez de recursos estão movendo os governos mundiais a instituir regulamentos rigorosos sobre as emissões e a eficiência energética (como os esquemas de comércio de carbono e/ou tecnologias de eficiência), nas economias dos mercados desenvolvidos e emergentes (ZAKARYA et al., 2015); e os consumidores, nos países em desenvolvimento, a se tornarem mais conscientes dos custos, da qualidade e da facilidade de uso de produtos e serviços (RAO, 2013b).

Assim, a orientação estratégica para a ecoinovação pode ser entendida como os recursos estratégicos da organização, que abrangem desde os avanços tecnológicos, voltados à preservação ambiental, até as escolhas, quanto ao desenvolvimento da inovação em produtos e processos com menos danos ao meio ambiente (HSU; TAN; ZAILANI, 2016; SEGARRAONA; PEIRO-SIGNES; PAYA-MARTINEZ, 2014).

Aplicada à execução das práticas de produção ecoeficientes e sustentáveis, a orientação estratégica promove a mudança de modelos de negócio lineares, baseados na produçãoextração-consumo-descartável, para modelos voltados a soluções focadas no longo prazo, com impacto em tecnologias, infraestrutura, estilo de vida e consumo (PANSERA, 2013).

Por meio desses novos modelos, direcionados à redução do dano ambiental, as inovações criam impactos significativos para o meio ambiente e/ou a sociedade, usando arquétipos de maximização da eficiência material e energética; a criação de valor, a partir dos resíduos; a substituição por processos renováveis e naturais; o incentivo à suficiência; a entrega de funcionalidade principal; e o desenvolvimento de soluções escalonáveis (BOCKEN et al., 2014).

Os resultados, para a sociedade, de organizações que seguem orientações estratégicas para a ecoinovação, vão desde a entrega de produtos mais sustentáveis em seu processo de criação de valor, à preocupação com as externalidades, criadas pelo uso, dentro do ciclo de vida, e a possibilidade de reciclagem e reuso desses produtos, com a redução das emissões de gases/ruídos ou de efeitos negativos para a saúde (BREM; IVENS, 2013). 
Ao contribuir com práticas sustentáveis, na gestão de operações e na adoção de programas ambientais, as organizações obtêm benefícios econômicos, melhoria do seu desempenho e maior competitividade global (GOTSCHOL; DE GIOVANNI; VINZI, 2014; KLEINDORFER; SINGHAL; WASSENHOVE, 2005).

Os esforços, realizados pelas organizações para evitar a poluição e reduzir as emissões de ruídos/gases prejudiciais ao meio ambiente, são recompensados com: (a) o aumento da sua eficiência e da vantagem de custo (HART; AHUJA; ARBOR, 1996); (b) a evolução da sua receita líquida (NIDUMOLU; PRAHALAD; RANGASWAMI, 2009); e, quando integrados às cadeias de valor, (c) o aperfeiçoamento do seu desempenho financeiro (CLEMENS; BAKSTRAN, 2010; ZHU; SARKIS; LAI, 2007b).

Considerando esses resultados, pesquisas e decisões estratégicas são direcionadas para compreender e expandir o uso dos fatores envolvidos na relação entre a orientação estratégica para a ecoinovação e a gestão das práticas de manufatura verde, tanto na gestão ambiental das operações (JAYARAM; AVITTATHUR, 2015) quanto na melhoria do desempenho organizacional (REHMAN; SETH; SHRIVASTAVA, 2016; ROY; KHASTAGIR, 2016). Então, sob o ponto de vista estratégico, a orientação para a ecoinovação é uma ferramenta de uso essencial nas organizações já estabelecidas, para a manutenção de sua posição competitiva; e nas novas empresas, que desejam entrar no mercado (DORAN; RYAN, 2016), mas são dependentes de fatores internos e externos.

A partir dos diferentes termos, utilizados na literatura para conceituar as inovações voltadas a otimizar e a minimizar o uso de recursos naturais, a seção seguinte trata do recorte desta pesquisa quanto à definição de ecoinovação.

\subsubsection{Ecoinovação}

De conceituação recente na literatura, a ecoinovação é apresentada por diferentes termos, como: inovação verde, inovação sustentável e inovação ambiental (SCHIEDERIG; TIETZE; HERSTATT, 2012). Essa sobreposição conceitual para descrever as inovações sustentáveis dificulta a delimitação da sua aplicação e dos seus valores práticos (CARRILLOHERMOSILLA; DEL RÍO; KÖNNÖLÄ, 2010) quanto à preservação de recursos, à representatividade nas ações a ela relacionadas (FRANCESCHINI; FARIA; JUROWETZKI, 2016), e à generalidade com a qual as suas características são tratadas (FALK; RYAN, 2007).

Dessa forma, o conhecimento dessas diferenças e dos campos de estudo específicos para cada termo é relevante para influenciar as políticas de sustentabilidade (FRANCESCHINI; 
FARIA; JUROWETZKI, 2016), e para contribuir com o crescimento das pesquisas relacionadas ao desenvolvimento sustentável e à inovação tecnológica, no que se refere à sua conceituação, seu entendimento, suas características e os efeitos produzidos (KLEWITZ; ZEYEN; HANSEN, 2012).

Os principais estudos e revisões da literatura, que determinam esse campo de estudo voltado à sustentabilidade (ARUNDEL; KEMP, 2009; FRANCESCHINI; FARIA; JUROWETZKI, 2016; OLTRA; KEMP; VRIES, 2010; RENNINGS, 2000; SCHIEDERIG; TIETZE; HERSTATT, 2012; XAVIER et al., 2017), bem como as revisões sistemáticas, permitem diferenciar os termos utilizados, delinear foco e motivações (ALBORT-MORANT et al., 2017; CARRILLO-HERMOSILLA; DEL RÍO; KÖNNÖL̈̈, 2010; DEL RÍO; PEÑASCO; ROMERO-JORDÁN, 2016; DÍAZ-GARCÍA; GONZÁLEZ-MORENO; SÁEZ-MARTÍNEZ, 2015; HOJNIK; RUZZIER, 2016; KARAKAYA; HIDALGO; NUUR, 2014), e explorar o progresso do tema e suas relações organizacionais.

A ascensão de trabalhos que discutem questões ambientais surgiu em meados dos anos 1990, incentivada pelo relatório Brundtland, de 1987, na literatura de negócios (ELKINGTON, 1998; PORTER; LINDE, 1995), na economia (JAFFE et al., 1995; JAFFE; PALMER, 1997; JAFFE; STAVINS, 1995), e no desenvolvimento de produtos (KEOLEIAN; MENEREY, 1994). A seguir (Quadro 1), está a agenda de pesquisa dos autores de ecoinovação, sendo que o Apêndice $\mathrm{C}$ detalha as principais características por eles levantadas.

Quadro 1 - Agenda de pesquisa da ecoinovação

(continua)

\begin{tabular}{ll}
\hline Autor(es) & Enfoque \\
\hline (ELKINGTON, 1998; PORTER; LINDE, 1995) & Negócios e gestão. \\
\hline (JAFFE et al., 1995; JAFFE; PALMER, 1997; JAFFE; STAVINS, & Econômico. \\
1995) & Desenvolvimento de produtos. \\
\hline (KEOLEIAN; MENEREY, 1994) & $\begin{array}{l}\text { Inovações em processos e produtos, } \\
\text { voltadas às questões de meio ambiente. }\end{array}$ \\
\hline $\begin{array}{l}\text { (ARUNDEL; KEMP, 2009; DE MARCHI, 2012; HOJNIK; } \\
\text { OLTRA; SAINT JEAN, 2009; TRIGUERO; MORENO- }\end{array}$ & \\
MONDÉJAR; DAVIA, 2013) & $\begin{array}{l}\text { Planejamento para a infraestrutura e } \\
\text { intervenções nos sistemas } \\
\text { organizacionais, comunitários e } \\
\text { estaduais. }\end{array}$ \\
\hline $\begin{array}{l}\text { (JOHNSON } \text { et al., 2004) } \\
\text { Desempenho e vantagem competitiva. }\end{array}$ \\
\hline (CHEN; LAI; WEN, 2006; PUJARI, 2006) & \begin{tabular}{l} 
Difusão internacional. \\
\hline (BEISE; RENNINGS, 2005)
\end{tabular} \\
\hline (MARKARD; RAVEN; TRUFFER, 2012; SCHOT; GEELS, 2008) & $\begin{array}{l}\text { Agenda de pesquisa de temática } \\
\text { sustentável. }\end{array}$ \\
\hline
\end{tabular}


Quadro 2 - Agenda de pesquisa da ecoinovação

(conclusão)

\begin{tabular}{ll}
\hline Autor(es) & Enfoque \\
\hline $\begin{array}{l}\text { (BRUNNERMEIER; COHEN, 2003; HORBACH, 2008; } \\
\text { HORBACH; RAMMER; RENNINGS, 2012; KESIDOU; }\end{array}$ & $\begin{array}{l}\text { Fatores determinantes e direcionadores } \\
\text { das inovações sustentáveis. }\end{array}$ \\
\hline $\begin{array}{l}\text { DEMIREL, 2012; QI } \text { et al., 2010) } \\
\text { CARRILLO-HERMOSILLA; DEL RÍO; KÖNNÖLÄ, 2010; } \text { et al., 2013; BOONS; LÜDEKE-FREUND, 2013; }\end{array}$ & $\begin{array}{l}\text { Modelos de negócios centrados em } \\
\text { ecoinovação. }\end{array}$ \\
DANGELICO; PUJARI, 2010) & $\begin{array}{l}\text { Relações com a cadeia de suprimentos } \\
\text { e manufatura. }\end{array}$ \\
\hline (CHIOU et al., 2011; GOLD; SEURING; BESKE, 2010) & $\begin{array}{l}\text { Desempenho financeiro das } \\
\text { organizações. }\end{array}$ \\
\hline (PRZYCHODZEN; PRZYCHODZEN, 2015) & \\
\hline
\end{tabular}

Fonte: Autora.

O trabalho de Rennings (2000), no início da década seguinte, consolidou e veio a delinear o conceito das inovações voltadas às questões de meio ambiente, sendo uma das principais referências para as pesquisas subsequentes (ARUNDEL; KEMP, 2009; DE MARCHI, 2012; HOJNIK; RUZZIER, 2016; HORBACH; RAMMER; RENNINGS, 2012; OLTRA; SAINT JEAN, 2009; TRIGUERO; MORENO-MONDÉJAR; DAVIA, 2013).

A partir desse estudo seminal, são abordados: o planejamento das inovações, quanto à infraestrutura e às intervenções nos sistemas organizacionais, comunitários e estaduais (JOHNSON et al., 2004); a influência do desempenho das inovações verdes e das ecoinovações na vantagem competitiva (CHEN; LAI; WEN, 2006; PUJARI, 2006); e a difusão internacional da inovação ambiental (BEISE; RENNINGS, 2005). Destacam-se, nessa linha, os estudos de agenda de pesquisa de temática sustentável (MARKARD; RAVEN; TRUFFER, 2012; SCHOT; GEELS, 2008), e os fatores determinantes e direcionadores das inovações sustentáveis (BRUNNERMEIER; COHEN, 2003; HORBACH, 2008; HORBACH; RAMMER; RENNINGS, 2012; KESIDOU; DEMIREL, 2012; QI et al., 2010).

Na última década, as discussões da ecoinovação têm sido centradas nos modelos de negócios das organizações (BOONS et al., 2013; BOONS; LÜDEKE-FREUND, 2013; CARRILLO-HERMOSILLA; DEL RÍO; KÖNNÖLÄ, 2010; DANGELICO; PUJARI, 2010), nas relações com a cadeia de suprimentos e manufatura (CHIOU et al., 2011; GOLD; SEURING; BESKE, 2010), e no desempenho financeiro das organizações (PRZYCHODZEN; PRZYCHODZEN, 2015).

A análise da literatura das inovações sustentáveis também permite vislumbrar a expansão das discussões dos mercados desenvolvidos (ALBORT-MORANT et al., 2018; AMORES-SALVADÓ; CASTRO; NAVAS-LÓPEZ, 2014; HOJNIK; RUZZIER, 2016) para 
os emergentes (CHENG; YANG; SHEU, 2014; LIN et al., 2014; WENG; CHEN; CHEN, 2015), bem como as tendências de estudos futuros, quanto a modelos de negócios voltados à ecoinovação e ao papel da colaboração para as soluções de alto desempenho (DANGELICO; PONTRANDOLFO, 2015; ROSCOE; COUSINS; LAMMING, 2016; XAVIER et al., 2017).

Apesar das variações do conceito de ecoinovação, ao longo de sua evolução, o objetivo em comum encontrado é desenvolver produtos, processos e serviços com menor efeito ambiental, foco na preservação da vida e no bem-estar, e uso mais eficiente dos recursos (HOJNIK; RUZZIER, 2016).

Além disso, segundo Fussler e James (1996), mesmo que haja diferenciação entre os termos utilizados nos desdobramentos da ecoinovação - inovação verde (DRIESSEN; HILLEBRAND, 2002), inovação ambiental (OLTRA; SAINT JEAN, 2009) e inovação sustentável (SCHIEDERIG; TIETZE; HERSTATT, 2012) - a preocupação comum entre estes conceitos concentra-se nas questões ambientais, em suas perspectivas futuras, e como estas inovações irão contribuir para a renovação do sistema de inovação, e sobrevivência das organizações (CARRILLO-HERMOSILLA; DEL RÍO; KÖNNÖL̈̈, 2010; REHMAN; SETH; SHRIVASTAVA, 2016).

Vale destacar, contudo, que a ecoinovação está focada nas atividades de ecodesign; e as inovações ambientais, nas políticas e nos regulamentos (FRANCESCHINI; FARIA; JUROWETZKI, 2016). Ademais, diferentemente da inovação verde, a ecoinovação não precisa ser desenvolvida com o objetivo de somente reduzir a carga ambiental (DRIESSEN; HILLEBRAND, 2002), pois ela deve contemplar atividades de conscientização sobre a necessidade da redução de recursos em todo o fluxo da cadeia de produção (CHARTER; CLARK, 2007; SCHIEDERIG; TIETZE; HERSTATT, 2012). Ao abordar todas as etapas do ciclo de vida do produto e de serviços, integrando as etapas de produção aos objetivos de redução dos efeitos no meio ambiente, a ecoinovação é voltada à satisfação do mercado, ao reduzir os impactos negativos (SCHIEDERIG; TIETZE; HERSTATT, 2012).

Assim, o uso do termo "ecoinovação" por esta pesquisa seguirá a delimitação proposta por Schiederig, Tietze e Herstatt (2012), e Franceschini, Faria e Jurowetzki (2016), isto é, são consideradas ecoinovações as inovações relacionadas à produção, à assimilação ou à exploração de produtos, de processos de produção, de serviços, ou de métodos de gestão e negócios, que sejam novidade para a organização, e que tenham como resultado a redução do risco ambiental, da poluição ou dos demais impactos negativos decorrentes de suas operações (ANTONIOLI; MAZZANTI, 2017; ARUNDEL; KEMP, 2009; BEISE; RENNINGS, 2005; OLTRA; SAINT JEAN, 2009). 
A partir do redesenho de sistemas e de produtos, as ecoinovações podem: substituir recursos e materiais não sustentáveis (BOCKEN et al., 2014; KLEWITZ; HANSEN, 2014); aumentar a durabilidade e a qualidade de produtos e serviços, a partir do foco em design, nos processos e na mentalidade do negócio (KIEFER et al., 2017); ampliar o ciclo de vida de produtos, reduzindo o ritmo de sua substituição e reparo (KAMMERER, 2009; KLEWITZ; HANSEN, 2014); e influenciar novos modelos de negócio (BOCKEN et al., 2014). Sua área de atuação está centrada, portanto, em integrar os processos de inovação às dimensões do desenvolvimento de produtos, de processos ou de soluções verdes, que considerem desde o design conceitual até os novos valores de sustentabilidade para atenuar os impactos ambientais, promovendo a conexão e a inclusão social (DAMANPOUR; ARAVIND, 2012).

Por essa perspectiva, a ecoinovação depende da governança institucional, da aquisição e da renovação dos conhecimentos, nas dimensões de: design, usuários, desenvolvimento de produtos e serviços, interação com instituições. Ela está, assim, vinculada à evolução de tecnologias pré-existentes, ao aumento da ecoeficiência, e aos novos paradigmas tecnológicos (CARRILLO-HERMOSILLA; DEL RÍO; KÖNNÖLÄ, 2010). Paralelamente, a partir das mudanças e das exigências da economia dos mercados, e das adaptações pelas instituições, formadas dentro e fora do mercado onde atuam, as inovações ecológicas evoluem quando o mercado se torna mais verde (FOXON; ANDERSEN, 2009).

O desenvolvimento de ecoinovações pelas organizações depende também de fatores internos, ou seja, da existência de um escopo estratégico, para: contemplar as alterações em produtos e processos; integrar os valores ambientais à empresa (CARRILLO-HERMOSILLA; DEL RÍO; KÖNNÖLÄ, 2010; EL-KAFAFI; LIDDLE, 2010; HORBACH; RAMMER; RENNINGS, 2012; RAMUS, STEGER, 2000); entender a mudança das percepções ecológicas dos clientes (CAI; ZHOU, 2014; DORAN; RYAN, 2012; TSAI et al., 2012; TESTA; IRALDO, 2010); desenvolver o enfoque da alta gestão em inovações que promovam iniciativas verdes (HSU; TAN; ZAILANI, 2016; TESTA; IRALDO, 2010; ZHANG et al., 2013).

A estruturação de novos valores ambientais (CHENG; YANG; SHEU, 2014), o investimento em capacitação, e a construção de uma cultura de sustentabilidade (INIGO; ALBAREDA, 2019) impulsionam as práticas de ecoinovação. A responsabilidade ambiental se reflete no aumento da interação de P\&D interna (HORBACH; RAMMER; RENNINGS, 2012), na evolução das inovações ambientais (TRIGUERO; MORENO-MONDÉJAR; DAVIA, 2013) e, consequentemente, em resultados positivos financeiros e de participação no mercado (MONTABON; SROUFE; NARASIMHAN, 2007; YU; HUO, 2019). 
A capacidade tecnológica e organizacional (KESIDOU; DEMIREL, 2012), nas áreas de controle da poluição, de fornecimento e de projetos de produtos verdes, e o uso eficiente da energia (KEMP; PEARSON, 2007) são outros fatores internos essenciais ao direcionamento estratégico ecoinovador.

Os fatores externos também exercem um papel relevante na orientação estratégica para a ecoinovação, em países desenvolvidos e emergentes. Em mercados desenvolvidos, como Japão, Alemanha e Estados Unidos, a orientação para a inovação é consequência do rigor e da estrutura das regulamentações existentes (POPP, 2006), sendo que, quanto maior o rigor, maior a probabilidade de desenvolvimento de P\&D (FRONDEL; HORBACH; RENNINGS, 2008). Em mercados emergentes, além dos fatores internos, como recursos, estruturas e capacidades principais da organização, as pressões externas induzem as empresas a adotar práticas proativas (CAI; LI, 2018).

Nesse sentido, associada à pressão do mercado consumidor, a pressão regulatória tem impulsionado a adoção de tecnologias mais limpas (ARIMURA et al., 2016; DEL RÍO GONZÁLEZ, 2009), aplicadas no final da cadeia de produção ou na economia de custos e nos sistemas de gerenciamento ambiental (FRONDEL; HORBACH; RENNINGS, 2008). Esses fatores impactam positivamente e reforçam o compromisso da organização em cultivar capacidades para a construção da cadeia logística sustentável, incluindo sua relação com as práticas de manufatura verde (CHEN; HUNG, 2014; HSU; TAN; ZAILANI, 2016).

A partir do papel da inovação frugal, no cenário de sustentabilidade do mundo global (BREM, 2017), para as estratégias de orientação sustentável (VILCHEZ; HIZ, 2018), e da preocupação quanto às questões de sustentabilidade, inseridas na estratégia de inovação frugal da organização (SANTOS; BORINI; OLIVEIRA JÚNIOR, 2020), a seção seguinte apresenta o conceito de inovação frugal, suas dimensões e os principais trabalhos que a abordam.

\subsection{INOVAÇÃO FRUGAL}

Alçada a tópico relevante dentro do campo da inovação, nos últimos anos, tanto em mercados emergentes quanto nos desenvolvidos, a inovação frugal traz na centralidade de seu conceito a possibilidade de inovar "mais com menos", reconsiderando o que se sabia, até então, sobre a natureza da inovação, suas motivações, meios e os impactos por ela gerados na sociedade (KHAN, 2016).

Originadas nos mercados emergentes ou em desenvolvimento, como resposta às necessidades dos consumidores da base da pirâmide (BoP - Base of Pyramid), as inovações 
frugais oferecem soluções específicas ao mercado, de alto valor agregado e baixo custo (RADJOU; PRABHU, 2012). Elas inovam de forma rápida, sob a restrição de recursos, redesenhando produtos, processos e modelos de negócios (SONI; KRISHNAN, 2014).

Mais do que uma tipologia (PISONI; MICHELINI; MARTIGNONI, 2018), por meio de sua abordagem, em desenvolver, produzir e gerenciar serviços com economia de recursos, a inovação frugal evita custos desnecessários (BREM; WOLFRAM, 2014; PRABHU; JAIN, 2015), promovendo soluções de qualidade e acessíveis aos clientes da base da pirâmide (HYVÄRINEN; KESKINEN; VARIS, 2016; NOCERA, 2012).

Por conta disso, as organizações podem repensar as suas práticas operacionais (HYVÄRINEN; KESKINEN; VARIS, 2016; ZESCHKY; WIDENMAYER; GASSMANN, 2011), contrastando a inovação frugal com processos, produtos e serviços ineficientes em energia, em consumo de matéria-prima e em danos ambientais (GUPTA; WANG, 2009).

Em suma, o conceito inicial da inovação frugal envolve a intersecção da variedade de atividades heterogêneas, realizadas pela organização, que vão desde o design à engenharia reversa e à manufatura enxuta, centradas no mercado de base da pirâmide e em suas necessidades sociais e econômicas (BHATTI, 2012; BHATTI; VENTRESCA, 2013).

Devido à novidade do conceito, para estudar a inovação frugal, é necessário destacar as diferenças e os pontos de inflexão com as demais inovações dos mercados emergentes. A literatura sobre o assunto apresenta algumas de suas características, conceituadas como inovação jugaad (BREM; WOLFRAM, 2014; PRABHU; JAIN, 2015; SHARMA; IYER, 2012), entre outros termos, para identificar as inovações que ocorrem em mercados emergentes (inovação reversa, inovação de custo, good-enough e disruptiva).

Apesar da relação entre os termos, há distinções que devem ser consideradas, para o aprofundamento das pesquisas sobre o assunto (ZESCHKY; WINTERHALTER; GASSMANN, 2014). Enquanto a inovação de custo e a good-enough são soluções de engenharia, que privilegiam alternativas de baixo custo, para produtos já existentes, em mercados desenvolvidos, a inovação frugal está baseada em novos desenvolvimentos, aplicados a produtos e serviços, por meio de novas tecnologias, voltadas a novos mercados, cuja arquitetura permite aplicações com preços mais baixos (WILLIAMSON, 2010; ZESCHKY; WINTERHALTER; GASSMANN, 2014). Mesmo sendo disruptiva (GOVINDARAJAN; KOPALLE, 2006; HART; CHRISTENSEN, 2002; RAO, 2013b), a inovação frugal pode atingir novos mercados, tendo, assim, uma proposta de valor inteiramente nova (ZESCHKY; WINTERHALTER; GASSMANN, 2014). 
Quanto à aproximação entre inovação reversa e inovação frugal, a literatura destaca sua inter-relação (GOVINDARAJAN; RAMAMURTI, 2011; ZEDTWITZ et al., 2015), tanto que, não raro, elas são apresentadas de maneira conjunta (BREM; IVENS, 2013). Isso se dá porque as inovações reversas são frugais, mas as frugais podem ser desenvolvidas em mercados emergentes, sem transferência aos mercados desenvolvidos (ROSCA; ARNOLD; BENDUL, 2017; SIMULA, HOSSAIN, HALME, 2015).

Sendo assim, a inovação frugal demonstra pertencer a uma dimensão de maior capacidade tecnológica, com abrangência na redução de custos, na entrada em novos mercados e em função da apresentação de novas tecnologias para o fortalecimento da competitividade das organizações (ZESCHKY; WINTERHALTER; GASSMANN, 2014).

A evolução das definições e o uso da inovação frugal podem ser analisados no contexto de três gerações (PISONI; MICHELINI; MARTIGNONI, 2018). Na primeira, as inovações estão voltadas aos produtos e aos serviços frugais, tendo baixo preço, design compacto, uso limitado de matérias-primas ou reutilização de componentes existentes, além de facilidade de uso e tecnologia de ponta (RAO, 2013b; TIWARI; HERSTATT, 2012c).

Nessa primeira geração, a inovação frugal está centrada nos critérios de acessibilidade (AGARWAL; BREM, 2012; AHUJA; CHAN, 2014; KAHLE et al., 2013; OJHA, 2014), em produtos de alto valor (BREM; WOLFRAM, 2014; HART; AHUJA; ARBOR, 1996; JHA; KRISHNAN, 2013; KAHLE; DUBIEL; ERNST, 2013), com baixo custo (AGARWAL; BREM, 2012; BREM; WOLFRAM, 2014; HART; AHUJA; ARBOR, 1996; JHA; KRISHNAN, 2013; OJHA, 2014), simplicidade (AGARWAL; BREM, 2012; BREM; WOLFRAM, 2014), robustez (GUPTA; WANG, 2009), sustentabilidade (BREM; WOLFRAM, 2014; HART; AHUJA; ARBOR, 1996; SHARMA; IYER, 2012), escalabilidade e eficiência (AHUJA; CHAN, 2014).

A característica marcante nos estudos supracitados é o delineamento de um modelopadrão de inovação, envolvendo pesquisas altamente estruturadas e dispendiosas (RADJOU; PRABHU, 2012), no qual as necessidades e o contexto dos cidadãos dos países emergentes são temas prioritários na discussão sobre o desenvolvimento de serviços e de produtos acessíveis, adequados e adaptados a uma realidade específica (BASU; BANERJEE; SWEENY, 2013).

A segunda geração é caracterizada pela diferenciação entre as formas de inovação, originadas em ambientes de recursos limitados (BREM; WOLFRAM, 2014; CUNHA et al., 2014; SONI; KRISHNAN, 2014; ZESCHKY; WINTERHALTER; GASSMANN, 2014), orientadas tanto ao mercado quanto aos processos (BASU; BANERJEE; SWEENY, 2013; PRABHU; JAIN, 2015). 
Na terceira geração, por sua vez, com a expansão dos mercados emergentes para os mercados desenvolvidos, há o retorno ao conceito central da inovação frugal, que envolve a redução significativa de custos, a concentração em funcionalidades básicas, e o nível de desempenho otimizado (WEYRAUCH; HERSTATT, 2016). O foco está no uso inteligente de recursos, transformando restrições em oportunidades e vantagens, direcionadas a produtos e serviços, no que diz respeito ao design, à funcionalidade, à qualidade e aos preços praticados (COLLEDANI et al., 2016).

Considerando estudos sobre inovações em ambientes de recursos limitados, com foco na redução de custos, na funcionalidade essencial e no uso sustentável de recursos (WEYRAUCH; HERSTATT, 2016), realizados em produtos, em processos, no marketing e na área organizacional (TIWARI; HERSTATT, 2012a), esta pesquisa se pauta no conceito de estratégia de inovação frugal de Santos, Borini e Oliveira Júnior. (2020). Para esses autores, o objetivo da solução tecnológica da inovação deve abranger, além da sustentabilidade econômica da organização, a sustentabilidade social e ambiental na criação de valor (PORTER; KRAMER, 2011), podendo ser aplicada em mercados desenvolvidos e emergentes.

Esta pesquisa, então, utiliza as seguintes dimensões da inovação frugal: (1) redução de custos, representando o empenho da organização em oferecer produtos e serviços acessíveis ao mercado, com a redução dos custos de processos, por meio da reorganização dos recursos empresariais já existentes (WEYRAUCH; HERSTATT, 2016; ZESCHKY; WIDENMAYER; GASSMANN, 2011; ZESCHKY; WINTERHALTER; GASSMANN, 2014); (2) foco na funcionalidade básica, que abrange o contexto da simplicidade e da baixa complexidade de uso, bem como a acessibilidade, a manutenção da qualidade, a potencialização do valor para o usuário, envolvendo aspectos relacionados à engenharia, tais como a forma e a durabilidade (FAROOQ, 2017; TIWARI; FISCHER; KALOGERAKIS, 2016; TIWARI; KALOGERAKIS; HERSTATT, 2014); e (3) ecossistema frugal, isto é, o conjunto de soluções eficientes e efetivas, em resposta às necessidades socioambientais dos clientes, de forma a empregar sustentabilidade ambiental e possibilitar parcerias no processo operacional com as empresas locais (ROSSETTO; BORINI, 2017).

A importância da extensão dos estudos dos impactos da inovação frugal nas organizações, tanto em mercados emergentes quanto naqueles já desenvolvidos, é justificada por fatores demográficos; pelas mudanças no papel dos países em desenvolvimento, dentro dos ecossistemas de inovação; e pela evolução das transformações tecnológicas, que aproximam esses mercados. 
Assim, a discussão sobre a aplicabilidade e os impactos gerados pela inovação frugal pode ser estendida aos mercados emergentes (ANGOT; PLÉ, 2015; GOVINDARAJAN; TRIMBLE, 2014; KHAN, 2016; TIWARI; FISCHER; KALOGERAKIS, 2016), nos quais esse tipo de inovação é alavancado pelo crescimento da população e por maior demanda de produtos destinados à classe média, com limitações de recursos, o que propicia a oportunidade de lidar com as lacunas institucionais existentes (BHATTI, 2012; PRAHALAD, 2012). Nesse sentido, deve-se também considerar que a população está em curva de envelhecimento, o que exigirá soluções frugais para a saúde e a assistência social, e a perspectiva de lento crescimento da economia nesses países (BOUND; THORNTON, 2012; HOSSAIN; SIMULA; HALME, 2016). Então, para tratar do crescimento das organizações, mesmo diante de tantas restrições (KHANNA; PALEPU; BULLOCK, 2010; ZESCHKY; WINTERHALTER; GASSMANN, 2014), há necessidade de mudar a mentalidade e o contexto, fatores pelos quais as inovações frugais foram exploradas até agora (BREM, 2017).

As transformações tecnológicas que aproximam esses mercados, impulsionadas pela atuação de multinacionais estrangeiras em países como China e Índia (BREM; IVENS, 2013; ZESCHKY; WIDENMAYER; GASSMANN, 2011), podem ser observadas na inclusão da inovação frugal nas políticas desses países, cujas economias puderam aprender e desenvolver suas capacidades inovadoras (AHMAD; RAMZAN, 2018; BOUND; THORNTON, 2012; DELLESTRAND, 2011; PRABHU; JAIN, 2015; XIE; LI, 2015), bem como na expansão dos centros de P\&D em subsidiárias, nas organizações locais e em grupos de inovação (HOSSAIN, 2016).

Nesse sentido, a fim de contribuir com as redes globais, em países emergentes, as multinacionais evoluíram de modelos de produção de imitação para atuar com a inovação em produtos e serviços (LI; KOZHIKODE, 2009). Para tanto, foram realizados investimentos em $\mathrm{P} \& \mathrm{D}$, e a aquisição de empresas no exterior, com fins de captar capital tecnológico (BREM; IVENS, 2013). Isso fez com que elas deixassem o papel secundário no painel de inovação global, para desenvolver suas próprias capacidades de inovação (GERYBADZE; REGER, 1997; LI; KOZHIKODE, 2009).

A literatura sobre operações, negócios e projetos enfatiza o papel das pressões institucionais para que as organizações desenvolvam estratégias e, consequentemente, capacidades de inovação (DADDI et al., 2016; DUBEY; GUNASEKARAN; SAMAR ALI, 2015; ZHU; HE, 2017), que sejam novas e diferenciadas das tradicionais, dentro de uma perspectiva de estratégia frugal, para trabalhar sob a restrição de recursos. (SANTOS; BORINI; OLIVEIRA JÚNIOR, 2020). 
Os hábitos e as crenças dos consumidores, como atores do ecossistema, e as regras de regulação das instituições formais influenciam as decisões das organizações, em seus processos de inovação frugal (OH et al., 2016; RONG; LIU; SHI, 2011; RONG; SHI, 2010). Nesse sentido, estudos demonstram que as regras e os regulamentos internacionais impulsionam as atividades de sustentabilidade e as inovações na cadeia de suprimentos, quando as organizações estão inseridas em redes globais de inovação (SHIBIN et al., 2018; ZHU; SARKIS, 2006; ZHU; SARKIS; LAI, 2007a).

No mercado desenvolvido europeu, por exemplo, regras e regulamentos visando à reciclagem de matérias-primas incentivam a inovação e a sustentabilidade na cadeia de suprimentos, assim como os regulamentos ambientais estimulam as organizações a reduzir o consumo de matéria-prima e se adequar aos padrões permitidos de emissão de resíduos, o que os leva, por conseguinte, a investir em tecnologia (JI; GUNASEKARAN; YANG, 2014). Já, para os mercados emergentes, a inovação frugal melhora a gestão da sustentabilidade, quanto à entrada de matérias-primas, ao valor das atividades e às saídas dos processos de inovação (BREM; IVENS, 2013).

Por ser uma perspectiva de inovação centrada nas necessidades dos clientes, ao inovar, as organizações ficam sob a influência da demanda, considerando o comportamento do consumidor, em um ambiente de recursos limitados, e o seu relacionamento com as questões de sustentabilidade (PISONI; MICHELINI; MARTIGNONI, 2018).

Com um mercado cada vez mais exigente, não só nos países em desenvolvimento, como também nos desenvolvidos, o critério de desempenho é representado pela qualidade das inovações frugais, cujos padrões são atendidos de maneira econômica, alinhada aos requisitos de funcionalidade básica e de baixo custo (SONI; KRISHNAN, 2014; TIWARI; HERSTATT, 2012c; WEYRAUCH; HERSTATT, 2016).

Concomitantemente, é crescente o conceito de vida frugal, de menor consumo de bens e de materiais (ALCOTT, 2008; LASTOVICKA et al., 1999). Assim, para economias em desenvolvimento, as questões centrais da influência do consumidor nos processos de inovação são a ausência de recursos e as condições financeiras desfavoráveis (SINGH; GUPTA; MONDAL, 2012). E, para o consumidor de mercados desenvolvidos, a preservação dos recursos naturais e o consumo frugal, como um estilo de vida, são elementos de pressão (PISONI; MICHELINI; MARTIGNONI, 2018), visto que se busca por soluções mais simples, com qualidade, e a preços acessíveis - fatores beneficiados pela abordagem da inovação frugal (COLLEDANI et al., 2016; MATZLER et al., 2014). A frugalidade, então, para esses consumidores, surge como um estilo de vida, que inclui consumo, atitudes (GOLDSMITH; 
FLYNN REINECKE; CLARK, 2014), virtudes (BOVE; NAGPAL; DORSETT, 2009), influência nas redes pessoais (LEE, 2016), e consciência ecológica e social (CHO; GUPTA; KIM, 2015).

Sendo assim, as ideias e as características da inovação frugal não apenas atendem aos consumidores de classe média ou baixa, em países emergentes, mas também ao cenário de desaceleração e o padrão de consumo, em países desenvolvidos (PANSERA, 2018; ROSCA; REEDY; BENDUL, 2018; TIWARI; FISCHER; KALOGERAKIS, 2016). Os atributos da inovação frugal, de diminuição substancial de custos, concentração em funcionalidades básicas e nível de desempenho otimizado, diferem entre mercados apenas quanto à sua forma de aplicação, a depender dos contextos locais e das necessidades (WEYRAUCH; HERSTATT, 2016). Essas características têm destacado papel da inovação frugal como alavanca para o crescimento da economia, sem danos ao ambiente (BREM, 2017).

Quanto aos contextos de colaboração, as abordagens frugais de inovação demonstram ser dependentes das estruturas dos ecossistemas onde elas estão inseridas (AROCENA; BO; SUTZ, 2015; DANDONOLI, 2013; DEDEHAYIR; MÄKINEN; ROLAND ORTT, 2016). Isso se explica porque, ao participar do ecossistema, novos conhecimentos resultam das interações e da exploração de processos entre os atores dos contextos institucional e social (MOORE, 1993). Instituições formais e informais, comunidades, consumidores e intermediários de inovação estão incluídos nessas complexas redes de conhecimento (ADNER, 2016; RONG; LIU; SHI, 2011). A mudança da forma de inovar, por meio dos ecossistemas, inclui colaborar com novos parceiros para a busca de oportunidades, de novos mercados e de aplicações, extrapolando as estruturas e as organizações pré-estabelecidas, e utilizando o conhecimento local, com investimentos e riscos financeiros menores (HYVÄRINEN; KESKINEN; VARIS, 2016).

Em relação à manufatura, mais do que estar direcionada ao mercado da base da pirâmide, a inovação frugal desafia os caminhos e os processos produtivos, pelos quais as organizações inovam (RADJOU; PRABHU, 2014), relacionando-se com as partes interessadas para atingir as metas de desenvolvimento sustentável (ROSCA; REEDY; BENDUL, 2018). Nesse sentido, em regiões dispersas, para que a sua capacidade de difusão seja alcançada, é necessário considerar a cultura organizacional e o ambiente de negócios, de forma simultânea, incluindo a cadeia de suprimentos, os fornecedores e a capacitação de profissionais (HOSSAIN, 2017).

Por suas características de facilidade de uso, acessibilidade, escalabilidade, robustez e proposta de valor atrativa (TIWARI; HERSTATT, 2012a), as inovações frugais rompem com 
padrões e paradigmas, na arquitetura de novos produtos, designados a ambientes de recursos limitados (KNORRINGA et al., 2016; RAY; RAY, 2011), ao mesmo tempo que impactam a percepção do preço final pago pelo cliente (JHA; KRISHNAN, 2013; SHARMA; IYER, 2012; WEYRAUCH; HERSTATT, 2016) e a diminuição de custos de manufatura e de fornecedores (TIWARI; HERSTATT, 2012c; WINTERHALTER et al., 2017).

Na perspectiva evolutiva da inovação (DOSI; NELSON, 2016; NELSON; WINTER, 2002), a inovação frugal surge devido ao processo sistêmico de interações entre diferentes atores e fatores internos e externos, para atender, de forma frugal, às necessidades da organização (CARRILLO-HERMOSILLA; DEL RÍO; KÖNNÖLÄ, 2010). Em virtude disso, ela possibilita iniciativas na cadeia de fornecimento e no desenvolvimento de produtos verdes, e tem maior eficiência, se comparada à abordagem de produtos convencionais (RAO, 2013b; SHARMA; IYER, 2012). Além disso, essa inovação pode redefinir modelos de negócios, reconfigurar cadeias de valor e redesenhar produtos em diferentes formas (BHATTI, 2012).

$\mathrm{O}$ avanço desses direcionamentos estratégicos tem apontado a inovação frugal como uma valiosa contribuição para o desenvolvimento sustentável, associando suas práticas aos conhecimentos da gestão ambiental, em áreas potenciais de geração de energia e manufatura, aplicadas com a redução do uso de recursos, a reutilização e a reciclagem (BREM, 2017; ROSCA; REEDY; BENDUL, 2018). Por meio dessas práticas, pode-se promover produtos que atendam às necessidades dos consumidores; criar crescimento econômico mais inclusivo, envolvendo as comunidades locais (KNORRINGA et al., 2016); além de gerar lucro às organizações (SCHALTEGGER; HANSEN; LÜDEKE-FREUND, 2016).

A inovação frugal, portanto, como conceito, ultrapassa fronteiras geográficas; supera as dificuldades financeiras e sociais, de forma inclusiva; e se projeta como solução para impulsionar o crescimento sustentável dos negócios e das nações, tanto para países em desenvolvimento quanto aos já desenvolvidos (AGARWAL; BREM; DWIVEDI, 2019; BREM, 2017).

\subsubsection{Estratégia de Inovação Frugal e Ecoinovação}

Diante das implicações da inovação frugal nos negócios e na capacidade de gerar inovações disruptivas (RAO, 2013b), o estudo de suas dimensões tem sido determinado pelo crescimento das análises de seu alinhamento com o campo da estratégia. Isso pode ser percebido nos trabalhos que discutem a restrição de recursos, como meio estratégico para as organizações alcançarem seus objetivos de competitividade e de sobrevivência no mercado (BHATTI, 2012; 
BHATTI; VENTRESCA, 2013), tanto em países emergentes quanto nos desenvolvidos (GOVINDARAJAN; RAMAMURTI, 2011).

Estando a frugalidade relacionada à escassez dos recursos, aos vazios institucionais e à tolerância em relação à incerteza, Soni e Krishnan (2014) fazem a associação entre a inovação frugal, a perspectiva estratégica da visão baseada em recursos, a teoria pautada na indústria e a teoria institucional. Recursos escassos, ambiente de ameaças, oportunidades de um mercado não explorado e a busca por competitividade dentro do mercado são questões que podem ser atendidas a partir das características da inovação frugal, a partir da perspectiva de estratégia de inovação (SHIBIN et al., 2018).

O estudo da inovação frugal integrada à evolução da sustentabilidade tem crescido significativamente nos últimos anos, no campo da gestão ambiental, da sustentabilidade e da inovação (ROSCA; REEDY; BENDUL, 2018), haja vista a vital importância dessa integração para as operações das organizações, com fins de aprender a fazer mais com menos recursos, e de enfrentar a crescente pressão social por sustentabilidade (CUNHA et al., 2014; RAO, 2013b).

Nesse sentido, os estudos realizados apontam soluções sustentáveis, amparadas por estratégias de inovação frugal no design de produtos e nos serviços, visando conter o consumo de matéria-prima (AGARWAL et al., 2016; ZESCHKY; WINTERHALTER; GASSMANN, 2014), atender às pressões sociais para integrar sustentabilidade em suas operações (CUNHA et al., 2014; RAO, 2017a), e como contribuição relevante para a implementação de ecoinovações em mercados emergentes e desenvolvidos (PISONI; MICHELINI; MARTIGNONI, 2018).

Sob essa ótica, percebe-se que, sendo a sustentabilidade um dos principais direcionadores estratégicos, no campo da gestão da inovação, para os próximos anos (HORN; BREM, 2013), a estratégia de inovação frugal é o primeiro passo para organizar o desenvolvimento da ecoinovação, e inserir inovações sustentáveis em suas operações produtivas (BAS, 2016, 2017; BASU; BANERJEE; SWEENY, 2013).

Por meio da interação entre as estratégias de inovação frugal e a orientação estratégica para a ecoinovação e as práticas de operação, é possível corrigir as falhas nos processos produtivos com impacto ambiental; recuperar componentes, ao fim do ciclo de vida de produtos; reciclar componentes e materiais (BAS, 2016); criar produtos de alta qualidade, com baixo custo e consumo econômico; e auxiliar no desenvolvimento sustentável (BREM, 2017; RAO, 2017b). 
A seguir (Quadro 2), estão elencados estudos da inovação frugal, em sinergia com aspectos voltados à ecoinovação (as informações detalhadas dos artigos estão no Apêndice F). 
Quadro 3 - Inovação Frugal e Ecoinovação

(continua)

\begin{tabular}{|c|c|}
\hline Artigo & Transversalidade com a ecoinovação \\
\hline$(\mathrm{RAO}, 2013 \mathrm{a})$ & $\begin{array}{l}\text { O Uso mínimo de recursos para realizar o funcionamento eficiente dos produtos. } \\
\text { ○ Reutilização de componentes e designs mais simples, que resultam em produtos sem acessórios. } \\
\circ \text { Motivadas pela escassez de recursos, regulamentos ambientais mais rigorosos e maior eficiência energética dos países. }\end{array}$ \\
\hline $\begin{array}{l}\text { (ZESCHKY; WINTERHALTER; } \\
\text { GASSMANN, 2014) }\end{array}$ & ○ Novos designs de produtos ou serviços, visando reduzir o consumo de matéria-prima. \\
\hline (BREM; WOLFRAM, 2014) & $\begin{array}{l}\text { - Ideia ecológica quanto à possibilidade de reaproveitamento de recursos obsoletos/antigas tecnologias de outras } \\
\text { empresas, como substituição de recursos ausentes (próprios), sem custos adicionais. }\end{array}$ \\
\hline (CUNHA et al., 2014) & $\begin{array}{l}\text { Criar um futuro, no qual as empresas enfrentam crescentes pressões sociais para integrar a sustentabilidade em suas } \\
\text { operações, e aprender a fazer mais com menos. }\end{array}$ \\
\hline (AGNIHOTRI, 2015) & $\begin{array}{l}\text { Em comparação com os tipos de inovações radicais e outros, a inovação de baixo custo é geralmente mais ecológica e } \\
\text { conservadora de recursos, por ser de natureza mais simples. }\end{array}$ \\
\hline (AGARWAL et al., 2016) & $\begin{array}{l}\text { ○ Acessíveis, adaptáveis, com custo-benefício satisfatório, criativas, fáceis de usar, flexíveis, alta qualidade, sofisticadas, } \\
\text { intuitivas e enxutas, eficientes, ambientais e verdes. }\end{array}$ \\
\hline (RAO, 2017a) & $\begin{array}{l}\text { P Produtos sofisticados de baixo custo, e consumo econômico de recursos, com forças para o desenvolvimento } \\
\text { sustentável, por meio da ciência e da tecnologia, para a melhoria da sociedade, preservando os recursos da Terra. }\end{array}$ \\
\hline (SHARMA; IYER, 2012) & $\begin{array}{l}\text { A inovação frugal pode contribuir para o estabelecimento de uma cadeia de fornecimento verde e o desenvolvimento } \\
\text { de produtos verdes. }\end{array}$ \\
\hline (LEVÄNEN et al., 2016) & $\begin{array}{l}\text { Nos setores de energia e água, as inovações frugais podem ser vistas como mais sustentáveis do que as soluções } \\
\text { existentes. }\end{array}$ \\
\hline (PISONI; MICHELINI; MARTIGNONI, 2018) & $\begin{array}{l}\text { ○ A inovação frugal é uma contribuição relevante para a implementação de inovações verdes, em mercados } \\
\text { desenvolvidos e em desenvolvimento. }\end{array}$ \\
\hline (HYVÄRINEN; KESKINEN; VARIS, 2016) & $\begin{array}{l}\text { Devido ao seu foco em soluções acessíveis e na simplicidade, elas constituem um meio com aptidão para o setor } \\
\text { privado, no engajamento em desafios de desenvolvimento relacionados à água. }\end{array}$ \\
\hline (SHAN; KHAN, 2016) & $\begin{array}{l}\text { Por meio da inovação frugal, soluções voltadas à sustentabilidade podem ser transferidas de mercados emergentes para } \\
\text { mercados desenvolvidos (inovação reversa). }\end{array}$ \\
\hline (BREM; IVENS, 2013) & o Reduzir a quantidade e o tipo de recursos necessários à produção de uma oferta de mercado. \\
\hline
\end{tabular}

Fonte: Autora 
Quadro 2 - Inovação Frugal e Ecoinovação

(conclusão)

\begin{tabular}{|c|c|}
\hline Artigo & Transversalidade com conceito de ecoinovação \\
\hline (BREM, 2017) & $\begin{array}{l}\text { O Para direções futuras, a expectativa é que a inovação frugal tenha uma alta habilidade para impulsionar o crescimento } \\
\text { sustentável dos negócios e das nações, sem danos ao planeta. }\end{array}$ \\
\hline (ROSCA; REEDY; BENDUL, 2018) & $\begin{array}{l}\text { Foco no uso frugal de recursos, na inclusão de atores de baixa renda; sua natureza, de reunir as partes interessadas, } \\
\text { oferece potencial para caminhos de desenvolvimento sustentável. Setores de energia e de saúde são chaves para as } \\
\text { inovações frugais sustentáveis. }\end{array}$ \\
\hline (KHAN, 2016) & $\begin{array}{l}\text { - Possibilita a realização de metas de sustentabilidade social, sendo um dos principais pilares do desenvolvimento } \\
\text { sustentável das organizações e países. } \\
\text { ( Motivar o uso da eletricidade, gerada por turbinas de energia movidas a vento, é uma mudança comportamental } \\
\text { positiva, que promove o comportamento ecológico. }\end{array}$ \\
\hline (BHATTI, 2012) & ○ Frugalidade trata de como algo é usado para a redução ou a eliminação de resíduos. \\
\hline (HOSSAIN; SIMULA; HALME, 2016) & $\begin{array}{l}\text { P Para países em desenvolvimento e desenvolvidos, como solução ao crescimento populacional, ao aquecimento global e } \\
\text { à crescente demanda por sustentabilidade e melhor utilização de recursos. }\end{array}$ \\
\hline (WEYRAUCH; HERSTATT, 2016) & $\begin{array}{l}\text { ○ Não envolve necessariamente escalabilidade e sustentabilidade. Inovações frugais podem contribuir para a } \\
\text { sustentabilidade, minimizando o uso de recursos. No entanto, ser sustentável, muitas vezes, não é o foco principal. }\end{array}$ \\
\hline (PRAHALAD, 2012) & $\begin{array}{l}\text { Para a solução do sistema de cozimento de alimentos, na área rural da Índia, o produto cumpriu seus compromissos } \\
\text { funcionais de ser livre de fumaça e possuir eficiência energética. }\end{array}$ \\
\hline (BOCKEN; SHORT, 2016) & $\begin{array}{l}\text { Atende aos modelos de suficiência, no ciclo de vida dos produtos, ao beneficiar clientes na redução de custo, na fase de } \\
\text { uso, ou nos modelos de menor lucro, em empresas sociais. }\end{array}$ \\
\hline (COLLEDANI et al., 2016) & $\begin{array}{l}\text { As restrições ambientais/recursos podem impulsionar a inovação de produtos e serviços, aumentando sua } \\
\text { acessibilidade e a performance de sustentabilidade, durante o seu design (RAO, 2013a) e, de acordo com o contexto de } \\
\text { mercado. }\end{array}$ \\
\hline$(\mathrm{RAO}, 2017 \mathrm{~b})$ & $\begin{array}{l}\text { ○ O uso de um fator de inovação frugal pode mudar a filosofia do design clássico e criar produtos que estejam } \\
\text { sincronizados com princípios e políticas para mitigar os impactos da mudança climática e da carência de recursos. }\end{array}$ \\
\hline
\end{tabular}

Fonte: Autora. 
A estratégia de inovação frugal, que atende às pressões institucionais e promove a competitividade para as organizações, vai além do propósito da eficiência de recursos, ou de lidar com a escassez em mercados emergentes. Diferentemente da orientação à inovação frugal, focada em mercados emergentes e no valor econômico das inovações para a organização, voltada ao valor compartilhado, a estratégia de inovação frugal traz, em seu conceito, para a criação de valor social e ambiental, o atendimento aos mercados desenvolvidos e emergentes, com uma proposta de valor econômico, social e ambiental (SANTOS; BORINI; OLIVEIRA JÚNIOR, 2020).

Dessa forma, a abordagem da estratégica frugal, em seu valor ambiental, não trata só da eficiência, focada na oferta de produtos que usam menos recursos em sua produção, mas de suficiência das inovações frugais, oferecendo produtos e serviços com a intenção de diminuir também a demanda do consumo de bens e de recursos (AGNIHOTRI, 2015; ROSCA; REEDY; BENDUL, 2018).

Sendo assim, essa abordagem incentiva a organização na busca e no desenvolvimento de oportunidades para além dos campos tradicionais de atuação, explorando novos mercados, produtos e estruturas organizacionais (HYVÄRINEN; KESKINEN; VARIS, 2016). O foco é atender às expectativas ambientais, com a redução do uso de materiais; preservar os recursos naturais, com novos desenhos de soluções (SCHIEDERIG; TIETZE; HERSTATT, 2012) e o uso eficiente dos recursos (BOCKEN; SHORT, 2016); mudar a mentalidade, ao idealizar produtos, processos e serviços de baixos custos, com qualidade, acessibilidade e colaboração em redes locais (BREM, 2017; SONI; KRISHNAN, 2014).

Nesse sentido, Rosca, Reedy e Bendul (2018) apontam abordagens de oferta e de demanda para direcionar a preservação ambiental à interação entre a estratégica de inovação frugal e a orientação para a ecoinovação e operações produtivas. Do lado da oferta: (a) fazer mais com menos (geração de lixo, reduzindo o uso de materiais, de emissões e de energia); (b) uso de tecnologias verdes, como a energia renovável; e (c) estratégias sustentáveis de simplicidade, desenho e ciclo de vida de produto, modularidade, uso de materiais ambientalmente amigáveis, manufatura limpa e desenho de soluções direcionadas ao usuário. Do lado da demanda: (a) crescente consciência e educação ambiental; (b) preferência por soluções fáceis de usar e personalizadas; (c) modelos de negócio baseados na suficiência; e (d) mudança no estilo de vida, no consumo e na forma de pensar (ROSCA; REEDY; BENDUL, 2018).

Para atender a essas abordagens, a literatura aponta a participação das organizações nos ecossistemas, com foco na restrição de custos e no design de produtos. A transversalidade entre 
os conceitos de ecoinovação e as dimensões da inovação frugal está apresentada a seguir (Quadro 3), sendo que o detalhamento pode ser visto no Apêndice E. 
Quadro 4 - Ecoinovação e dimensões da inovação frugal

(continua)

Artigo

(RENNINGS, 2000)

Transversalidade com as dimensões da inovacão frugal

Benefícios secundários: redução de custos, aumento da competitividade, criação de novos mercados para produtos e processos voltados ao meio ambiente, e uso desses produtos (custos/funcionalidade).

O custo ambiental para as organizações (quando é preciso pagar as taxas de poluição) é maior do que o custo de controlar a poluição e os resíduos (custos).

A política de inovação reduz os custos de inovação tecnológica, institucional e social, especialmente nas fases de invenção e de introdução no mercado (custos).

Rede científica para a avaliação do impacto ambiental, estabelecida em níveis nacional, regional e local, são importantes para a discussão da inovação (ecossistema).

(THEYEL, 2000)

Projetos e gestão dos resíduos: redução dos custos totais e de inovações ambientais na organização (custos).

Produtos e processos redesenhados a partir do ciclo de vida, para torná-los mais seguros e compatíveis ambientalmente.

O ciclo de vida de um produto é estudado para fechar loops de produção, encontrar formas de reciclar resíduos e produtos, para evitar a poluição (ecossistema/funcionalidade).

(BRUNNERMEIER; COHEN, 2003)

Inovação ambiental: resposta ao aumento nos custos de redução não implica necessariamente em aumento do lucro líquido. É bem possível que, apesar dessas inovações, haja altos custos e oportunidade de desviar recursos para P\&D ambiental (custo).

(BEISE; RENNINGS, 2005)

A trajetória tecnológica da energia eólica na Dinamarca foi caracterizada por maior variedade e flexibilidade, possibilitando reduções de custos de cerca de $50 \%$ (custos).

(PUJARI, 2006)

Benefícios do produto ocorrem em paralelo à relação custo-eficácia técnica e económica (custos/funcionalidade).

Desenvolvimento de produtos mais ecológicos tem estreita colaboração com os fornecedores, com o uso técnicas de gestão ambiental e seleção de fornecedores (ecossistema).

(CHEN; LAI; WEN, 2006)

Quanto mais investimento em inovações verdes, melhor a vantagem competitiva, e custo mais baixo, se comparado aos concorrentes (custos).

Materiais que preservam recursos e reduzem o consumo de matéria-prima no desenvolvimento de produtos, e produtos que favorecem o reuso, a reciclagem e a decomposição (ecossistema).

(REHFELD; RENNINGS; ZIEGLER, 2007)

Soluções para utilização básica e opções de reciclagem, redução dos custos de tratamento de resíduos e reciclagem no planejamento e desenvolvimento do produto (custos)

Fonte: Autora. 
Quadro 3 - Ecoinovação e dimensões da inovação frugal

(conclusão)

\begin{tabular}{|c|c|}
\hline Artigo & Transversalidade com as dimensões da inovação frugal \\
\hline (WAGNER, 2007) & $\begin{array}{l}\text { Parceiros de colaboração, envolvidos direta ou indiretamente com questões ambientais, como órgãos do governo e } \\
\text { sindicatos; e fornecedores de matéria-prima e revendedores de varejo, têm relação significativa com ecoinovações de } \\
\text { produtos (ecossistema). }\end{array}$ \\
\hline (HELLSTRÖM, 2007) & $\begin{array}{l}\text { As dimensões ambientais são fontes potenciais de inovação de processos e de produtos, quanto aos aspectos do } \\
\text { processo de fabricação, uso do produto, fim da vida útil e redesenho de funções. Essas dimensões respondem a } \\
\text { problemas existentes em rearranjos, a fim de torná-los mais ecológicos (ecossistema/funcionalidade). }\end{array}$ \\
\hline (TRIEBSWETTER; WACKERBAUER, 2008) & $\begin{array}{l}\text { Custos e pressão competitiva, assim como o avanço tecnológico, são os maiores estímulos às inovações ambientais, } \\
\text { assim como a pressão do mercado e a pressão do cliente (custos). }\end{array}$ \\
\hline \multirow[t]{2}{*}{ (HORBACH, 2008) } & Processos operacionais voltados a soluções de sustentabilidade ambiental (ecossistema). \\
\hline & Custos e adequação às medidas regulatórias são determinantes para inovações ambientais (custos). \\
\hline (WAGNER, 2008) & $\begin{array}{l}\text { A existência de atividades, como sistema de reciclagem, fornece incentivos à realização de inovações de produtos } \\
\text { ambientais, pois essas inovações permitem a distribuição do custo operacional do sistema pela quantidade maior de } \\
\text { produtos produzidos (custos). }\end{array}$ \\
\hline (CHEN, 2008) & $\begin{array}{l}\text { As competências essenciais verdes das empresas, envolvendo aprendizado coletivo e gestão ambiental, têm efeitos } \\
\text { positivos no desempenho de inovação de produtos, processos e imagem verde (ecossistema). }\end{array}$ \\
\hline (FRONDEL; HORBACH; RENNINGS, 2008) & $\begin{array}{l}\text { As atividades de redução do impacto ambiental estão correlacionadas a fortes impactos ambientais dos processos de } \\
\text { produção de uma instalação: instalações mais poluidoras são mais propensas a inovar e a fazer rearranjos produtivos de } \\
\text { redução do que as menos poluentes (ecossistema). }\end{array}$ \\
\hline \multirow[t]{3}{*}{ (ARUNDEL; KEMP, 2009) } & $\begin{array}{l}\text { Os benefícios ambientais de uma inovação podem constituir o efeito colateral de outros objetivos, como reciclar metais } \\
\text { pesados para reduzir custo (custos). }\end{array}$ \\
\hline & $\begin{array}{l}\text { A implementação de tecnologias de produção mais limpas é impulsionada pela aptidão de aumentar a eficiência da } \\
\text { fabricação e reduzir os custos das operações (custos). }\end{array}$ \\
\hline & $\begin{array}{l}\text { As inovações de processo e a reciclagem foram, muitas vezes, introduzidas em resposta à necessidade de cumprir os } \\
\text { regulamentos, mas, muitas delas também para obter economia de custos (não relacionados ao ambiente) ou para } \\
\text { melhorar a imagem ambiental da empresa (ecossistema/custos). }\end{array}$ \\
\hline
\end{tabular}

Fonte: Autora. 
O processo de inovação envolve uma diversidade de atores do ecossistema da organização, desde empresas multinacionais, empreendedores e comunidades locais, a organizações não governamentais (PANSERA; OWEN, 2014). Ele é caracterizado por rearranjos de processos de produção, voltados à sustentabilidade (FRONDEL; HORBACH; RENNINGS, 2008; REHFELD; RENNINGS; ZIEGLER, 2007), que promovem o aumento de eficiência e de escolha, e a contenção no uso de matéria-prima, favorecendo o reuso, a reciclagem, a decomposição e processos de gestão dos resíduos (CARRILLO-HERMOSILLA; DEL RÍO; KÖNNÖLÄ, 2010; CHEN; LAI; WEN, 2006).

Por meio das parcerias com fornecedores locais (HORBACH; RAMMER; RENNINGS, 2012; PUJARI, 2006) e a rede científica, para a avaliação do impacto ambiental, são gerados conhecimentos e tecnologias coletivos (CHEN, 2008; OLTRA; SAINT JEAN, 2009; RENNINGS, 2000; WAGNER, 2007). Essa atuação, dentro de um ecossistema, é fator determinante para que a ecoinovação ocorra (CAINELLI; MAZZANTI; ZOBOLI, 2011; HORBACH, 2008; WAGNER, 2007), impactando positivamente em eficiência energética e material (DE MARCHI, 2012), e no desenvolvimento de produtos, serviços e processos ambientais (TRIGUERO; MORENO-MONDÉJAR; DAVIA, 2013).

A proposta de valor econômico, gerada pelas estratégias de inovação frugal, é alcançada pela possibilidade de redução de custos no tratamento de resíduos, e de reciclagem no planejamento e no desenvolvimento das inovações (REHFELD; RENNINGS; ZIEGLER, 2007; WAGNER, 2008), bem como na contenção dos custos operacionais (KESIDOU; DEMIREL, 2012). Espera-se, também, que, além da eficiência no uso de recursos e a economia de matérias-primas, seja possível a redução dos custos de penalização da poluição, quando a organização atende às regulamentações ambientais (CAI; LI, 2018).

No caso de inovações de tecnologia de produção limpa, a estratégia de redução de custos operacionais ou o fortalecimento da imagem ambiental da organização podem ser direcionadores da inovação, sendo mais importantes do que a pressão da regulação ambiental propriamente dita (ARUNDEL; KEMP, 2009; HORBACH, 2008; KEMP; PONTOGLIO, 2011). Dessa forma, a redução de custos pode ser alcançada pela atenuação das despesas futuras, pelo redesenho de produtos e serviços, por uma reengenharia de processos de produção (RAO, 2013a), e por investimentos em tecnologias de controle da poluição, na contenção de penalidades e de multas ambientais (FERRON-VILCHEZ; DE LA TORRE-RUIZ; ORTIZ-DE MANDOJANA, 2015). Embora o custo ao mercado das inovações sustentáveis ainda seja um fator limitante, em alguns casos, para a aquisição de produtos verdes (REHFELD; RENNINGS; ZIEGLER, 2007), a percepção do valor agregado é compensadora, sobretudo no que tange aos 
produtos ecoinovadores, desenvolvidos a partir de estratégias de inovação frugal, pois eles permitem a redução dos custos de uso, como no caso da energia elétrica (KAMMERER, 2009).

Estudos no setor da água comprovam a visão de impacto na cadeia de valor, ao demonstrar a avaliação da sustentabilidade centrada em soluções de baixo custo, e a acessibilidade e a simplicidade. Esse é o resultado de uma nova mentalidade na atuação em novos mercados, com a colaboração entre parceiros, o desenvolvimento de novas aplicações de qualidade, e a substituição de práticas ambientalmente indesejáveis por outras sustentáveis (HYVÄRINEN; KESKINEN; VARIS, 2016).

A literatura apresenta (Apêndice G) exemplos de soluções tecnológicas em setores consolidados, como o automobilístico e o bancário. Exemplos disso são o Tata Nano, um dos casos mais emblemáticos de inovação frugal, que, além de ser o carro mais barato, é o que menos polui na Índia; e o caixa de atendimento automático, que não requer ar condicionado e consome 90\% menos energia do que os modelos tradicionais (AGNIHOTRI, 2015).

A Philips, multinacional de mercado desenvolvido, e globalizada em mercados emergentes, tem obtido benefícios ecológicos na abordagem do ciclo de vida do produto, ao reduzir o consumo de recursos, de energia, de materiais perigosos e de embalagens, e por promover maior reciclagem, a partir de projetos modulares, que aumentam o ciclo de vida do produto e diminuem a defasagem (SHAN; KHAN, 2016).

Esses exemplos apoiam o argumento de Basu, Banerjee e Sweeny (2013), de que uma das principais forças da ecoinovação, desenvolvida sob uma estratégia de inovação frugal, consiste na capacidade de resolver os desafios de sustentabilidade das organizações. Essas inovações reforçam o argumento de que os países não são pobres demais para inovar (PANSERA, 2012; PANSERA; OWEN, 2014); ao contrário, processos produtivos frugais já são realizados com base na economia de recursos, tornando esses países não apenas laboratórios, mas campos de provas ideais para práticas e soluções frugais e ecoinovadoras (PANSERA, 2012).

Os resultados da influência da estratégia de inovação frugal na orientação para a ecoinovação e a manufatura verde são percebidos em toda a cadeia de valor das organizações, desde a escolha das matérias-primas, dos processos e da manufatura, até as vendas ao cliente final. Eles incluem o estímulo ao reuso de materiais, à reciclagem, à biodegradabilidade dos produtos, e à revalorização dos subprodutos e dos resíduos de sua manufatura (BAS, 2016). O uso consciente dos recursos naturais para os processos de produção (BAUD, 2016); o foco nos canais locais de fabricação, aquisição e distribuição (ROSCA; ARNOLD; BENDUL, 2017); as características minimalistas de produto; os requisitos funcionais de produtos e serviços; o uso 
de tecnologias verdes e de recursos locais (BASU; BANERJEE; SWEENY, 2013), também são condições presentes nas ecoinovações desenvolvidas com proposições estratégicas frugais.

Relacionados ao ciclo de vida dos produtos, a redução de material na embalagem, o uso de produtos reciclados ou biodegradáveis, e o redesenho de funções para a vida útil estão alinhados às perspectivas de promover um ecossistema mais frugal, com funcionalidades que tornem os produtos mais ecológicos (DANGELICO; PUJARI, 2010; HELLSTRÖM, 2007; THEYEL, 2000). Sob a lente de competitividade, isso permite a atenuação dos custos de operação (HORBACH; RAMMER; RENNINGS, 2012), a criação de novos mercados (RENNINGS, 2000), e a resposta à pressão do mercado e do cliente para o desenvolvimento de produtos, processos e serviços mais sustentáveis (TRIEBSWETTER; WACKERBAUER, 2008).

Por fim, a redução dos custos de processo, dos custos finais de produto para o mercado, e a atenuação das despesas futuras são ações que influenciam a evolução do desempenho das organizações (RAO, 2013a). Por promover a melhoria do desempenho, elas representam um incentivo à implantação de práticas ambientais na organização, pois, a partir do desenvolvimento das capacidades de gestão ambiental, as organizações podem obter aumento da sua performance organizacional (HART; AHUJA; ARBOR, 1996) e operacional (KLASSEN; WHYBARK, 1999; RUSSO; FOUTS; RUSSO, 1997).

Considerando o efeito de moderação da inovação frugal na manufatura verde, a seção seguinte trata do conceito, da abrangência e dos impactos da manufatura verde nas organizações, apresentando os estudos da área e sua importância no desenvolvimento sustentável.

\subsection{MANUFATURA VERDE}

Originados na Alemanha, na década de 1960, os conceitos de manufatura verde evoluíram, no diz respeito ao seu escopo, à natureza das atividades e ao foco. Inicialmente centradas em tecnologias para tratamento e controle dos resíduos, no final do processo produtivo (conhecidas como end-of-pipe), as atividades se expandiram para estratégias abrangentes de negócios verdes, contemplando os benefícios obtidos em toda a cadeia de valor, conforme apresentado a seguir (Figura 2) (REHMAN; SETH; SHRIVASTAVA, 2016). 
Figura 2 - Evolução das atividades de manufatura

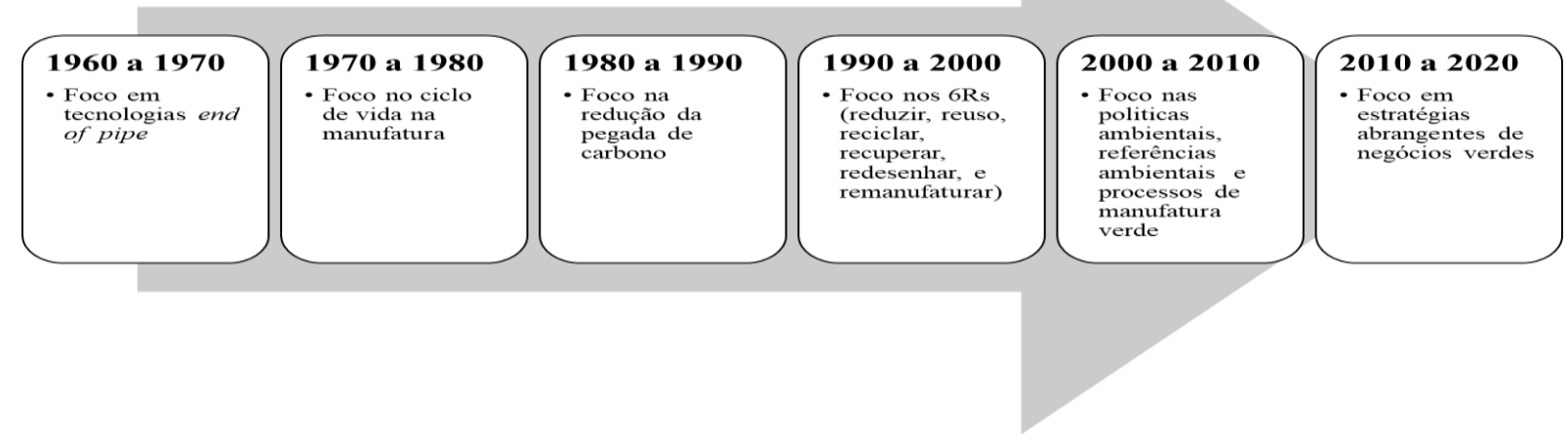

Fonte: Autor "adaptado de" Rehman, Seth e Shrivastava,2016, p. 42

A evolução do conceito de manufatura, bem como o foco de atividades e de processos produtivos, estão essencialmente centrados no crescimento da percepção dos impactos das atividades produtivas, em seus consequentes problemas ambientais, e nas questões de diminuição do consumo de recursos (GARTNER, 2004; SHRIVASTAVA; SHRIVASTAVA, 2017).

Paralelamente a isso, os novos padrões e requisitos de consumo dos clientes; a tecnologia pautada em práticas “verdes", aplicada à geração de energia, ao uso e à produção de produtos com menor impacto ambiental; e a atenuação dos resíduos tóxicos, no processo de fabricação, estão auxiliando as organizações no alcance do seu objetivo de um desempenho operacional mais sustentável (ALVI; AHMED; CHATURVEDI, 2013; DEIF, 2011).

Essas mudanças nos paradigmas da manufatura fazem com que áreas de estudo de práticas sustentáveis, como a da manufatura verde, inseridas na gestão das cadeias globais de suprimentos, tornem-se um dos temas mais importantes para o campo da sustentabilidade ambiental (HAZEN; CEGIELSKI; HANNA, 2011).

O conceito de manufatura verde reflete esse novo paradigma nas atividades de produção, que abrange tecnologias atualizadas e inovações, como resultado de estratégias ambientais, com fins de tornar a organização mais ecoeficiente (DEIF, 2011). Desse modo, representam as práticas de manufatura, realizadas pela organização, para aumento do ciclo de vida de produtos: a redução do uso de matéria-prima, os produtos livres de substâncias tóxicas e poluentes, a avaliação do ciclo de vida e de sua consequente carga ambiental, e produtos redutores do consumo de recursos ambientais finitos (HSU; TAN; ZAILANI, 2016).

Ao considerar o impacto ambiental e o consumo de recursos, durante o ciclo de vida do produto, assim como o design, a fabricação, a embalagem, o transporte, o uso e a reciclagem, 
até a eliminação dos resíduos (AHMAD; KHAN; MITTAL, 2015; DAM; PETKOVA, 2014; DE GIOVANNI, 2012; SHRIVASTAVA; SHRIVASTAVA, 2017), a manufatura verde representa a estratégia de desenvolvimento sustentável, nos processos modernos de fabricação de bens (SHRIVASTAVA; SHRIVASTAVA, 2017).

Em seu sentido amplo, a manufatura verde é uma abordagem sustentável das atividades de design e de engenharia que, aplicadas ao desenvolvimento de produtos ou à operação do sistema de fabricação, têm por fim tratar dos objetivos ambientais, econômicos e sociais da sustentabilidade (DEIF, 2011).

Entendida como um sistema, cujo objetivo é potencializar a eficiência de recursos, a manufatura verde integra atividades de design de produtos e processos, de forma a influenciar o planejamento e o controle da manufatura, ao identificar, quantificar, avaliar e gerenciar o fluxo de resíduos (MARUTHI; RASHMI, 2015). Além desses fatores, ela auxilia na redução de custos de matéria-prima e na garantia da eficiência na produção, com menores despesas decorridas de acidentes ambientais e da segurança ocupacional (ZHU; SARKIS; LAI, 2007b).

Entre os processos da manufatura verde, estão incluídas atividades de reduzir, reutilizar, reciclar, recuperar, redesenhar e remanufaturar (6Rs), objetivando a conservação e o gerenciamento dos resíduos, a proteção ambiental, a atuação diante das políticas regulatórias ambientais e o controle à poluição (JAYAL et al., 2010).

Nesse contexto, eliminar o desperdício de recursos, promover a reciclagem, reduzir as emissões perigosas (DEIF, 2011), assim como conter a quantidade de lixo direcionado aos aterros sanitários (SHRIVASTAVA; SHRIVASTAVA; 2017) são exemplos de atividades que visam minimizar o desperdício e a poluição provenientes das indústrias.

Assim, o reflexo da conscientização ambiental é percebido nas atividades de design ecológico de produtos, no uso de matérias-primas e de embalagens não agressoras do meio ambiente, e nos meios de distribuição e de reutilização sustentável, após o fim da vida útil de produtos, abrangendo, dessa maneira, todas as fases de produção (SRIVASTAVA, 2007). Está incluída, também, a criação de produtos que consomem menos material e energia, reduzindo ou substituindo o uso de materiais tóxicos, não renováveis e que não podem ser reciclados (DEIF, 2011).

Os processos de design de produtos sustentáveis e ecológicos envolvem a otimização do uso de recursos; a atenuação da poluição, gerada pelos processos; o reprocessamento de resíduos; a recuperação de energia, por meio da utilização de subprodutos de outras indústrias; e a ecoinovação, com o uso de novas tecnologias e de conhecimentos, para tornar os produtos 
mais eficientes, tanto em sua utilização quanto na sua produção (SHRIVASTAVA; SHRIVASTAVA, 2017).

Em relação aos impactos das pressões externas, o ambiente institucional leva as organizações a investir, em suas operações, em iniciativas ecológicas. As decisões organizacionais na manufatura, voltadas às questões ambientais, estão baseadas na maior conscientização global dos riscos ambientais, por parte dos consumidores (ALVI; AHMED; CHATURVEDI, 2013; SHRIVASTAVA; SHRIVASTAVA, 2017); no aumento dos custos de energia e de insumos; na pressão regulatória e em políticas ambientais mais rigorosas; e na competitividade, por meio dos avanços tecnológicos (SHRIVASTAVA; SHRIVASTAVA, 2017).

A pressão do ambiente institucional sobre a manufatura verde também ocorre pelo envolvimento das comunidades locais, de grupos de pressão pelas causas ambientais (VACHON; KLASSEN, 2006) e por melhoria da produtividade ambientalmente consciente, no mercado global (AHMAD; KHAN; MITTAL, 2015), exigindo das organizações uma reação proativa em suas estratégias (DE OLIVEIRA et al., 2018).

Sob esse ambiente, a implementação das atividades e de processos da manufatura verde ocorre como forma de controle das pressões regulatórias e competitivas (BAI; SARKIS; DOU, 2015), para atender aos anseios dos consumidores por inovações verdes (JAYARAM; AVITTATHUR, 2015), tendo como resultado o aumento do desempenho econômico, operacional e ambiental (CHIEN; SHIH, 2007; ROY; KHASTAGIR, 2016).

A análise da literatura demostra que há uma sinergia entre as práticas de manufatura verde e a evolução dos desempenhos operacional e organizacional. Organizações com resultados financeiros satisfatórios em desempenho organizacional estão, invariavelmente, obtendo progressos também em seu desempenho operacional. E, nesse contexto, a gestão das práticas ambientais está relacionada positivamente à melhora das performances operacional e organizacional (ALVAREZ GIL; JIMÉNEZ; LORENTE, 2001; KONAR; COHEN, 2001; SANNI, 2018; SZWILSKI, 2000), tanto em países desenvolvidos (KONAR; COHEN, 2001; SANNI, 2018; SZWILSKI, 2000; XIAO et al., 2018) quanto naqueles em desenvolvimento (FAMIYEH et al., 2018; ZHU; SARKIS; LAI, 2007b).

O impacto positivo dos processos de manufatura verde no desempenho operacional e organizacional é resultado de várias frentes de ações da organização, ou seja, a adoção de práticas de manufatura, orientadas por uma estratégia voltada às ecoinovações, envolve cada vez mais a empresa no desenho de produtos ambientais e de processos que os suportem, o que 
potencializa seu desempenho organizacional e operacional (HUANG; LI, 2017; MONTABON; SROUFE; NARASIMHAN, 2007; THEYEL; HOFMANN, 2015).

Ao redesenhar seus processos de produção, por exemplo, substituindo suas entradas por insumos menos poluentes, ou implantando materiais reciclados, para o desenho de novos produtos, há redução da poluição (DAI; CANTOR; MONTABON, 2017) e, consequentemente, melhora operacional, no âmbito da retenção do impacto negativo ambiental, além da contenção do uso de recursos poluentes e da melhora organizacional, sob o ponto de vista de pressões regulatórias e do mercado consumidor. Logo, por meio do aprimoramento do desempenho ambiental, as organizações podem alcançar avanços positivos em seu desempenho geral (INIGO; ALBAREDA, 2019; RAMANATHAN, 2018).

A seguir (Quadro 4), estão alguns resultados de pesquisas que sustentam como fator positivo a existência da relação entre as práticas de manufatura verde e o desempenho nas organizações. O Apêndice D apresenta as informações das amostras, isto é, os países de realização das pesquisas e a metodologia utilizada por cada autor.

Quadro 5 - Relação entre manufatura verde e desempenho

\begin{tabular}{|c|c|c|}
\hline Artigo & $\begin{array}{l}\text { Desempenho } \\
\text { Operacional }\end{array}$ & $\begin{array}{r}\text { Desempenho } \\
\text { Organizacional/Financeiro }\end{array}$ \\
\hline (SROUFE, 2003) & Positivo & Positivo \\
\hline $\begin{array}{l}\text { (MONTABON; SROUFE; NARASIMHAN, } \\
\text { 2007) }\end{array}$ & Positivo & Negativo \\
\hline (PRZYCHODZEN; PRZYCHODZEN, 2015) & Não testado & Positivo \\
\hline (FAMIYEH et al., 2018) & Positivo & Não testado \\
\hline (MELNYK; SROUFE; CALANTONE, 2003) & Positivo & Não testado \\
\hline (THEYEL; HOFMANN, 2015) & Positivo & Não testado \\
\hline (RAO; HOLT, 2005) & Não testado & Negativo \\
\hline (REINHARDT, 1998) & Negativo & Não testado \\
\hline (ZHU; SARKIS, 2004) & Positivo e negativo & Não testado \\
\hline
\end{tabular}

Fonte: Autora

Apesar de a maioria dos autores defender que as práticas de manufatura verde refletem positivamente no desempenho organizacional (MONTABON; SROUFE; NARASIMHAN, 2007; SROUFE, 2003; THEYEL; HOFMANN, 2015), alguns argumentam que nem todas as organizações conseguem alcançar os benefícios da implementação de estratégias 
ambientalmente responsáveis (REINHARDT, 1998), ou que o resultado dessa relação é negativo (RAO; HOLT, 2005; ZHU; SARKIS, 2004).

Para os autores que defendem a relação positiva, a adoção tecnológica, a redução de custos e o foco em atender às regulamentações ambientais estão relacionados à melhoria do desempenho organizacional. Esses resultados organizacionais ecoeficientes decorrem do uso de tecnologias pró-ambientais (MAJUMDAR; MARCUS, 2001) e da existência de certificações, que elevam a reputação e a performance ambiental (GUOYOU et al., 2012; SEMENOVA; HASSEL, 2008).

Ao utilizar técnicas, como o lean manufacturing (manufatura limpa), a diminuição do tempo de produção, devido ao foco na eliminação de resíduos, e a produção de produtos em quantidades reduzidas, a organização é capaz de responder com flexibilidade às mudanças de demanda, volume, tipo, mix e entrega de produtos (FAMIYEH et al., 2018).

Sendo a redução dos custos a principal razão para as práticas de manufatura verde (HASAN, 2013), o menor custo operacional decorre da diminuição do consumo de matériaprima e de energia (YU; HUO, 2019); do desenvolvimento de capacidades internas voltadas à atenuação dos custos; do aumento da eficiência; da atração de novos fornecedores (KUMAR; TEICHMAN; TIMPERNAGEL, 2012); e da mitigação dos riscos de multas por impacto ambiental, dos honorários legais e dos custos do seguro ambiental (SHRIVASTAVA, 1995).

Portanto, organizações com práticas de manufatura verde obtêm melhor resultado financeiro, relativo à redução dos custos operacionais, se comparadas às que não adotam essas práticas (PRZYCHODZEN; PRZYCHODZEN, 2015). A vantagem de custos surge, assim, como um fator competitivo, quando a manufatura verde assume, como foco, as discussões e o desenvolvimento das capacidades produtivas (CHRISTMANN, 2000; PORTER; LINDE, 1995). Ao tornar as organizações mais sustentáveis, há crescimento no lucro, aumento da participação de mercado (HSU; TAN; ZAILANI, 2016) e da competitividade (GOLICIC; SMITH, 2013; KLEINDORFER; SINGHAL; WASSENHOVE, 2005; LAI; WONG, 2012; TESTA; IRALDO, 2010)

Em contrapartida, para alguns autores, enquanto a existência de certificações, como a ISO 14001 e a sua integração nas atividades, melhora o desempenho ambiental e financeiro (MELNYK; SROUFE; CALANTONE, 2003; YIN; SCHMEIDLER, 2009) em determinados mercados; em outros, trata-se de um investimento não refletido na cadeia de valor da organização, por produzir baixo retorno sobre os ativos (ZHAO, 2008). 
Nesse sentido, Rao e Holt (2005) argumentam que as práticas de manufatura verde não têm impactos diretos no desempenho econômico ou organizacional, sendo que, para melhorias na performance organizacional serem percebidas, outras ações são necessárias, dentro de um conceito mais amplo de cadeia de suprimentos sustentável. Os retornos marginais seriam, então, decrescentes, em relação às medidas ambientais, e inovações radicais precisariam ser realizadas para o efeito ser sentido (MURPHY; GOULDSON, 2000). Assim, não haveria relação direta entre o desempenho ambiental e o desempenho financeiro, mensurados pelo retorno sobre ativos ou sobre o patrimônio (BUSCH; HOFFMANN, 2011).

No entanto, de forma sinérgica, o avanço do desempenho organizacional é possível, como consequência das medidas tomadas pela organização, em suas operações, quanto à diminuição do desperdício e do custo, por meio de iniciativas sustentáveis (CLOSS; SPEIER; MEACHAM, 2011). Sendo assim, espera-se que, ao implementar práticas de gestão ambiental, os indicadores tradicionais de desempenho operacional, como o de entrega, sejam, no mínimo, preservados (LAMBERT; COOPER, 2000) ou aprimorados, devido ao uso de novas tecnologias de otimização de rotas de transporte, à economia de consumo de combustível, e aos investimentos em mecanismos de entrega que utilizam energia renovável (FAMIYEH et al., 2018).

Os estudos iniciais da relação entre as práticas de manufatura verde e o desempenho operacional demonstram que essas ações podem, de fato, melhorar a qualidade das operações e reduzir os custos de produção, assim como promover o aumento da eficiência dos processos, reduzindo o uso de matéria-prima e os custos de tratamento de resíduos (CHRISTMANN, 2000; HART; AHUJA; ARBOR, 1996; SHRIVASTAVA, 1995). Por isso, quanto mais a organização estiver envolvida em práticas de manufatura verde, mais forte será seu desempenho operacional, representado pela entrega, adequação e melhorias das especificações de produtos, pelo custo unitário de produção, e pelo crescimento na posição de mercado (SROUFE, 2003).

A melhoria operacional, portanto, é resultado da estratégia de baixo consumo de energia, de água e de matéria-prima; do uso de tecnologias limpas; e da contenção de emissão de gases (CAI; LI, 2018), se mensurada pelo retorno sobre: as vendas (ROS - Return On Sales), os ativos (ROA - Return On Assets), o patrimônio (ROE - Return On Equity) (AMBEC; LANOIE, 2008; HART; AHUJA; ARBOR, 1996), e o investimento (ROI - Return On Investment) (INIGO; ALBAREDA, 2019). Assim, a orientação estratégica para a ecoinovação, operacionalizada na manufatura verde, tem capacidades operacionais vitais para atender às expectativas dos clientes e da empresa, quanto à sustentabilidade ambiental (DAI; CANTOR; MONTABON, 2017). 
Comparando as atividades e as práticas da manufatura verde em países emergentes e desenvolvidos, resultados similares foram encontrados (HASAN, 2013; KUMAR; TEICHMAN; TIMPERNAGEL, 2012; PORTER; LINDE, 1995; SROUFE, 2003), quanto à capacidade de redução de custos (KUMAR; TEICHMAN; TIMPERNAGEL, 2012; PORTER; LINDE, 1995), à melhoria da qualidade de produtos e de processos (LINTON; KLASSEN; JAYARAMAN, 2007; SROUFE, 2003), ao desempenho de entrega (SZWILSKI, 2000; VIJAYVARGY; THAKKAR; AGARWAL, 2017), e ao desempenho de flexibilidade das organizações (ROBERT; ROBERT; STEVEN, 2005; SROUFE, 2003).

Assim como na Alemanha, na China, a gestão ambiental é resultado do aumento das pressões de mercado e regulatórias, e de pressões internas para a melhoria da competitividade de suas práticas (AZEVEDO; CARVALHO; CRUZ MACHADO, 2011; ZHU; SARKIS; LAI, 2007b). Já, em países emergentes, como a Índia, ocorreram significativas alterações nos mercados da indústria de manufatura (SETH; TRIPATHI, 2005, 2006), e maior consciência verde e de qualidade ambiental (REHMAN; SETH; SHRIVASTAVA, 2016). Isso se deu em razão de o país ter se tornado um centro de produção e de fornecimento de bens e serviços (SETH; TRIPATHI, 2005, 2006), bem como pelos seguintes motivos: crescente demanda dos consumidores por produtos verdes, aumento da competitividade global e do uso dos insumos, custos de energia, pressões regulatórias ambientais mais rígidas e constantes (HASANBEIGI; PRICE; LIN, 2012), mão de obra qualificada e barata, e políticas de incentivo para atrair investimentos estrangeiros diretos (SETH; PANIGRAHI, 2015). Contudo, ainda persiste, na gestão organizacional desse país, a visão de que os impactos ambientais, gerados pela manufatura, são obstáculos, não oportunidades para melhorias (ZHAN et al., 2018).

Outros países emergentes têm obtido resultados positivos com o uso da manufatura verde para alcance das estratégias de ecoinovação. Entre eles, está a China, reconhecida pela produção de baixo custo, e afamada pelos problemas sociais e ambientais causados por uma rápida industrialização e pela fraca aplicação de regulamentações ambientais (HU; CHENG, 2013; YUNFENG; LAIKE, 2010). Embora as questões ambientais estejam no centro das discussões do país nos últimos anos (ZHU; SARKIS, 2006), as soluções chinesas para a manufatura verde ainda estão no início de sua implementação (REHMAN; SETH; SHRIVASTAVA, 2016; YANG et al., 2019); mesmo assim, a China já se tornou o maior investidor de energia renovável no mundo (PANSERA, 2013).

Ao implementar práticas de manufatura verde, como design de produtos para reuso, reciclagem e recuperação; e por demonstrar comprometimento da gestão, com certificações ambientais e uma rede de colaboração com clientes e fornecedores, a China tem alcançado 
resultados positivos na redução de custos de compra de matéria-prima, na taxa de descarte e nos custos de energia (ZHU; SARKIS, 2004). Outro exemplo do avanço da manufatura em país emergente é Ghana, na África, onde as práticas verdes na manufatura das organizações têm obtido resultados positivos e significativos para o aumento de desempenho em entregas, custo e flexibilidade (FAMIYEH et al., 2018).

Desta forma, exemplos das relações da manufatura tem apontado para influência no desempenho organizacional e operacional das organizações, em países desenvolvidos e emergentes, apontando um caminho no qual é possível crescer em competitividade e atender ao ambiente institucional de pressões do mercado e regulatório.

\subsection{DEFINIÇÃO DAS HIPÓTESES}

Motivadas por regulamentações ambientais cada vez mais rigorosas (RAO, 2013a) e pela crescente pressão social por produtos, processos e serviços ambientalmente amigáveis (BASU; BANERJEE; SWEENY, 2013; CUNHA et al., 2014), as ecoinovações, desenvolvidas sob estratégias de inovação frugal, são relevantes para mercados desenvolvidos e em desenvolvimento (HOSSAIN; SIMULA; HALME, 2016; PISONI; MICHELINI; MARTIGNONI, 2018).

Para as economias avançadas, esse processo não visa apenas à diminuição dos custos de produção, mas ao aumento da produtividade, de forma sustentável (BOYER, 2015; BRADBURY; MIDDLEMISS, 2015; HOPPE et al., 2015). Com a inovação frugal integrada à sustentabilidade, novas oportunidades em produtos e de mercado são exploradas, além das operações tradicionais, o que muda o direcionamento estratégico organizacional e as demais estruturas existentes (HYVÄRINEN; KESKINEN; VARIS, 2016).

Em relação à população de mercados emergentes, por sua vez, a inserção de tecnologias limpas e eficientes, para a realização de tarefas domésticas de energia, melhora as condições da qualidade de vida em iluminação, aquecimento, acesso à água e comunicação (LEVÄNEN et al., 2016; NUMMINEN; LUND, 2017).

A consequência desse novo modelo de negócio de ecoinovação, influenciado por estratégias de inovação frugal, é a possibilidade de melhoria da eficiência energética desses países (AGARWAL et al., 2016; BHATTI, 2012; BHATTI; VENTRESCA, 2013), e meio de recuperação econômica para os emergentes (BHATTI, 2012) e desenvolvidos (ANDERSEN, 2015). 
Atender aos critérios de sustentabilidade, por meio da estratégia de inovação frugal, depende da inovação em produtos e serviços, com foco nas suas funcionalidades centrais e na simplicidade (BASU; BANERJEE; SWEENY, 2013; BREM; IVENS, 2013; RAO, 2013b). No contexto dos desafios do desenvolvimento sustentável, as características da inovação frugal são reconhecidas pelas organizações como recursos para atingir as estratégias de negócios ambientais (BREM, 2017; HYVÄRINEN; KESKINEN; VARIS, 2016; KUO, 2017), visto que as práticas ambientais indesejáveis ou ineficientes podem ser repensadas e substituídas por soluções melhores (LEVÄNEN et al., 2016). Para tanto, as inovações frugais passam a representar ferramentas avançadas de ciência e de tecnologia, nas fases de design e de engenharia, além de envolver profissionais capacitados para projetar inovações frugais aprimoradas (RAO, 2017a).

O histórico da inovação frugal e a imprescindibilidade de as organizações lidarem com essas limitações, seja devido às desacelerações econômicas nos mercados desenvolvidos, seja pela competição, ascensão, e pressões regulatórias e sociais por produtos ecologicamente amigáveis nos mercados emergentes (CUNHA et al., 2014), apresentam um caminho promissor para as ecoinovações, influenciadas pela inovação frugal e suas relações com a manufatura verde e o desempenho das organizações.

Empresas locais e multinacionais, influenciadas por estratégias de inovação frugal, em suas operações e na orientação para a ecoinovação, escolhem matérias-primas, definem suas atividades de P\&D e da cadeia de distribuição (AGNIHOTRI, 2015; RADJOU; PRABHU, 2012), e atendem às pressões do ambiente institucional, por meio de tecnologias de baixo custo, com características de: (a) desenho e manufatura frugal, como o mínimo uso de recursos, desenho simplificado e durabilidade; (b) acessibilidade, isto é, produto de baixo custo e fornecimento de serviço de energia mais acessível; (c) adequação à demanda local; (d) sustentabilidade ambiental, pelo uso de fontes locais de energia renovável e de materiais reciclados; e (e) padrão frugal de uso de energia (NUMMINEN; LUND, 2017).

É exemplo disso a Unilever que, em 2011, para alcançar resultados financeiros, alinhou às suas atividades estratégias frugais de retenção do impacto ambiental dos seus produtos, minimizando a emissão de sua frota de distribuição e utilizando matérias-primas de fontes sustentáveis (HOSSAIN, 2018).

Quanto aos impactos na manufatura verde, é por meio das estratégias frugais, aplicadas à orientação para a ecoinovação, que a organização se motiva a comprometer seus recursos e cultivar capacidades para a construção de uma cadeia logística sustentável (CHEN; HUNG, 2014; HSU; TAN; ZAILANI, 2016). Essa é uma forma de maximizar o valor derivado de 
recursos limitados (SINGH; GUPTA; MONDAL, 2012), proporcionando benefícios econômicos, sociais, e conservando recursos naturais, como água, energia e materiais (HOSSAIN, 2018). Além disso, é uma abordagem inclusiva para a inovação, que maximiza valor aos clientes e acionistas e à sociedade, reduzindo, simultaneamente, o uso de recursos financeiros e naturais (ROSCA; ARNOLD; BENDUL, 2017).

Por meio da frugalidade e da simplicidade no design, do uso mínimo de recursos (AGNIHOTRI, 2015; RAO, 2017a; WEYRAUCH; HERSTATT, 2016), e da reutilização de componentes (BREM; WOLFRAM, 2014), essas inovações podem contribuir para a cadeia de fornecimento e de desenvolvimento de uma manufatura ambientalmente sustentável (KHAN, 2016; ROSCA; REEDY; BENDUL, 2018; SHARMA; IYER, 2012).

A revisão da literatura sobre os impactos da estratégia de inovação frugal, considerando os aspectos econômicos, sociais e ambientais aplicados aos mercados emergentes e desenvolvidos, permite argumentar que as organizações optantes por essa estratégia adquirem maior resultado na relação entre as suas orientações para a ecoinovação e as efetivas práticas de manufatura verde. Ou seja, quanto maior a adoção de estratégias que privilegiam a consciência de custos, a funcionalidade central e a atuação no ecossistema, melhor o resultado da interação entre orientações sustentáveis e os resultados na cadeia produtiva. Para testar esses argumentos, este estudo propõe as hipóteses a seguir.

H1a - Quanto maior o efeito de moderação da inovação frugal, maior é a relação entre a orientação estratégica para a ecoinovação e a manufatura verde.

H1b - Quanto maior o efeito de moderação da inovação frugal, maior é a relação entre a orientação estratégica para a ecoinovação e a manufatura verde, em organizações de países emergentes.

H1c - Quanto maior o efeito de moderação da inovação frugal, maior é a relação entre a orientação estratégica para a ecoinovação e a manufatura verde, em organizações de países desenvolvidos.

Para a discussão da evolução do desenvolvimento das abordagens voltadas às práticas de preservação de recursos e de sustentabilidade nas organizações, é necessário considerar o ambiente e as instituições envolvidas nas soluções e nas respostas aos impactos ambientais, em seus ciclos de produção (JABBOUR et al., 2014). Para as ecoinovações, as instituições formais e informais, sob a forma de regulamentações e de pressão dos clientes, são identificadas como os principais direcionadores de estratégias e de práticas de manufatura (BOONS et al., 2013; MONTALVO, 2008; PORTER; LINDE, 1995; REHFELD; RENNINGS; ZIEGLER, 2007), envolvendo investimentos em produtos e tecnologias de produção limpas, redes de colaboração, 
suporte gerencial e desenvolvimento de capacidades em iniciativas ambientais (HUANG et al., 2016).

Para mercados emergentes e desenvolvidos, as pressões institucionais têm papéis e impactos diferentes no direcionamento ambiental das organizações (HORBACH, 2016; HORBACH; RAMMER; RENNINGS, 2012; HUANG et al., 2016). Os impactos são resultado do padrão tecnológico específico de cada país, o que influencia os domínios distintos da ecoinovação (HORBACH, 2016) e das regulamentações, que motivam as inovações de economia de custos, em campos emergentes da ecoinovação, como a contenção de uso de material e de energia (HORBACH, 2016; HORBACH; RAMMER; RENNINGS, 2012). Dessa forma, organizações de mercados emergentes e desenvolvidos devem ser analisadas em suas estratégias e orientação, sob a perspectiva do ambiente institucional no qual estão inseridas.

De qualquer modo, apesar dos diferentes motivos e fins, em ambos os mercados, essas pressões têm influenciado a adoção de estratégias para a ecoinovação. Para os mercados emergentes, atender às regulamentações incentiva os investimentos em $\mathrm{P} \& \mathrm{D}$ ambiental e reduz os custos com as penalidades por dano ao meio ambiente; em contrapartida, há o risco de a imposição de leis ambientais firmes impactar negativamente o crescimento econômico, ou até ameaçar as empresas de manufatura (ABDULRAHMAN; GUNASEKARAN; SUBRAMANIAN, 2014; LIU; LOW; HE, 2014).

Nesses países emergentes, para atender às regulamentações, há barreiras na decisão entre a disponibilidade de recursos financeiros para reduzir os impactos ambientais e atender ao crescimento da industrialização e da urbanização nacional (MATHIYAZHAGAN; SENGUPTA; MATHIVATHANAN, 2019; PERESEINA et al., 2014). Contudo, com a diminuição de recursos e o aumento dos danos ambientais, governos de países como a China, com ausência anterior de políticas e de instâncias governamentais ambientalmente rigorosas e consistentes (ZHANG; WEN, 2008), passaram a estabelecer regulamentos ambientais, que revertem a imagem de poluidores e atendem às pressões internacionais necessárias à exportação de seus produtos (CHEN, 2008; ZHU; SARKIS; LAI, 2013).

$\mathrm{O}$ interesse dos fabricantes em manter e expandir seu mercado internacional tem levado as organizações a repensar suas estratégias de ecoinovação, de acordo com as pressões externas de regulamentações locais e internacionais, e a adotar práticas de manufatura que preservem os recursos naturais (LAI; WONG, 2012; ZHU; SARKIS; LAI, 2013). Essas pressões institucionais internacionais estão associadas positivamente às práticas ambientais proativas, como a implantação de ISO 14001, auditorias ambientais e gerenciamento da qualidade ambiental da manufatura (Total Quality Environmental Management System - TQEMS). 
De forma específica, as exportações e o alcance dos produtos por clientes estrangeiros, preocupados com as questões ambientais dos produtos, são dois fatores principais, que levam os fabricantes chineses a adotar práticas de gestão ambiental e de manufatura verde (CHRISTMANN; TAYLOR, 2001; LAI; WONG; CHENG, 2012). Assim, tornando-se mais competitivos, é maior a probabilidade de que as inovações ambientais ocorram nesses países (BRUNNERMEIER; COHEN, 2003).

Com base nos estudos dos mercados desenvolvidos, à medida que os regulamentos ficam mais rigorosos, e as pressões externas induzem as organizações a adotar práticas proativas de ecoinovação e de manufatura verde em suas estratégias (CAI; LI, 2018), maior é o investimento em suas operações, a fim de atingir a conformidade-padrão para atuar em ecoinovação, evitando, com isso, penalidades e multas ambientais (FERRON-VILCHEZ; DE LA TORRE-RUIZ; ORTIZ-DE MANDOJANA, 2015). Isso resulta em diferentes tipos de ecoinovação - inovação em produtos, processos, organizacional, tecnológica, ambiental e em P\&D (HOJNIK; RUZZIER, 2016).

A pressão regulatória, portanto, mostra-se como um fator influenciador da orientação estratégica para a ecoinovação, tanto em países emergentes quanto em países em desenvolvidos, o que leva este estudo a propor as hipóteses a seguir.

H2a - Quanto maior o efeito de moderação da inovação frugal, maior é a relação entre a pressão regulatória e a orientação estratégica para a ecoinovação.

H2b - Quanto maior o efeito de moderação da inovação frugal, maior é a relação entre a pressão regulatória e a orientação estratégica para a ecoinovação, em organizações de países emergentes.

H2c - Quanto maior o efeito de moderação da inovação frugal, maior é a relação entre a pressão regulatória e a orientação estratégica para a ecoinovação, em organizações de países desenvolvidos.

Como instituição informal, que influencia a orientação estratégica para a ecoinovação e a manufatura verde, está a percepção do mercado sobre o envolvimento da organização com a inovação, em parcerias com órgãos do governos, fornecedores e revendedores (WAGNER, 2007). E, no que tange à geração de benefícios privados ou agregados aos produtos verdes, podem ser citadas a diminuição do consumo de energia, melhor qualidade e durabilidade de produto, a possibilidade de reparos, a atualização e as condições de descarte adequado, além da atenuação dos impactos na saúde (KAMMERER, 2009).

Os produtos ecológicos, então, precisam ser entendidos pelos consumidores como ambientalmente amigáveis (TRIGUERO; MORENO-MONDÉJAR; DAVIA, 2013), sendo 
esse um importante direcionador das decisões estratégicas em relação ao produto (consumo de energia, contenção de emissões de poluentes e reciclagem) (HORBACH; RAMMER; RENNINGS, 2012) e à fonte de competitividade das organizações, em mercados desenvolvidos (KAMMERER, 2009; REHFELD; RENNINGS; ZIEGLER, 2007).

Para os mercados emergentes, a demanda dos clientes ainda não atingiu a mesma maturidade de hábitos sustentáveis dos países desenvolvidos, em níveis de renda e padrão de vida, tampouco a consciência ambiental é tão apurada quanto a dos consumidores daqueles mercados (LI, 2014).

Além disso, empresas poluentes, notadas pelo seu impacto negativo no meio ambiente, estão sob a pressão do mercado, para a melhoria de sua imagem e da competitividade, frente às indústrias consideradas sustentáveis (KUNAPATARAWONG; MARTÍNEZ-ROS, 2016). Isso as estimula a inovar na prevenção da poluição, com fins da redução de custos, do aumento da produtividade e da obtenção de vantagens competitivas (LEAL-RODRÍGUEZ et al., 2018; THEYEL, 2000).

Considerando a consciência ambiental e a disponibilidade dos consumidores para pagar por produtos provenientes da ecoinovação (HORBACH, 2008; JANSSON, 2011; SAMMER; WÜSTENHAGEN, 2006), a pressão institucional dos clientes influencia a orientação estratégica para a ecoinovação, levando às hipóteses a seguir.

H3a - Quanto maior o efeito de moderação da inovação frugal, maior é a relação entre a pressão do mercado consumidor e a orientação estratégica para a ecoinovação.

H3b - Quanto maior o efeito de moderação da inovação frugal, maior é a relação entre a pressão do mercado consumidor e a orientação estratégica para a ecoinovação, em organizações de países emergentes.

H3c - Quanto maior o efeito de moderação da inovação frugal, maior é a relação entre a pressão do mercado consumidor e a orientação estratégica para a ecoinovação, em organizações de países desenvolvidos.

Nos últimos anos, estudos têm demonstrado a relação entre a ecoinovação e ganhos de performance, apontando os seguintes reflexos da orientação de ecoinovação: aumento da produtividade e qualidade dos processos (MAJUMDAR; MARCUS, 2001); influência positiva no valor de mercado e benefícios operacionais (SEMENOVA; HASSEL, 2008); e melhoria dos resultados financeiros e de indicadores de receita (AMBEC; LANOIE, 2008; GUOYOU et al., 2012; HART; AHUJA; ARBOR, 1996; PRZYCHODZEN; PRZYCHODZEN, 2015). 
Em contrapartida, algumas pesquisas argumentam que essa relação entre ecoinovação e performance organizacional é negativa (MURPHY; GOULDSON, 2000), ou não é percebida pela organização (FERNANDO; SHARFMAN; UYSAL, 2010).

Este estudo defende que a implementação de práticas de gestão ambiental nas organizações, como reflexo da orientação estratégica para ecoinovação, impacta positivamente o desempenho organizacional, em seus indicadores de entrega (FAMIYEH et al., 2018; SZWILSKI, 2000; VIJAYVARGY; THAKKAR; AGARWAL, 2017), já que essa orientação possui, entre as suas características, a simplificação de uso e do processo da produção de inovações, exigindo novas abordagens de manufatura para redesenhar e repensar essas inovações (STAHEL, 2005). Destacam-se, também, as práticas que desenvolvem habilidades e estratégias para monitorar e gerenciar o efeito das operações no ambiente natural (MONTABON; SROUFE; NARASIMHAN, 2007).

Ao adotar a manufatura verde, com produtos de reuso e reciclados, diminuir o consumo de materiais e o uso de energia, e avaliar a carga ambiental dos processos de produção, as organizações têm efeito positivo, tanto em seu desempenho ambiental quanto financeiro (CHIEN; SHIH, 2007).

Considerando a busca da demanda futura de produtos e processos ambientalmente corretos, a principal implicação desses indicadores é que, se uma empresa deseja ver efeitos mensuráveis no desempenho da empresa, por meio das práticas de manufatura verde, a reciclagem, a contenção de emissão de resíduos, a remanufatura e o design ambiental parecem ser as ações que, provavelmente, terão maior impacto (PRZYCHODZEN; PRZYCHODZEN, 2015). Sendo assim, a ecoinovação se torna uma estratégia relevante, não só para atender às expectativas do mercado consumidor e às legislações e normas, mas para gerar um melhor desempenho organizacional e operacional (JANSSON, 2011).

Essa correlação, entre a ecoinovação e o desempenho das organizações, é demonstrada pela implementação de práticas de gestão ambiental táticas (foco interno e externo), operacionais (atividades de manufatura) ou estratégicas de ecoinovação (MONTABON; SROUFE; NARASIMHAN, 2007). Os resultados no desempenho decorrem da integração ambiental das estratégias com ações operacionais de redução de custos de longo prazo (BURGOS-JIMÉNEZ et al., 2013; DUBEY; GUNASEKARAN; SAMAR ALI, 2015).

$\mathrm{O}$ desempenho financeiro está relacionado à capacidade de desenvolvimento e à rentabilidade das empresas, como o crescimento do lucro e o retorno sobre as vendas (FLYNN; HUO; ZHAO, 2010). Estudos dos impactos da orientação ambiental sobre o desempenho financeiro apontam resultados positivos e reiteram os benefícios da orientação estratégica para 
a ecoinovação na organização (CAO; SCHNIEDERJANS, 2004; CHAN et al., 2012; YU; HUO, 2019).

Como práticas táticas internas, a orientação ambiental, por meio da consciência de uma responsabilidade para com o meio ambiente, na gestão e na cultura dos funcionários, reflete-se nos resultados financeiros, sejam estes de retorno sobre os investimentos nas adaptações e atualizações, sejam no retorno sobre as vendas e a respectiva receita (YU; HUO, 2019).

Como resultado da orientação estratégica para a ecoinovação, as organizações têm experimentado o aumento das suas vendas, a atração de novos mercados de consumo, a melhora da sua vantagem competitiva, a diferenciação de seus produtos e, consequentemente, o aprimoramento do seu desempenho financeiro (ARUNDEL; KEMP, 2009; CHIOU et al., 2011; DANGELICO; PONTRANDOLFO, 2015; DEL RÍO; PEÑASCO; ROMERO-JORDÁN, 2015; GUOYOU et al., 2012; PORTER; LINDE, 1995).

Nesse sentido, Cai e Li (2018) argumentam que, além da atenuação das despesas com as penalidades ambientais e da redução dos custos de operação, os produtos de ecoinovação podem elevar os lucros da empresa e, por conseguinte, seu desempenho organizacional, em decorrência da oferta de uma diversidade de produtos verdes e do progresso na participação de mercado, em virtude da construção de uma imagem verde frente aos seus clientes.

Considerando o envolvimento das empresas em estratégicas reativas, com fins do desenvolvimento e da implementação de práticas sustentáveis, para a melhoria da performance operacional (DE OLIVEIRA et al., 2018; PRAJOGO et al., 2012) e organizacional (CAI; LI, 2018; CALANTONE; CAVUSGIL; ZHAO, 2002), são propostas as hipóteses a seguir.

H4a - Quanto maior o efeito de moderação da inovação frugal, maior é a relação entre a manufatura verde e o desempenho das organizações.

H4b - Quanto maior o efeito de moderação da inovação frugal, maior é a relação entre a manufatura verde e o desempenho, em organizações de países emergentes.

H4c - Quanto maior o efeito de moderação da inovação frugal, maior é a relação entre a manufatura verde e o desempenho, em organizações de países desenvolvidos.

\subsection{SÍNTESE DO REFERENCIAL E MODELO CONCEITUAL}

As Seções 2.1 a 2.5 apresentaram a revisão da literatura e as hipóteses acerca do papel do ambiente institucional como forma de pressão regulatória e do mercado consumidor sobre as estratégias de ecoinovação; e da influência dessas estratégias nas práticas da manufatura verde e nos resultados do desempenho da organização. 
Nesse contexto, a literatura de inovação frugal propõe a influência de suas dimensões de custo, funcionalidade e ecossistema, como fatores relevantes para que as organizações alcancem seus propósitos sociais, econômicos e de sustentabilidade, nas relações entre a estratégica de ecoinovação, a manufatura verde e o desempenho.

De acordo com essa literatura, foram propostas quatro hipóteses, representadas a seguir (Quadro 5), juntamente com os estudos nos quais elas estão fundamentadas. 
Quadro 6 - Hipóteses do modelo teórico proposto

(continua)

\begin{tabular}{|c|c|c|}
\hline DIMENSÃO & HIPÓTESE & FUNDAMENTAÇÃO TEÓRICA \\
\hline $\begin{array}{l}\text { ORIENTAÇÃO } \\
\text { ESTRATÉGICA PARA A } \\
\text { ECOINOVAÇÃO E A } \\
\text { MANUFATURA VERDE }\end{array}$ & $\begin{array}{l}\text { H1a - Quanto maior o efeito de moderação da inovação frugal, maior é a relação } \\
\text { entre a orientação estratégica para a ecoinovação e a manufatura verde. } \\
\text { H1b - Quanto maior o efeito de moderação da inovação frugal, maior é a relação } \\
\text { entre a orientação estratégica para a ecoinovação e a manufatura verde, em } \\
\text { organizações de países emergentes. } \\
\text { H1c - Quanto maior o efeito de moderação da inovação frugal, maior é a relação } \\
\text { entre a orientação estratégica para a ecoinovação e a manufatura verde, em } \\
\text { organizações de países desenvolvidos. }\end{array}$ & $\begin{array}{l}\text { (HOSSAIN; SIMULA; HALME, 2016; } \\
\text { HYVÄRINEN; KESKINEN; VARIS, 2016; } \\
\text { LEVÄNEN et al., 2016; NUMMINEN; LUND, } \\
\text { 2017; PISONI; MICHELINI; MARTIGNONI, } \\
\text { 2018). }\end{array}$ \\
\hline PRESSÃO REGULATÓRIA & $\begin{array}{l}\text { H2a - Quanto maior o efeito de moderação da inovação frugal, maior é a relação } \\
\text { entre a pressão regulatória e a orientação estratégica para a ecoinovação. } \\
\text { H2b - Quanto maior o efeito de moderação da inovação frugal, maior é a relação } \\
\text { entre a pressão regulatória e a orientação estratégica para a ecoinovação, } \\
\text { em organizações de países emergentes. } \\
\text { H2c - Quanto maior o efeito de moderação da inovação frugal, maior é a relação } \\
\text { entre a pressão regulatória e a orientação estratégica para a ecoinovação, em } \\
\text { organizações de países desenvolvidos. }\end{array}$ & $\begin{array}{l}\text { (BOONS } \text { et al., 2013; CHEN, 2008; } \\
\text { MONTALVO, 2008; PORTER; LINDE, 1995; } \\
\text { REHFELD; RENNINGS; ZIEGLER, 2007; ZHU; } \\
\text { SARKIS; LAI, 2013) }\end{array}$ \\
\hline
\end{tabular}

Fonte: Autora 
Quadro 5 - Hipóteses do modelo teórico proposto

(conclusão)

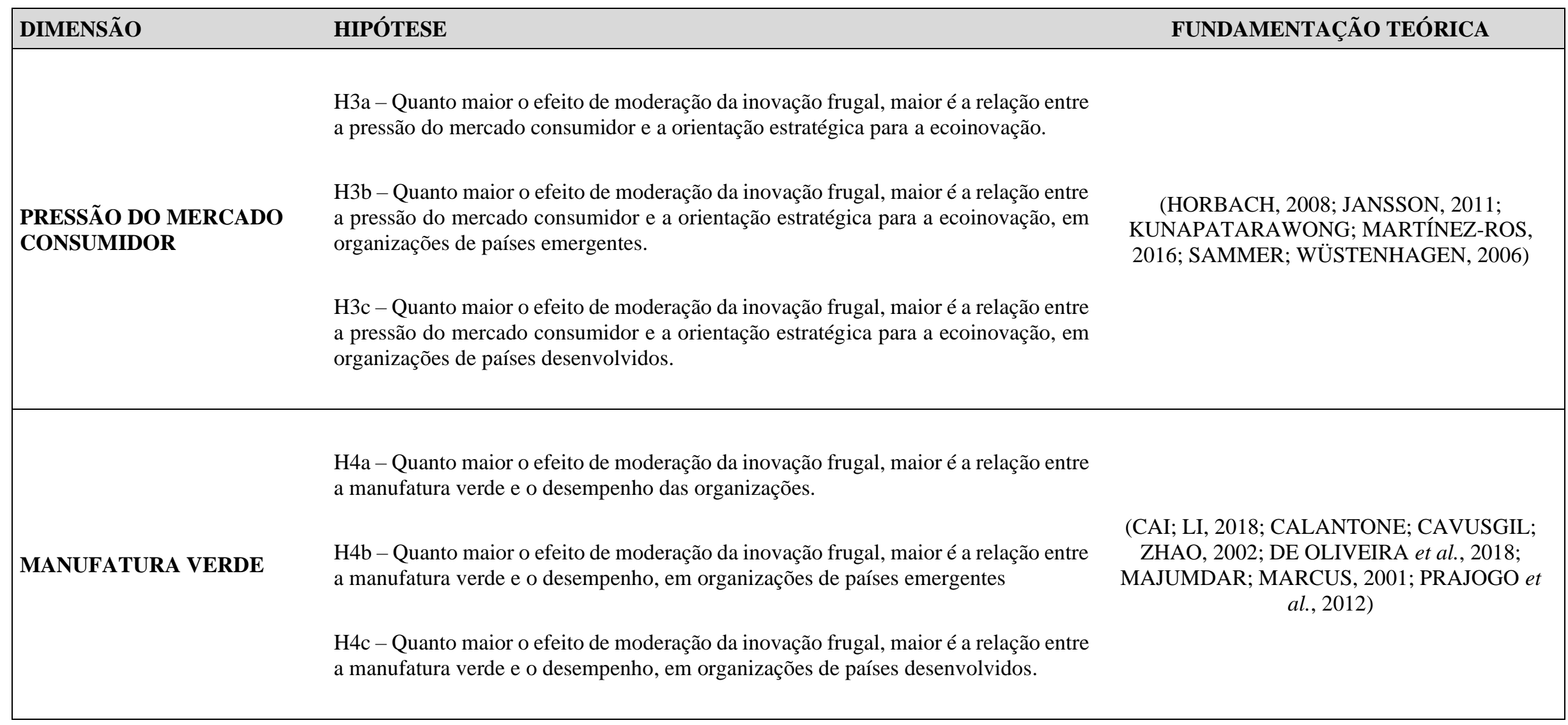

Fonte: Autora. 
A seguir (Figura 3), está o modelo conceitual proposto pela pesquisa, com a identificação das hipóteses, dos construtos e das relações estabelecidas entre eles, sendo que o resultado do desempenho está subdividido em organizacional e operacional.

Figura 3 - Modelo conceitual da pesquisa

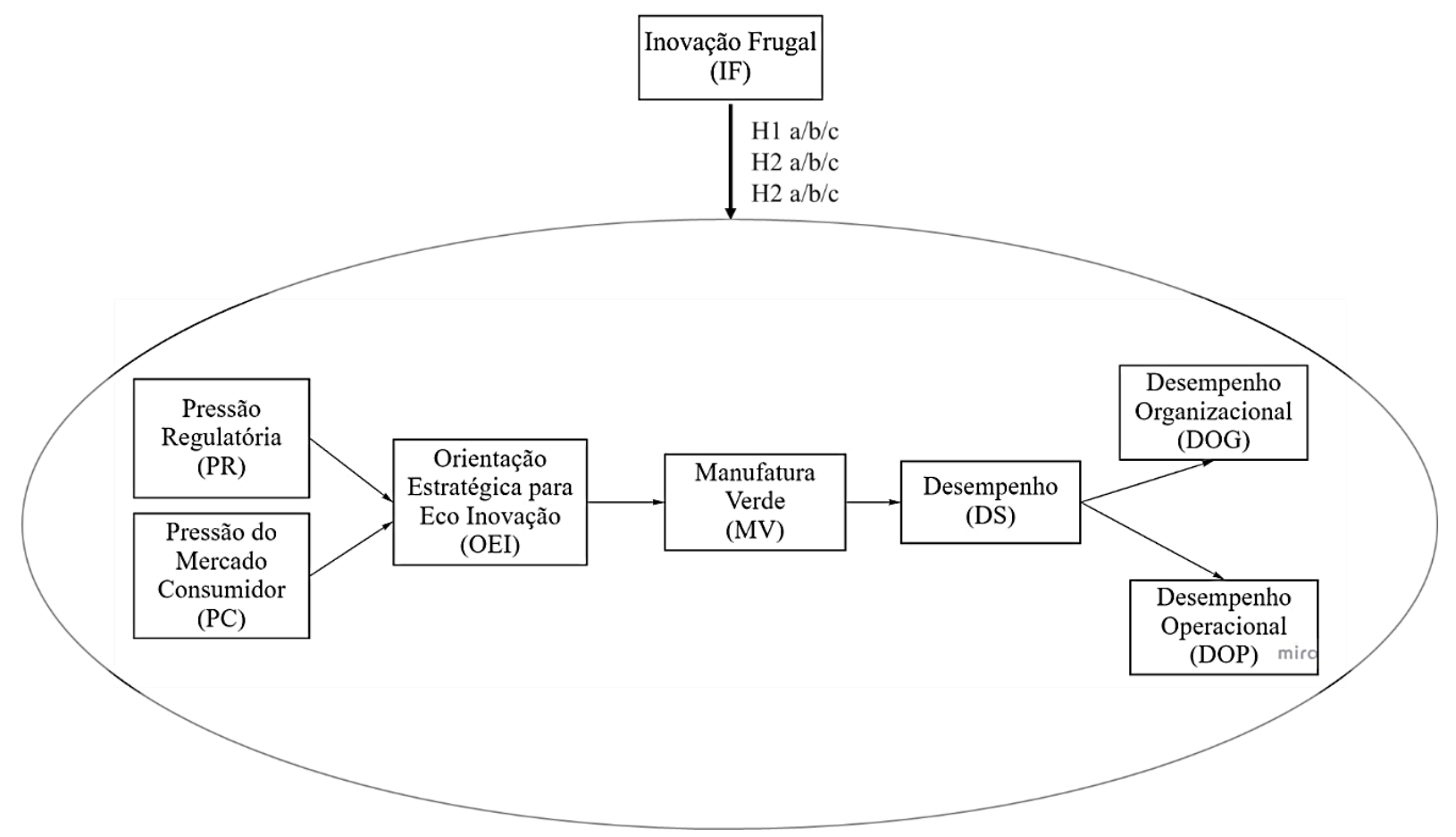

Fonte: Autora. 


\section{METODOLOGIA}

Neste capítulo, está descrita a metodologia escolhida para a gestão da pesquisa, iniciando com seus aspectos gerais e as questões operacionais especificadas. São, então, abordados: a natureza da pesquisa, o método e a técnica, as hipóteses e o design de pesquisa, com a definição das variáveis e dos indicadores, do universo e da amostra, do instrumento de coleta e dos procedimentos de campo e de análise de dados.

\subsection{NATUREZA DA PESQUISA}

A definição da metodologia se pautou nas perguntas de pesquisa a serem respondidas, isto é: (1) As organizações com maior incidência de inovação frugal têm melhor resultado na relação entre a orientação estratégica para a ecoinovação e a manufatura verde? (2) Há diferença entre países emergentes e desenvolvidos na relação entre as pressões do ambiente institucional, a orientação estratégica, a manufatura verde e o desempenho?

Considerando as pesquisas exploratórias, descritivas e causais (ZIKMUND, 2006), optou-se pela descritiva, devido ao fato de ela observar, analisar e relacionar fatos e fenômenos, de acordo com a frequência, a natureza, as características e as correlações com outros fenômenos (CERVO; BERVIAN, 2002).

O uso de pesquisas descritivas tem por fim testar hipóteses baseadas na teoria, com característica comprobatória (HAIR et al., 2005). Sendo assim, esse tipo de pesquisa demonstra ser o mais adequado ao estudo das relações do ambiente institucional, representado pelas pressões regulatórias e do mercado consumidor, pela orientação estratégica para a ecoinovação, por práticas da manufatura verde e pelos desempenhos organizacional e operacional, sob o efeito da moderação categórica de organizações mais e menos frugais.

Diante da proposta de estudo dessas relações, a abordagem escolhida foi a quantitativa, uma vez que foram coletados e analisados dados numéricos para testes estatísticos, por meio de modelos de previsão (CRESWELL, 2010).

Para responder às questões de pesquisa, a partir das premissas formuladas, a associação entre a pressão regulatória, a pressão do mercado consumidor, a orientação estratégica para a ecoinovação, as práticas de manufatura verde e o desempenho, para organizações com a estratégia de inovação mais ou menos frugal, foi aplicada um survey de coleta de dados primários, realizado no segundo semestre de 2019. 
Sendo assim, o procedimento metodológico utilizado para esta pesquisa é classificado como formal, descritivo, positivista e de natureza quantitativa (COOPER; SCHINDLER, 2016; CRESWELL, 2010).

\subsubsection{Pesquisa bibliográfica}

Com o objetivo de levantar os principais autores, as abordagens e os resultados relacionados às pressões regulatórias e do mercado consumidor, à orientação estratégica para a ecoinovação, à inovação frugal, à manufatura verde e ao desempenho, foi realizada uma revisão da literatura (Figura 4).

Figura 4 - Cronologia de publicações das referências utilizadas

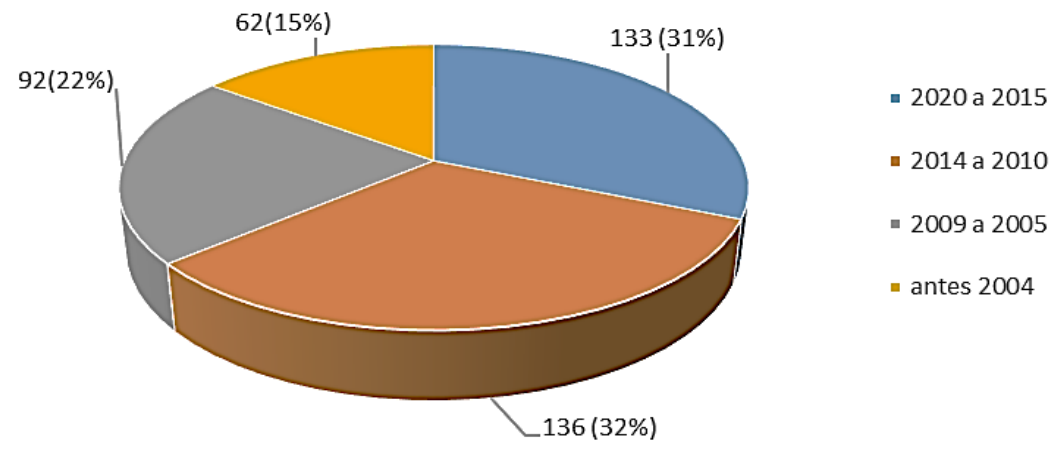

Fonte: Autora.

A seguir (Figura 5), estão representadas as fontes das referências bibliográficas, privilegiando as publicações em periódicos qualificados pelas bases de dados internacionais (SCImago) e nacionais (Qualis 2016-2020), como A1 e A2 (83\% da literatura utilizada), ou B1 e B2 (7\%). Das 423 obras consultadas, 97\% estão em periódicos, em livros e em relatórios internacionais. 
Figura 5 - Fonte de origem das referências bibliográficas

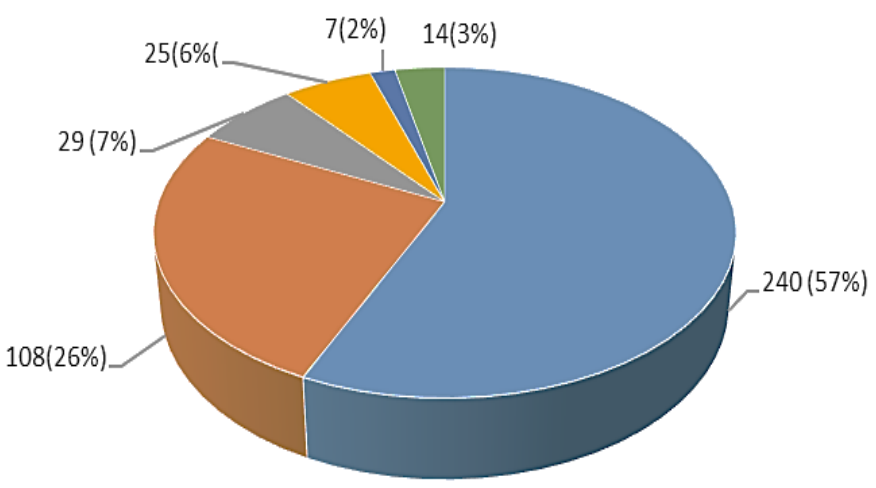

- A1

- $\mathrm{A} 2$

- $\mathrm{B} 1 / \mathrm{B} 2 / \mathrm{B} 3$

- Livros

- Relatórios internacionais

॥ Conferências e tese

Fonte: Autora.

\subsection{MÉTODO E TÉCNICA}

A definição de método e da técnica parte do entendimento das características individuais dos métodos e de suas aplicações no estudo dos fenômenos da área de negócios. Ao inferir o todo por meio de suas partes, o método indutivo considera para a análise uma amostra com determinada quantidade de casos escolhidos no universo ao qual pertencem. O método dedutivo, por sua vez, deduz as razões e as causas do fenômeno, a partir do todo, ou seja, por meio das afirmações mais amplas, conhece-se as partes; sendo assim, a verdade ou a conclusão sobre o todo torna as partes também verdadeiras (HEGENBERG; ARAÚJO JUNIOR; HEGENBERG, 2012). Já o método hipotético-dedutivo lida com os problemas científicos, por meio da definição e da testagem de hipóteses explicativas, apoiadas em base empírica. Pelo uso da probabilidade e da estatística, a partir dos dados coletados, as hipóteses propostas poderão ser ou não suportadas para a análise do fenômeno (HEGENBERG; ARAÚJO JUNIOR; HEGENBERG, 2012).

Para a pesquisa aqui proposta, foi utilizado o método hipotético-dedutivo, partindo-se de uma base teórica existente de estudos, capaz de dar fundamento teórico às relações entre os construtos testados, a fim de entender a lógica dessas relações. Como técnica, utilizou-se o levantamento (survey) de amostra do universo de organizações em mercados emergentes e desenvolvidos. 


\subsection{DEFINIÇÃO DAS VARIÁVEIS E INDICADORES}

O objetivo de utilizar variáveis métricas para a análise de fenômenos é refletir, a partir dos dados coletados de uma população, acerca da quantidade relativa ou da magnitude dos fatos observados (FAVERO et al., 2009). Essas variáveis estão relacionadas às características ou aos atributos dos indivíduos e das organizações, variando entre escalas validadas e categorias mensuradas (CRESWELL, 2010).

O modelo investigativo desta pesquisa é composto por variáveis independentes, dependentes e uma moderadoras categórica. Ao mesmo tempo que as variáveis independentes podem influenciar ou prever as variáveis dependentes, estas últimas são objeto de observação dos pesquisadores para a análise de resultados e de experiências (CRESWELL, 2010). Já a variável moderadora categórica, inserida no modelo de interação das variáveis independentes, com efeito sobre a relação entre estas e as dependentes, também deve ser considerada para a análise de influências e de consequências das variações (MCCLAVE; BENSON; SINCICH, 2009).

Ao propor um modelo de investigação, os construtos tornam-se variáveis não observadas ou mensuradas diretamente, sendo seu comportamento indicado por meio da manifestação das suas variáveis indicadoras ou manifestas (CRESWELL,2010). Ressalta-se que, para a aplicação nos instrumentos de pesquisa, deve-se utilizar as variáveis indicadoras ou observáveis (MONECKE; LEISCH, 2012).

Os construtos podem ser de natureza endógena ou exógena, dependendo do tipo de variável associada no modelo de pesquisa. Os endógenos estão associados às variáveis dependentes ou de resultado em, pelo menos, uma relação causal. A variação em um construto endógeno é explicada por variáveis presentes no modelo. Os construtos exógenos não possuem antecessores e, por isso, não são influenciados por nenhuma outra variável (HAIR et al., 2005), mas identificados nas variáveis independentes, devido à sua atuação como preditoras de outras variáveis ou construtos.

A seguir (Figura 6), está descrito o modelo operacional da relação entre as variáveis endógenas e exógenas. A moderação da estratégia de inovação frugal, na relação entre a orientação estratégica para a ecoinovação e a manufatura verde, para teste das hipóteses, não está representada no desenho, todavia, ela foi considerada e testada estatisticamente para a análise multigrupo, realizada com o auxílio do software SmartPLS. 
Figura 6 - Modelo conceitual de pesquisa

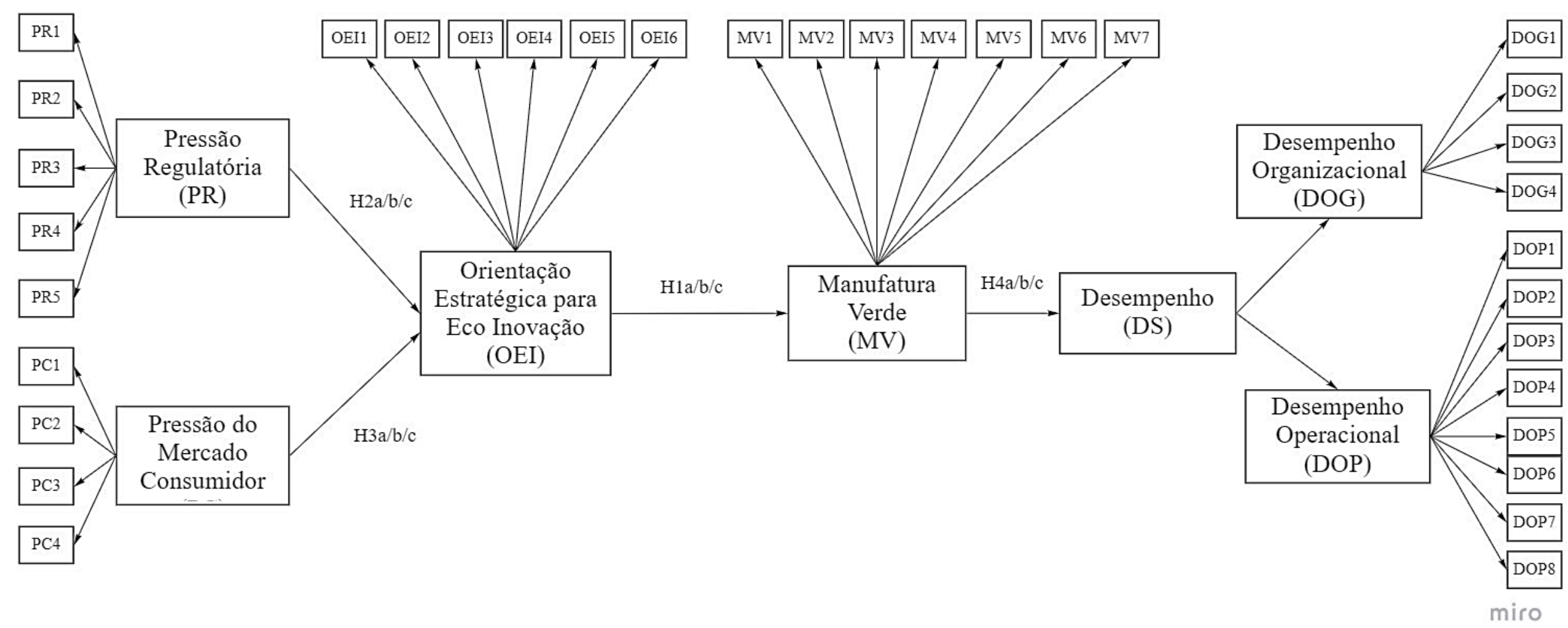

Fonte: Autora. 
No modelo adotado, são variáveis endógenas: orientação estratégica para a ecoinovação (OEI), manufatura verde (MV), desempenho operacional (DOP) e desempenho organizacional (DOG); e variáveis exógenas: pressão regulatória (PR) e pressão do mercado consumidor (PC); tendo a variável inovação frugal (IF) como moderadora categórica (mais frugal/menos frugal) da relação existente entre a estratégica para a ecoinovação (OEI) e a variável manufatura verde (MV), refletindo como as estratégias de inovação frugal, desenvolvidas pela organização, podem influenciar na relação entre a orientação estratégica de ecoinovação e a manufatura verde.

Ao estabelecer o construto de inovação frugal como variável moderadora categórica, a pesquisa tem a intenção de analisar o fenômeno da relação entre as orientações estratégicas para a ecoinovação e as práticas de manufatura verde, observando se elas são influenciadas positivamente pelas estratégias de inovação frugal; ou seja, se as estratégias de inovação frugal têm efeito de potencializar essa relação, quando aplicadas, melhorando-a em efeito e em magnitude.

Considerando a natureza de teste das teorias existentes para um fenômeno social, por meio das construções e do inter-relacionamento das variáveis presentes nas pesquisas quantitativas (CRESWELL, 2010), as variáveis dependentes e independentes são necessárias ao conhecimento do tipo de relação estabelecida entre elas (positiva, negativa ou desconhecida) e à magnitude desses relacionamentos.

A seguir, estão descritos cada um dos construtos deste estudo, isto é, as variáveis exógenas, endógenas e a moderadora categórica, definida como mais frugal e menos frugal.

O construto exógeno "pressão regulatória" foi mensurado peça escala Likert de sete pontos, a fim de verificar a importância da regulação para as estratégias de ecoinovação na organização, variando de um (mais baixa concordância) a sete (mais alta concordância). Esse construto representa os instrumentos de controle e a pressão regulatória dos padrões de emissão e de produção tecnológica, bem como os riscos legais envolvidos, a supervisão do governo e as penalidades às quais a organização está sujeita (HUANG et al., 2016).

O construto exógeno "pressão do mercado consumidor" mensura, por meio da escala Likert de sete pontos, a importância da pressão do mercado consumidor para as estratégias de ecoinovação na organização, variando de um (mais baixa concordância) a sete (mais alta concordância). Esse construto representa a pressão dos consumidores sobre as organizações para a conscientização sobre os aspectos ambientais, na forma de produtos ambientalmente amigáveis, do comportamento ambiental da organização, e da pressão dos consumidores por 
cadeias de suprimentos que envolvam fornecedores ambientalmente ativos e conscientes (verdes) (HUANG et al., 2016).

O construto central do modelo é a "manufatura verde" (MV), mensurada por uma escala Likert de sete pontos, variando de um (mais baixa concordância) a sete (mais alta concordância). Esse construto representa as práticas de manufatura realizadas pela organização para: aumento do ciclo de vida de produtos; diminuição do uso de matéria-prima; criação de produtos livres de substâncias tóxicas e poluentes; avaliação do ciclo de vida e de sua consequente carga ambiental; e criação de produtos que reduzem o consumo de recursos ambientais finitos (HSU; TAN; ZAILANI, 2016).

O construto "orientação estratégica para ecoinovação" (OEI) também foi mensurado pela escala Likert de sete pontos, variando de um (mais baixa concordância) a sete (mais alta concordância). Esse construto representa a orientação da organização para adequar os recursos às inovações verdes, com apoio da gestão para as inovações em processos e de produtos verdes, a avaliação do ciclo de vida verde dos produtos, as estratégicas com objetivos de iniciativas verdes e baseadas em uma cultura organizacional de inovação, e treinamento e educação em inovações verdes (HSU; TAN; ZAILANI, 2016).

O construto endógeno "desempenho" é de segunda ordem, sendo a sua manifestação identificada por dois outros construtos, isto é, "desempenho organizacional" (DOG) e “desempenho operacional" (DOP), mensurados também pela escala Likert de sete pontos, variando de um (mais baixa concordância) a sete (mais alta concordância), em comparação com a concorrência. Para o desempenho operacional (DOP), foram mensurados: custos operacionais e preços, comparados à concorrência; adequação às especificações e à qualidade de desempenho de produtos; tempo e velocidade de entrega; e flexibilidade na capacidade de produção e na variedade de produtos (PRAJOGO et al., 2012). Para o desempenho organizacional (DOG), foram mensurados: retorno sobre o investimento; crescimento de vendas, de mercado e de lucro da organização, comparado à concorrência (CALANTONE; CAVUSGIL; ZHAO, 2002).

O construto endógeno "inovação frugal” (IF), considerado nesta pesquisa como variável moderadora categórica da relação entre a orientação estratégica para a ecoinovação e a manufatura verde, foi estruturado em duas fases.

Na primeira fase, a IF foi mensurada pela escala Likert de sete pontos, quanto à concordância sobre a importância das atividades para a organização, variando de um (mais baixa concordância) a sete (mais alta concordância). Esse construto representa as atividades relacionadas às dimensões: (a) custo, que mensura se as soluções de produtos e de serviços 
oferecidas pela organização são de baixo custo e qualidade, e se os processos envolvidos estão focados na redução de custos e na economia dos recursos organizacionais dentro do processo operacional; (b) funcionalidade, que mensura se o produto ou o serviço está centrado em uma funcionalidade, sem a adição de frugalidades, que promove a facilidade de uso e a entrega de durabilidade de produtos e de serviços; e (c) ecossistema de inovação, que mensura a eficiência e a eficácia das soluções, diante das necessidades sociais e ambientais dos clientes, bem como a sustentabilidade ambiental no processo operacional, e as parcerias locais para o desenvolvimento de soluções (ROSSETTO; BORINI, 2017).

$\mathrm{Na}$ segunda fase, para transformar essa variável em categórica, mais ou menos frugal, foi adotada a média dos indicadores do construto de inovação frugal, conforme apresentado, mais adiante (Tabela 3), na análise descritiva das variáveis latentes por país, na amostra, na Seção 4.

A média encontrada para esse construto foi de 5,64, sendo utilizada como premissa para a divisão da variável categórica, determinando, desse modo, que organizações com a média de seus indicadores da escala de inovação frugal acima de seis fossem consideradas como mais frugais; e as com índices abaixo desse valor, como menos frugais.

A adoção desse parâmetro é confirmada pela média desse construto, tanto na análise descritiva, realizada pelos países da amostra, quanto sob a perspectiva de países emergentes e desenvolvidos. A seguir (Quadro 6), está o detalhamento dos construtos e dos indicadores utilizados nesta pesquisa. 
Quadro 7 - Construto e variáveis do modelo de pesquisa

(continua)

\begin{tabular}{|c|c|c|c|c|}
\hline Construto & Indicador & Código & Descrição & $\begin{array}{l}\text { Fontes } \\
\text { teóricas }\end{array}$ \\
\hline \multirow{5}{*}{$\begin{array}{l}\text { Pressão } \\
\text { regulatória } \\
(\mathrm{PR})\end{array}$} & \multirow{5}{*}{$\begin{array}{l}\text { Pressão } \\
\text { regulatória } \\
\text { para a } \\
\text { ecoinovação }\end{array}$} & PR1 & Padrões de emissão & \multirow{5}{*}{$\begin{array}{l}\text { (HUANG } \text { et } \\
\text { al., 2016) }\end{array}$} \\
\hline & & PR2 & Padrões de produção tecnológica & \\
\hline & & PR3 & Riscos legais & \\
\hline & & PR4 & Supervisão governamental & \\
\hline & & PR5 & Penalidades & \\
\hline \multirow{4}{*}{$\begin{array}{l}\text { Pressão do } \\
\text { mercado } \\
\text { consumidor } \\
(\mathrm{PC})\end{array}$} & \multirow{4}{*}{$\begin{array}{l}\text { Pressão do } \\
\text { mercado } \\
\text { consumidor } \\
\text { para a } \\
\text { ecoinovação }\end{array}$} & PC 1 & $\begin{array}{l}\text { Maior conscientização sobre questões ambientais entre } \\
\text { nossos clientes. }\end{array}$ & \multirow{4}{*}{$\begin{array}{l}\text { (HUANG et } \\
\text { al., 2016) }\end{array}$} \\
\hline & & PC 2 & $\begin{array}{l}\text { Preferências dos clientes por produtos ecologicamente } \\
\text { corretos. }\end{array}$ & \\
\hline & & PC 3 & $\begin{array}{l}\text { A atenção contínua dos clientes ao comportamento } \\
\text { ambiental da nossa empresa. }\end{array}$ & \\
\hline & & $\mathrm{PC} 4$ & Clientes que buscam fornecedores verdes. & \\
\hline \multirow{6}{*}{$\begin{array}{l}\text { Orientação } \\
\text { estratégica } \\
\text { para a } \\
\text { ecoinovação } \\
\text { (OEI) }\end{array}$} & \multirow{6}{*}{$\begin{array}{l}\text { Práticas } \\
\text { realizadas } \\
\text { na } \\
\text { organização, } \\
\text { voltadas à } \\
\text { ecoinovação }\end{array}$} & OEI 1 & $\begin{array}{l}\text { Nossa organização aloca recursos adequados às } \\
\text { inovações verdes. }\end{array}$ & \multirow{6}{*}{$\begin{array}{c}\text { (HSU; TAN; } \\
\text { MOHAMAD } \\
\text { ZAILANI, } \\
2016)\end{array}$} \\
\hline & & OEI 2 & $\begin{array}{l}\text { Nossa alta gestão apoia inovações de processos que } \\
\text { promovem iniciativas verdes. }\end{array}$ & \\
\hline & & OEI 3 & $\begin{array}{l}\text { Nossa alta gestão apoia inovações de produtos que } \\
\text { promovem iniciativas verdes. }\end{array}$ & \\
\hline & & OEI 4 & $\begin{array}{l}\text { A avaliação do ciclo de vida é um critério importante, } \\
\text { enquanto desenvolvemos novos produtos. }\end{array}$ & \\
\hline & & OEI 5 & $\begin{array}{l}\text { Nossa organização compete em objetivos direcionados à } \\
\text { inovatividade e às iniciativas verdes. }\end{array}$ & \\
\hline & & OEI 6 & $\begin{array}{l}\text { Nossa organização conduz agressivamente treinamento e } \\
\text { educação baseados em iniciativas verdes. }\end{array}$ & \\
\hline \multirow{10}{*}{$\begin{array}{l}\text { Inovação } \\
\text { frugal (IF) }\end{array}$} & \multirow{10}{*}{$\begin{array}{l}\text { Práticas } \\
\text { realizadas } \\
\text { na } \\
\text { organização, } \\
\text { voltadas às } \\
\text { dimensões } \\
\text { de inovação } \\
\text { frugal }\end{array}$} & IF 1 & $\begin{array}{l}\text { A funcionalidade é central do produto/serviço e não há } \\
\text { funcionalidades adicionais. }\end{array}$ & \multirow{10}{*}{$\begin{array}{c}\text { (ROSSETTO; } \\
\text { BORINI, } \\
2017)\end{array}$} \\
\hline & & IF 2 & A facilidade de uso do produto/serviço. & \\
\hline & & IF 3 & $\begin{array}{l}\text { A questão de durabilidade do produto/serviço (não } \\
\text { estraga fácil). }\end{array}$ & \\
\hline & & IF 4 & $\begin{array}{l}\text { Soluções eficientes e eficazes para as necessidades } \\
\text { sociais/ambientais dos clientes. }\end{array}$ & \\
\hline & & IF 5 & $\begin{array}{l}\text { Soluções que oferecem produtos/serviços "bons e } \\
\text { baratos". }\end{array}$ & \\
\hline & & IF 6 & Redução significativa de custos no processo operacional. & \\
\hline & & IF 7 & $\begin{array}{l}\text { A economia de recursos organizacionais no processo } \\
\text { operacional. }\end{array}$ & \\
\hline & & IF 8 & $\begin{array}{l}\text { O rearranjo dos recursos organizacionais no processo } \\
\text { operacional. }\end{array}$ & \\
\hline & & IF 9 & A sustentabilidade ambiental no processo operacional. & \\
\hline & & IF 10 & Parcerias com empresas locais no processo operacional. & \\
\hline
\end{tabular}

Fonte: Autora. 
Quadro 6-Construto e variáveis do modelo de pesquisa

(conclusão)

\begin{tabular}{|c|c|c|c|c|}
\hline Construto & Indicador & Código & Descrição & $\begin{array}{l}\text { Fontes } \\
\text { teóricas }\end{array}$ \\
\hline \multirow{7}{*}{$\begin{array}{l}\text { Manufatura } \\
\text { verde (MV) }\end{array}$} & \multirow{7}{*}{$\begin{array}{l}\text { Práticas } \\
\text { realizadas na } \\
\text { organização, } \\
\text { voltadas à } \\
\text { manufatura } \\
\text { verde }\end{array}$} & MV 1 & $\begin{array}{l}\text { Minha organização produz produtos com partes de } \\
\text { reuso ou recicladas, como plástico reciclável e } \\
\text { vidro. }\end{array}$ & \multirow{7}{*}{$\begin{array}{c}\text { (HSU; TAN; } \\
\text { MOHAMAD } \\
\text { ZAILANI, } \\
\text { 2016;). }\end{array}$} \\
\hline & & MV 2 & $\begin{array}{l}\text { Minha organização usa a avaliação de ciclo de vida } \\
\text { para estimar a carga ambiental de produtos. }\end{array}$ & \\
\hline & & MV 3 & $\begin{array}{l}\text { Minha organização produz produtos que são livres } \\
\text { de substâncias tóxicas e perigosas, como chumbo, } \\
\text { mercúrio e cromo. }\end{array}$ & \\
\hline & & MV 4 & $\begin{array}{l}\text { Minha organização desenha produtos, assegurando } \\
\text { que eles tenham partes recicláveis e reutilizáveis. }\end{array}$ & \\
\hline & & MV 5 & $\begin{array}{l}\text { Minha organização produz produtos que reduzem o } \\
\text { consumo de materiais e de energia durante o seu } \\
\text { uso. }\end{array}$ & \\
\hline & & MV 6 & $\begin{array}{l}\text { Minha organização reduz o consumo de energia em } \\
\text { produtos, durante sua manufatura e transporte. }\end{array}$ & \\
\hline & & MV 7 & $\begin{array}{l}\text { Minha organização aumenta o tempo de vida de } \\
\text { produtos, resultando em maior eficiência e } \\
\text { produtividade. }\end{array}$ & \\
\hline \multirow{8}{*}{$\begin{array}{l}\text { Desempenho } \\
\text { operacional } \\
\text { (DOP) }\end{array}$} & \multirow{8}{*}{$\begin{array}{l}\text { Desempenho } \\
\text { operacional, } \\
\text { em relação aos } \\
\text { concorrentes }\end{array}$} & DOP 1 & Custos operacionais & \multirow{8}{*}{$\begin{array}{l}\text { (PRAJOGO et } \\
\text { al., 2012) }\end{array}$} \\
\hline & & DOP 2 & Competitividade de preços de novos produtos & \\
\hline & & DOP 3 & Conformidade de especificações & \\
\hline & & DOP 4 & Qualidade de desempenho do produto & \\
\hline & & DOP 5 & Tempo de entrega de produtos & \\
\hline & & DOP 6 & Velocidade de entrega de produtos & \\
\hline & & DOP 7 & Flexibilidade de capacidade de produção & \\
\hline & & DOP 8 & Variedade de produtos & \\
\hline \multirow{4}{*}{$\begin{array}{l}\text { Desempenho } \\
\text { operacional } \\
\text { (DOG) }\end{array}$} & \multirow{4}{*}{$\begin{array}{l}\text { Desempenho } \\
\text { organizacional, } \\
\text { em relação aos } \\
\text { concorrentes }\end{array}$} & DOG 1 & Retorno sobre investimento (ROI. & \multirow{4}{*}{$\begin{array}{l}\text { CALANTONE; } \\
\text { CAVUSGIL; } \\
\text { ZHAO, 2002). }\end{array}$} \\
\hline & & DOG 2 & Retorno sobre ativos & \\
\hline & & DOG 3 & Crescimento de vendas & \\
\hline & & DOG 4 & Crescimento da rentabilidade & \\
\hline
\end{tabular}

Fonte: Autora. 


\subsection{UNIVERSO DA AMOSTRA}

A unidade de análise desta pesquisa é constituída por organizações com atividades de manufatura, nos seguintes países: Brasil, Índia, Alemanha e Estados Unidos da América (EUA), sendo os respondentes CEO, presidentes, diretores e gerentes.

A escolha para a coleta de dados se deve à importância desses países no campo de pesquisa da inovação frugal, da ecoinovação e da manufatura verde, sendo a centralização dos estudos iniciais na Índia (RAO, 2013a) justificada por esse país ser frequentemente reconhecido como cenário ideal para testes de inovações frugais, aplicadas em mercados emergentes e desenvolvidos (TIWARI; HERSTATT, 2012a).

Nesse sentido, Índia (48\%) e Estados Unidos (11\%) representam as maiores fontes de inovação frugal (HOSSAIN, 2017). E, honrando a origem do conceito de manufatura verde (REHMAN; SETH; SHRIVASTAVA, 2016), as organizações alemãs têm demonstrado a relevância das relações entre a ecoinovação e as práticas de manufatura (FRONDEL; HORBACH; RENNINGS, 2008; HORBACH, 2008; KAMMERER, 2009; TRIEBSWETTER; WACKERBAUER, 2008).

Ademais, as quatro nações escolhidas, incluindo o Brasil, constam na lista dos dez países com maior publicação na área de gestão da cadeia de manufatura verde (DE OLIVEIRA et al., 2018), mesmo que a natureza das relações entre ecoinovação, manufatura verde e inovação frugal ainda seja limitada no Brasil.

Para a validação de face do questionário, com o objetivo de prever fatos que pudessem interferir negativamente nos resultados da pesquisa e de considerá-lo fidedigno, válido e operacional, ele foi encaminhado a profissionais de inovação, em empresas no Brasil, e a acadêmicos, especialistas em inovação, sustentabilidade e métricas de pesquisa (CRESWELL, 2010). Essa validação permite identificar possíveis problemas na qualidade do entendimento do survey, quanto ao preenchimento e ao significado dos itens das escalas, e a mitigação do risco de viés de compreensão por formulação ambígua ou confusa (PODSAKOFF et al., 2003; PODSAKOFF; ORGAN, 1986). Após o retorno de especialistas e executivos, as escalas do questionário foram adaptadas, de acordo com as sugestões de melhorias.

O convite à participação nesta pesquisa foi direcionado de modo on-line aos responsáveis por gestão, em nível de decisão executiva na organização, sendo os questionários enviados na língua inglesa para Alemanha, EUA e Índia (língua original das escalas), e na língua portuguesa, aos respondentes do Brasil. Por se tratar de uma coleta de dados realizada 
em países de diferentes línguas, os questionários foram validados, quanto à sua compreensão e à integridade da tradução, por meio de back-translation.

Para definir o tamanho mínimo da amostra da análise de equações estruturais (AEE), foram considerados os critérios de estimação da fórmula de Westland (2010) e o software G*Power. Segundo Hair et al. (2005, p. 484), esse tamanho deve ser de pelo menos cinco respondentes para cada parâmetro estimado, considerando-se mais adequada a proporção de dez respondentes por parâmetro, ao utilizar a análise de equações estruturais. Pela fórmula de Westland (2010), a dimensão da amostra (n) é calculada a partir do número de itens ou de indicadores $(\mathrm{p})$ e de variáveis latentes ou fatores $(\mathrm{k})$ do modelo: $\mathrm{n} \geq 50 \mathrm{r}^{2}-450 \mathrm{r}+1100$, sendo que $\mathrm{r}=p / \mathrm{k}$ (Westland, 2010).

De acordo com essa fórmula, considerando 45 indicadores (p) e sete variáveis latentes (k), o valor de $r=6,43$ exigiria pelo menos uma amostra de $n \geq 274$ observações. Segundo o cálculo da dimensão da amostra, pelas recomendações de Hair et al. (2005, p. 484), a quantidade de observações desejada deveria ser de $n=450$.

Para o uso do software G*Power no cálculo da amostra mínima (FAUL et al., 2007), autores sugerem 0,80 de poder de teste, $\mathrm{f} 2$ mediano $=0,15$, sendo considerado o construto com maior número de preditores (RINGLE; DA SILVA; BIDO, 2014), que, nesta pesquisa, é “orientação estratégica de ecoinovação", com dois preditores.

De acordo com o cálculo realizado pelo software G*Power (Figura 7), a amostra mínima calculada deveria ser de 68 casos; porém, seguindo a recomendação de Ringle, Da Silva e Bido (2014), para a consistência do modelo, a amostra precisa ter o dobro ou o triplo do valor indicado, ou seja, entre 136 e 204 observações. Após a coleta, obteve-se 303 respostas do setor de manufatura, sendo 173 de organizações em países emergentes (Brasil e Índia), e 130 em países desenvolvidos (Alemanha e Estados Unidos da América), atendendo aos critérios de dimensionamento tanto de Ringle, Da Silva e Bido (2014) quanto de Westland (2010). 
Figura 7 - Cálculo da amostra no software $G^{*}$ Power

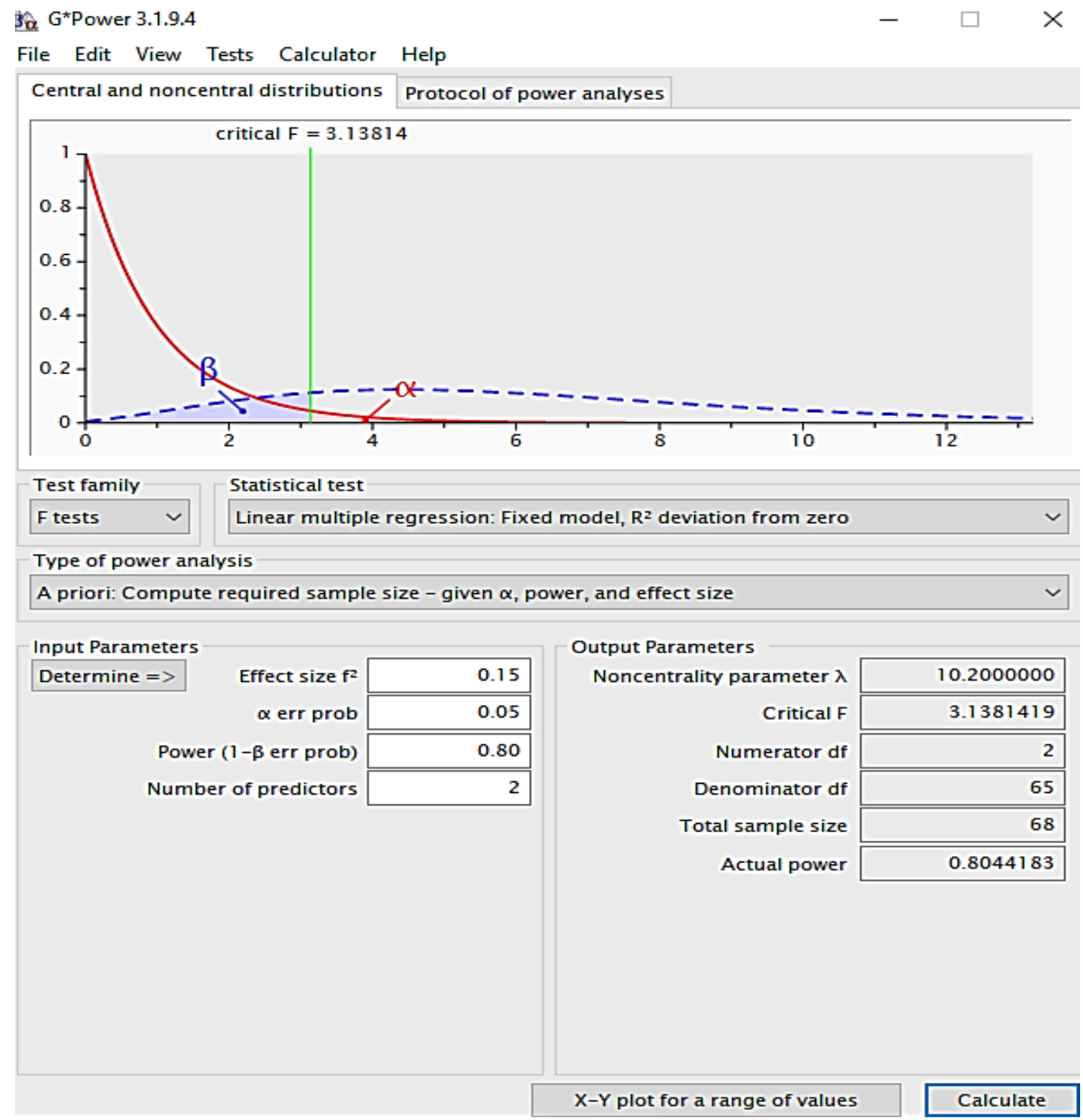

Fonte: Autora.

A partir da definição da amostra necessária, são determinados os procedimentos de campo, e a escolha, a validação e a aplicação do instrumento de coleta, conforme a Seção 3.5, a seguir.

\subsection{INSTRUMENTAL DE PESQUISA E PROCEDIMENTOS DE CAMPO}

$\mathrm{O}$ instrumento de coleta utilizado foi o survey online, que oferece a vantagem de economia de tempo e de recursos, além da facilidade de administração da coleta e do armazenamento de dados, e a possibilidade de elaboração de relatórios (NAIR; ADAMS, 2009). 
Para a coleta de dados, que ocorreu entre os meses de julho e agosto de 2019, foi contratada uma empresa especializada em provisão de bases de pesquisa, chamada Toluna, modalidade amplamente utilizada, devido à sua adequação a critérios de qualidade dos dados para os propósitos acadêmicos (KOTABE, 2002). A empresa utiliza uma plataforma para a elaboração da pesquisa, o envio dos questionários e a coleta das respostas às questões, sendo consideradas válidas como aspectos de gestão apenas as observações de questionários completos. Vale destacar que a empresa oferece uma bonificação aos respondentes, como motivação para os questionários serem respondidos na sua totalidade.

$\mathrm{O}$ perfil dos respondentes foi de, preferencialmente, CEO, presidentes, diretores e gerentes de organizações com práticas de manufatura verde e orientadas para a ecoinovação; e, para o envio dos questionários, selecionou-se os contatos de organizações com práticas declaradas sustentáveis e de preservação dos recursos naturais.

Os respondentes da pesquisa foram questionados sobre a sua concordância em relação às questões apresentadas no survey, em escala métrica (HAIR et al., 2005) Likert, entre um (menor discordância) e sete (maior concordância). O uso dessa escala objetiva verificar a concordância do entrevistado em relação às afirmações que demonstram a favorabilidade em relação a um fato ou opinião. As questões respondidas estão nos Apêndices A (versão em inglês) e B (versão em português).

O instrumento de pesquisa está dividido em três partes, apresentando: (1) os objetivos da pesquisa, a importância da cooperação do respondente para o sucesso do estudo, e a garantia do sigilo das informações fornecidas. Com foco nos respondentes desejados para a pesquisa (CEO, presidentes, diretores e gerentes), a primeira pergunta do questionário possuía característica de exclusão, ou seja, caso o respondente não ocupasse o cargo esperado, sua participação na pesquisa era finalizada; (2) as escalas validadas para as respostas, pois o uso de escalas validadas por estudos anteriores tem a vantagem de facilitar a execução da pesquisa, dando ao pesquisador a confiança necessária de que elas já foram testadas, validadas e constituem indicadores adequados dos conceitos analisados (HYMER; LAMB; BULMER, 2006); e (3) a questão demográfica, em relação ao tamanho da organização.

Para evitar a variância comum do método e diminuir a fadiga do respondente, quando múltiplas questões devem ser respondidas, dentro de um mesmo contexto, levando à interpretação da relação causal entre variáveis dependentes e independentes, as questões online foram aplicadas com perguntas em ordem aleatória para cada respondente. 


\subsection{ANÁLISE DOS DADOS}

A análise dos dados foi realizada em três etapas, utilizando as seguintes ferramentas: (a) análise e tratamento dos dados coletados (Excel); (b) análises descritivas (SPSS); e (c) análise por meio da modelagem de equações estruturais (SEM - Structural Equation Modeling SmartPLS 3.0).

Na primeira etapa, para início do tratamento dos dados e das análises, as planilhas, com as informações coletadas em sua forma bruta, foram extraídas da plataforma da empresa de coleta contratada, para a identificação da quantidade de dados de cada mercado, do preenchimento integral dos campos questionados e da aderência das respostas, conforme o escopo da pesquisa. Nessa fase, os dados foram codificados e preparados, de acordo com as nomenclaturas das variáveis e o formato adequado para uso nos softwares de análise estatística SPSS e SmartPLS.

Na segunda etapa, foi utilizado o software SPSS para a elaboração das estatísticas descritivas, considerando as amostras dos países emergentes e as dos desenvolvidos, mais a amostra com todas as respostas. Como está indicado na Seção 4.2, as médias dos indicadores, a média dos construtos, o desvio-padrão e o teste - $\mathrm{t}$ derivaram da amostra total, considerando a variável moderadora categórica de inovação frugal. A análise, nessa fase, teve por objetivo identificar possíveis discrepâncias entre as amostras, capazes de interferir nos resultados da fase seguinte, de modelagem da equação estrutural.

A terceira etapa, da modelagem de equações estruturais (MEE), ou Structural Equation Modeling (SEM), ocorreu de acordo com o método dos mínimos quadrados parciais (RINGLE; DA SILVA; BIDO, 2014; HAIR et al., 2005; HAIR; RINGLE; SARTSTEDT, 2014; HENSELER; RINGLE; SINKOVICS, 2009). Nessa fase, para alcançar o objetivo desta pesquisa, foram utilizados: o software SmartPLS, para a análise da modelagem das equações estruturais; e o teste de invariância da composição (MICOM) e a análise multigrupo, para analisar o efeito moderador.

A escolha do PLS-SEM para modelagem e análise se deu em virtude do enfoque de sua abordagem em previsão, exploração e capacidade de lidar com modelos complexos, servindo melhor a propósitos preditivos e exploratórios, envolvidos em situações da teoria em desenvolvimento (FORNELL; LARCKER, 1981; SOSIK; KAHAI; PIOVOSO, 2009). Nas modelagens dessas teorias, o foco está em obter a melhor previsão de um conjunto específico de relações estruturais entre as variáveis de interesse (SOSIK; KAHAI; PIOVOSO, 2009). Outros argumentos também corroboram a escolha do PLS-SEM: a melhoria de teoria já 
existente; a descoberta de novas relações causais, negligenciadas em análise anteriores; a descoberta de heterogeneidade; as análises multigrupo, procedimentos mais exploratórios ou orientados a previsões; a identificação de fatores contextuais relevantes, como a definição de segmentos ou de subgrupos, de dados não normais; e a constatação de que o modelo causal compreende muitos construtos, relações de caminho e indicadores, além de elementos avançados, como variáveis moderadoras ou componentes hierárquicos (HAIR et al., 2017, 2019; HENSELER; SARSTEDT, 2013; RICHTER et al., 2016).

Para uso da MEE, os seguintes pressupostos foram observados e avaliados para a continuidade da análise: (1) não deve haver uma relação causal recíproca dentro do modelo, ou seja, o modelo de caminhos deve ser recursivo; (2) toda variável latente tem, pelo menos, um indicador atribuído; (3) os indicadores devem ser atribuídos apenas uma vez para cada variável latente; e (4) o modelo deve ser composto por apenas uma estrutura, ou seja, não deve haver diferentes modelos não relacionados.

Como fase de análise anterior à comparação do caminho estrutural entre mais e menos frugais, foi necessário confirmar que a mensuração dos dados entre os grupos é equivalente ao procedimento Measurement Invariance of the Composite Models (MICOM), cujo objetivo é garantir que os grupos sejam comparados, a partir da análise de que os resultados no modelo estrutural não têm origem em dados diferentes.

Por fim, na análise multigrupo, executa-se o teste paramétrico Partial Least Squares Multi-group Analysis (PLS-MGA), no software SmartPLS 3.0, já que, por meio dos testes bicaudais, os valores de $p \leq 0,01 ; p \leq 0,05 ; p \leq 0,10$ e $p \geq 0,90 ; p \geq 0,95 ; p \geq 0,99$, para as estimativas do caminho estrutural em comparação, indicam a existência de diferenças estatisticamente significativas das características dos grupos. 


\section{RESULTADOS}

Para a interpretação dos dados, foi realizada a estimação do modelo de mensuração, por meio da análise univariada; e do modelo estrutural, pela análise multivariada. Inicialmente, foram exploradas as características estatísticas descritivas das amostras, abordando a distribuição de cargos e o tamanho das organizações respondentes. No exame do modelo de mensuração, foram analisadas as cargas e os pesos fatoriais, em relação aos demais indicadores do construto; e para a análise do modelo estrutural, foram utilizados os coeficientes estruturais estimados e os índices da capacidade preditiva do modelo.

\subsection{DESCRIÇÃO DA AMOSTRA ESTUDADA}

A análise descritiva das amostras, realizada por intermédio do software Excel, inclui as 303 organizações respondentes da pesquisa, distribuídas nos países selecionados (Tabela 1), com os cargos ocupados e a distribuição do tamanho da empresa.

Tabela 1 - Distribuição de cargos e tamanho das empresas

\begin{tabular}{|c|c|c|c|c|c|c|}
\hline & & $\begin{array}{r}\text { Índia } \\
(73) \\
\end{array}$ & $\begin{array}{r}\text { Brasil } \\
(\mathbf{1 0 0}) \\
\end{array}$ & $\begin{array}{r}\text { EUA } \\
(53) \\
\end{array}$ & $\begin{array}{r}\text { Alemanha } \\
(77) \\
\end{array}$ & $\begin{array}{l}\text { Total } \\
(303) \\
\end{array}$ \\
\hline \multirow{3}{*}{ Cargo } & $\begin{array}{l}\text { Proprietário, Presidente } \\
\text { ou Vice-Presidente }\end{array}$ & $7(10 \%)$ & $5(5 \%)$ & $15(28 \%)$ & $5(6 \%)$ & $32(10 \%)$ \\
\hline & Diretor ou C-Level & $25(34 \%)$ & $34(34 \%)$ & $21(40 \%)$ & $26(34 \%)$ & $106(35 \%)$ \\
\hline & Gerente & $41(56 \%)$ & $61(61 \%)$ & $17(32 \%)$ & $46(60 \%)$ & $165(55 \%)$ \\
\hline \multirow{5}{*}{ Tamanho } & Até 50 funcionários & $2(3 \%)$ & $4(4 \%)$ & $5(9 \%)$ & - & $11(4 \%)$ \\
\hline & $\begin{array}{l}\text { De } 51 \text { a } 250 \\
\text { funcionários }\end{array}$ & $13(18 \%)$ & $12(12 \%)$ & $10(19 \%)$ & $18(24 \%)$ & $53(17,5 \%)$ \\
\hline & $\begin{array}{l}\text { De } 251 \text { a } 500 \\
\text { funcionários }\end{array}$ & $11(15 \%)$ & $29(29 \%)$ & $9(17 \%)$ & $28(36 \%)$ & $77(25 \%)$ \\
\hline & $\begin{array}{l}\text { De } 501 \text { a } 1000 \\
\text { funcionários }\end{array}$ & $16(22 \%)$ & $18(18 \%)$ & $11(21 \%)$ & $17(22 \%)$ & $62(20,5 \%)$ \\
\hline & $\begin{array}{l}\text { Mais de } 1000 \\
\text { funcionários }\end{array}$ & $31(42 \%)$ & $37(37 \%)$ & $18(34 \%)$ & $14(18 \%)$ & $100(33 \%)$ \\
\hline TOTAL & & 73 & 100 & 53 & 77 & 303 \\
\hline
\end{tabular}

Fonte: Autora.

A análise descritiva demonstra que as amostras são compostas por empresas acima de 251 funcionários: Brasil (84\%), Índia (79\%), Alemanha (76\%) e Estados Unidos (72\%), 
prevalecendo as de médio a grande porte, de acordo com classificação do IBGE (Instituto Brasileiro de Geografia e Estatística).

A pesquisa foi respondida predominantemente por gerentes, na Alemanha (60\%), Brasil (61\%) e Índia (56\%); e, nos Estados Unidos, por diretores/C-level (40\%). Sendo assim, a amostra de 303 respondentes foi respondida, em sua maioria, por gerentes (55\%), e por empresas de manufatura de grande porte, acima de 501 funcionários $(53,5 \%)$.

A seguir, estão as análises da média e do desvio-padrão de cada variável, tanto as independentes quanto as dependentes, mensuradas para os construtos.

\subsection{ANÁLISES UNIVARIADAS}

As análises univariadas visam compreender o comportamento das respostas, no nível das variáveis independentes e dependentes. De acordo com o modelo conceitual proposto, são dois os construtos considerados independentes: pressão regulatória (PR) e pressão do mercado consumidor (PC); e quatro os dependentes: orientação estratégica para a ecoinovação (OEI), manufatura verde (MV), desempenho organizacional (DOG) e desempenho operacional (DOP).

A seguir (Tabela 2), está a análise descritiva das variáveis latentes por país da amostra. Dentre os países, a Alemanha apresenta as menores médias para todas as variáveis mensuradas de um a sete, e os maiores desvios-padrão para IF (inovação frugal), MV (manufatura verde), DOP (desempenho operacional) e DOG (desempenho organizacional), apontando para uma maior distribuição de concordância entre os indicadores mensurados. Entre os países emergentes, o Brasil apresenta as maiores médias em todos os construtos.

Tabela 2 - Análise descritiva das variáveis latentes por país

\begin{tabular}{lllllllll}
\hline & Índia (73) & \multicolumn{3}{c}{ Brasil (100) } & \multicolumn{3}{c}{ Estados Unidos (53) } & \multicolumn{2}{l}{ Alemanha (77) } \\
\hline & Média & \multirow{2}{*}{$\boldsymbol{\sigma}$} & Média & $\boldsymbol{\sigma}$ & Média & $\boldsymbol{\sigma}$ & Média & \multirow{2}{*}{$\boldsymbol{~}$} \\
\hline IF & 5,7972 & 0,8561 & 5,9430 & 0,9241 & 5,9906 & 0,8932 & 4,8688 & 1,3016 \\
OEI & 5,7338 & 1,0329 & 5,9833 & 1,0643 & 5,8208 & 1,4318 & 4,9610 & 1,3870 \\
MV & 5,6766 & 1,0321 & 5,9286 & 1,0764 & 5,9784 & 1,0589 & 4,9406 & 1,1912 \\
DOP & 5,8819 & 0,8632 & 6,0725 & 0,7679 & 5,9434 & 0,9935 & 4,9188 & 1,2936 \\
DOG & 5,8507 & 0,8399 & 6,0625 & 0,8978 & 5,8019 & 1,0393 & 4,9773 & 1,4091 \\
PR & 4,9417 & 1,6453 & 5,4600 & 1,4593 & 5,5094 & 1,5295 & 4,6883 & 1,4036 \\
PC & 5,1597 & 1,6122 & 5,7950 & 1,4197 & 5,6887 & 1,2850 & 4,6851 & 1,5035 \\
\hline
\end{tabular}

Fonte: Autora. 
Os resultados das médias dos construtos são maiores na amostra de países emergentes, se comparados com a amostra dos países desenvolvidos, e com a amostra total (Tabela 3).

Tabela 3 - Análise descritiva das variáveis latentes em países emergentes, desenvolvidos e na totalidade dos países

\begin{tabular}{lcccrlr}
\hline & \multicolumn{2}{c}{ Desenvolvidos (130) } & \multicolumn{2}{c}{ Emergentes (170) } & \multicolumn{2}{c}{ Total (303) } \\
\hline & Média & $\boldsymbol{\sigma}$ & Média & $\boldsymbol{\sigma}$ & Média & $\boldsymbol{\sigma}$ \\
\hline IF & 5,3262 & 1,2751 & 5,8820 &, 89663 & 5,6427 & 1,1089 \\
OEI & 5,3115 & 1,4628 & 5,8789 & 1,0555 & 5,6347 & 1,2764 \\
MV & 5,3637 & 1,2450 & 5,8231 & 1,0624 & 5,6254 & 1,1651 \\
DOP & 5,3365 & 1,2803 & 5,9927 & 0,8122 & 5,7103 & 1,0878 \\
DOG & 5,3135 & 1,3307 & 5,9738 & 0,8778 & 5,6896 & 1,1419 \\
PR & 5,0231 & 1,5059 & 5,2430 & 1,5565 & 5,1483 & 1,5363 \\
PC & 5,0942 & 1,4975 & 5,5290 & 1,5313 & 5,3419 & 1,5296 \\
\hline
\end{tabular}

Fonte: Elaborada pela autora (2020).

Para verificar a igualdade das médias entre os grupos de organizações mais e menos frugais, a seguir (Tabela 4), estão os resultados estatísticos de médias, o desvio-padrão, o erropadrão, bem como o teste $t$ entre os grupos, sendo que todas as variáveis, em suas médias significativamente diferentes de $\mathrm{p}<1 \%$, demonstraram a existência da diferença entre as amostras, viabilizando a análise multigrupo.

Tabela 4 - Estatísticas de grupo

(continua)

\begin{tabular}{|c|c|c|c|c|c|c|}
\hline & Grupo & $\mathbf{N}$ & Média & $\begin{array}{l}\text { Desvio- } \\
\text { Padrão }\end{array}$ & $\begin{array}{l}\text { Erro-padrão } \\
\text { da média }\end{array}$ & $\mathbf{t}$ \\
\hline & 0 & 154 & 4,8593 & 1,25377 & 0,10103 & \\
\hline \multirow[t]{3}{*}{ OEI } & 1 & 149 & 6,4237 & 0,67717 & 0,05548 & \\
\hline & Variâncias iguais assumidas & & & & & $17,508 * *$ \\
\hline & 0 & 154 & 4,8980 & 1,06175 & 0,08556 & \\
\hline \multirow[t]{3}{*}{ MV } & 1 & 149 & 6,3768 & 0,69018 & 0,05654 & \\
\hline & Variâncias iguais assumidas & & & & & $17,984 * *$ \\
\hline & 0 & 154 & 5,0130 & 1,05362 & 0,08490 & \\
\hline \multirow[t]{3}{*}{ DOP } & 1 & 149 & 6,4279 & 0,48569 & 0,03979 & \\
\hline & Variâncias iguais assumidas & & & & & $19,250 * *$ \\
\hline & 0 & 154 & 5,0276 & 1,16651 & 0,09400 & \\
\hline \multirow[t]{2}{*}{ DOG } & 1 & 149 & 6,3742 & 0,56325 & 0,04614 & \\
\hline & Variâncias iguais assumidas & & & & & $14,894 * *$ \\
\hline
\end{tabular}


Tabela 5 - Estatísticas de grupo

(conclusão)

\begin{tabular}{lllllll}
\hline & Grupo & N & Média & $\begin{array}{l}\text { Desvio- } \\
\text { Padrão }\end{array}$ & $\begin{array}{l}\text { Erro-padrão } \\
\text { da média }\end{array}$ & t \\
\hline & 0 & 154 & 4,5416 & 1,31117 & 0,10566 & \\
PR & 1 & 149 & 5,7785 & 1,49705 & 0,12264 & \\
& Variâncias iguais assumidas & & & & & $7,751^{* *}$ \\
\hline \multirow{3}{*}{ PC } & 0 & 154 & 4,7565 & 1,39031 & 0,11203 & \\
& 1 & 149 & 5,9497 & 1,42581 & 0,11681 & \\
& Variâncias iguais assumidas & & & & & $7,897 * *$ \\
\hline
\end{tabular}

Fonte: Autora.

Nota: Grupo: $0=$ menos frugal; 1 = mais frugal; $\mathrm{N}=$ quantidade da amostra .

Nível de significância: $* *=p<0,001$.

A seguir (Tabela 5), estão os resultados da análise de estatísticas de grupo para os países emergentes, sob a perspectiva multigrupo, mais e menos frugais. Todas as variáveis, em suas médias, são significativamente diferentes nas amostras, e $\mathrm{p}<1 \%$, viabilizando a análise multigrupo.

Tabela 6 - Estatística de grupo emergente

\begin{tabular}{|c|c|c|c|c|c|c|}
\hline & Grupo & $\mathbf{N}$ & Média & $\begin{array}{l}\text { Desvio- } \\
\text { padrão }\end{array}$ & $\begin{array}{l}\text { Erro- } \\
\text { padrão da } \\
\text { média }\end{array}$ & $\mathbf{t}$ \\
\hline \multirow{3}{*}{ OEI } & 0 & 74 & 5,1869 & 1,02032 & 0,11861 & \multirow[b]{3}{*}{$-8,701 * *$} \\
\hline & 1 & 99 & 6,3751 & 0,77606 & 0,07800 & \\
\hline & Variâncias iguais assumidas & & & & & \\
\hline \multirow{3}{*}{ MV } & 0 & 74 & 5,1486 & 1,00445 & 0,11676 & \multirow[b]{3}{*}{$-8,629 * *$} \\
\hline & 1 & 99 & 6,3247 & 0,78798 & 0,07920 & \\
\hline & Variâncias iguais assumidas & & & & & \\
\hline \multirow{3}{*}{ DOP } & 0 & 74 & 5,4139 & 0,77882 & 0,09054 & \multirow[b]{3}{*}{$-10,165 *$} \\
\hline & 1 & 99 & 6,4179 & 0,51883 & 0,05214 & \\
\hline & Variâncias iguais assumidas & & & & & \\
\hline \multirow{3}{*}{ DOG } & 0 & 74 & 5,4459 & 0,92923 & 0,10802 & \multirow[b]{3}{*}{$-7,994 *:$} \\
\hline & 1 & 99 & 6,3662 & 0,57953 & 0,05825 & \\
\hline & Variâncias iguais assumidas & & & & & \\
\hline \multirow{3}{*}{ PR } & 0 & 74 & 4,8919 & 1,22494 & 0,14240 & \multirow[b]{3}{*}{$-2,632 * *$} \\
\hline & 1 & 99 & 5,5091 & 1,71649 & 0,17251 & \\
\hline & Variâncias iguais assumidas & & & & & \\
\hline \multirow{3}{*}{ PC } & 0 & 74 & 5,1959 & 1,27494 & 0,14821 & \multirow[b]{3}{*}{$-2,529 * *$} \\
\hline & 1 & 99 & 5,7803 & 1,65341 & 0,16617 & \\
\hline & Variâncias iguais assumidas & & & & & \\
\hline
\end{tabular}

Fonte: Autora.

Nota: Grupo: $0=$ menos frugal; $1=$ mais frugal $; \mathrm{N}=$ quantidade da amostra .

Nível de significância: $* *=p<0,001$. 
A seguir (Tabela 6), estão os resultados da análise estatística de grupo dos países desenvolvidos, sob a perspectiva multigrupo, mais e menos frugais. Todas as variáveis, em suas médias, são significativamente diferentes nas amostras, e $\mathrm{p}<1 \%$, viabilizando a análise multigrupo.

Tabela 7 - Estatísticas de grupo desenvolvido

\begin{tabular}{|c|c|c|c|c|c|c|}
\hline & Grupo & $\mathbf{N}$ & Média & $\begin{array}{l}\text { Desvio- } \\
\text { padrão }\end{array}$ & $\begin{array}{l}\text { Erro-padrão da } \\
\text { média }\end{array}$ & $\mathbf{t}$ \\
\hline \multirow{3}{*}{ OEI } & 0 & 80 & 4,5563 & 1,37435 & 0,15366 & \\
\hline & 1 & 50 & 6,5200 & 0,40775 & 0,05766 & \\
\hline & $\begin{array}{c}\text { Variâncias iguais } \\
\text { assumidas }\end{array}$ & & & & & $-9,824 * *$ \\
\hline \multirow{3}{*}{ MV } & 0 & 80 & 4,6661 & 1,06661 & 0,11925 & \\
\hline & 1 & 50 & 6,4800 & 0,42492 & 0,06009 & \\
\hline & $\begin{array}{c}\text { Variâncias iguais } \\
\text { assumidas }\end{array}$ & & & & & $-11,457 * *$ \\
\hline \multirow{3}{*}{ DOP } & 0 & 80 & 4,6422 & 1,14006 & 0,12746 & \\
\hline & 1 & 50 & 6,4475 & 0,41657 & 0,05891 & \\
\hline & $\begin{array}{c}\text { Variâncias iguais } \\
\text { assumidas }\end{array}$ & & & & & $-10,745^{* *}$ \\
\hline \multirow{3}{*}{ DOG } & 0 & 80 & 4,6406 & 1,23366 & 0,13793 & \\
\hline & 1 & 50 & 6,3900 & 0,53490 & 0,07565 & \\
\hline & $\begin{array}{c}\text { Variâncias iguais } \\
\text { assumidas }\end{array}$ & & & & & $-9,475 * *$ \\
\hline \multirow{3}{*}{ PR } & 0 & 80 & 4,2175 & 1,31214 & 0,14670 & \\
\hline & 1 & 50 & 6,3120 & 0,66291 & 0,09375 & \\
\hline & $\begin{array}{c}\text { Variâncias iguais } \\
\text { assumidas }\end{array}$ & & & & & $-10,472 * *$ \\
\hline \multirow{3}{*}{$\mathrm{PC}$} & 0 & 80 & 4,3500 & 1,37599 & 0,15384 & \\
\hline & 1 & 50 & 6,2850 & 0,70712 & 0,10000 & \\
\hline & $\begin{array}{c}\text { Variâncias iguais } \\
\text { assumidas }\end{array}$ & & & & & $-9,204 * *$ \\
\hline
\end{tabular}

Fonte: Autora.

Nota: Grupo: $0=$ menos frugal; $1=$ mais frugal; $\mathrm{N}=$ quantidade da amostra.

Nível de significância: $* *=p<0,001$.

Considerando a amostra que reúne países emergentes e desenvolvidos, a seguir (Tabela 7), estão as médias e o desvio-padrão de cada variável. Vale ressaltar que os construtos foram mensurados por meio das variáveis descritas no Apêndice B.

Quanto aos construtos relacionados à pressão do ambiente institucional, os resultados demonstram a maior média para a variável PR2, "padrões de produção tecnológica" e PC4 
“clientes que buscam fornecedores verdes", indicando uma relevância dos padrões tecnológicos dessa variável sobre os riscos legais ou a penalidade à qual a organização está sujeita.

Em relação à orientação estratégica para a ecoinovação e a manufatura verde, a tabela apresenta maior média para a variável OEI5, "nossa organização compete em objetivos direcionados à inovatividade e às iniciativas verdes", e MV7, "minha organização aumenta o tempo de vida de produtos, resultando em maior eficiência e produtividade", indicando os esforços das organizações na busca por soluções que mantenham a produtividade, mas estejam alinhadas às iniciativas inovadoras verdes.

Quanto ao desempenho, os resultados apresentam maior média para as variáveis DOP4, DOG1 e DOG4, representando resultados positivos operacionais de qualidade de desempenho do produto, do retorno sobre o investimento e do crescimento da rentabilidade. 
Tabela 8 - Média e desvio-padrão das variáveis dos construtos

(continua)

\begin{tabular}{|c|c|c|c|c|}
\hline Construto & Variável & Descrição & Média & $\sigma$ \\
\hline \multirow{5}{*}{$\begin{array}{l}\text { Pressão } \\
\text { regulatória }\end{array}$} & PR1 & Padrões de emissão & 5,11 & 1,818 \\
\hline & PR2 & Padrões de produção tecnológica & 5,40 & 1,696 \\
\hline & PR3 & Riscos legais & 5,06 & 1,750 \\
\hline & PR4 & Supervisão governamental & 5,13 & 1,691 \\
\hline & PR5 & Penalidades & 5,06 & 1,793 \\
\hline \multirow{4}{*}{$\begin{array}{l}\text { Pressão do } \\
\text { mercado } \\
\text { consumidor }\end{array}$} & PC 1 & Maior conscientização sobre questões ambientais entre nossos clientes. & 5,21 & 1,746 \\
\hline & PC 2 & Preferências dos clientes por produtos ecologicamente corretos. & 5,41 & 1,701 \\
\hline & PC 3 & A atenção contínua dos clientes ao comportamento ambiental da nossa empresa. & 5,30 & 1,660 \\
\hline & $\mathrm{PC} 4$ & Clientes que buscam fornecedores verdes. & 5,44 & 1,616 \\
\hline \multirow{5}{*}{$\begin{array}{l}\text { Orientação } \\
\text { estratégica para } \\
\text { a ecoinovação }\end{array}$} & OEI_1 & Nossa organização aloca recursos adequados para as inovações verdes. & 5,63 & 1,543 \\
\hline & OEI_2 & Nossa alta gestão apoia inovações de processos que promovem iniciativas verdes. & 5,50 & 1,527 \\
\hline & OIE_3 & Nossa alta gestão apoia inovações de produtos que promovem iniciativas verdes. & 5,64 & 1,505 \\
\hline & OIE_4 & A avaliação do ciclo de vida é um critério importante, enquanto desenvolvemos novos produtos. & 5,64 & 1,460 \\
\hline & OIE_5 & Nossa organização compete em objetivos direcionados à inovatividade e às iniciativas verdes. & 5,69 & 1,366 \\
\hline \multirow{7}{*}{$\begin{array}{l}\text { Manufatura } \\
\text { verde }\end{array}$} & MV 1 & Minha organização produz produtos com partes de reuso ou recicladas, como plástico reciclável e vidro. & 5,43 & 1,650 \\
\hline & MV 2 & Minha organização usa avaliação de ciclo de vida para estimar a carga ambiental de produtos. & 5,46 & 1,491 \\
\hline & MV 3 & Minha organização produz produtos que são livres de substâncias tóxicas e perigosas, como chumbo, mercúrio e cromo. & 5,64 & 1,582 \\
\hline & MV 4 & Minha organização desenha produtos para assegurar que eles tenham partes recicláveis e reutilizáveis. & 5,61 & 1,433 \\
\hline & MV 5 & Minha organização produz produtos que reduzem o consumo de materiais e de energia durante o uso. & 5,66 & 1,409 \\
\hline & MV 6 & Minha organização reduz o consumo de energia em produtos, durante sua manufatura e transporte. & 5,71 & 1,340 \\
\hline & MV 7 & Minha organização aumenta o tempo de vida de produtos, resultando em maior eficiência e produtividade. & 5,85 & 1,204 \\
\hline
\end{tabular}

Fonte: Autora. 
Tabela 7 - Média e desvio-padrão das variáveis dos construtos

(conclusão)

\begin{tabular}{|c|c|c|c|c|}
\hline Construto & Variável & Descrição & Média & $\sigma$ \\
\hline \multirow{8}{*}{$\begin{array}{l}\text { Desempenho } \\
\text { Operacional }\end{array}$} & DOP 1 & Custos operacionais & 5,31 & 1,608 \\
\hline & DOP 2 & Competitividade de preços de novos produtos & 5,66 & 1,352 \\
\hline & DOP 3 & Conformidade de especificações & 5,78 & 1,279 \\
\hline & DOP 4 & Qualidade de desempenho do produto & 5,88 & 1,227 \\
\hline & DOP 5 & Tempo de entrega de produtos & 5,75 & 1,404 \\
\hline & DOP 6 & Velocidade de entrega de produtos & 5,78 & 1,330 \\
\hline & DOP 7 & Flexibilidade de capacidade de produção & 5,76 & 1,302 \\
\hline & DOP 8 & Variedade de produtos & 5,76 & 1,25 \\
\hline \multirow{4}{*}{$\begin{array}{l}\text { Desempenho } \\
\text { Organizacional }\end{array}$} & DOG 1 & Retorno sobre investimento (ROI) & 5,72 & 1,243 \\
\hline & DOG 2 & Retorno sobre ativos & 5,65 & 1,309 \\
\hline & DOG 3 & Crescimento de vendas & 5,67 & 1,341 \\
\hline & DOG 4 & Crescimento da rentabilidade & 5,72 & 1,264 \\
\hline
\end{tabular}

Fonte: Autora 
Realizada a análise do comportamento das variáveis, referente aos construtos dependentes e independentes, bem como da variável moderadora categórica, a seção seguinte primeiramente analisa as premissas estatísticas e, em seguida, o modelo de equações estruturais.

\subsection{ANÁLISES MULTIVARIADAS}

Para as análises multivariadas, foi utilizada a modelagem de equações estruturais (MEE), por meio das etapas de avaliação dos modelos de mensuração e estrutural, e da moderação.

\subsubsection{Avaliação do modelo de mensuração}

Para análise preliminar do modelo conceitual, foram realizados os testes de mensuração, a fim de determinar a necessidade de extração de indicadores dos construtos para ajuste. Sendo assim, ao considerar todas as variáveis observadas para as amostras coletadas na Índia, no Brasil, nos EUA e na Alemanha, e os critérios de validade discriminante, de acordo com o estipulado por Fornell e Larcker (1981), eles não foram atingidos para algumas das variáveis latentes.

Por conta disso, para ajuste, foram analisados os resultados de cargas cruzadas entre os indicadores, de modo que aqueles com cargas cruzadas altas foram excluídos (Tabela 8), reduzindo, com isso, a correlação entre as variáveis latentes (BIDO; DA SILVA, 2019) e, consequentemente, alcançando a validade discriminante das amostras. Com os indicadores extraídos, os remanescentes foram considerados no modelo (mais ajustado) para a Índia. 
Tabela 9 - Indicadores excluídos

\begin{tabular}{|c|c|c|c|}
\hline País & Construto & Código & Descrição \\
\hline \multirow[b]{2}{*}{ Alemanha } & \multirow{2}{*}{$\begin{array}{l}\text { Manufatura } \\
\text { verde (MV) }\end{array}$} & MV_6 & Reduz o consumo de energia durante a fabricação e o transporte. \\
\hline & & MV_7 & $\begin{array}{l}\text { Aumenta a vida útil do produto, resultando em maior eficiência e } \\
\text { produtividade. }\end{array}$ \\
\hline \multirow{2}{*}{ EUA } & \multirow{2}{*}{$\begin{array}{l}\text { Desempenho } \\
\text { operacional } \\
\text { (DOP) }\end{array}$} & DOP_3 & Melhor compatibilidade entre produto/serviço e especificações. \\
\hline & & DOP_8 & Melhor variedade de produto/serviço. \\
\hline Brasil & $\begin{array}{l}\text { Manufatura } \\
\text { verde }(\mathrm{MV})\end{array}$ & MV_1 & Produz produtos com conteúdo reutilizado, como plástico e vidro. \\
\hline \multirow{7}{*}{ Índia } & \multirow{3}{*}{$\begin{array}{l}\text { Manufatura } \\
\text { verde (MV) }\end{array}$} & $\mathrm{MV}_{-} 1$ & $\begin{array}{l}\text { Produz produtos com conteúdo reutilizado ou reciclado, como } \\
\text { plástico e vidro. }\end{array}$ \\
\hline & & MV_2 & $\begin{array}{l}\text { Usa a avaliação do ciclo de vida para observar a poluição } \\
\text { ambiental dos produtos. }\end{array}$ \\
\hline & & MV_4 & $\begin{array}{l}\text { Projeta produtos, garantindo que eles tenham conteúdo reciclável } \\
\text { ou reutilizável. }\end{array}$ \\
\hline & $\begin{array}{l}\text { Desempenho } \\
\text { organizacional } \\
\text { (DOG) }\end{array}$ & DOG_3 & Melhor crescimento de market share. \\
\hline & \multirow{3}{*}{$\begin{array}{l}\text { Desempenho } \\
\text { operacional } \\
\text { (DOP) }\end{array}$} & $\mathrm{DOP}_{-} 1$ & Custos operacionais menores. \\
\hline & & DOP_2 & Preços de produtos/serviços mais competitivos. \\
\hline & & DOP_6 & Melhor velocidade de entrega. \\
\hline
\end{tabular}

Fonte: Autora.

Com a finalidade de avaliar a existência de variação do método comum, foi aplicado o teste de fator único de Harman (HARMAN, 1967; PODSAKOFF et al., 2003; PODSAKOFF; ORGAN, 1986), e uma análise fatorial não girada, em todas as variáveis de pesquisa. A variância é resultado de mais de um fator indicativo de que não há variação do método comum. E, para avaliar cada um dos construtos e seus respectivos indicadores, a seguir (Tabela 9), estão as cargas fatoriais externas, resultantes da análise fatorial confirmatória, cujo objetivo é verificar se todas essas cargas confirmam cada um dos fatores apresentados no modelo teórico. 
Tabela 10 - Cargas externas

\begin{tabular}{|c|c|c|c|c|c|c|c|c|c|c|c|c|c|c|c|c|c|}
\hline \multicolumn{6}{|c|}{ BRASIL } & \multicolumn{6}{|c|}{ EUA } & \multicolumn{6}{|c|}{ ALEMANHA } \\
\hline DOG & DOP & MV & OEI & $\mathbf{P C}$ & PR & DOG & DOP & MV & OEI & $\mathbf{P C}$ & PR & DOG & DOP & MV & OEI & $\mathbf{P C}$ & PR \\
\hline 0,816 & 0,576 & 0,475 & 0,551 & 0,257 & 0,275 & 0,898 & 0,803 & 0,759 & 0,651 & 0,572 & 0,658 & 0,946 & 0,833 & 0,785 & 0,610 & 0,640 & 0,694 \\
\hline 0,832 & 0,679 & 0,520 & 0,548 & 0,346 & 0,269 & 0,909 & 0,730 & 0,718 & 0,647 & 0,598 & 0,555 & 0,943 & 0,847 & 0,784 & 0,700 & 0,653 & 0,703 \\
\hline 0,817 & 0,644 & 0,517 & 0,537 & 0,403 & 0,284 & 0,851 & 0,688 & 0,626 & 0,592 & 0,586 & 0,673 & 0,909 & 0,820 & 0,772 & 0,625 & 0,679 & 0,668 \\
\hline 0,472 & 0,646 & 0,478 & 0,382 & 0,131 & 0,169 & 0,584 & 0,789 & 0,783 & 0,763 & 0,599 & 0,484 & 0,758 & 0,861 & 0,760 & 0,702 & 0,516 & 0,636 \\
\hline 0,727 & 0,832 & 0,666 & 0,724 & 0,426 & 0,329 & 0,683 & 0,717 & 0,675 & 0,587 & 0,510 & 0,304 & 0,693 & 0,823 & 0,728 & 0,682 & 0,502 & 0,560 \\
\hline 0,438 & 0,744 & 0,549 & 0,461 & 0,203 & 0,244 & 0,768 & 0,887 & 0,750 & 0,686 & 0,521 & 0,659 & 0,753 & 0,863 & 0,698 & 0,663 & 0,544 & 0,631 \\
\hline 0,583 & 0,779 & 0,589 & 0,513 & 0,254 & 0,154 & 0,706 & 0,854 & 0,731 & 0,644 & 0,461 & 0,649 & 0,811 & 0,885 & 0,752 & 0,667 & 0,608 & 0,625 \\
\hline 0,687 & 0,808 & 0,647 & 0,651 & 0,342 & 0,294 & 0,676 & 0,848 & 0,722 & 0,741 & 0,492 & 0,391 & 0,823 & 0,870 & 0,765 & 0,635 & 0,660 & 0,682 \\
\hline 0,384 & 0,473 & 0,564 & 0,415 & 0,446 & 0,415 & 0,620 & 0,696 & 0,823 & 0,545 & 0,470 & 0,263 & 0,672 & 0,735 & 0,850 & 0,640 & 0,550 & 0,646 \\
\hline 0,486 & 0,620 & 0,836 & 0,669 & 0,323 & 0,292 & 0,741 & 0,823 & 0,925 & 0,744 & 0,674 & 0,450 & 0,737 & 0,744 & 0,862 & 0,727 & 0,710 & 0,755 \\
\hline 0,466 & 0,606 & 0,888 & 0,619 & 0,376 & 0,270 & 0,731 & 0,794 & 0,907 & 0,775 & 0,713 & 0,512 & 0,762 & 0,712 & 0,862 & 0,624 & 0,661 & 0,679 \\
\hline 0,594 & 0,726 & 0,846 & 0,575 & 0,263 & 0,223 & 0,720 & 0,849 & 0,899 & 0,817 & 0,663 & 0,551 & 0,638 & 0,700 & 0,784 & 0,658 & 0,560 & 0,523 \\
\hline 0,550 & 0,559 & 0,684 & 0,846 & 0,492 & 0,453 & 0,737 & 0,816 & 0,809 & 0,936 & 0,739 & 0,613 & 0,615 & 0,698 & 0,699 & 0,899 & 0,491 & 0,609 \\
\hline 0,599 & 0,683 & 0,684 & 0,844 & 0,472 & 0,461 & 0,654 & 0,751 & 0,733 & 0,937 & 0,742 & & 0,601 & 0,685 & 0,684 & 0,902 & 0,460 & 0,609 \\
\hline 0,616 & 0,645 & 0,561 & 0,841 & 0,405 & 0,485 & 0,622 & 0,787 & 0,768 & 0,911 & 0,690 & 0,522 & 0,670 & 0,691 & 0,692 & 0,874 & 0,508 & 0,594 \\
\hline 0,587 & 0,628 & 0,669 & 0,869 & 0,406 & 0,449 & 0,667 & 0,762 & 0,723 & 0,913 & 0,698 & 0,422 & 0,621 & 0,685 & 0,755 & 0,875 & 0,489 & 0,584 \\
\hline 0,491 & 0,597 & 0,535 & 0,789 & 0,410 & 0,474 & 0,668 & 0,800 & 0,790 & 0,964 & 0,745 & 0,572 & 0,532 & 0,668 & 0,636 & 0,876 & 0,505 & 0,571 \\
\hline 0,441 & 0,505 & 0,441 & 0,786 & 0,454 & 0,479 & 0,645 & 0,766 & 0,773 & 0,953 & 0,732 & 0,540 & 0,618 & 0,690 & 0,710 & 0,871 & 0,581 & 0,666 \\
\hline 0,342 & 0,326 & 0,392 & 0,516 & 0,894 & 0,741 & 0,618 & 0,476 & 0,548 & 0,502 & 0,837 & 0,646 & 0,610 & 0,588 & 0,596 & 0,464 & 0,881 & 0,794 \\
\hline 0,350 & 0,290 & 0,317 & 0,461 & 0,923 & 0,688 & 0,561 & 0,534 & 0,607 & 0,681 & 0,903 & 0,612 & 0,706 & 0,675 & 0,734 & 0,581 & 0,931 & 0,786 \\
\hline 0,395 & 0,365 & 0,436 & 0,491 & 0,928 & 0,733 & 0,608 & 0,599 & 0,640 & 0,785 & 0,907 & 0,618 & 0,570 & 0,480 & 0,624 & 0,456 & 0,862 & 0,748 \\
\hline 0,394 & 0,345 & 0,398 & 0,440 & 0,859 & 0,591 & 0,580 & 0,605 & 0,736 & 0,736 & 0,915 & 0,471 & 0,615 & 0,593 & 0,675 & 0,530 & 0,894 & 0,706 \\
\hline 0,298 & 0,329 & 0,412 & 0,536 & 0,687 & 0,894 & 0,635 & 0,570 & 0,444 & 0,534 & 0,538 & 0,941 & 0,521 & 0,534 & 0,575 & 0,585 & 0,636 & 0,770 \\
\hline 0,304 & 0,274 & 0,256 & 0,526 & 0,684 & 0,892 & 0,625 & 0,593 & 0,564 & 0,575 & 0,679 & 0,877 & 0,528 & 0,612 & 0,688 & 0,589 & 0,699 & 0,852 \\
\hline 0,286 & 0,247 & 0,281 & 0,496 & 0,702 & 0,911 & 0,697 & 0,551 & 0,451 & 0,471 & 0,581 & 0,891 & 0,707 & 0,618 & 0,669 & 0,519 & 0,748 & 0,841 \\
\hline 0,316 & 0,282 & 0,350 & 0,435 & 0,671 & 0,880 & 0,614 & 0,505 & 0,372 & 0,487 & 0,545 & 0,916 & 0,725 & 0,680 & 0,675 & 0,601 & 0,761 & 0,889 \\
\hline
\end{tabular}

Fonte: Autora. 
Para verificar a existência de problemas de multicolinearidade nos dados (se o valor for maior que cinco), ou a tolerância (menor que dois), que devem ser sanados antes da análise do modelo estrutural, foram calculados os fatores de inflação da variação (HAIR et al., 2014), constatando a presença de multicolinearidade nos construtos relacionados. (Tabela 10).

Tabela 11 - Colinearidade estatística - VIF externo

\begin{tabular}{|c|c|c|c|c|}
\hline & ÍNDIA & BRASIL & EUA & ALEMANHA \\
\hline DOG_1 & 1,410 & 1,663 & 2,426 & 4,593 \\
\hline DOG_2 & 1,731 & 2,348 & 2,668 & 4,400 \\
\hline DOG_4 & 1,729 & 2,024 & 2,253 & 2,796 \\
\hline DOP_3 & 1,835 & 1,519 & 2,137 & 2,626 \\
\hline DOP_4 & 1,920 & 2,491 & 2,384 & 2,436 \\
\hline DOP_5 & 1,279 & 1,713 & 4,059 & 2,684 \\
\hline DOP_7 & 1,837 & 1,865 & 4,501 & 3,771 \\
\hline DOP_8 & 1,958 & 2,230 & 2,649 & 3,265 \\
\hline MV_3 & 2,044 & 1,163 & 2,109 & 2,221 \\
\hline MV_5 & 1,667 & 2,102 & 3,872 & 2,213 \\
\hline MV_6 & 1,538 & 2,783 & 3,287 & 2,269 \\
\hline MV_7 & 1,737 & 2,014 & 2,873 & 1,664 \\
\hline OEI_1 & 1,939 & 2,751 & 4,399 & 4,235 \\
\hline OEI_2 & 2,723 & 2,754 & 4,711 & 4,118 \\
\hline OIE_3 & 2,313 & 2,581 & 4,633 & 3,385 \\
\hline OIE_4 & 2,308 & 2,909 & 4,466 & 3,249 \\
\hline OIE_5 & 2,583 & 2,093 & 4,439 & 3,786 \\
\hline OIE_6 & 2,319 & 2,099 & 4,028 & 3,535 \\
\hline PC_1 & 2,735 & 3,101 & 2,497 & 2,976 \\
\hline PC_2 & 4,063 & 3,902 & 3,268 & 4,067 \\
\hline PC_3 & 4,272 & 4,016 & 3,097 & 2,477 \\
\hline PC_4 & 4,839 & 2,626 & 3,380 & 3,010 \\
\hline PR_1 & 3,106 & 2,764 & 4,262 & 1,589 \\
\hline PR_2 & 3,973 & 2,761 & 2,577 & 2,341 \\
\hline PR_3 & 3,540 & 3,498 & 3,128 & 2,491 \\
\hline PR_4 & 2,356 & 2,953 & 4,652 & 3,296 \\
\hline
\end{tabular}

Fonte: Autora

O modelo de mensuração está associado à consistência (confiabilidade) e ao rigor (validade) das variáveis (HAIR, 2010). Para avaliar esses critérios, verificou-se a amostra quanto à confiabilidade da consistência interna de suas variáveis, e o coeficiente $\alpha$ de Cronbach. O coeficiente $\alpha$ de Cronbach foi maior que 0,7 e menor que 0,95, indicando a existência de consistência interna. E, para avaliar a validade convergente, utilizou-se a variância média 
extraída (AVE), já que quanto maior ela for, mais representativos são os indicadores do construto, sendo essa relação maior do que 0,5 (HAIR, 2010).

De acordo com Bido e Silva (2019), para modelos com variáveis latentes de segunda ordem, os resultados da validade convergente e de confiabilidade são apresentados em três etapas/modelos: (1) de mensuração das variáveis latentes de primeira ordem; (2) de mensuração das variáveis latentes do modelo estrutural; e (3) estrutural (que será apresentado na Seção 4.3.2).

Os resultados das variáveis latentes de primeira ordem (Tabela 11) demonstram que a AVE dos construtos é maior que 0,5 em ambos os modelos de mensuração, confirmando sua validade convergente. A confiabilidade composta padronizada maior que 0,7 indica construtos homogêneos (WERTS et al., 1974).

Tabela 12 - Validade convergente e confiabilidade de $1^{\mathrm{a}}$ ordem

\begin{tabular}{|c|c|c|c|c|c|c|c|c|c|c|c|c|}
\hline & \multicolumn{3}{|c|}{ ÍNDIA } & \multicolumn{3}{|c|}{ BRASIL } & \multicolumn{3}{|c|}{ USA } & \multicolumn{3}{|c|}{ ALEMANHA } \\
\hline \multicolumn{13}{|c|}{ VC e CF de $1^{\text {a }}$ ordem } \\
\hline & $\boldsymbol{\alpha}^{\mathrm{a}}$ & $\mathrm{CC}^{\mathrm{b}}$ & $\mathbf{A V E} \mathbf{E}^{\mathrm{c}}$ & $\boldsymbol{\alpha}^{\mathrm{a}}$ & $\mathrm{CC}^{\mathrm{b}}$ & $\mathbf{A V E} \mathbf{E}^{\mathrm{c}}$ & $\alpha^{\mathbf{a}}$ & $\mathbf{C C}^{\mathbf{b}}$ & $\mathbf{A V E}^{\mathrm{c}}$ & $\boldsymbol{\alpha}^{\mathbf{a}}$ & $\mathrm{CC}^{\mathrm{b}}$ & $\mathbf{A V E}^{\mathbf{c}}$ \\
\hline DOG & 0.770 & 0.867 & 0.686 & 0,760 & 0,862 & 0,675 & 0,864 & 0,917 & 0,786 & 0,925 & 0,953 & 0,870 \\
\hline DOP & 0.817 & 0.874 & 0.584 & 0,820 & 0,875 & 0,585 & 0,876 & 0,910 & 0,671 & 0,912 & 0,935 & 0,741 \\
\hline MV & 0.805 & 0.873 & 0.632 & 0,794 & 0,869 & 0,630 & 0,912 & 0,938 & 0,791 & 0,861 & 0,906 & 0,706 \\
\hline OEI & 0.880 & 0.909 & 0.624 & 0,909 & 0,930 & 0,688 & 0,972 & 0,977 & 0,876 & 0,943 & 0,955 & 0,780 \\
\hline PC & 0.937 & 0.954 & 0.839 & 0,923 & 0,945 & 0,812 & 0,914 & 0,939 & 0,794 & 0,915 & 0,940 & 0,796 \\
\hline PR & 0.921 & 0.941 & 0.801 & 0,917 & 0,941 & 0,800 & 0,928 & 0,948 & 0,822 & 0,859 & 0,905 & 0,704 \\
\hline
\end{tabular}

Fonte: Autora.

Nota: $\mathrm{a}=$ Alfa de Cronbach $\alpha ; \mathrm{b}=$ confiabilidade composta (padronizada); $\mathrm{c}=$ média da variância extraída.

A seguir (Tabela 12), estão os resultados de mensuração das variáveis latentes, no modelo estrutural, com os valores de alfa de Cronbach, de confiabilidade composta, e de variância média extraída (AVE) para as variáveis latentes de: desempenho (DS), manufatura verde (MV), orientação estratégica para a ecoinovação (OEI), pressão regulatória (PR), e pressão de mercado consumidor (PC), confirmando a validade convergente e a confiabilidade do modelo.

De forma a aplicar a validação discriminante do modelo de mensuração, utilizou-se o critério de Fornell e Larcker (1981), que permite a comparação entre a raiz quadrada da AVE e a correlação entre os construtos de variáveis latentes. Para validação, o quadrado da AVE de cada construto deve ser maior do que as correlações entre ele e os demais construtos (HAIR et 
al., 2014). A AVE e a CR da variável latente de segunda ordem (desempenho) foram calculadas de forma manual (BIDO; DA SILVA, 2019).

Tabela 13 - Validade convergente e confiabilidade estrutural

\begin{tabular}{|c|c|c|c|c|c|c|c|c|c|c|c|c|}
\hline & \multicolumn{3}{|c|}{ ÍNDIA } & \multicolumn{3}{|c|}{ BRASIL } & \multicolumn{3}{|c|}{ USA } & \multicolumn{3}{|c|}{ ALEMANHA } \\
\hline \multicolumn{13}{|c|}{ VC e CF de $2^{\text {a }}$ ordem ou estrutural } \\
\hline & $\alpha^{\mathrm{a}}$ & $\mathbf{C C}^{\mathbf{b}}$ & $\mathbf{A V E}^{\mathbf{c}}$ & $\alpha^{\mathbf{a}}$ & $\mathbf{C C}^{\mathbf{b}}$ & $\mathbf{A V E}^{\mathbf{c}}$ & $\alpha^{\mathbf{a}}$ & $\mathbf{C C}^{\mathbf{b}}$ & $\mathbf{A V E} \mathbf{E}^{\mathbf{c}}$ & $\alpha^{\mathrm{a}}$ & $\mathbf{C C}^{\mathbf{b}}$ & $\mathbf{A V E}^{\mathbf{c}}$ \\
\hline DS & 0,881 & 0,794 & 0,658 & 0,881 & 0,773 & 0,630 & 0,925 & 0,887 & 0,797 & 0,952 & 0,892 & 0,806 \\
\hline MV & 0,805 & 0,873 & 0,632 & 0,794 & 0,869 & 0,630 & 0,912 & 0,938 & 0,791 & 0,861 & 0,906 & 0,706 \\
\hline OEI & 0,880 & 0,909 & 0,624 & 0,909 & 0,930 & 0,688 & 0,972 & 0,977 & 0,876 & 0,943 & 0,955 & 0,780 \\
\hline PC & 0,937 & 0,954 & 0,839 & 0,923 & 0,945 & 0,812 & 0,914 & 0,939 & 0,794 & 0,915 & 0,940 & 0,796 \\
\hline PR & 0,921 & 0,941 & 0,801 & 0,917 & 0,941 & 0,800 & 0,928 & 0,948 & 0,822 & 0,859 & 0,905 & 0,704 \\
\hline
\end{tabular}

Fonte: Autora.

Nota: $\mathrm{a}=$ Alfa de Cronbach $\alpha ; \mathrm{b}=$ confiabilidade composta (padronizada); $\mathrm{c}=$ média da variância extraída.

A seguir (Tabela 13), estão os resultados confirmados da validade discriminante dos modelos de mensuração das variáveis de $1^{\mathrm{a}}$ ordem (variáveis latentes) e estrutural, sendo que os valores, destacados na diagonal da tabela, representam a raiz quadrada da AVE das variáveis e são maiores do que os valores da correlação com as demais variáveis.

Tabela 14 - Validade discriminante de $1^{\mathrm{a}}$ e $2^{\mathrm{a}}$ ordem ou estrutural

(continua)

\begin{tabular}{|c|c|c|c|c|c|c|c|c|c|c|c|c|}
\hline \multicolumn{7}{|c|}{ ÍNDIA } & \multicolumn{6}{|c|}{ BRASIL } \\
\hline $\begin{array}{l}\text { VD de } 1^{a} \\
\text { ordem }\end{array}$ & 1 & 2 & 3 & 4 & 5 & 6 & 1 & 2 & 3 & 4 & 5 & 6 \\
\hline DOG & $\mathbf{0 , 8 2 8}$ & & & & & & 0,822 & & & & & \\
\hline DOP & 0,758 & 0,794 & & & & & 0,773 & 0,775 & & & & \\
\hline MV & 0,592 & 0,790 & $\mathbf{0 , 8 2 5}$ & & & & 0,614 & 0,772 & 0,794 & & & \\
\hline OEI & 0,554 & 0,702 & 0,819 & 0,790 & & & 0,663 & 0,729 & 0,726 & $\mathbf{0 , 8 3 0}$ & & \\
\hline $\mathrm{PC}$ & 0,043 & 0,163 & 0,200 & 0,237 & 0,916 & & 0,410 & 0,368 & 0,429 & 0,531 & 0,901 & \\
\hline PR & 0,071 & 0,141 & 0,255 & 0,263 & 0,820 & 0,895 & 0,336 & 0,317 & 0,363 & 0,560 & 0,767 & 0,894 \\
\hline $\begin{array}{l}\text { VD do modelo } \\
\text { estrutural }\end{array}$ & 1 & 2 & 3 & 4 & 5 & & 1 & 2 & 3 & 4 & 5 & \\
\hline DS & 0,811 & & & & & & 0,799 & & & & & \\
\hline MV & 0,761 & $\mathbf{0 , 8 2 5}$ & & & & & 0,751 & 0,794 & & & & \\
\hline OEI & 0,689 & 0,819 & 0,790 & & & & 0,745 & 0,726 & 0,830 & & & \\
\hline $\mathrm{PC}$ & 0,123 & 0,200 & 0,237 & 0,916 & & & 0,408 & 0,429 & 0,531 & 0,901 & & \\
\hline PR & 0,123 & 0,255 & 0,263 & 0,820 & 0,895 & & 0,344 & 0,363 & 0,560 & 0,767 & 0,894 & \\
\hline
\end{tabular}

Fonte: Autora. 
Tabela 15 - Validade discriminante de $1^{\mathrm{a}}$ e $2^{\mathrm{a}}$ ordem ou estrutural

(conclusão)

\begin{tabular}{lllllllllllllll}
\hline \multicolumn{1}{c}{ USA } & \multicolumn{1}{c}{ ALEMANHA } \\
$\begin{array}{l}\text { VD de 1 } \\
\text { ordem }\end{array}$ & $\mathbf{1}$ & $\mathbf{2}$ & $\mathbf{3}$ & $\mathbf{4}$ & $\mathbf{5}$ & $\mathbf{6}$ & $\mathbf{1}$ & $\mathbf{2}$ & $\mathbf{3}$ & $\mathbf{4}$ & $\mathbf{5}$ & $\mathbf{6}$ \\
\hline DOG & $\mathbf{0 , 8 8 7}$ & & & & & & $\mathbf{0 , 9 3 3}$ & & & & & \\
DOP & 0,837 & $\mathbf{0 , 8 9 9}$ & & & & & 0,893 & $\mathbf{0 , 8 6 1}$ & & & & \\
MV & 0,793 & 0,892 & $\mathbf{0 , 8 8 9}$ & & & & 0,837 & 0,860 & $\mathbf{0 , 8 4 0}$ & & & \\
OEI & 0,712 & 0,834 & 0,819 & $\mathbf{0 , 9 3 6}$ & & & 0,692 & 0,777 & 0,790 & $\mathbf{0 , 8 8 3}$ & & \\
PC & 0,660 & 0,627 & 0,716 & 0,774 & $\mathbf{0 , 8 9 1}$ & & 0,704 & 0,659 & 0,741 & 0,573 & $\mathbf{0 , 8 9 2}$ & \\
PR & 0,708 & 0,615 & 0,510 & 0,574 & 0,650 & $\mathbf{0 , 9 0 6}$ & 0,738 & 0,729 & 0,778 & 0,687 & 0,848 & $\mathbf{0 , 8 3 9}$ \\
\hline VD do modelo & $\mathbf{1}$ & $\mathbf{2}$ & $\mathbf{3}$ & $\mathbf{4}$ & $\mathbf{5}$ & & $\mathbf{1}$ & $\mathbf{2}$ & $\mathbf{3}$ & $\mathbf{4}$ & $\mathbf{5}$ & \\
estrutural & $\mathbf{1}$ & & & & & & & & & \\
\hline DS & $\mathbf{0 , 8 9 3}$ & & & & & & $\mathbf{0 , 8 9 8}$ & & & & & \\
MV & 0,889 & $\mathbf{0 , 8 8 9}$ & & & & & 0,874 & $\mathbf{0 , 8 4 0}$ & & & & \\
OEI & 0,818 & 0,819 & $\mathbf{0 , 9 3 6}$ & & & & 0,762 & 0,790 & $\mathbf{0 , 8 8 3}$ & & & \\
PC & 0,668 & 0,716 & 0,774 & $\mathbf{0 , 8 9 1}$ & & & 0,696 & 0,741 & 0,573 & $\mathbf{0 , 8 9 2}$ & & \\
PR & 0,679 & 0,510 & 0,574 & 0,650 & $\mathbf{0 , 9 0 6}$ & & 0,753 & 0,778 & 0,687 & 0,848 & $\mathbf{0 , 8 3 9}$ & \\
\hline
\end{tabular}

Fonte: Autora.

\subsubsection{Avaliação do modelo estrutural}

As hipóteses propostas por este estudo estão centradas na análise dos resultados das equações estruturais, considerando a amostra que reúne todos os países de coleta do questionário (Índia, Brasil, Estados Unidos e Alemanha), segmentados em emergentes e desenvolvidos.

Sendo assim, a avaliação do modelo estrutural a seguir (Tabela 14) mostra o teste t de significância, que valida as relações existentes entre as variáveis latentes da amostra dos quatro países: Índia e Brasil (países emergentes), e EUA e Alemanha (países desenvolvidos).

Os resultados indicam como significativas, para países desenvolvidos (USA e Alemanha), as relações ente MV e DS, OEI e MV, PC e OEI ( $p<0,05$ e p<0,01); e para os mercados emergentes (Índia e Brasil), as relações entre MV e DS, OEI e MV, e PR e OEI.

Tais resultados chamam a atenção para a diferença entre as amostras, no que diz respeito às influências significativas das pressões do ambiente institucional no construto orientação estratégica para a ecoinovação (OEI), sendo que, nos países desenvolvidos, ela é exercida pelo mercado consumidor (PC); e, nos mercados emergentes, pelos instrumentos regulatórios. 
Tabela 16 - Teste de significância (Boostrapping) - Desenvolvidos e emergentes

\begin{tabular}{llllll|lllll}
\hline & \multicolumn{1}{c}{ DESENVOLVIDOS } & \multicolumn{7}{c}{ EMERGENTES } \\
\hline & $\boldsymbol{\lambda}$ & $\mathbf{f 2}$ & $\mathbf{t}$ & $\mathbf{p}$ & $\mathbf{r}^{\mathbf{2}}$ & $\boldsymbol{\lambda}$ & $\mathbf{f 2}$ & $\mathbf{t}$ & $\mathbf{p}$ & $\mathbf{r}^{\mathbf{2}}$ \\
\hline DS -> DOG & 0,957 & 10,983 & 124,799 & 0,000 & 0,916 & 0,909 & 4,782 & 58,163 & 0,000 & 0,826 \\
DS -> DOP & 0,981 & 26,028 & 267,285 & 0,000 & 0,963 & 0,963 & 12,626 & 160,322 & 0,000 & 0,926 \\
MV -> DS & 0,891 & 3,871 & 32,214 & 0,000 & 0,793 & 0,760 & 1,365 & 18,089 & 0,000 & 0,575 \\
OEI -> MV & 0,811 & 1,926 & 16,512 & 0,000 & 0,656 & 0,759 & 1,362 & 19,222 & 0,000 & 0,574 \\
PC -> OEI & 0,395 & 0,119 & 1,914 & 0,046 & & 0,168 & 0,013 & 1,069 & 0,285 & \\
PR -> OEI & 0,355 & 0,096 & 1,714 & 0,087 & 0,495 & 0,299 & 0,040 & 2,162 & 0,031 & 0,188 \\
\hline
\end{tabular}

Fonte: Autora.

Nota: $\lambda=$ coeficiente estrutural; $t=$ valor-t $; \mathrm{p}=$ valor- $\mathrm{p}(\mathrm{p}<0,05 ; \mathrm{p}<0,01) ; \mathrm{f} 2=$ coeficiente de Cohen.

O teste de significância dos parâmetros para a amostra total dos países é confirmado em todas as relações do modelo operacional (Tabela 15).

Tabela 17 - Teste de significância (Bootstrapping) - Total

\begin{tabular}{llllll}
\hline & $\boldsymbol{7}$ & $\mathbf{f 2}$ & $\mathbf{t}$ & $\mathbf{p}$ & $\mathbf{r}^{\mathbf{2}}$ \\
\hline DS -> DOG & 0,944 & 8,255 & 132,696 & 0,000 & 0,892 \\
DS -> DOP & 0,976 & 20,376 & 299,181 & 0,000 & 0,953 \\
MV -> DS & 0,840 & 2,392 & 37,694 & 0,000 & 0,704 \\
OEI -> MV & 0,799 & 1,762 & 24,058 & 0,000 & 0,637 \\
PC -> OEI & 0,303 & 0,051 & 2,250 & 0,025 & 0,325 \\
PR -> OEI & 0,302 & 0,050 & 2,482 & 0,013 & \\
\hline Fonte: Autora & & & &
\end{tabular}

Fonte: Autora.

Nota: $\lambda=$ coeficiente estrutural; $\mathrm{t}=$ valor- $\mathrm{t} ; \mathrm{p}=$ valor- $\mathrm{p}(\mathrm{p}<0,05) ; \mathrm{f} 2=$ coeficiente de Cohen.

Por meio da técnica bootstrapping, com 500 interações, observou-se que, para todas as amostras, as relações entre manufatura verde (MV) e desempenho (DS), e entre orientação estratégica para a ecoinovação (OEI) e manufatura verde (MV) são positivas e significativas (t $>1,96$ e $\mathrm{p}<0,05)$.

$\mathrm{Na}$ análise da amostra dos países desenvolvidos, quanto às pressões institucionais, são significativas as relações entre a pressão do mercado consumidor (PC) e a orientação estratégica para a ecoinovação (OEI); enquanto, na amostra de países emergentes, é a pressão regulatória (PR) que tem efeito positivo e significativo nesse construto.

A avaliação da qualidade de ajuste do modelo foi realizada por meio do indicador do tamanho de efeito (f2) ou indicador de Cohen, cuja finalidade é avaliar a utilidade de cada construto para o ajuste do modelo. Os valores $0,02,0,15$ e 0,35 são considerados, 
respectivamente, indicadores de pequena, média e grande "utilidade" do construto (HAIR et al., 2014).

Para a análise das hipóteses propostas por este estudo, a seção seguinte trata da avaliação da moderação da inovação frugal no modelo estrutural, considerando a amostra total, com os quatro países, e as segmentadas em países emergentes e desenvolvidos.

\subsubsection{Avaliação da moderação no modelo estrutural}

O teste das hipóteses foi realizado por meio da avaliação da moderação da inovação frugal no modelo estrutural. Pela técnica estatística de multigrupo, utilizando modelos estruturais PLS (Partial Least Squares - Mínimos Quadrados Parciais), é possível realizar comparações das estimativas preditivas dos modelos, em diferentes grupos de respondentes. As comparações multigrupos requerem a determinação da invariância da medida (realizada pelo teste de mesmo nome), para a garantia da validade dos resultados e das conclusões (MILLSAP, 2012), assegurando, com isso, a equidade de mensuração, a invariância da composição, a igualdade das médias e das variâncias, e, sobretudo, se os construtos podem ser comparados.

O primeiro passo consiste no teste da invariância da configuração, feito pela análise qualitativa dos itens, sob a perspectiva de garantir a equidade na mensuração dos grupos. Para assegurar os resultados desse teste, nesta pesquisa, foram utilizados o mesmo instrumento (survey) e itens para a mensuração das variáveis nos dois grupos (mais e menos frugais).

O segundo passo tem o objetivo de estabelecer a invariância de medição de modelos compostos (MICOM), de acordo com as etapas estabelecidas por Henseler, Ringle e Sardedt (2015): (1) invariância configural; (2) invariância composicional; e (3) a igualdade de valores médios e variações compostas. Para que a invariância de medição parcial seja confirmada, é necessário que as Etapas 1 (invariância composicional) e 2 (variância composicional) sejam estabelecidas. A confirmação da invariância da medição parcial para todas as variáveis latentes do modelo, no PLS, permite que os pesquisadores prossigam em suas pesquisas, com a comparação dos coeficientes de caminho, por meio de uma análise multigrupo (HENSELER et al., 2015).

A análise da invariância composicional identifica se os grupos podem ser comparados, a partir das correlações e de sua significância estatística. Os valores de p valor encontrados (Tabela 16) demonstram a invariância da composição para todos os construtos, e que a comparação entre grupos é de p valores não significativos, para que o próximo passo possa ser dado (HAIR et al., 2017a). 
Tabela 18 - Invariância composicional

\begin{tabular}{|c|c|c|c|c|c|c|c|c|c|}
\hline & \multicolumn{3}{|c|}{ TOTAL } & \multicolumn{3}{|c|}{ EMERGENTES } & \multicolumn{3}{|c|}{ DESENVOLVIDOS } \\
\hline & $\begin{array}{l}\text { Correlação } \\
\text { c }(=1)\end{array}$ & $\begin{array}{l}\text { Quantil } \\
5 \%\end{array}$ & Valor $\mathrm{p}$ & $\begin{array}{l}\text { Correlação } \\
\text { c }(=1)\end{array}$ & $\begin{array}{l}\text { Quantil } \\
5 \%\end{array}$ & Valor $\mathrm{p}$ & $\begin{array}{l}\text { Correlação } \\
\text { c }(=1)\end{array}$ & $\begin{array}{l}\text { Quantil } \\
5 \%\end{array}$ & Valor $\mathrm{p}$ \\
\hline DOG & 1.000 & 0,999 & 0,973 & 0,998 & 0,994 & 0,275 & 1.000 & 0,999 & 0,147 \\
\hline DOP & 1.000 & 0,999 & 0,468 & 0,998 & 0,995 & 0,632 & 1.000 & 0,999 & 0,803 \\
\hline DS & 1.000 & 1.000 & 0,495 & 0,999 & 0,997 & 0,425 & 1.000 & 0,999 & 0,279 \\
\hline MV & 0,999 & 0,997 & 0,736 & 0,996 & 0,989 & 0,534 & 0,999 & 0,998 & 0,659 \\
\hline OEI & 1.000 & 0,999 & 0,144 & 0,998 & 0,996 & 0,144 & 1.000 & 0,999 & 0,275 \\
\hline $\mathrm{PC}$ & 1.000 & 0,999 & 0,826 & 0,998 & 0,995 & 0,880 & 0,998 & 0,995 & 0,652 \\
\hline PR & 0,999 & 0,998 & 0,275 & 0,997 & 0,992 & 0,835 & 0,997 & 0,991 & 0,835 \\
\hline
\end{tabular}

Fonte: Autora.

Os resultados das etapas de análise da invariância e da variância composicional confirmam a invariância da medição parcial, o que possibilita a análise multigrupo e, consequentemente, o teste das hipóteses propostas, iniciando-se pelos testes de permutação de coeficiente de caminho, padronizados entre os grupos, e pela análise das relações entre os construtos (HAIR et al., 2017b).

Para essa fase, espera-se que as diferenças entre os caminhos sejam estatisticamente significativas. Testando primeiramente a amostra de países emergentes e desenvolvidos, por meio de 1000 permutações, o coeficiente de caminho para os países desenvolvidos, apenas envolvendo as relações de segunda ordem DS-DOG, DS-DOP, apresentou valor $\mathrm{p}<0,001$ para os grupos, evidenciando a presença de diferença significativa nas duas relações, o que confirma a existência de relação entre os grupos mais e menos frugais. E, quanto à amostra de países emergentes, as relações de OEI-MV e DS-DOP são significativas, sendo $\mathrm{p}<1 \%$ e $\mathrm{p}<5 \%$, respectivamente (Tabela 17). 
Tabela 19 - Coeficientes de caminho (Permutação) - Desenvolvidos e emergentes

\begin{tabular}{l|llll|llll}
\hline \multicolumn{3}{c}{ DESENVOLVIDOS } & \multicolumn{4}{c}{ EMERGENTES } \\
\hline & $\begin{array}{l}\text { PCO } \\
\text { (Mais) }\end{array}$ & $\begin{array}{l}\text { PCO } \\
\text { (Menos) }\end{array}$ & $\begin{array}{l}\text { PCOD } \\
\text { (Mais- } \\
\text { Menos) }\end{array}$ & valor-p & $\begin{array}{l}\text { PCO } \\
\text { (Mais) }\end{array}$ & $\begin{array}{l}\text { PCO } \\
\text { (Menos) }\end{array}$ & $\begin{array}{l}\text { PCOD } \\
\text { (Mais- } \\
\text { Menos) }\end{array}$ & valor-p \\
\hline DS -> DOG & 0,835 & 0,941 & $-0,106$ & 0,000 & 0,871 & 0,889 & $-0,018$ & 0,545 \\
DS -> DOP & 0,944 & 0,969 & $-0,025$ & 0,001 & 0,956 & 0,932 & 0,024 & 0,042 \\
MV -> DS & 0,864 & 0,799 & 0,065 & 0,282 & 0,678 & 0,635 & 0,042 & 0,643 \\
OEI -> MV & 0,774 & 0,660 & 0,114 & 0,337 & 0,842 & 0,560 & 0,281 & 0,000 \\
PC -> OEI & 0,179 & 0,321 & $-0,142$ & 0,786 & 0,361 & 0,059 & 0,302 & 0,390 \\
PR -> OEI & 0,441 & 0,233 & 0,208 & 0,703 & $-0,013$ & 0,561 & $-0,574$ & 0,061 \\
\hline
\end{tabular}

Fonte: Autora.

Nota: $\mathrm{PCO}=$ Path Coeficients Original; PCOD = Path Coeficients Original Difference.

Considerando a amostra total e 1000 permutações, abrangendo países emergentes e desenvolvidos, os resultados (Tabela 18) indicam que as relações DS-DOG e OEI-MV são significativas, com $\mathrm{p}<1 \%$, confirmando a existência de diferença estatística nessas relações, comparando os grupos de organizações mais e menos frugais.

Tabela 20 - Coeficientes de caminho (Permutação) - Total

\begin{tabular}{lrrrr}
\hline & \multicolumn{3}{c}{ TOTAL } \\
\hline & PCO(Mais) & PCO (Menos) & PCOD (Mais-Menos) & valor-p \\
\hline DS -> DOG & 0,862 & 0,930 & $-0,068$ & 0,000 \\
DS -> DOP & 0,951 & 0,962 & $-0,011$ & 0,098 \\
MV -> DS & 0,707 & 0,751 & $-0,044$ & 0,370 \\
OEI -> MV & 0,829 & 0,638 & 0,191 & 0,000 \\
PC -> OEI & 0,317 & 0,252 & 0,065 & 0,813 \\
PR -> OEI & 0,054 & 0,350 & $-0,296$ & 0,261 \\
\hline
\end{tabular}

Fonte: Autora.

Nota: PCO = Path Coeficients Original; PCOD = Path Coeficients Original Difference.

Na comparação dos grupos de dados, para distinguir entre as abordagens paramétricas e não paramétricas (HAIR et al., 2017a), a partir de 5000 subamostras, foram realizados o teste PLS-MGA (HENSELER; RINGLE; SINKOVICS, 2009) e o teste $\mathrm{t}$ - Welch-Satterthwaite (HAIR et al., 2017a). Considerando a natureza não paramétrica do PLS-SEM (HAIR, 2017b, p. 150), o resultado do teste PLS-MGA serviu de base para a análise.

Os testes apresentaram resultado estatisticamente significativo $(\mathrm{p}<0,05)$ para as relações entre OEI e MV, para análise de mercados emergentes; já, quanto aos mercados desenvolvidos, 
não há evidências de que haja diferenças estatísticas significativas entre as organizações mais e menos frugais (Tabela 19).

Tabela 21 - Testes paramétricos e não paramétricos - Desenvolvidos e emergentes

\begin{tabular}{lllllll}
\hline \multicolumn{3}{c}{ DESENVOLVIDOS } & \multicolumn{3}{c}{ EMERGENTES } \\
\hline & $\begin{array}{l}\text { PLS- MGA } \\
\text { Mais/Menos }\end{array}$ & $\begin{array}{l}\text { Paramétrico } \\
\text { Mais/Menos }\end{array}$ & $\begin{array}{l}\text { Welch } \\
\text { Mais/Menos }\end{array}$ & $\begin{array}{l}\text { PLS- MGA } \\
\text { Mais/Menos }\end{array}$ & $\begin{array}{l}\text { Paramétrico } \\
\text { Mais/Menos }\end{array}$ & $\begin{array}{l}\text { Welch } \\
\text { Mais/Menos }\end{array}$ \\
\hline DS -> DOG & 0,997 & 0,013 & 0,041 & 0,706 & 0,598 & 0,593 \\
DS -> DOP & 0,954 & 0,096 & 0,129 & 0,076 & 0,182 & 0,206 \\
MV -> DS & 0,160 & 0,387 & 0,330 & 0,339 & 0,653 & 0,669 \\
OEI -> MV & 0,156 & 0,370 & 0,311 & 0,008 & 0,013 & 0,017 \\
PC -> OEI & 0,692 & 0,640 & 0,623 & 0,144 & 0,300 & 0,295 \\
PR -> OEI & 0,219 & 0,480 & 0,460 & 0,993 & 0,006 & 0,006 \\
\hline Fon
\end{tabular}

Fonte: Autora.

Nota: $\mathrm{p}<0,05$ significativo.

Para a amostra total, que considera países emergentes e desenvolvidos, com análise dos grupos mais e menos frugais, os resultados (Tabela 20) apontam uma relação estatística significativa $(\mathrm{p}<0,05)$, nos testes paramétricos e não paramétricos, na relação entre OEI e MV.

Tabela 22 - Testes paramétrico e não paramétrico - Total

\begin{tabular}{llll}
\hline & \multicolumn{3}{c}{ TOTAL } \\
\hline & $\begin{array}{l}\text { PLS-MGA } \\
\text { Mais/Menos }\end{array}$ & $\begin{array}{l}\text { Paramétrico } \\
\text { Mais/Menos }\end{array}$ & $\begin{array}{l}\text { Welch } \\
\text { Mais/Menos }\end{array}$ \\
\hline DS -> DOG & 0,998 & 0,005 & 0,006 \\
DS -> DOP & 0,857 & 0,299 & 0,302 \\
MV -> DS & 0,779 & 0,457 & 0,457 \\
OEI -> MV & 0,013 & 0,024 & 0,025 \\
PC -> OEI & 0,384 & 0,786 & 0,786 \\
PR -> OEI & 0,925 & 0,147 & 0,147 \\
\hline
\end{tabular}

Fonte: Autora.

Nota: $\mathrm{p}<0,05$ significativo.

A seguir, estão os resultados do teste de hipótese da análise multigrupo (bootstrapping) para os países desenvolvidos e emergentes (Tabela 21); e a análise da força e de sentido das relações, considerando a amostra total desta pesquisa (Tabela 22). 
Tabela 23 - Teste de hipótese da análise multigrupo (Bootstrapping) - Desenvolvidos e emergentes

\begin{tabular}{|c|c|c|c|c|c|c|c|c|c|c|c|c|}
\hline & \multicolumn{6}{|c|}{ DESENVOLVIDOS } & \multicolumn{6}{|c|}{ EMERGENTES } \\
\hline & $\begin{array}{l}\text { PCO } \\
\text { (Mais) }\end{array}$ & $\begin{array}{l}\text { PCO } \\
\text { (Menos) }\end{array}$ & $\begin{array}{l}\text { t } \\
\text { (Mais) }\end{array}$ & $\begin{array}{l}\mathbf{t} \\
\text { (Menos) }\end{array}$ & $\begin{array}{l}\mathbf{p} \\
\text { (Mais) }\end{array}$ & $\begin{array}{l}\mathbf{p} \\
\text { (Menos) }\end{array}$ & \begin{tabular}{|l|} 
PCO \\
(Mais)
\end{tabular} & $\begin{array}{l}\text { PCO } \\
\text { (Menos) }\end{array}$ & $\begin{array}{l}\mathbf{t} \\
\text { (Mais) }\end{array}$ & $\begin{array}{l}\text { t } \\
\text { (Menos) }\end{array}$ & $\begin{array}{l}\mathbf{p} \\
\text { (Mais) }\end{array}$ & $\begin{array}{l}\mathbf{p} \\
\text { (Menos) }\end{array}$ \\
\hline DS -> DOG & 0,835 & 0,941 & 16,909 & 72,382 & 0,000 & 0,000 & 0,871 & 0,889 & 37,467 & 37,022 & 0,000 & 0,000 \\
\hline DS -> DOP & 0,944 & 0,969 & 64,293 & 122,695 & 0,000 & 0,000 & 0,956 & 0,932 & 95,750 & 56,366 & 0,000 & 0,000 \\
\hline MV -> DS & 0,864 & 0,799 & 22,340 & 14,674 & 0,000 & 0,000 & 0,678 & 0,635 & 13,099 & 7,493 & 0,000 & 0,000 \\
\hline OEI $->\mathrm{MV}$ & 0,774 & 0,660 & 12,155 & 7,118 & 0,000 & 0,000 & 0,842 & 0,560 & 12,366 & 5,985 & 0,000 & 0,000 \\
\hline $\mathrm{PC}->\mathrm{OEI}$ & 0,179 & 0,321 & 0,877 & 1,572 & 0,381 & 0,117 & 0,361 & 0,059 & 1,815 & 0,285 & 0,070 & 0,776 \\
\hline PR -> OEI & 0,441 & 0,233 & 2,182 & 1,189 & 0,030 & 0,235 & $-0,013$ & 0,561 & 0,091 & 3,953 & 0,928 & 0,000 \\
\hline
\end{tabular}

Fonte: Autora.

Nota: $\mathrm{PCO}=$ Path Coeficients Original; $\mathrm{t}>1,96 ; \mathrm{p}<0,05$ significativo.

Tabela 24 - Teste de hipótese da análise multigrupo (Bootstrapping) - Total

\begin{tabular}{|c|c|c|c|c|c|c|}
\hline \multicolumn{7}{|c|}{ TOTAL } \\
\hline & $\begin{array}{l}\text { PCO } \\
\text { (Mais) }\end{array}$ & $\begin{array}{l}\text { PCO } \\
\text { (Menos) }\end{array}$ & $\begin{array}{l}\text { t } \\
\text { (Mais) }\end{array}$ & $\begin{array}{l}\mathbf{t} \\
(\text { Menos })\end{array}$ & $\begin{array}{l}\mathbf{p} \\
\text { (Mais) }\end{array}$ & $\begin{array}{l}\text { p } \\
\text { (Menos) }\end{array}$ \\
\hline $\mathrm{DS}->\mathrm{DOG}$ & 0,862 & 0,930 & 39,532 & 89,255 & 0,000 & 0,000 \\
\hline DS -> DOP & 0,951 & 0,962 & 114,046 & 150,224 & 0,000 & 0,000 \\
\hline MV -> DS & 0,707 & 0,751 & 17,748 & 16,822 & 0,000 & 0,000 \\
\hline OEI -> MV & 0,829 & 0,638 & 13,930 & 10,574 & 0,000 & 0,000 \\
\hline PC -> OEI & 0,317 & 0,252 & 1,828 & 1,519 & 0,068 & 0,129 \\
\hline PR -> OEI & 0,054 & 0,350 & 0,394 & 2,310 & 0,694 & 0,021 \\
\hline
\end{tabular}

Fonte: Autora.

Nota: $\mathrm{PCO}=$ Path Coeficients Original; $\mathrm{t}>1,96 ; \mathrm{p}<0,05$ significativo 
A seguir (Figuras 8 a 13), estão as representações gráficas dos coeficientes de caminhos e t-valor, resultados mostrados nas Tabelas 21 e 22.

Figura 8 - Modelo final da amostra, desenvolvido com o efeito da moderação mais frugal

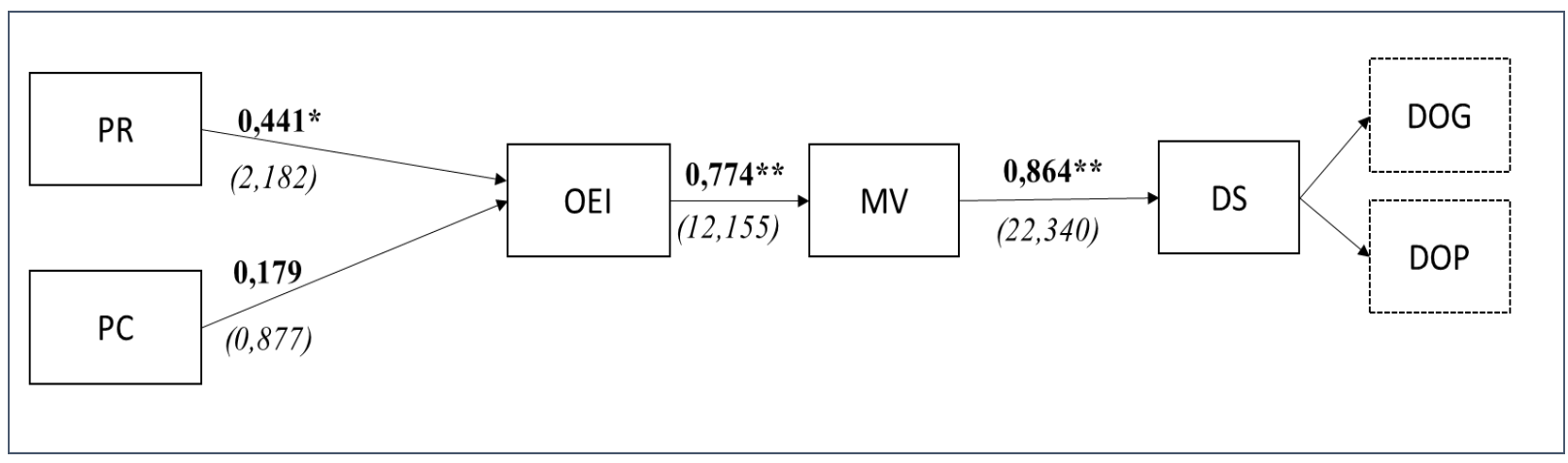

Fonte: Autora.

Nota: * $\mathrm{p}<0,05 ; * * \mathrm{p}<0,001$; DOG e DOP são variáveis de segunda ordem.

Figura 9 - Modelo final da amostra, desenvolvido com o efeito da moderação menos frugal

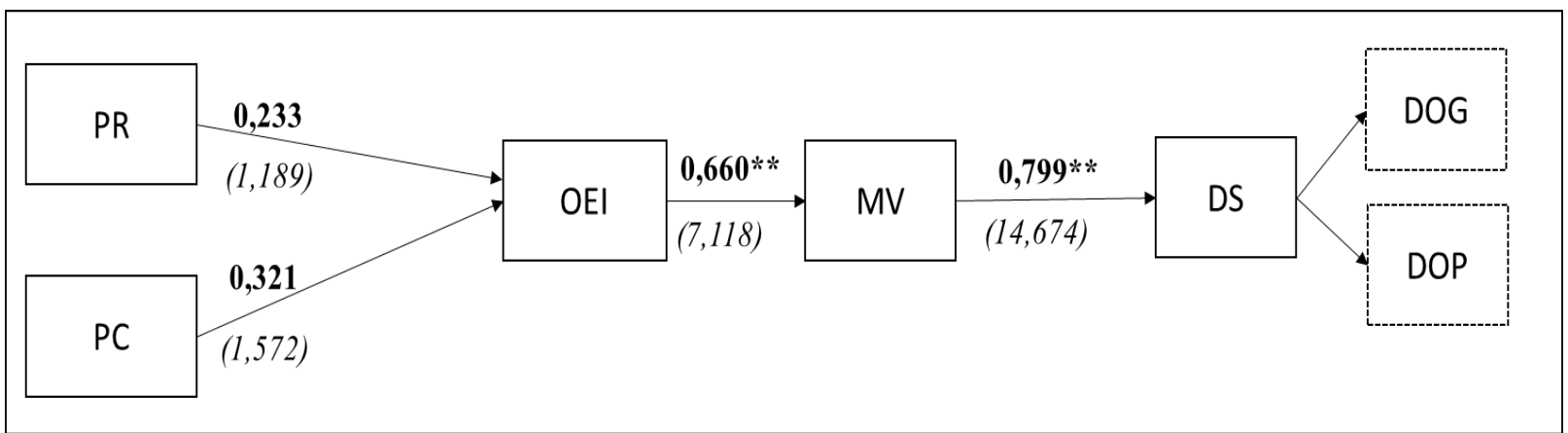

Fonte: Autora.

Nota: * $\mathrm{p}<0,05 ; * * \mathrm{p}<0,001 ;$ DOG e DOP são variáveis de segunda ordem.

Figura 10 - Modelo final da amostra emergente, com o efeito da moderação mais frugal

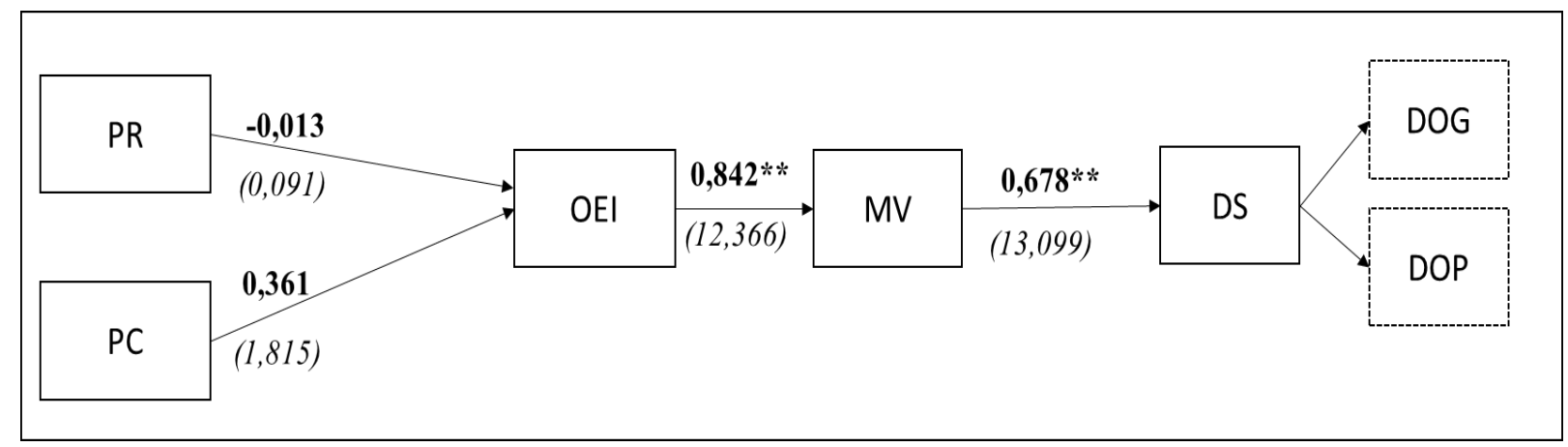

Fonte: Autora.

Nota: * $\mathrm{p}<0,05 ; * * \mathrm{p}<0,001$; DOG e DOP são variáveis de segunda ordem. 
Figura 11 - Modelo final da amostra emergente, com o efeito da moderação menos frugal

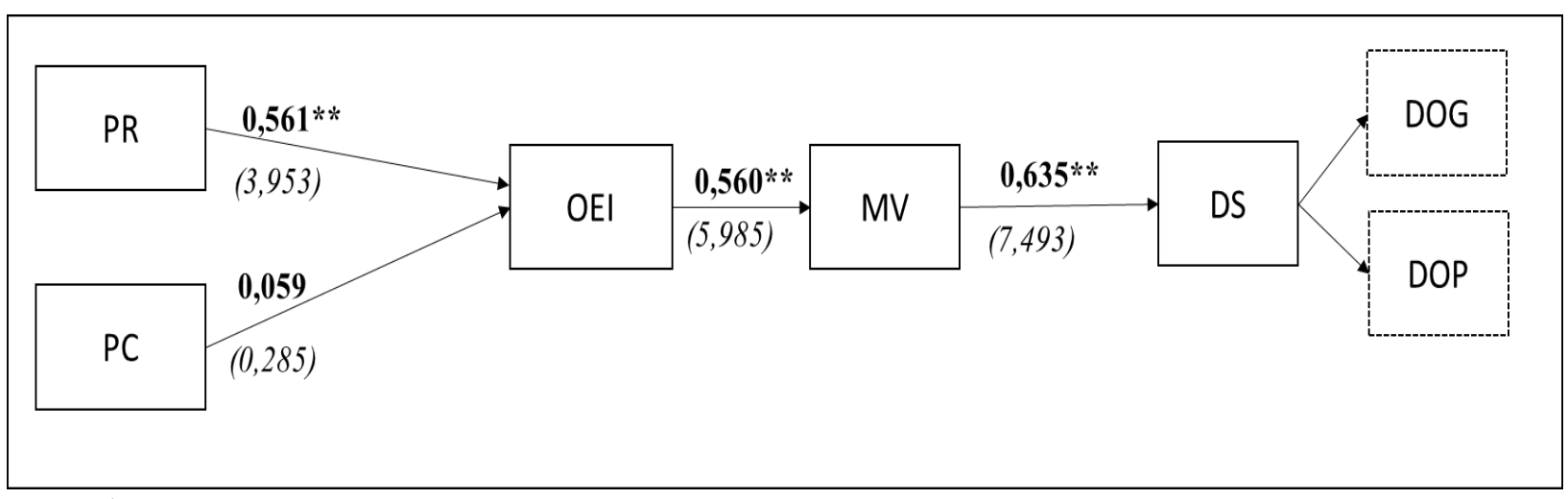

Fonte: Autora.

Nota: * $\mathrm{p}<0,05 ; *$ p $<0,001 ;$ DOG e DOP são variáveis de segunda ordem.

Figura 12 - Modelo final da amostra total, com o efeito da moderação mais frugal

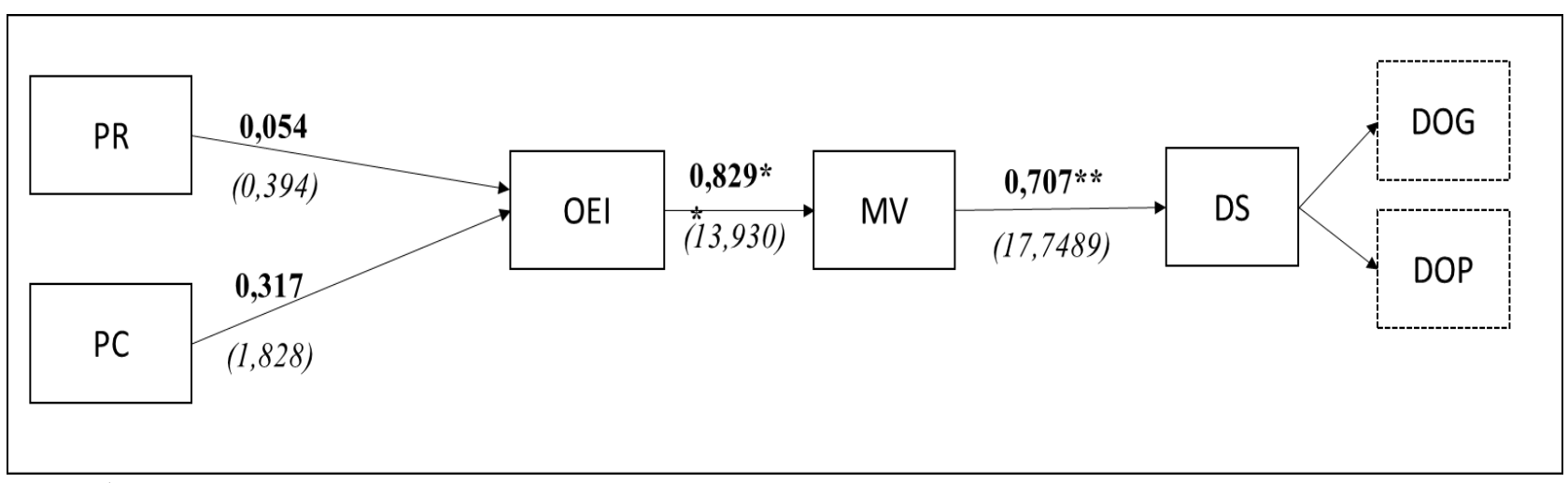

Fonte: Autora.

Nota: * $\mathrm{p}<0,05 ; * * \mathrm{p}<0,001 ;$ DOG e DOP são variáveis de segunda ordem.

Figura 13 - Modelo final da amostra total, com o efeito da moderação menos frugal

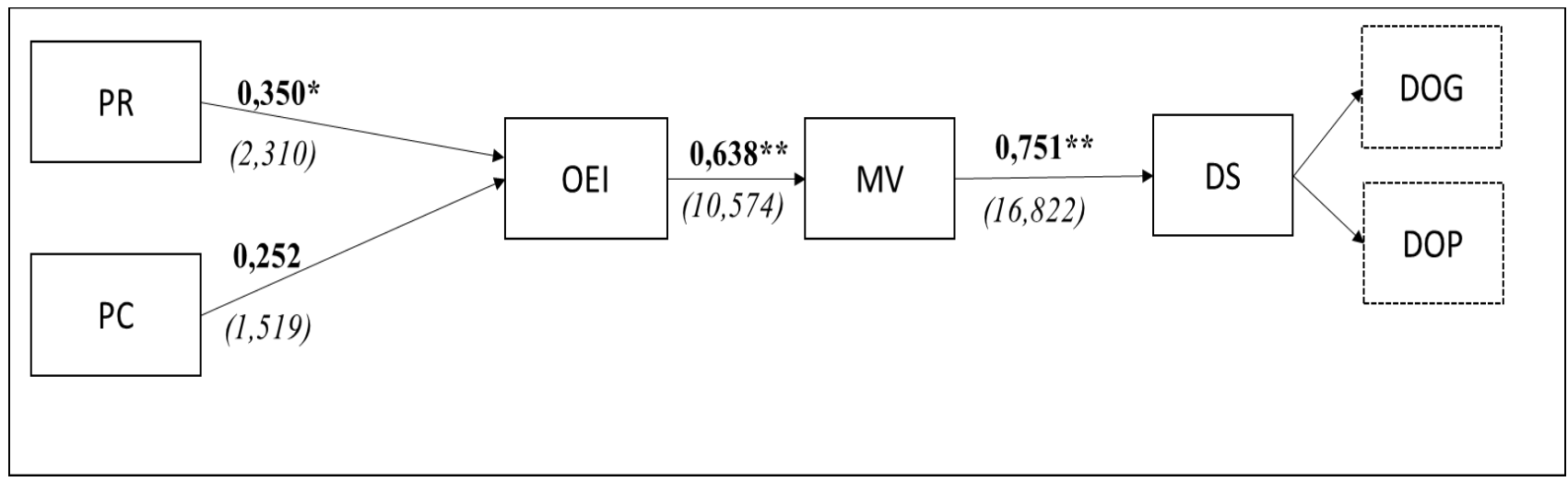

Fonte: Autora.

Nota: ${ }^{*} \mathrm{p}<0,05 ;{ }^{*} \mathrm{p}<0,001 ;$ DOG e DOP são variáveis de segunda ordem.

As análises mostradas nas Tabelas 19 e 20, com os testes paramétricos e não paramétricos, e o bootstrapping, permitem verificar que: na amostra total de países emergentes e desenvolvidos, a relação entre OEI e MV é significativa para os grupos mais e menos frugais; 
e os testes não paramétricos confirmam a existência de diferença estatisticamente significativa na relação entre os grupos. Ou seja, para a amostra que reúne países emergentes (Índia e Brasil) e desenvolvidos (EUA e Alemanha), pode-se afirmar que as organizações mais frugais têm relação mais forte $(\mathrm{PCO}$ mais frugal $=0,829 ; \mathrm{PCO}$ menos frugal $=0,638)$ entre a orientação estratégica para a ecoinovação e a manufatura verde.

Esse resultado suporta a hipótese H1a - quanto maior o efeito da inovação frugal, maior a relação entre OEI e MV, em mercados emergentes. As hipóteses H2a, H3a, e H4a não foram suportadas, pois, apesar da relação significativa entre PR e OEI para o grupo de organizações menos frugais, e MV e DS para os grupos mais e menos frugais, os testes entre os grupos não indicaram evidências estatísticas de que essas relações eram diferentes.

Para os testes com a amostra de mercados emergentes, a relação entre OEI e MV é significativa para os grupos mais e menos frugais, e os testes não paramétricos confirmam que há diferença estatisticamente significativa na relação entre eles. Então, para mercados emergentes, pode-se afirmar que as organizações mais frugais têm relação mais forte (PCO mais frugal $=0,842 ;$ PCO menos frugal $=0,560$ ) entre a orientação estratégica para a ecoinovação e a manufatura verde.

Esse resultado suporta a hipótese $\mathrm{H} 1 \mathrm{~b}$ - quanto maior o efeito de moderação da inovação frugal, maior é a relação entre OEI e MV, em mercados emergentes. As hipóteses H2b, H3b e H4b não foram suportadas, pois, apesar da relação significativa entre PR e OEI para o grupo de organizações menos frugais, e entre MV e DS para os grupos mais e menos frugais, os testes entre os grupos não indicaram evidências estatísticas de que essas relações eram diferentes.

Para mercados desenvolvidos, apesar de significativas as relações entre OEI e MV para os grupos mais e menos frugais; e entre PR e OEI para o grupo de organizações mais frugais, a comparação estatística multigrupo não apresenta evidências de que há diferença nas relações entre esses grupos, ou seja, de que a inovação frugal atue como moderadora nessas relações, tornando-as mais fortes. Dessa forma, não foram suportadas as hipóteses H1c, H2c, H3c e H4c, conforme aponta o resumo dos resultados do teste das hipóteses, apresentado a seguir (Quadro 7).

Vale ressaltar que, de modo complementar, foram feitos o teste e a análise para considerar se o efeito de moderação da inovação frugal, na relação entre a orientação estratégica e a manufatura verde, pode ser observado nas amostras de empresas de grande porte (acima de 501 funcionários) e de médias e pequenas organizações. Como a quantidade de empresas mais e menos frugais é desequilibrada em ambas as amostras (das 162 organizações respondentes na amostra de grandes empresas, apenas 20 foram consideradas menos frugais; e na amostra de 
141 empresas de médio e pequeno porte, apenas 46 são menos frugais), a análise de multigrupos não pôde ser aplicada.

\section{Quadro 8 - Resumo dos resultados das hipóteses}

\begin{tabular}{|c|c|c|}
\hline Hipótese & Descrição & Status \\
\hline $\mathrm{H} 1 \mathrm{a}$ & $\begin{array}{l}\text { Quanto maior o efeito de moderação da inovação frugal, maior é a relação entre } \\
\text { a orientação estratégica para a ecoinovação e a manufatura verde. }\end{array}$ & Suportada \\
\hline $\mathrm{H} 1 \mathrm{~b}$ & $\begin{array}{l}\text { Quanto maior o efeito de moderação da inovação frugal, maior é a relação entre } \\
\text { a orientação estratégica para a ecoinovação e a manufatura verde, em } \\
\text { organizações de países emergentes. }\end{array}$ & Suportada \\
\hline $\mathrm{H} 1 \mathrm{c}$ & $\begin{array}{l}\text { Quanto maior o efeito de moderação da inovação frugal, maior é a relação entre } \\
\text { a orientação estratégica para a ecoinovação e a manufatura verde, em } \\
\text { organizações de países desenvolvidos. }\end{array}$ & Não suportada \\
\hline $\mathrm{H} 2 \mathrm{a}$ & $\begin{array}{l}\text { Quanto maior o efeito de moderação da inovação frugal, maior é a relação entre } \\
\text { a pressão regulatória e a orientação estratégica para a ecoinovação. }\end{array}$ & Não suportada \\
\hline $\mathrm{H} 2 \mathrm{~b}$ & $\begin{array}{l}\text { Quanto maior o efeito de moderação da inovação frugal, maior é a relação entre } \\
\text { a pressão regulatória e a orientação estratégica para a ecoinovação, em } \\
\text { organizações de países emergentes. }\end{array}$ & Não suportada \\
\hline $\mathrm{H} 2 \mathrm{c}$ & $\begin{array}{l}\text { Quanto maior o efeito de moderação da inovação frugal, maior é a relação entre } \\
\text { a pressão regulatória e a orientação estratégica para a ecoinovação, em } \\
\text { organizações de países desenvolvidos. }\end{array}$ & Não suportada \\
\hline $\mathrm{H} 3 \mathrm{a}$ & $\begin{array}{l}\text { Quanto maior o efeito de moderação da inovação frugal, maior é a relação entre } \\
\text { a pressão do mercado consumidor e a orientação estratégica para a ecoinovação. }\end{array}$ & Não suportada \\
\hline $\mathrm{H} 3 \mathrm{~b}$ & $\begin{array}{l}\text { Quanto maior o efeito de moderação da inovação frugal, maior é a relação entre } \\
\text { a pressão do mercado consumidor e a orientação estratégica para a ecoinovação, } \\
\text { em organizações de países emergentes. }\end{array}$ & Não suportada \\
\hline $\mathrm{H} 3 \mathrm{c}$ & $\begin{array}{l}\text { Quanto maior o efeito de moderação da inovação frugal, maior é a relação entre } \\
\text { a pressão do mercado consumidor e a orientação estratégica para a ecoinovação, } \\
\text { em organizações de países desenvolvidos. }\end{array}$ & Não suportada \\
\hline $\mathrm{H} 4 \mathrm{a}$ & $\begin{array}{l}\text { Quanto maior o efeito de moderação da inovação frugal, maior é a relação entre } \\
\text { a manufatura verde e o desempenho das organizações. }\end{array}$ & Não suportada \\
\hline $\mathrm{H} 4 \mathrm{~b}$ & $\begin{array}{l}\text { Quanto maior o efeito de moderação da inovação frugal, maior é a relação entre } \\
\text { a manufatura verde e o desempenho, em organizações de países emergentes. }\end{array}$ & Não suportada \\
\hline $\mathrm{H} 4 \mathrm{c}$ & $\begin{array}{l}\text { Quanto maior o efeito de moderação da inovação frugal, maior é a relação entre } \\
\text { a manufatura verde e o desempenho, em organizações de países desenvolvidos. }\end{array}$ & Não suportada \\
\hline
\end{tabular}

Fonte: Autora. 


\section{DISCUSSÃO DOS RESULTADOS}

A discussão dos resultados tem como ponto de partida as duas perguntas propostas por esta pesquisa: (1) As organizações com maior incidência de inovação frugal têm melhor resultado na relação entre a orientação estratégica para a ecoinovação e a manufatura verde? (2) Há diferença entre países emergentes e desenvolvidos, na relação entre as pressões do ambiente institucional, a orientação estratégica, a manufatura verde e o desempenho?

Feitas as perguntas, os objetivos principais deste estudo consistia em validar que, quanto maior a estratégia de inovações frugais nas organizações, maior a relação existente entre a orientação estratégica para a ecoinovação e a manufatura verde; e que há diferença nessas relações, quando comparados os países emergentes e desenvolvidos.

Nesse contexto, esta pesquisa também verificou a influência: (a) das pressões institucionais de mercado e regulatória na orientação estratégica para a ecoinovação, quanto maior a estratégia de inovação frugal na organização; e (b) da relação entre a manufatura verde e o desempenho organizacional, quanto maior a estratégia de inovação frugal na empresa; além de (c) comparar os resultados das relações entre as pressões do ambiente institucional e a orientação estratégica para a ecoinovação, a manufatura verde e o desempenho, em mercados desenvolvidos e emergentes, quanto maior o efeito de moderação da inovação frugal.

Logo, a discussão de resultados está estruturada para atender a esses objetivos e discutir: a estratégia de inovação frugal na relação entre a orientação estratégica para a ecoinovação e a manufatura verde; a influência da estratégia de inovação frugal nas relações entre as pressões regulatória e de mercado e a orientação estratégica para a ecoinovação, e entre a manufatura verde e o desempenho; e as implicações entre os mercados emergentes e desenvolvidos.

\subsection{A INCIDÊNCIA DA INOVAÇÃO FRUGAL NA RELAÇÃO ENTRE A ORIENTAÇÃO ESTRATÉGICA PARA A ECOINOVAÇÃO E A MANUFATURA VERDE}

A literatura sobre o impacto das estratégias organizacionais de ecoinovação e de manufatura verde demonstra a importância da existência desse relacionamento para o desenvolvimento sustentável e para os objetivos ambientais da organização (CAINELLI; DE MARCHI; GRANDINETTI, 2015; DANGELICO; PUJARI, 2010; GONZÁLEZ-MORENO; SÁEZ-MARTÍNEZ; DÍAZ-GARCÍA， 2013; SEGARRA-OÑA; PEIRÓ-SIGNES; MONDÉJAR-JIMÉNEZ, 2016). 
Assim, a orientação estratégica para a ecoinovação pode ser entendida como os recursos estratégicos da organização, que abrangem desde os avanços tecnológicos voltados à preservação ambiental, até as escolhas quanto ao desenvolvimento de inovação em produtos e em processos com menos danos ao meio ambiente (HSU; TAN; ZAILANI, 2016; SEGARRAONA; PEIRO-SIGNES; PAYA-MARTINEZ, 2014).

A relação com a manufatura verde promove a mudança de modelos de negócio lineares, baseados na produção-extração-consumo-descartável, para os voltados: (a) às soluções focadas no longo prazo, com impacto em tecnologias, infraestrutura, estilo de vida e consumo (PANSERA, 2013); (b) às inovações de impactos reduzidos para o meio ambiente; (c) à criação de valor, a partir de resíduos; (d) à substituição por elementos renováveis e processos naturais; (e) ao incentivo à suficiência; (f) à entrega de funcionalidade principal; e (g) ao desenvolvimento de soluções escalonáveis (BOCKEN et al., 2014).

Os resultados obtidos nesta pesquisa, acerca da relação significativa entre a orientação estratégica para a ecoinovação e as práticas de manufatura verde, confirmam os estudos sobre a importância dessa relação para o ecossistema de sustentabilidade, e contribuem para a literatura, por incluir o efeito moderador da inovação frugal como fator de influência e de fortalecimento de tal relação.

A análise da literatura demonstra que a inovação frugal é constantemente relacionada aos fatores de sustentabilidade ecológica, social e econômica, por oferecer produtos que minimizam o uso de recursos e são mais acessíveis financeiramente do que as soluções convencionais do mercado (ALBERT, 2019; CUNHA et al., 2014). Então, sendo a sustentabilidade um dos principais direcionadores estratégicos, no campo da gestão da inovação, para os próximos anos (HORN; BREM, 2013), a inovação frugal é considerada como o primeiro passo para organizar o desenvolvimento da ecoinovação, e inserir inovações sustentáveis em suas operações produtivas (BAS, 2016, 2017; BASU; BANERJEE; SWEENY, 2013).

A abordagem sustentável da inovação frugal permite: criar um design de produtos e serviços, visando à diminuição de consumo de matéria-prima (AGARWAL et al., 2016; ZESCHKY; WINTERHALTER; GASSMANN, 2014); corrigir falhas nos processos produtivos com impacto ambiental; recuperar componentes, ao fim do ciclo de vida de produtos; reciclar componentes e materiais (BAS, 2016); criar produtos de alta qualidade, com baixo custo e consumo econômico (BREM, 2017; RAO, 2017b); e - como contribuição relevante - implementar ecoinovações em mercados emergentes e desenvolvidos (PISONI; MICHELINI; MARTIGNONI, 2018). 
Quanto à atração por produtos com características frugais, os consumidores, por necessidade ou escolha, optam por aqueles que tenham, de forma combinada, atributos de custos, simplicidade, qualidade básica e sustentabilidade ambiental (VON JANDA et al., 2020).

Assim, a hipótese H1a (Quadro 8) testou a relação entre a orientação estratégica para a ecoinovação e a manufatura verde, sob o efeito da moderação da inovação frugal.

Quadro 9 - Resumo do resultado da hipótese H1a

\begin{tabular}{|l|l|l|}
\hline Hipótese & Descrição & Status \\
\hline H1a & $\begin{array}{l}\text { Quanto maior o efeito de moderação da inovação frugal, maior é a relação entre } \\
\text { a orientação estratégica para a ecoinovação e a manufatura verde. }\end{array}$ & Suportada \\
\hline
\end{tabular}

Fonte: Autora.

A análise da amostra total, que considera países emergentes e desenvolvidos para a relação moderada pela inovação frugal, aponta a potencialização, em força, da relação entre a orientação estratégica para a ecoinovação das organizações e as suas práticas de manufatura verde, com foco em funcionalidades centrais, isto é: o desenvolvimento de soluções baseadas em baixo custo final e de processos; parcerias locais para processos operacionais; e soluções eficientes e eficazes para as necessidades sociais e ambientais. Então, quanto mais essas dimensões de inovação estão presentes, como forma de incidência de inovação frugal, interagindo nessa relação, melhor o resultado das estratégias ecoinovadoras: reutilização e reciclagem, produtos e processos com menor impacto ambiental, melhora de vida útil, eficiência e produtividade.

Confirma-se, dessa forma, a hipótese H1a, em que a IF fortalece a relação entre a OEI e a MV, de modo que o efeito interativo de alto nível da OEI e o alto nível da IF podem facilitar a implementação das práticas de MV. Assim, o ambiente dinâmico de soluções frugais torna a orientação estratégica para a ecoinovação das organizações mais eficaz, estimulando as práticas de produção de produtos reciclados ou reutilizados; a atenuação do consumo de energia, tanto na produção quanto no benefício aos usuários finais dos produtos; e o design de novos produtos, mais sustentáveis ecologicamente.

Esses resultados evidenciam que, além da característica de desenvolvimento de produtos e de serviços voltados a atender vazios institucionais de mercados emergentes (KHANNA; PALEPU; BULLOCK, 2010), ou apenas mais baratos, a inovação frugal apresenta o potencial de alavancar a orientação estratégica das organizações para alcançar seus objetivos sustentáveis de produção e de design de novos produtos e/ou serviços. 
Esses achados confirmam os estudos sobre a dimensão da sustentabilidade como diferencial estratégico para a inovação frugal (SANTOS; BORINI; OLIVEIRA JÚNIOR, 2020; SHIBIN et al., 2018; WEYRAUCH; HERSTATT, 2016), e a visão dessas inovações como inerentemente verdes, sendo solução para as necessidades ecológicas e modelo para a criação de inovações de baixa intervenção ambiental (KHAN, 2016). Além disso, evidencia-se que há claro potencial para: contribuir com o desenvolvimento sustentável, por meio do menor consumo de recursos, como efeito da substituição das práticas indesejáveis ou ineficientes (HYVÄRINEN; KESKINEN; VARIS, 2016); maximizar a eficiência de material e de energia; e encorajar a suficiência (ROSCA; ARNOLD; BENDUL, 2017).

Dessa forma, as evidências dos estudos na literatura, que identificam uma conexão relativa entre a inovação frugal e a sustentabilidade, demonstram que, em termos gerais, a inovação frugal tem, dentre as suas dimensões, atributos intrínsecos à sustentabilidade, no que se refere a proteger a capacidade existente de recursos ambientais, a preservar a integridade ambiental da comunidade, e a exponenciar as estratégias da cadeia de suprimentos verdes (ALBERT, 2019). Além disso, esses benefícios podem ser alcançados por países emergentes e desenvolvidos (PISONI; MICHELINI; MARTIGNONI, 2018).

Quanto à função de moderadora da relação entre a orientação estratégica e a manufatura verde, os resultados confirmam que o impacto da inovação frugal é indireto sobre a sustentabilidade, do ponto de vista ecológico (LEVÄNEN et al., 2016; ROSCA; ARNOLD; BENDUL, 2017; SHARMA; IYER, 2012). Ou seja, não se questiona o papel da inovação frugal como fator de alcance dos propósitos ambientais da organização, mas se argumenta que a inovação frugal atua de forma indireta, em estratégias ambientais e práticas verdes, como, de fato, foi confirmado nos resultados desta pesquisa.

Ao demonstrar a necessidade da presença da orientação estratégica para a ecoinovação, e o efeito potencial da inovação frugal, caso a organização queira melhoras nos seus processos de manufatura verde, esses resultados aprofundam a discussão da efetiva colaboração da inovação frugal em um modelo de alcance da sustentabilidade ambiental nas organizações.

Como fator moderador, e consequente impacto positivo na força para a implementação das práticas de manufatura verde, a inovação frugal pode exercer um importante papel quanto à competitividade da organização. Como parte essencial para o desenvolvimento sustentável, a implementação de práticas de manufatura verde está intrinsecamente relacionada a uma melhor reputação para o mercado consumidor, à economia de custos desnecessários, e à promoção da pesquisa e do design (MARUTHI; RASHMI, 2015). 
Assim, as diferentes práticas ecoinovadoras na manufatura, como a prevenção da poluição e a administração dos produtos, levam a resultados competitivos distintos, por meio dos menores custos de fabricação e melhor qualidade do produto, desde a atração de novos clientes e o fortalecimento da imagem da empresa, à promoção e ao estímulo às ideias inovadoras na organização (RUSINKO, 2007).

Essas ideias inovadoras surgem nas organizações que praticam a manufatura verde, concentrada nas áreas de energia, produtos e processos verdes, nas operações de negócios, sendo motivadas por: pressões regulatórias, crescente atração do mercado por produtos verdes, avanços tecnológicos, novas oportunidades de mercado e aumento do uso de insumos e custos (SHIBIN et al., 2018; SHRIVASTAVA; SHRIVASTAVA, 2017).

Para o desenvolvimento dessas áreas, com foco na manufatura verde, a perspectiva ambiental da organização é ampliada para outras partes interessadas, internas e externas, como P\&D, design de produtos, compras e fornecedores (RUSINKO, 2007), que, por meio da inovação de produtos verdes e da inovação de processos verdes levam à vantagem competitiva (CHIOU et al., 2011). Tais características de organizações líderes em sustentabilidade estão alinhadas à orientação estratégica para a ecoinovação, que agrega as iniciativas internas, em uma abordagem colaborativa, voltada aos negócios sustentáveis (FORMENTINI; TATICCHI, 2016).

Sendo assim, quanto maior a intensidade de manufatura verde, representada por reuso, reciclagem e diminuição de insumos na organização, menores os custos diretos, indiretos e totais, além de haver maior eficiência e maior potencial de inovação (TAN et al., 2016). Assim, ao potencializar a manufatura verde, por meio da inovação frugal, a organização, consequentemente: aprimora seus fundamentos de competitividade; desenvolve melhores condições de competir por custos; ganha em eficiência e qualidade; tem maior produtividade; cumpre melhor às regulamentações, respondendo satisfatoriamente às pressões institucionais; e aumenta as barreiras de entrada de concorrentes e as oportunidades de entrar em novos mercados, por meio das ecoinovações (CHIOU et al., 2011).

Esses resultados, obtidos pela moderação, podem ser explicados a partir dos pontos de sinergia apresentados pela literatura, em relação às dimensões da inovação frugal e aos propósitos e características da ecoinovação, decorrentes da orientação estratégica da organização.

Alinhada à intenção de criar novos produtos e processos relacionados à ecoinovação, ou seja, ao ecodesign (FRANCESCHINI; FARIA; JUROWETZKI, 2016), a dimensão de funcionalidade da inovação frugal torna os produtos mais simples, duráveis e centrados em suas 
funções principais (WEYRAUCH; HERSTATT, 2016), atendendo, assim, à perspectiva de desenhar novos produtos e processos, sustentáveis desde o início, repensando as formas de reciclar e de tratar os resíduos (THEYEL, 2000).

A sinergia entre o propósito da ecoinovação e a dimensão de funcionalidade demonstra que a inovação frugal pode ser utilizada para alterar a maneira pela qual os produtos são desenvolvidos, atuando de forma conjunta com o ecodesign, para atender às necessidades de clientes e às políticas de atenuação de impactos ambientais, levando em consideração a escassez de recursos.

Estudos recentes sugerem que a formação de ecossistemas frugais estimula as soluções ecoinovadoras e sustentáveis, por meio de projetos colaborativos e parcerias, cujo foco está nas soluções socioambientais. Isto é, projetos de inovação, orientados por soluções e critérios frugais, que promovem a arquitetura de redes de parcerias (com fornecedores, clientes, governo e demais empresas locais), estimulam o alinhamento entre os interesses para a diminuição dos impactos ambientais e o desenvolvimento de produtos e processos mais sustentáveis (HORBACH; RAMMER; RENNINGS, 2012; PUJARI, 2006).

A formação de ecossistemas frugais também promove soluções que preservam recursos, reduzem o consumo, e facilitam o reuso, a reciclagem e a decomposição (CHEN; LAI; WEN, 2006; DANGELICO; PUJARI, 2010), além de facilitar os arranjos de processos voltados à sustentabilidade ambiental (HORBACH, 2008), que são essenciais às instalações de organizações mais poluidoras e propensas a inovar (FRONDEL; HORBACH; RENNINGS, 2008).

O resultado da hipótese H1a corrobora o estudo de Rao (2017a), ao apontar que a inovação frugal, sob a perspectiva de sua dimensão de ecossistema, pode impactar, em força, o desenvolvimento sustentável, por meio da tecnologia para a preservação dos recursos ambientais existentes.

Ao atribuir a redução de custos aos processos operacionais e às soluções de baixo custo aos clientes finais, a inovação frugal auxilia nos propósitos da ecoinovação de obter a diminuição de custos e de atender às pressões competitivas, por intermédio dos avanços tecnológicos ambientais (HORBACH; RAMMER; RENNINGS, 2012; TRIEBSWETTER; WACKERBAUER, 2008).

As pesquisas em ecoinovação demonstram que a diminuição de custos se torna mais importante para a implementação de produção limpa do que a pressão das regulamentações ambientais (KEMP; PONTOGLIO, 2011), e que essa redução ocorre desde a implementação das inovações tecnológicas, nas fases de desenvolvimento do produto, à sua introdução no 
mercado (RENNINGS, 2000), passando pelo planejamento da produção para o tratamento de resíduos e a reciclagem (ARUNDEL; KEMP, 2009; REHFELD; RENNINGS; ZIEGLER, 2007).

Ao reduzir os custos operacionais, a inovação frugal atende a uma das principais razões da manufatura verde (YU; HUO, 2019): ela reduz o uso de matéria-prima e de energia, mitigando o risco de multas ambientais, e desenvolvendo capacidades internas e ecoeficiência (KUMAR; TEICHMAN; TIMPERNAGEL, 2012).

Como resultado, há a otimização da performance financeira da organização, quando comparada às que não adotam tais práticas (PRZYCHODZEN; PRZYCHODZEN, 2015); o crescimento do lucro; a evolução da participação de mercado (HSU; TAN; ZAILANI, 2016); e maior competitividade (GOLICIC; SMITH, 2013; KLEINDORFER; SINGHAL; WASSENHOVE, 2005; LAI; WONG, 2012; TESTA; IRALDO, 2010)

Logo, o fortalecimento da relação entre a orientação estratégica para a ecoinovação e a manufatura verde, pela moderação da inovação frugal, é resultado da interação entre o conjunto de suas dimensões, e as características e os propósitos da ecoinovação e da manufatura verde.

\subsection{A INOVAÇÃO FRUGAL PARA A ECOINOVAÇÃO E AS RELAÇÕES ENTRE O AMBIENTE INSTITUCIONAL, A ORIENTAÇÃO ESTRATÉGICA PARA A ECOINOVAÇÃO, A MANUFATURA VERDE E O DESEMPENHO}

Os estudos da teoria institucional sugerem que atender aos propósitos de produção de bens e adaptar-se ao ambiente de atuação, de forma conjunta com fornecedores, clientes, concorrentes e atores de pressão externa, tais como reguladores, associações, mídia e profissionais (HININGS; GEGENHUBER; GREENWOOD, 2018), envolve estabelecer estratégias de inovação e o desenvolvimento de novos produtos, que tragam proposições de valor a essas interações (FUENFSCHILLING; TRUFFER, 2014; VARGO; WIELAND; AKAKA, 2015).

Nesse sentido, o ambiente institucional afeta a definição de inovações e de práticas verdes, estabelecidas pelas organizações, como forma de atender às pressões do ambiente institucional e manter-se competitiva (BERRONE et al., 2013; DE OLIVEIRA et al., 2018; YU LIN; HUI HO, 2008).

Inserida na realidade do crescente número de empresas que estão criando vantagens competitivas e desenvolvendo processos sustentáveis (BERRONE et al., 2013; CHEN, 2008), 
em meio a regulamentações cada vez mais rígidas e maior consciência dos consumidores (SARKIS; GONZALEZ-TORRE; ADENSO-DIAZ, 2010), a discussão acerca das práticas verdes e da inovação ganha importância para as empresas de manufatura (BERRONE et al., 2013; CHEN; LAI; WEN, 2006; CHIOU et al., 2011), pois ela aponta para uma vantagem competitiva, obtida pelo foco na inovação de produtos e de processos verdes, bem como em suas consequências para: economia de custos, melhor eficiência, produtividade, qualidade de produto, reputação da empresa e maiores oportunidades de entrada em novos mercados (CHIOU et al., 2011).

Para o desenvolvimento das ecoinovações, as pressões das regulamentações e dos clientes são tidas como os principais direcionadores de estratégias (BOONS et al., 2013; HOJNIK; RUZZIER, 2016; HUANG et al., 2016) para atender aos propósitos financeiros da organização e obter a legitimidade social (SUCHMAN, 1995).

Impulsionando a ecoinovação organizacional, em $\mathrm{P} \& \mathrm{D}$, e em produtos e processos (HOJNIK; RUZZIER, 2016), a pressão regulatória leva a organização a adquirir tecnologia ambientalmente amigável, para controle e prevenção ambiental (SHARMA, 2000; SHARMA; PABLO; VREDENBURG, 1999; VERBEKE; BUYSSE, 2003), na mesma medida em que os consumidores mais conscientes cada vez mais desejam produtos resultantes de processos de manufatura mais flexíveis, sendo baratos e com menor consumo de insumos (SEGARRAONA; PEIRO-SIGNES; PAYA-MARTINEZ, 2014).

Por meio das hipóteses H2a e H3a (Quadro 9), foi analisado se as inovações frugais têm papel de interação sobre as relações do ambiente institucional (pressões regulatória e do mercado consumidor).

Quadro 10 - Resumo dos resultados das hipóteses H2a e H3a

\begin{tabular}{|l|l|r|}
\hline Hipótese & \multicolumn{1}{|c|}{ Descrição } & Status \\
\hline H2a & $\begin{array}{l}\text { Quanto maior o efeito da moderação da inovação frugal, maior é a relação entre } \\
\text { a pressão regulatória e a orientação estratégica para a ecoinovação. }\end{array}$ & Não suportada \\
\hline H3a & $\begin{array}{l}\text { Quanto maior o efeito da moderação da inovação frugal, maior é a relação entre } \\
\text { a pressão do mercado consumidor e a orientação estratégica para a ecoinovação. }\end{array}$ & Não suportada \\
\hline
\end{tabular}

Fonte: Autora.

Os resultados obtidos para a amostra total, de países emergentes e desenvolvidos, confirmam os estudos em que ambas, pressão regulatória e pressão do mercado consumidor, influenciam a orientação estratégica para a ecoinovação (CHEN; LAI; WEN, 2006; FUENFSCHILLING; TRUFFER, 2014; VARGO; WIELAND; AKAKA, 2015). No entanto, 
analisada a interação da inovação frugal nessas relações, as hipóteses propostas de maior influência do ambiente institucional sobre as dimensões de funcionalidade central, da redução de custos e da criação de ecossistema sustentável na organização, não foram suportadas.

Para as hipóteses relacionadas à pressão regulatória, os resultados indicam que o fato de as organizações, em sua estratégia de ecoinovação, serem mais ou menos frugais, não impacta na força da orientação para a ênfase e a criação de iniciativas verdes, a partir da pressão para atender aos padrões de emissão de poluentes e de produção tecnológica, reduzir os riscos legais e respeitar à supervisão governamental.

Quanto à pressão do mercado consumidor, devido à maior conscientização sobre as questões ambientais e às preferências por empresas e produtos ecologicamente corretos, que influenciam a orientação estratégica para a ecoinovação nas empresas, os resultados também demonstram que ser mais ou menos frugal não interfere para que essa pressão seja exercida de forma mais efetiva, ou que auxilie a organização a ter maior orientação estratégica para a ecoinovação.

Estudos anteriores atestaram a influência da inovação frugal sobre o design de produtos e serviços, para atender às pressões sociais pela integração de sustentabilidade nas operações das organizações (CUNHA et al., 2014; RAO, 2017a), bem como na diminuição dos custos de penalização da poluição, quando a organização atende às regulamentações ambientais (CAI; LI, 2018).

No caso de inovações de tecnologia para a produção limpa, a importância da estratégia de redução de custos operacionais, presente na inovação frugal, e o fortalecimento da imagem ambiental da organização, por meio da adoção da contenção de uso de matéria-prima, demostraram ser direcionadores de inovação mais importantes do que a pressão da regulação ambiental exercida sobre as empresas (ARUNDEL; KEMP, 2009; HORBACH, 2008; KEMP; PONTOGLIO, 2011).

Os resultados apontados nesta pesquisa, no entanto, demonstram que a interação das dimensões da inovação frugal (se a organização é mais ou menos frugal) não é significativa na relação entre a pressão regulatória ou de mercado consumidor e a orientação estratégica para a ecoinovação.

A literatura demonstra que o processo de transformação da manufatura em padrões verdes passa por mudanças nos níveis operacionais, de processos, estratégico e de gestão da organização (DEIF, 2011). Essas mudanças são motivadas por: compromisso executivo, processos verdes, implementação de atividades de design, processo de compras verdes, 
soluções voltadas à logística reversa, envolvimento e capacitação de funcionários, tendências de legislações, valor para o acionista e opinião pública (MITTAL; SANGWAN, 2014).

Diante de tais motivadores, e na busca pela competitividade, as organizações consideram a orientação estratégica para a ecoinovação um fator relevante para atender às expectativas de mercado e às legislações e normas, e para gerar progresso de suas medidas de desempenho (JANSSON, 2011). No modelo conceitual, os autores tratam como resultados decorrentes das tratativas dos fatores críticos, na implementação das práticas de manufatura verde: o desempenho financeiro e operacional, a vantagem competitiva, a melhoria contínua das operações, os resultados financeiros positivos aos acionistas, e o aprimoramento do desempenho da cadeia verde de suprimentos (REHMAN; SETH; SHRIVASTAVA, 2016).

Entre as medidas de desempenho, os resultados da relação entre a implementação e a presença de práticas de manufatura verde, em suas perspectivas operacional e organizacional, têm sido amplamente discutidos e relacionados, na literatura, ao desempenho ambiental (CALANTONE; GARCIA; DROGE, 2003; FAMIYEH et al., 2018; MELNYK; SROUFE; CALANTONE, 2003; MONTABON; SROUFE; NARASIMHAN, 2007).

Os resultados desta pesquisa corroboram a influência da manufatura verde para a competitividade da organização, representada por seus desempenhos organizacional e operacional - visão consolidada por estudos anteriores, quando as organizações estão direcionadas a orientar, investir e implementar ações de evolução da sua atuação ambiental.

Como resultado da estratégia ambiental adotada, a manufatura verde parte do redesenho de processos de produção, e da substituição dos insumos utilizados por outros menos poluentes, incorrendo na diminuição dos impactos ambientais gerados por sua operação (DAI; CANTOR; MONTABON, 2017). Ao melhorar a eficiência operacional, há menor desperdício global e redução dos custos operacionais (CLOSS; SPEIER; MEACHAM, 2011), proporcionando à organização aumento do lucro e maior participação de mercado. Se essas ações forem alinhadas às expectativas de produtos ambientais dos clientes (HSU; TAN; ZAILANI, 2016), haverá, consequentemente, maior competitividade (KLEINDORFER; SINGHAL; WASSENHOVE, 2005; PRZYCHODZEN; PRZYCHODZEN, 2015; TESTA; IRALDO, 2010).

Dessa forma, ao estabelecer estratégias de melhoria de desempenho ambiental, as organizações obtêm avanços no seu desempenho geral (INIGO; ALBAREDA, 2019; RAMANATHAN, 2018). Especificamente, há melhoria nos aspectos de retorno sobre as vendas, os investimentos e os ativos, gerados pela diferenciação de mercado, com produtos ambientalmente sustentáveis; e no uso de tecnologia avançada, para controle da poluição e a gestão de riscos ambientais (INIGO; ALBAREDA, 2019). Ou seja, quanto mais envolvidas em 
práticas de manufatura verde, maior o desempenho operacional (CAI; LI, 2018; SROUFE, 2003); e quanto mais integradas essas práticas estiverem à gestão ambiental, melhor os resultados de desempenho da organização (VIJAYVARGY; THAKKAR; AGARWAL, 2017).

Embora estudos anteriores tenham apresentado impacto positivo da manufatura verde e medidas de desempenho econômico, moderadas por práticas de gestão da cadeia sustentável, como o just in time e a gestão da qualidade total (TQM - Total Quality Management) (MADITATI et al., 2018), eles não trataram da moderação da inovação frugal na relação entre a manufatura verde e o desempenho operacional e organizacional; daí o ineditismo e a contribuição desta pesquisa.

A influência da manufatura verde no desempenho das organizações é confirmada pela literatura, sendo que, nos resultados desta pesquisa, essa relação foi analisada por meio da hipótese H4a (Quadro 10).

Quadro 11 - Resumo do resultado da hipótese H4a

\begin{tabular}{|l|l|r|}
\hline Hipótese & \multicolumn{1}{|c|}{ Descrição } & Status \\
\hline H4a & $\begin{array}{l}\text { Quanto maior o efeito de moderação da inovação frugal, maior é a relação entre } \\
\text { a manufatura verde e o desempenho das organizações. }\end{array}$ & Não suportada \\
\hline
\end{tabular}

Fonte: Autora.

A literatura, que trata da relação entre a manufatura verde e o desempenho organizacional, destaca a redução de custos como a principal razão para implementar a manufatura verde na organização (HASAN, 2013), seja nos custos de fabricação, seja na atenuação dos custos com penalidades e multas (SHRIVASTAVA, 1995).

Esperava-se, pois, que, na existência da inovação frugal na organização, com a redução de custos como uma de suas dimensões, ocorresse o aumento da força da relação entre esses construtos. Ou seja, que organizações com práticas de manufatura verde implementadas, e com maior incidência de inovação frugal, tivessem melhor resultado em desempenho do que as organizações em que as dimensões da inovação frugal estão menos presentes.

Os resultados dos testes de hipóteses demonstram que, apesar do efeito significativo e positivo nos resultados da moderação das organizações mais e menos frugais na relação entre a manufatura verde e o desempenho, não há evidências estatísticas que haja diferenças entre esses grupos. 


\subsection{ANÁlisE E IMPLICAÇÕES ENTRE MERCADOS EMERGENTES E DESENVOLVIDOS}

A discussão de capacidades em inovação para negócios direcionados por soluções resultantes de inovações frugais tem sido considerada para a aplicação, tanto em mercados emergentes quanto em desenvolvidos (ANGOT; PLÉ, 2015; GOVINDARAJAN; TRIMBLE, 2014; KHAN, 2016; TIWARI; FISCHER; KALOGERAKIS, 2016). No entanto, são esperados diferentes resultados do modelo de análise, considerando os padrões tecnológicos distintos entre os grupos de países, os vários domínios da ecoinovação (HORBACH, 2016), e as regulamentações específicas, que motivam as inovações em campos emergentes da ecoinovação. (HORBACH, 2016; HORBACH; RAMMER; RENNINGS, 2012). Por isso, para a análise e as implicações entre mercados emergentes e desenvolvidos, foram testadas hipóteses das relações para cada grupo de países.

As hipóteses H1b e H1c (Quadro 11) testaram as relações da orientação estratégica para a ecoinovação e a manufatura verde, moderadas pela inovação frugal, para a amostra de países emergentes e de desenvolvidos.

Quadro 12 - Resumo dos resultados das hipóteses H1b e H1c

\begin{tabular}{|l|l|r|}
\hline Hipótese & \multicolumn{1}{|c|}{ Descrição } & Status \\
\hline H1b & $\begin{array}{l}\text { Quanto maior o efeito de moderação da inovação frugal, maior é a relação entre } \\
\text { a orientação estratégica para a ecoinovação e a manufatura verde, em } \\
\text { organizações de países emergentes. }\end{array}$ & Nuada suportada \\
\hline H1c & $\begin{array}{l}\text { Quanto maior o efeito de moderação da inovação frugal, maior é a relação entre } \\
\text { a orientação estratégica para a ecoinovação e manufatura verde, em } \\
\text { organizações de países desenvolvidos. }\end{array}$ & \\
\hline
\end{tabular}

Fonte: Autora.

Quanto aos mercados emergentes, com a confirmação da hipótese H1b, os resultados corroboram os estudos da inovação frugal para países em desenvolvimento, como forma de alcançar objetivos econômicos, sociais e de sustentabilidade (BASU; BANERJEE; SWEENY, 2013; BREM; IVENS, 2013; BREM; WOLFRAM, 2014; HORN; BREM, 2013; LEVÄNEN et al., 2016).

Para esses países em desenvolvimento, a inovação frugal apresenta relevante impacto na melhoria da poluição do ar, da qualidade de água potável, e da produção de energia (LEVÄNEN et al., 2016), trazendo à tona a perspectiva na qual a inovação frugal possibilita iniciativas de desenvolvimento de produtos verdes (RAO, 2013a; SHARMA; IYER, 2012) e se 
destaca como um mecanismo importante para a contribuição ao desenvolvimento sustentável (BREM, 2017).

O efeito significativo e positivo da moderação da inovação frugal demonstra que, quanto mais a organização atribui importância aos indicadores relativos a essa inovação, maior é a força da relação entre a orientação estratégica para a ecoinovação e a manufatura verde, inserindo a perspectiva de que a inovação frugal, nos países emergentes, pode fortalecer e auxiliar os esforços voltados aos objetivos sustentáveis, diante das inúmeras dificuldades enfrentadas (BASU; BANERJEE; SWEENY, 2013). Além disso, esse resultado reforça a ideia de que a inovação frugal pode ser um impulso à sustentabilidade, ainda não explorada em sua totalidade pela organização (WOHLFART et al., 2015).

Diante de pressões externas, seja de regulamentos, seja de consumidores, envolvendo a orientação estratégica voltada à ecoinovação, a inovação frugal desponta como fator de evolução à operacionalização dessas estratégias, tornando-as práticas produtivas, por meio do empenho dedicado: à reorganização dos recursos disponíveis para a redução de custos (WEYRAUCH; HERSTATT, 2016), ao desenvolvimento focado na simplicidade de soluções; à valorização pelo usuário final, quanto à engenharia (FAROOQ, 2017) e à entrega de soluções ambientais eficientes (ROSSETTO; BORINI, 2017; SANTOS; BORINI; OLIVEIRA JÚNIOR, 2020).

A confirmação da hipótese H1b também traz a reflexão sobre a evolução do papel da inovação frugal nos países emergentes. Inicialmente desenvolvidas para preencher os vazios institucionais desses países, em sua primeira geração, o modelo da inovação frugal esteve centrado em atender às necessidades e ao contexto da base da pirâmide, desenvolvendo serviços acessíveis, adequados e adaptados àquela realidade (BASU; BANERJEE; SWEENY, 2013). Nessa perspectiva, as organizações estão orientadas à inovação frugal, promovendo soluções de proposição tecnológica para atender às limitações financeiras desses mercados (SANTOS; BORINI; OLIVEIRA JÚNIOR, 2020).

Ao encontrar resultados positivos da interação da inovação frugal aos propósitos de sustentabilidade ecológica da organização, argumenta-se que a inovação, para esses países, pode representar a terceira geração no uso inteligente de recursos, com fins de superar restrições e direcionar produtos e serviços, que incorporem design, funcionalidade, qualidade e preços (COLLEDANI et al., 2016). Dessa forma, além das características iniciais de custos, centralidade em funcionalidades básicas e no nível de desempenho otimizado, houve também uma expansão da proposição de valor das inovações, que passou de apenas econômico para 
social, econômico e ambiental, evoluindo, assim, para uma estratégia de inovação frugal, ou para uma orientação de inovação frugal com valor compartilhado.

Evoluir para uma atuação alinhada a uma estratégia de inovação frugal representa igualmente a evolução dos mercados, localizados em países emergentes, que podem atender adicionalmente aos países desenvolvidos, alcançada pelas inovações de produtos e de processos desenvolvidos pela organização. Com foco em seu conceito principal, as inovações frugais na terceira geração demonstram a sua transferência de países emergentes para os desenvolvidos (WEYRAUCH; HERSTATT, 2016), incluindo as soluções voltadas à sustentabilidade (SHAN; KHAN, 2016).

Alguns estudos ajudam a compreender o caminho e as motivações dessa evolução, relacionada ao desenvolvimento de soluções com aspectos ambientais e a participação desses países em redes globais de inovação. A literatura recente de inovação frugal tem apontado soluções desenvolvidas com princípios de atenuação de impacto ambiental, com o uso de fontes de energia sustentáveis, o menor consumo de matéria-prima e a diminuição de resíduos de produção (DRESSLER; BUCHER, 2018; HOSSAIN, 2017; LEVÄNEN et al., 2016; URPELAINEN, 2016). Isso confirma que as abordagens de desenvolvimento de produtos de base frugal, em países como China e Índia, têm o potencial de mudar os modelos tradicionais de desenvolvimento de produtos verdes (SHARMA; IYER, 2012).

Inseridas em redes e cadeias globais de inovação e de produção, as organizações, em países em desenvolvimento, estão sujeitas a atender aos padrões, às regras e aos regulamentos internacionais ambientais, impulsionando as atividades de sustentabilidade e as inovações na cadeia de suprimentos de inovação (SHIBIN et al., 2018; ZHU; SARKIS, 2006; ZHU; SARKIS; LAI, 2007a).

$\mathrm{Na}$ Índia, por ser um centro de produção e de fornecimento de bens e de serviços, isso resultou em uma expansão da performance competitiva da base industrial de manufatura (SETH; TRIPATHI, 2005, 2006), motivada por maior consciência verde, novas exigências de qualidade (REHMAN; SETH; SHRIVASTAVA, 2016), e políticas de incentivo para a atrair investimentos estrangeiros diretos à inovação (SETH; PANIGRAHI, 2015).

Reflexos nos esforços sustentáveis dessa participação nas cadeias de produção são identificados também na China e em Ghana. Apesar das discussões de soluções de manufatura verde serem recentes nas organizações chinesas (REHMAN; SETH; SHRIVASTAVA, 2016; YANG et al., 2019), o país se tornou o maior investidor em energia renovável no mundo (PANSERA, 2013), e tem adotado práticas de manufatura verde e de gestão ambiental para atender às pressões regulamentares e de clientes, para a exportação (LAI; WONG, 2012; ZHU; 
SARKIS; LAI, 2013). Para Ghana, o aumento do desempenho em entregas, o custo e a flexibilidade necessários à participação em redes globais, decorrem das práticas verdes na manufatura nas organizações (FAMIYEH et al., 2018).

A análise da literatura e os resultados desta pesquisa permitem argumentar que a evolução das competências desenvolvidas pela inovação frugal, com o objetivo de superar o contexto de restrições, deram condições a esses países de atender a mercados emergentes e desenvolvidos. Estando inseridas nas redes globais, as organizações têm que seguir os regulamentos e as exigências ambientais internacionais e, quanto mais presentes as competências da inovação frugal, melhores os resultados obtidos em orientação estratégica para a ecoinovação e, por extensão, mais práticas de manufatura verde realizadas.

Os resultados da hipótese H1c expõem a diferença entre os mercados emergentes e os desenvolvidos, quanto ao papel da inovação frugal. Os estudos para mercados desenvolvidos indicam que há conexão entre a inovação frugal e resultados ecológicos, no que diz respeito ao potencial para contribuir com o desenvolvimento sustentável, pelo uso reduzido de recursos, a substituição de práticas, e com fins de incentivar a suficiência das operações de produção (KHAN, 2016; ROSCA; ARNOLD; BENDUL, 2017; WEYRAUCH; HERSTATT, 2016).

Apesar desses estudos, a análise dos resultados desta pesquisa para os países desenvolvidos confirmam que o foco dessa inovação ainda está nos países emergentes (ALBERT, 2019). A interação da inovação frugal com a orientação estratégica para a ecoinovação e a manufatura verde, nos países desenvolvidos, não apresenta a mesma oportunidade de alcance ou o fortalecimento das relações voltadas aos objetivos sustentáveis, que ocorre em países emergentes.

Logo, a hipótese H1c não foi suportada, pois, para os mercados desenvolvidos, apesar da comprovada consciência ecológica e social, busca-se por uma vida voltada a produtos mais simples e com qualidade (COLLEDANI et al., 2016; MATZLER et al., 2014). Desse modo, a relação entre a orientação estratégica para a ecoinovação e as práticas de manufatura verde varia, em sua força, independentemente da interação das dimensões da inovação frugal. Ou seja, mesmo que a organização desempenhe a inovação frugal, com foco em reduzir seus custos, desenvolver produtos de fácil uso, com qualidade e que tenham aspectos sustentáveis, essas inovações não possuem a propriedade de melhorar a relação estratégica com as práticas produtivas.

Esse resultado diverge do encontrado por Albert (2019), na revisão da literatura, em que a inovação frugal é responsável por efeitos positivos na sustentabilidade ecológica nos países desenvolvidos e emergentes. Porém, o mesmo autor também argumenta sobre as ameaças da 
inovação frugal, considerando que, em mercados emergentes, a inovação encontra um ambiente característico de restrição de recursos e de busca pela acessibilidade, que proporciona uma maior amplitude de uso da inovação frugal, diferentemente do ambiente mais maduro e estável, encontrado nos mercados desenvolvidos.

A ausência de significância da interação da inovação frugal na relação entre a orientação estratégica para a ecoinovação e a manufatura verde pode ser pensada sob a perspectiva da ameaça que a inovação frugal representa para esses mercados, quanto à canibalização e ao efeito rebote (ALBERT, 2019). Considerando a ameaça de os clientes substituírem produtos de maior valor por inovações frugais, reduzindo receita e volume de vendas, ou do maior consumo de produtos, devido à maior acessibilidade e, consequentemente, o aumento do uso de energia e de material, as inovações frugais, nesses mercados, não teriam como objetivo estratégico principal a entrega de produtos ecológicos. Isso se dá porque, para esses mercados, o foco está nos benefícios de sustentabilidade econômica, alcançados pela redução de custos de produção, e nos aspectos sociais, sem exercer influência no desenvolvimento voltado à economia de recursos (WOHLFART et al., 2015) e, por conseguinte, sem influenciar significativamente as relações de alcance dos objetivos sustentáveis.

Com significativo impacto na escolha das estratégias, as pressões do mercado consumidor e regulatória (CHEN; LAI; WEN, 2006) têm efeitos distintos na promoção do direcionamento ambiental das organizações, quando são comparados os mercados emergentes e desenvolvidos (HORBACH, 2016; HORBACH; RAMMER; RENNINGS, 2012; HUANG et al., 2016). Sendo assim, os testes e a análise da relação das pressões institucionais na orientação estratégica para a ecoinovação, nesta pesquisa, consideraram separadamente esses mercados.

Por meio das hipóteses H2b e H2c, e H3b e H3c (Quadro 12), foi analisado se as inovações frugais têm papel de interação sobre as relações do ambiente institucional (pressão regulatória e pressão do mercado consumidor), quando analisados os países emergentes e os desenvolvidos.

Quadro 13 - Resumo dos resultados das hipóteses H2b e H2c, H3b e H3c

(continua)

\begin{tabular}{|l|l|r|}
\hline Hipótese & \multicolumn{1}{|c|}{ Descrição } & Status \\
\hline H2b & $\begin{array}{l}\text { Quanto maior o efeito de moderação da inovação frugal, maior é a relação entre } \\
\text { a pressão regulatória e a orientação estratégica para a ecoinovação, em } \\
\text { organizações de países emergentes. }\end{array}$ & suportada \\
\hline H2c & $\begin{array}{l}\text { Quanto maior o efeito de moderação da inovação frugal, maior é a relação entre } \\
\text { a pressão regulatória e a orientação estratégica para a ecoinovação, em } \\
\text { organizações de países desenvolvidos. }\end{array}$ & Não suportada \\
\hline
\end{tabular}


Quadro 14 - Resumo dos resultados das hipóteses H2b e H2c, H3b e H3c

\begin{tabular}{|l|l|c|}
\hline H3b & $\begin{array}{l}\text { Quanto maior o efeito de moderação da inovação frugal, maior é a relação entre } \\
\text { a pressão do mercado consumidor e a orientação estratégica para a ecoinovação, } \\
\text { em organizações de países emergentes. }\end{array}$ & Não suportada \\
\hline H3c & $\begin{array}{l}\text { Quanto maior o efeito de moderação da inovação frugal, maior é a relação entre } \\
\text { a pressão do mercado consumidor e a orientação estratégica para a ecoinovação, } \\
\text { em organizações de países desenvolvidos. }\end{array}$ & Não suportada \\
\hline
\end{tabular}

Fonte: Autora.

Os resultados obtidos confirmam os estudos para mercados emergentes, que indicam a pressão regulatória como predecessora na construção da cultura gerencial de ecoinovação (HUANG et al., 2016), na atração de investimentos em P\&D (YANG; TSENG; CHEN, 2012), na transferência de tecnologia e no desenvolvimento das práticas de produção (CHAKRABORTY; CHATTERJEE, 2017).

Diante da imagem de organizações poluidoras, em mercados emergentes, como a China, as regulamentações passaram a desempenhar um importante papel no estabelecimento de estratégias de ecoinovação, com a finalidade de recuperar a imagem (CHEN, 2008; ZHU; SARKIS; LAI, 2013) e atender às exigências para atingir o mercado internacional (LAI; WONG, 2012; ZHU; SARKIS; LAI, 2013).

Quanto à pressão do mercado consumidor, apesar de ela exercer um impacto direto em desenvolvimento de $\mathrm{P} \& \mathrm{D}$ e nas redes de colaboração, no desempenho ambiental, seu efeito é indireto, não chegando a afetar as estratégias de ecoinovação (HUANG et al., 2016). Para esses mercados, a consciência ambiental dos consumidores ainda é ausente ou não significativa, devido ao baixo padrão de renda para adquirir produtos ecológicos, ou ao baixo padrão de vida, sem alinhamento com as questões ambientais (LI, 2014; MATHIYAZHAGAN; SENGUPTA; MATHIVATHANAN, 2019).

No cenário de mercados emergentes, em contrapartida, como o obtido para a amostra total de países, não há evidências estatísticas nos resultados para afirmar que a inovação frugal pode exercer efeito moderador nessas relações. Dessa modo, ela não influencia, de forma significativa, em como as regulamentações e as penalidades ambientais são tratadas organizacionalmente.

A partir da literatura existente, em que a pressão regulatória das regulamentações ambientais proporciona maior investimento em $\mathrm{P} \& \mathrm{D}$, aumento na transferência de tecnologia, e desenvolvimento de práticas de produção verde (CHAKRABORTY; CHATTERJEE, 2017; YANG; TSENG; CHEN, 2012), e maior eficiência energética (RAO, 2013a) nos mercados 
emergentes, pode-se supor a possibilidade de a inovação frugal ser precedida pela pressão regulatória, não por um construto que atue moderando a relação entre essa pressão e a orientação estratégica para a ecoinovação.

Por meio da hipótese H2c, foi testado o efeito moderador da inovação frugal na relação da orientação estratégica para a ecoinovação, em países desenvolvidos. Inicialmente, os resultados relativos à pressão dos clientes confirmaram estudos anteriores, mas não a influência da pressão regulatória, visto que, nesses países, ela é significativa nas estratégias de ecoinovação para a economia de custos, relacionados à energia limpa (ARIMURA et al., 2016) e ao uso de materiais avançados e de energia (HORBACH, 2016; HORBACH; RAMMER; RENNINGS, 2012).

Ao mesmo tempo, esperava-se, para esses mercados, que, à medida que os regulamentos ficassem mais rigorosos, maior seria o investimento das organizações em suas operações para atingir a conformidade, tornando-se ambientalmente proativas em suas estratégias (FERRONVILCHEZ; DE LA TORRE-RUIZ; ORTIZ-DE MANDOJANA, 2015), resultando em diferentes tipos de ecoinovação (HOJNIK; RUZZIER, 2016).

No entanto, nos últimos anos, a literatura têm apontado para o impacto que o posicionamento político dos governantes dos países pode ter no desenvolvimento sustentável, como ocorre com os governos republicanos nos Estados Unidos, por exemplo, que ocasionaram a reversão das políticas ambientais, enfraquecendo a pressão regulatória que elas poderiam exercer sobre as estratégias organizacionais (HEJNY, 2018).

Essas evidências respondem ao questionamento da análise de Bomberg (2017) sobre os primeiros 100 dias de governo de Donald Trump, ao prever ausência de força das regulamentações para obter orçamentos federais para $\mathrm{P} \& \mathrm{D}$, ou apoio tecnológico à tecnologia limpa, podendo retardar tendências positivas nas áreas de eficiência energética e de diminuição da emissão de carbono.

Nesse contexto, a pressão do mercado consumidor, sob a forma dos grupos de defesa ambiental, pode funcionar como o principal instrumento contra a contenção e o colapso das políticas ambientais (HEJNY, 2018). Os resultados da pesquisa confirmam que o direcionamento dos clientes na busca por uma reputação ambiental da organização, e a disposição em pagar por produtos que sejam ambientalmente amigáveis, influenciam a orientação estratégica para a ecoinovação (CARTER; KALE; GRIMM, 2000; FLORIDA, 1996).

O mercado consumidor, cada vez mais consciente dos riscos ambientais do consumo e do uso dos recursos, tem formado socialmente novas expectativas quanto aos produtos e 
serviços adquiridos (DORAN; RYAN, 2016; KESIDOU; DEMIREL, 2012), exercendo seu poder de pressão para a moldagem de novas estratégias organizacionais, que considerem e incorporem seus interesses nas condutas das empresas, em relação ao desempenho sustentável e ao impacto ambiental (IRANMANESH et al., 2019).

Quanto a esse cenário de mercados desenvolvidos, como o obtido para a amostra total de países (desenvolvidos e emergentes), não há evidências estatísticas nos resultados para afirmar que a inovação frugal pode exercer efeito moderador nessas relações. Como consequência, a hipótese $\mathrm{H} 2 \mathrm{c}$ não pôde ser suportada.

De forma análoga à discussão realizada para a hipótese H1c, os resultados demonstram que as organizações reconhecem a inovação frugal em suas atividades, porém, o reflexo dos aspectos de custo, funcionalidade e ecossistema, nas questões relacionadas às pressões do ambiente institucional (regulatória e do mercado consumidor), não tem efeito sobre a orientação estratégica para a ecoinovação.

Considerando a influência, confirmada na literatura e nos resultados desta pesquisa, da manufatura verde no desempenho das organizações, por meio das hipóteses H4b e H4c (Quadro 13), foi analisado se as inovações frugais têm papel de interação sobre a relação da manufatura verde com o desempenho das organizações.

Quadro 15 - Resumo dos resultados das hipóteses H4b e H4c

\begin{tabular}{|l|l|r|}
\hline Hipótese & \multicolumn{1}{|c|}{ Descrição } & Status \\
\hline H4b & $\begin{array}{l}\text { Quanto maior o efeito de moderação da inovação frugal, maior é a relação entre } \\
\text { a manufatura verde e o desempenho, em organizações de países emergentes. }\end{array}$ & Não suportada \\
\hline H4c & $\begin{array}{l}\text { Quanto maior o efeito de moderação da inovação frugal, maior é a relação entre } \\
\text { a manufatura verde e o desempenho, em organizações de países desenvolvidos. }\end{array}$ & Não suportada \\
\hline
\end{tabular}

Fonte: Autora.

Os resultados confirmam os estudos dos impactos desses fatores no desempenho operacional e organizacional, em mercados desenvolvidos (SANNI, 2018; XIAO et al., 2018) e emergentes (FAMIYEH et al., 2018; ZHU; SARKIS; LAI, 2007b). Para países emergentes, a evolução do desempenho é resultado: das mudanças verdes no modelo de produção (SETH; TRIPATHI, 2005, 2006); do design de produtos, que contemplam o reuso, a reciclagem e a recuperação; do comprometimento com as certificações ambientais (ZHU; SARKIS, 2004); do desenvolvimento, aliado à maior consciência verde; e da busca por qualidade de produtos ambientais pelos consumidores (REHMAN; SETH; SHRIVASTAVA, 2016). 
De forma análoga, para os países desenvolvidos, a manufatura verde apresenta-se como fator para a competitividade, ao associar diferentes tipos de práticas de fabricação sustentáveis a resultados competitivos distintos, como a redução dos custos (KUMAR; TEICHMAN; TIMPERNAGEL, 2012; RUSINKO, 2007), e a oportunidade de aumento da qualidade de produtos e de processos (AGARWAL et al., 2016).

Assim como na amostra total de organizações, para aquelas com apenas países desenvolvidos ou emergentes, a presença de estratégias de inovação frugal não interage de forma significativa na relação, ao ponto de impactar a força com que as práticas ambientais de produção podem melhorar o desempenho na organização. 


\section{CONCLUSÕES E CONSIDERAÇÕES FINAIS}

Diante do cenário de discussão das capacidades das organizações e dos governos em alcançar crescimento econômico, ao mesmo tempo em que lidam com a escassez (DRESSLER; BUCHER, 2018), aumenta a importância de investigar, em profundidade, se e como as inovações frugais podem estimular o desenvolvimento sustentável (ROSCA; REEDY; BENDUL, 2018).

Estudos relacionados a países emergentes e desenvolvidos já abordam o seu potencial em possibilitar o desenvolvimento sustentável (BHATTACHARYYA et al., 2017; HYVÄRINEN; KESKINEN; VARIS, 2016; KHAN, 2016; KNORRINGA et al., 2016), e a implementação de inovações verdes frugais, em produtos, processos e na cadeia de suprimentos (HYVÄRINEN; KESKINEN; VARIS, 2016; SHARMA; IYER, 2012); e de como mensurar a sustentabilidade ambiental das inovações frugais (KHAN, 2016; LEVANEN et al., 2016), bem como se ela pode ser entendida como estratégia para alcançar as questões sociais e ambientais (MOURTZIS et al., 2016; RAO, 2017a).

Sob regulamentações ambientais cada vez mais rigorosas e a crescente pressão social por produtos ambientalmente amigáveis, as inovações frugais surgem como uma alavanca para atender aos propósitos de desenvolvimento sustentável das organizações, em mercados em desenvolvimento e desenvolvidos (BASU; BANERJEE; SWEENY, 2013; HOSSAIN; SIMULA; HALME, 2016; PISONI; MICHELINI; MARTIGNONI, 2018).

Essas discussões, sobre a relação entre a orientação estratégica, as práticas organizacionais de manufatura verde e os impactos do ambiente institucional, quando essas organizações também possuem estratégias de inovação frugal, ainda são incipientes e devem ser exploradas quanto à importância dos resultados organizacionais (ROSCA; REEDY; BENDUL, 2018).

Sob essa perspectiva, buscou-se, por meio desta pesquisa, contribuir com as discussões que envolvem essa relação, respondendo às questões: (1) As organizações com maior incidência de inovação frugal têm resultados melhores na relação entre a orientação estratégica para a ecoinovação e a manufatura verde? (2) Há diferença entre países emergentes e desenvolvidos, na relação entre as pressões do ambiente institucional, a orientação estratégica, a manufatura verde e o desempenho?

Para respondê-las, três objetivos foram seguidos e alcançados, a saber: (1) a influência das pressões institucionais (de mercado e regulatória) na orientação estratégica para a ecoinovação, em relação à manufatura verde, quanto maior a estratégia de inovação frugal na 
organização; (2) a influência da relação entre a orientação estratégica para a ecoinovação e a manufatura verde no desempenho da organização, quanto maior a estratégia de inovação frugal; e (3) a comparação dos resultados das relações entre as pressões de mercado e regulatória, a orientação estratégica para a ecoinovação e a manufatura verde, em organizações de mercados desenvolvidos e emergentes, quanto maior a estratégia de inovação frugal.

A partir desses questionamentos, foram direcionados os interesses desta pesquisa, utilizando amostras de países emergentes (Brasil e Índia) e desenvolvidos (Alemanha e Estados Unidos da América), em uma análise quantitativa, tendo sido obtidos resultados relevantes para as áreas acadêmicas e gerenciais, conforme está descrito nas conclusões específicas do estudo.

\subsection{CONCLUSÕES ESPECÍFICAS}

O objetivo deste estudo é fornecer um nova visão sobre o efeito moderador da inovação frugal (IF), na relação entre a orientação estratégica para a ecoinovação (OEI) e a manufatura verde (MV); e, como consequência, nos demais construtos, ou seja, na relação das pressões do ambiente institucional (PR e PC) sobre a orientação estratégica para a ecoinovação (OEI), a manufatura verde (MV) e o desempenho da organização (DS).

Em primeiro lugar, esta pesquisa enfatiza a relação positiva existente entre os construtos, confirmando as evidências sobre esse tema, identificadas na literatura. Nesse sentido, tanto a pressão regulatória quanto a pressão do mercado consumidor têm impacto positivo e significativo na orientação estratégica para a ecoinovação, que, por sua vez, impacta na manufatura verde. Também é comprovada a influência das práticas de manufatura verde sobre o desempenho da organização.

Em segundo lugar, como foco principal desta pesquisa, o efeito de moderação da inovação frugal indica que as organizações mais frugais têm maior resultado na relação entre a orientação estratégica para a ecoinovação e a manufatura verde, do que as organizações menos frugais. Porém, nas relações entre as pressões do ambiente institucional e a orientação estratégica para a ecoinovação, e entre a manufatura verde e o desempenho, não há evidências que ser mais frugal difere nos resultados obtidos pelas organizações menos frugais.

Independente de setor, a escassez de recursos é uma realidade para as organizações de mercados emergentes ou desenvolvidos, assim como as pressões do ambiente institucional por soluções mais sustentáveis e a busca por competitividade. A análise da amostra total, com os países emergentes e desenvolvidos, demonstra que as organizações mais frugais, por meio de um conjunto, com foco na funcionalidade principal dos produtos, em soluções satisfatórias e de 
baixo custo, no rearranjo dos processos operacionais, na qualidade das soluções e de parcerias com empresas locais, no processo operacional, têm melhor resultado na relação entre a sua orientação estratégica para a ecoinovação e a manufatura verde.

Assim, a partir desses resultados, a inovação frugal se estabelece como potencial alavanca para que as organizações possam melhorar o impacto da orientação estratégica para a construção de uma cultura inovadora e das iniciativas verdes sobre a implementação de práticas de produção voltadas à atenuação do impacto ambiental.

Para essa relação, analisadas as hipóteses propostas, foram encontradas diferenças entre mercados emergentes e desenvolvidos. Para os emergentes, os resultados corroboram os estudos da inovação frugal como forma de alcançar objetivos econômicos, sociais e de sustentabilidade (BASU; BANERJEE; SWEENY, 2013; BREM; IVENS, 2013b; BREM; WOLFRAM, 2014; HORN; BREM, 2013; LEVÄNEN et al., 2016). O efeito significativo e positivo da inovação frugal, como moderadora da relação entre a OEI e a MV, traz a visão de que desenvolver as dimensões da inovação frugal, nesses países, fortalece e auxilia os esforços voltados aos objetivos ambientais, mesmo sob um cenário de restrições e de vazios institucionais. Esse resultado reforça o argumento de que a inovação frugal pode ser um impulso à sustentabilidade ainda não explorada em sua totalidade pela organização (WOHLFART et al., 2015).

Para os países desenvolvidos, por sua vez, não foram encontradas evidências de que ser mais ou menos frugal exerça diferença na relação entre a OEI e a MV, ou seja, para esses mercados, o grau de importância que a organização atribui à IF não apresenta a mesma oportunidade de fortalecimento das relações voltadas aos objetivos sustentáveis, que ocorre em países em desenvolvimento. Assim, ao atribuir maior ou menor importância às dimensões da inovação frugal, esses países não obtêm a melhoria da relação entre a sua orientação estratégica para a ecoinovação e as práticas produtivas ambientais.

A análise da relação das pressões regulatória e de mercado consumidor sobre a orientação estratégica para a ecoinovação confirma os estudos que atestam a influência do ambiente institucional sobre as estratégias para as iniciativas ecoinovadoras (CHEN; LAI; WEN, 2006; FUENFSCHILLING; TRUFFER, 2014; VARGO; WIELAND; AKAKA, 2015). Porém, analisada a interação da inovação frugal nessas relações, as hipóteses propostas de maior influência do ambiente institucional sobre o efeito de maior importância às dimensões de funcionalidade central, de redução de custos e do ecossistema na organização, não foram suportadas. Nas amostras de países emergentes e desenvolvidos, os resultados apresentam 
comportamentos distintos, quanto à influência das pressões ambientais consideradas nesta pesquisa.

Para países emergentes, os resultados confirmam estudos anteriores, sobre a importância da pressão regulatória no papel de predecessora da construção de uma cultura de inovação, da orientação tecnológica voltada à sustentabilidade e, consequentemente, das práticas de produção verde (CHAKRABORTY; CHATTERJEE, 2017). Para esse mercado, também é confirmada a ausência ou a baixa consciência ambiental dos consumidores, na forma de pressão do mercado, para a orientação de estratégias ambientais nas organizações (MATHIYAZHAGAN; SENGUPTA; MATHIVATHANAN, 2019). Sendo assim, a hipótese de efeito da inovação frugal, como moderadora da relação entre a PR e a PC, na OEI, não foi confirmada.

Para mercados desenvolvidos, os estudos anteriores apresentam como resultado de pressões regulatórias mais rigorosas, o desenvolvimento de tecnologias limpas e de tipos de ecoinovação, e o uso de materiais avançados e de energia. Porém, os resultados desta pesquisa divergem desses estudos, não mostrando evidências do papel de predecessora da pressão regulatória. Considerando o papel das diretrizes governamentais no ambiente institucional, o resultado dessa hipótese deve ser pensado quanto à reversão das políticas ambientais, em âmbito federal, nos Estados Unidos da América, no período da coleta de dados desta pesquisa.

Quanto à pressão do mercado consumidor, ela exerce um papel de influência na OEI nos países desenvolvidos, seja pela existência de consciência ambiental dos clientes (DORAN; RYAN, 2016), seja como defesa contra a contenção das políticas ambientais (HEJNY, 2018). Assim, a hipótese de efeito da inovação frugal como moderadora da relação entre a PR e a PC, na OEI, para esses países, também não foi confirmada.

Os resultados das hipóteses, propostas para o efeito da IF na relação entre a MV e o DS, indicaram, igualmente, que elas não foram suportadas. Sendo a redução de custos uma das dimensões da inovação frugal, esperava-se que, quanto maior a importância dessas dimensões para a organização, maior a influência no seu desempenho. Apesar dos resultados da amostra total e das amostras de países desenvolvidos e em desenvolvimento confirmarem os estudos positivos dessa relação, entre a MV e o DS, nos aspectos organizacionais e operacionais (FAMIYEH et al., 2018; SANNI, 2018; XIAO et al., 2018), não foram encontradas evidências de que a maior ou menor interação da inovação frugal tenha impacto sobre a força ou a direção dessa relação. 
Os resultados descritos respondem à pergunta de pesquisa proposta, e apresentam contribuições acadêmicas, gerenciais e para políticas públicas, conforme está apontado na seção a seguir.

\subsection{CONTRIBUIÇÕES DE PESQUISA}

A contribuição desta tese pode ser avaliada sob três aspectos específicos, sendo que, em primeiro lugar, ela contribui com a teoria acadêmica sobre o papel da inovação frugal para o fortalecimento da relação entre a orientação estratégica para a ecoinovação e a manufatura verde. Ou seja, ao adotar uma estratégia de inovação frugal, que tenha proposição de valor econômico, social e ambiental, voltada a países desenvolvidos e em desenvolvimento, as organizações têm melhor condições para que as estratégias orientadas à redução e à preservação de recursos ambientais obtenham maior impacto sobre as práticas da manufatura verde.

Alinhada a esse propósito, ao utilizar países emergentes e desenvolvidos, a pesquisa demonstra o potencial do conceito para além das fronteiras geográficas, isto é, como forma de suprir necessidades financeiras e sociais, e também de se projetar como solução para impulsionar o crescimento sustentável nesses países (AGARWAL; BREM; DWIVEDI, 2019; ALBERT, 2019; BREM, 2017).

Os resultados contribuem, ao propor que a inovação frugal pode auxiliar na diminuição das barreiras para a implantação de aspectos da gestão da cadeia de suprimentos verdes (Green Supply Chain Management - GSCM), e por preencher a lacuna de estudos comparativos entre diferentes países, com legislações, incentivos regulatórios e relação com mercado, específicas nas análises das práticas de manufatura verde (DE OLIVEIRA et al., 2018).

Diante da necessidade de estudos que apresentem fatores que possam influenciar na implementação das práticas de manufatura, quanto à reutilização e à preservação de recursos naturais (JABBOUR et al., 2014), a inovação frugal é inserida no cenário dos estudos de GSCM, com potencial de inserção também nos estudos de gestão de cadeias de suprimentos sutentáveis (Sustainable Supply Chain Management - SSCM), em razão de suas dimensões econômica, social e ambiental. Então, em suma, a inovação frugal é apresentada como fator que pode influenciar a implementação das práticas de manufatura, no que diz respeito à reutilização e à preservação de recursos naturais (JABBOUR et al., 2014).

Em segundo lugar, esta pesquisa confirma os estudos que atestam a importância da inovação frugal para os mercados emergentes, como solução às limitações de recursos, com fins de alcançar estratégias voltadas à sustentabilidade, evidenciando que, para esses países, as 
organizações mais frugais conseguem um melhor resultado na relação entre a orientação estratégica para a ecoinovação e a realização das práticas de manufatura verde. Para as organizações em mercados desenvolvidos, a intensidade da interação de estratégias de inovação frugal não é evidenciada como significativa para a mesma relação.

A consequência dessa interação entre estratégias de inovação frugal nessas relações é a possibilidade de aumento da eficiência energética desses países (AGARWAL et al., 2016; BHATTI, 2012; BHATTI; VENTRESCA, 2013), e meio de recuperação econômica para os emergentes (BHATTI, 2012), bem como para atender à ascensão e às pressões regulatórias e sociais por produtos ecologicamente amigáveis (CUNHA et al., 2014).

Desse modo, este estudo complementa a literatura da teoria institucional (LAWRENCE; SIMON, 2008; SHU et al., 2016; SMINK; HEKKERT; NEGRO, 2015; VARGO; WIELAND; AKAKA, 2015), ao mostrar que os impactos das interações das dimensões da inovação frugal, como estratégia para a organização atender aos seus propósitos socioeconômicos e de sustentabilidade podem ter níveis de estratégia distintos (orientação versus execução), a depender do nível de desenvolvimento do país.

Este estudo oferece também implicações práticas, que atendem a diversas partes interessadas, envolvendo governo, gestores e outros interessados. Os resultados ajudam a compreender as relações complexas entre a sociedade, as empresas e o meio ambiente.

Diante das dificuldades de implementar modelos de negócio de inovação sustentável em países emergentes (BIRKIN et al., 2009; SHRIMALI et al., 2011), esta pesquisa contribui quantitativamente, já que a inovação frugal, originalmente desenvolvida por esses países como resposta às lacunas institucionais (KHANNA; PALEPU; BULLOCK, 2010; TAAL et al., 2012), pode ser utilizada como estratégia pela qual as organizações podem alcançar seus objetivos locais e globais de sustentabilidade e de competitividade (KUO, 2017; SHIBIN et al., 2018; WEYRAUCH; HERSTATT, 2016).

A visão dos fatores que possibilitam alcançar esses objetivos pode auxiliar no entendimento das relações entre as práticas ambientais de fabricação e os resultados competitivos, quanto a custos, qualidade, capacidade de inovação e imagem perante o mercado. Nesse sentido, os resultados relativos às diferenças do ambiente institucional desta pesquisa apresentam quais são os seus elementos direcionadores, nos diferentes grupos de países e, por conseguinte, como devem ser adequadas as estratégias gerenciais voltadas à ecoinovação e à manufatura verde.

Quanto à contribuição para as políticas públicas, os resultados desta pesquisa aprimoram a reflexão sobre o efeito do ambiente institucional, considerando as pressões 
regulatória e dos clientes na orientação estratégica para a ecoinovação; a adoção de políticas que estimulam, suportam e impulsionam o desenvolvimento de inovações ecoinovadoras; e no direcionamento da implementação de práticas de manufatura verde (DORAN; RYAN, 2016; FRANCESCHINI; PANSERA, 2015).

Embora haja uma crescente quantidade de publicações que aplicam o conceito de inovação frugal (PISONI; MICHELINI; MARTIGNONI, 2018), o uso de uma escala para ela e, consequentemente, as análises quantitativas sobre o efeito desse construto não foram aplicadas em um modelo, que abarca a relação da orientação estratégica para a ecoinovação e a manufatura verde, como o realizado por este estudo. Ademais, o conhecimento existente sobre os aspectos ecológicos das inovações frugais está baseado em pesquisas conceituais, necessitando, ainda, de uma abordagem quantitativa (HOSSAIN, 2017).

\subsection{LIMITAÇÕES DE ESTUDO}

Apesar dessa pesquisa entregar contribuições significativas em relação às teorias, às práticas gerenciais e às políticas públicas, ela também apresenta algumas limitações, sendo uma delas referente ao uso de medidas de percepção e não de observação. Tendo sido a coleta realizada por meio de questionários, o fenômeno foi relatado sob a visão ou percepção do respondente, não a partir da sua observação. Embora seja uma limitação, ela é amplamente compreensível, haja vista a dificuldade em se obter dados de observação para a amostra necessária, diante de ausência de tempo hábil para atender aos diversos mercados abordados nesta pesquisa e, por extensão, conseguir acesso ao recurso financeiro correspondente. Devese, então, reconhecer que as medidas de percepção oferecem limitação de validade e de confiabilidade, pois podem apresentar variações de entendimento e de replicabilidade.

Mesmo com os questionários direcionados à C-level, e aos gerentes e proprietários de organizações, existe o risco, reconhecido em pesquisas de uso survey, da veracidade da declaração de cargo dos respondentes. A análise das respostas, porém, indicaram que eles correspondiam, de fato, ao cargo relatado, tendo sido considerados os filtros de seleção de respondentes determinados junto à empresa de coleta de dados.

Diante dos objetivos propostos por esta pesquisa, foram utilizadas empresas de manufatura, sem distinção do setor ao qual elas pertenciam. Isso limitou o conhecimento sobre a existência de setores específicos, nos quais a inovação frugal e as relações de estratégia para a ecoinovação e a manufatura verde têm maior ou menor influência. Considerar um equilíbrio 
de diferentes setores, nesse sentido, poderia dar uma visão mais ampla do efeito de moderação da inovação frugal.

Este estudo considera as pressões externas, isto é, a regulatória e a do mercado consumidor, como determinantes da orientação estratégica para a ecoinovação; todavia, além desses fatores, outros poderiam ser observados, como a turbulência de mercado e a tecnológica, a estrutura organizacional (SOUSA; VOSS, 2008), e fatores internos, como capital humano, apoio organizacional e desenvolvimento das capacidades internas da organização (BERRONE et al., 2013).

Países sofrem pressões regulatórias distintas, mas, nos resultados apresentados, que abarcam as amostras de mercados emergentes e desenvolvidos, elas foram analisadas com base nas mesmas regras, regulamentações e normas. A adoção desse critério apresenta a limitação de não considerar as especificidades regulamentares de cada país.

Em países desenvolvidos, são relevantes as questões de posicionamento político dos governos atuantes, como no caso dos Estados Unidos da América, em que o enfraquecimento da pressão regulatória sobre as organizações é reflexo de mandatos republicanos (HEJNY, 2018). E o histórico de leis relacionadas às questões ambientais, no caso da Alemanha que, motivada pela economia de diversificação, e voltada a reduzir e a reutilizar a quantidade de resíduos gerados, no campo de regulamentos e de leis para a gestão do lixo ambiental, desde 1972, tem encorajado a eliminação total de aterros sanitários, e apoiado a implementação das diretrizes da União Europeia (OGUNMAKINDE, 2019).

Para países emergentes, como o Brasil e a Índia, as políticas de regulação ambiental ainda estão em construção e revisão, com a finalidade de atender amplamente a todos os setores, e obter eficiência na implementação de práticas verdes de produção e de desenvolvimento de produtos. Em terras brasileiras, a última versão da Lei da Política Nacional de Meio Ambiente, de 1981, necessita de revisão para aumentar o rigor e permitir a adoção de práticas de uma produção avançada limpa (AUGUSTO DE OLIVEIRA et al., 2019). Na Índia, apesar da pressão das regulamentações ambientais para o uso de corantes proporcionar maior investimento em $\mathrm{P} \& \mathrm{D}$, e maior transferência de tecnologia e desenvolvimento às organizações locais, nas práticas de produção, ainda há setores com ausência de regulamentação (CHAKRABORTY; CHATTERJEE, 2017).

A sobreposição dos termos utilizados para a ecoinovação e a inovação verde oferece a dificuldade de delimitação desses conceitos, pois há inovações voltadas a atender às necessidades por resultados mais sustentáveis com novos produtos, processos e serviços, tanto na literatura de ecoinovação quanto na de inovação verde. Vale salientar que esta pesquisa foi 
baseada na diferenciação de Schiederig, Tietze e Herstatt (2012), contudo, a literatura de inovação verde também pode ser utilizada para explicar essas relações, por estar alinhada com o conceito adotado.

O construto de inovação frugal considera indicadores das dimensões de custos, funcionalidade e ecossistemas, mas, neste estudo, não foi feita a análise do efeito da inovação frugal em cada uma de suas dimensões, o que ressalta as possibilidades de aprofundamento, em pesquisas futuras.

\subsection{SUGESTÕES DE ESTUDOS FUTUROS}

Os resultados desta pesquisa possibilitam identificar oportunidades para estudos futuros, com fins de aprofundar e expandir o conhecimento sobre o efeito da inovação frugal nas organizações.

Na literatura existente, alguns antecedentes dispersos de ecoinovação já foram propostos e testados empiricamente, tais como os stakeholders regulatórios e os organizacionais (clientes, fornecedores e funcionários), além de grupos e organizações ambientais, meios de comunicação (HORBACH; RAMMER; RENNINGS, 2012), e as inerentes turbulências tecnológicas e de mercado.

Nesse sentido, há uma influência positiva da turbulência das tecnologias verdes para a construção de uma consciência ambiental dos clientes e da inovação verde, em países emergentes (LISI; ZHU; YUAN, 2020), sendo que os resultados desta pesquisa, acerca do efeito da inovação frugal nesses mercados, abrem possibilidade de estudos futuros, com a inclusão de variáveis da turbulência de mercado e tecnológica no modelo ora proposto.

Nesta pesquisa, a inovação frugal foi analisada como moderadora das relações entre a orientação estratégica, a ecoinovação e a manufatura verde. Para mercados emergentes, foi confirmado seu papel como fator de efeito moderador da relação; porém, esse resultado não pôde ser confirmado nos mercados desenvolvidos. Sabendo do crescimento da importância da inovação frugal para esses mercados (PANSERA, 2018; ROSCA; REEDY; BENDUL, 2018), estudos futuros podem analisar esse construto atuando em outros papéis, nessa relação, como mediador entre a orientação estratégica para a ecoinovação e a manufatura verde, por exemplo.

Para a análise da relação entre a manufatura verde e o desempenho, foram considerados o desempenho organizacional e o operacional, mas, como sugestão, pode-se explorar o efeito da inovação frugal sobre tais construtos, de forma desagregada. 
Quanto ao estudo de setores específicos, as relações entre a inovação frugal e o desenvolvimento sustentável podem ser expandidas para setores com a literatura já desenvolvida, como o de energia (BEISE; RENNINGS, 2005; KAMMERER, 2009), de química (THEYEL, 2000), da indústria automobilística (OLTRA; SAINT JEAN, 2009), e da tecnologia (CHEN, 2008; CHEN; LAI; WEN, 2006); e para setores pouco explorados e com altos índices de processos de produção e de produtos que causam impacto ambiental, como o têxtil (DENG et al., 2020) .

Este estudo discutiu os impactos da inovação frugal, sob a perspectiva da sustentabilidade ecológica; no entanto, é possível expandir os resultados encontrados, em pesquisas futuras, para a sustentabilidade social, ou seja, analisar o papel da inovação frugal no aumento da qualidade de vida, nos países desenvolvidos e emergentes.

E, por fim, como extensão dos resultados obtidos, pode-se comparar países emergentes, como Brasil e Índia, com fins de identificar as diferenças e o estágio do desenvolvimento sustentável de cada um deles. 


\section{REFERÊNCIAS}

ABDULRAHMAN, M. D.; GUNASEKARAN, A.; SUBRAMANIAN, N. Critical barriers in implementing reverse logistics in the Chinese manufacturing sector. International Journal of Production Economics, v. 147, p. 460-471, Jan. 2014.

ADNER, R. Ecosystem as Structure: An Actionable Construct for Strategy. Journal of Management, v. 43, n. 1, p. 39-58, Nov. 2016.

AGARWAL, N. et al. A systematic literature review of constraint-based innovations: State of the art and future perspectives. IEEE Transactions on Engineering Management, v. 64, n. 1, p. 3-15, 2016.

AGARWAL, N.; BREM, A. Frugal and Reverse Innovation - Literature Overview and Case Study Insights from a German MNC in India and China. In: INTERNATIONAL

CONFERENCE ON ENGINEERING, TECHNOLOGY AND INNOVATION, 18., Munich. Anais [...]. Munich: IEE, 2012. p. 1-11.

AGARWAL, N.; BREM, A.; DWIVEDI, S. Frugal and Reverse Innovation for Harnessing the Business Potential of Emerging Markets - the Case of a Danish MNC. International Journal of Innovation Management, v. 2050009, p. 1-15, 2019.

AGNIHOTRI, A. Low-cost innovation in emerging markets. Journal of Strategic Marketing, v. 23, n. 5, p. 399-411, Oct. 2015.

AHMAD, N.; RAMZAN, I. The relationship of Green Product Innovation Performance with Corporate Competitive Advantage and Brand Image. Arabian Journal of Business and Management Review (Kuwait Chapter ), v. 7, n. 2, p. 42-51, 2018.

AHMAD, S.; KHAN, T. A.; MITTAL, A. Green Manufacturing helps to control global warming: A critical review. International Journal of Engineering Sciences \& Research Technology, v. 4, n. 2, p. 444-449, 2015.

AHUJA, S.; CHAN, Y. E. Beyond traditional IT-enabled innovation: Exploring frugal IT capabilities. In: AMERICAS CONFERENCE ON INFORMATION SYSTEMS, 20, Savannah, 2014. Anais [...], Savannah, Geórgia, USA, 2014. p. 1-12.

ALBERT, M. Sustainable frugal innovation - The connection between frugal innovation and sustainability. Journal of Cleaner Production, v. 237, p. 117747, 2019.

ALBORT-MORANT, G. et al. Developing green innovation performance by fostering of organizational knowledge and coopetitive relations. Review of Managerial Science, v. 12, n. 2, p. 499-517, Dec. 2018.

ALBORT-MORANT, G. et al. Mapping the Field: A Bibliometric Analysis of Green Innovation. Sustainability, v. 9, n. 6, p. 1011, Nov. 2017.

ALCOTT, B. The sufficiency strategy: Would rich-world frugality lower environmental impact? Ecological Economics, v. 64, n. 4, p. 770-786, Feb. 2008. 
ALVAREZ GIL, M. J.; JIMÉNEZ, J. B.; LORENTE, J. J. C. An analysis of environmental management, organizational context and performance of Spanish hotels. The International Journal of Management Science, v. 29, n. 6, p. 457-471, 2001.

ALVI, S.; AHMED, S.; CHATURVEDI, S. K. Approaching Green Manufacturing in Iron and Steel Industry. International Journal of Mechanical Enginerring and Robotics Research, v. 2, n. 3, p. 108-112, Jul. 2013.

AMBEC, S.; LANOIE, P. Does It Pay to Be Green? A Systematic Overview. Academic Journal of Economic Studies, v. 22, n. 4, p. 45-62, 2008.

AMORES-SALVADÓ, J.; CASTRO, G. M. DE; NAVAS-LÓPEZ, J. E. Green corporate image: Moderating the connection between environmental product innovation and firm performance. Journal of Cleaner Production, v. 83, p. 356-365, 2014.

ANDERSEN, M. M. Frugal innovation and green business models. In: THE INTERNATIONAL SOCIETY FOR PROFESSIONAL INNOVATION MANAGEMENT (ISPIM) INNOVATION SYMPOSIUM, Manchester, 2015. Anais [...]. Manchester, England: ISPIM. p. 1-19.

ANG, S. H.; BENISCHKE, M. H.; DOH, J. P. The Interactions of Institutions on Foreign Market Entry Mode. Strategic Management Journal, v. 36, n. 10, p. 1536-1553, May. 2015.

ANGOT, J.; PLÉ, L. Serving poor people in rich countries: The bottom-of-the-pyramid business model solution. Journal of Business Strategy, v. 36, n. 2, p. 3-15, Apr. 2015.

ANTONIOLI, D.; MAZZANTI, M. Towards a green economy through innovations: The role of trade union involvement. Ecological Economics, v. 131, p. 286-299, Jan. 2017.

ARIMURA, T. H. et al. The effect of ISO 14001 on environmental performance: Resolving equivocal findings. Journal of Environmental Management, v. 166, p. 556-566, Oct. 2016.

ARNOLD, M. G.; HOCKERTS, K. The greening dutchman: Philips' process of green flagging to drive sustainable innovations. Business Strategy and the Environment, v. 20, n. 6, p. 394-407, Oct. 2011.

AROCENA, R.; BO, G.; SUTZ, J. Knowledge policies and universities in developing countries: Inclusive development and the "developmental university". Technology in Society, v. 41, p. 10-20, May. 2015.

ARUNDEL, A.; KEMP, R. Measuring eco-innovation. Maastricht, The Netherlands: United Nations University (UNU) - Maastricht Economic and Social Research and Training Centre on Innovation and Technology (MERIT), 2009. p. 1-40. (Working Paper Series n. \#2009017). Disponível em: https://www.oecd.org/env/consumption-innovation/43960846.pdf. Acesso em: 12 dez. 2020.

AUGUSTO DE OLIVEIRA, J. et al. Cleaner Production practices, motivators and performance in the Brazilian industrial companies. Journal of Cleaner Production, v. 231, p. 359-369, Sept. 2019. 
AZEVEDO, S. G.; CARVALHO, H.; CRUZ MACHADO, V. The influence of green practices on supply chain performance: A case study approach. Transportation Research Part E: Logistics and Transportation Review, v. 47, n. 6, p. 850-871, Nov. 2011.

AZZONE, G.; NOCI, G. Seeing ecology and "green" innovations as a source of change. Journal of Organizational Change Management, v. 11, n. 2, p. 94-111, Apr. 1998.

BAI, C.; SARKIS, J.; DOU, Y. Corporate sustainability development in China: Review and analysis. Industrial Management and Data Systems, v. 115, n. 1, p. 5-40, Feb. 2015.

BANERJEE, S. B. Managerial perceptions of corporate environmentalism: interpretations from industry and strategic implications for organizations. Journal of Management Studies, v. 38, n. 4, p. 489-513, Dec. 2001.

BAS, C. Le. Do non-technological innovations and CSR matter for environmental innovation? An empirical analysis of a sample of innovators. Int. J. Sustainable Development, v. 20, n. 1-2, p. 68-91, Apr. 2017.

BAS, C. Le. Frugal Innovation,Sustainable Innovation, Reverse Innovation: Why do they look like? Why are they different? Journal of Innovation Economics \& Management, v. 21, n. 3, p. 9-26, 2016.

BASU, K.; PALAZZO, G. Corporate Social Resonsability: A Process Model of Sensemaking. Academy of Management Review, v. 33, n. 1, p. 122-136, Jan. 2008.

BASU, R. R.; BANERJEE, P. M.; SWEENY, E. G. Frugal Innovation Core Competencies To Address Global Sustainability Introduction: A Call For Global Sustainability. Journal of Management for Global Sustainability, v. 2, p. 63-82, 2013.

BAUD, I. Moving Towards Inclusive Development? Recent Views on Inequalities, Frugal Innovations, Urban Geo-Technologies, Gender and Hybrid Governance. European Journal of Development Research, v. 28, n. 2, p. 119-129, 2016.

BEISE, M.; RENNINGS, K. Lead markets and regulation: A framework for analyzing the international diffusion of environmental innovations. Ecological Economics, v. 52, n. 1, p. 517, Jan. 2005.

BERRONE, P. et al. Necessity as the mother of "green" inventions: Institutional pressures and environmental innovations. Strategic Management Journal, v. 34, n. 8, p. 891-909, 2013.

BERRY, M. A.; RANDINELLI, D. A. Proactive Corporate Environmental Management. Academy of Management Executive, v. 12, n. 2, p. 38-50, 1998.

BHATTACHARYYA, O. et al. Criteria to assess potential reverse innovations: Opportunities for shared learning between high- and low-income countries. Globalization and Health, v. 13, n. 1, p. 1-8, 2017. 
BHATTI, Y. What is frugal, What is innovation? Towards a theory of frugal innovation. Feb. 2012. Disponível em: https://papers.ssrn.com/sol3/papers.cfm?abstract_id=2005910. Acesso em: 11 dez. 2020.

BHATTI, Y. A.; VENTRESCA, M. How Can 'Frugal Innovation' Be Conceptualized? Jan. 2013. Disponível em: http://dx.doi.org/10.2139/ssrn.2203552. Acesso em: 11 dez. 2020.

BIDO, D. D. S.; DA SILVA, D. SmartPLS 3: especificação, estimação, avaliação e relato. Administração: Ensino e Pesquisa, v. 20, n. 2, p. 488-536, 2019.

BIRKIN, F. et al. New Sustainable Business Models in China. Business Strategy and the Environment, v. 18, n. 1, p. 64-77, 2009.

BOCKEN, N. M. P. et al. A literature and practice review to develop sustainable business model archetypes. Journal of Cleaner Production, v. 65, p. 42-56, 2014.

BOCKEN, N. M. P.; SHORT, S. W. Towards a sufficiency-driven business model:

Experiences and opportunities. Environmental Innovation and Societal Transitions, v. 18, p. 41-61, 2016.

BOMBERG, E. Environmental politics in the Trump era: an early assessment.

Environmental Politics, v. 26, n. 5, p. 956-963, 2017.

BOONS, F. et al. Sustainable innovation, business models and economic performance: An overview. Journal of Cleaner Production, v. 45, p. 1-8, 2013.

BOONS, F.; LÜDEKE-FREUND, F. Business models for sustainable innovation: State-ofthe-art and steps towards a research agenda. Journal of Cleaner Production, v. 45, p. 9-19, 2013.

BOUND, K.; THORNTON, I. Our frugal future: Lessons from India's innovation system. Nesta Operating Company, p. 1-94, Jul. 2012. Disponível em:

https://media.nesta.org.uk/documents/our_frugal_future.pdf. Acesso em: 10 dez. 2020.

BOVE, L. L.; NAGPAL, A.; DORSETT, A. D. S. Exploring the determinants of the frugal shopper. Journal of Retailing and Consumer Services, v. 16, n. 4, p. 291-297, 2009.

BOYER, R. H. W. Grassroots innovation for urban sustainability: Comparing the diffusion pathways of three ecovillage projects. Environment and Planning A, v. 47, n. 2, p. 320-337, 2015.

BRADBURY, S.; MIDDLEMISS, L. The role of learning in sustainable communities of practice. Local Environment, v. 20, n. 7, p. 796-810, 2015.

BREM, A. Frugal Innovation - Past, Present, and Future. IEEE ENGINEERING MANAGEMENT REVIEW, v. 45, n. 3, p. 37-41, 2017.

BREM, A.; IVENS, B. Do Frugal and Reverse Innovation Foster Sustainability? Introduction of a Conceptual Framework. Journal of Technology Management for Growing

Economies, v. 4, n. 2, p. 31-50, 2013. 
BREM, A.; WOLFRAM, P. Research and development from the bottom up - introduction of terminologies for new product development in emerging markets. Journal of Innovation and Entrepreneurship, v. 3, n. 9, 2014.

BRUNNERMEIER, S. B.; COHEN, M. A. Determinants of environmental innovation in US manufacturing industries. Journal of Environmental Economics and Management, v. 45, n. 2, p. 278-293, 2003.

BURGOS-JIMÉNEZ, J. DE et al. Environmental protection and financial performance: an empirical analysis in Wales. International Journal of Operations \& Production Management, v. 33, n. 8, p. 981-1018, 2013.

BUSCH, T.; HOFFMANN, V. H. How hot is your bottom line? linking carbon and financial performance. Business and Society, v. 50, n. 2, p. 233-265, 2011.

CAI, W G..; LI, G. The drivers of eco-innovation and its impact on performance: Evidence from China. Journal of Cleaner Production, v. 176, p. 110-118, 2018.

CAI, W. G.; ZHOU, X. L. On the drivers of eco-innovation: Empirical evidence from China. Journal of Cleaner Production, v. 79, p. 239-248, 2014.

CAINELLI, G.; DE MARCHI, V.; GRANDINETTI, R. Does the development of environmental innovation require different resources? Evidence from Spanish manufacturing firms. Journal of Cleaner Production, v. 94, p. 211-220, 2015.

CAINELLI, G.; MAZZANTI, M.; ZOBOLI, R. Environmental innovations, complementarity and local/global cooperation: evidence from North-East Italian industry. International Journal of Technology, Policy and Management, v. 11, n. 3/4, p. 328-368, 2011.

CALANTONE, R. J.; CAVUSGIL, S. T.; ZHAO, Y. Learning orientation, firm innovation capability, and firm performance. Industrial Marketing Management, v. 31, n. 6, p. 515$524,2002$.

CALANTONE, R. J.; GARCIA, R.; DROGE, C. The Effects of Environmental Turbulence on New Product Development Strategy Planning. Product Innovation Management, v. 20, n. 2, p. 90-103, 2003.

CAO, D.; LI, H.; WANG, G. Impacts of isomorphic pressures on BIM adoption in construction projects. Journal of Construction Engineering and Management, v. 140, n. 12, p. 1-9, 2014.

CAO, Q.; SCHNIEDERJANS, M. J. Empirical study of the relationship between operations strategy and information systems strategic orientation in an e-commerce environment. International Journal of Production Research, v. 42, n. 15, p. 2915-2939, 2004.

CARAYANNIS, E. G. et al. Business Model Innovation as Antecedent of Sustainable Enterprise Excellence and Resilience. Journal of the Knowledge Economy, v. 5, n. 3, p. 440-463, 2014. 
CARRILLO-HERMOSILLA, J.; DEL RÍO, P.; KÖNNÖLÄ, T. Diversity of eco-innovations: Reflections from selected case studies. Journal of Cleaner Production, v. 18, n. 10-11, p. 1073-1083, 2010.

CARRILLO-HERMOSILLA, J.; GONZÁLEZ, P. DEL R.; KÖNNÖLÄ, T. Eco-innovation: when sustainability and competitiveness shake hands. 1st. ed. New York: MacMillan, Palgrave, 2009.

CARTER, C. R.; KALE, R.; GRIMM, C. M. Environmental purchasing and firm performance: an empirical investigation. Transportation Research Part, v. 36, p. 219-228, 2000 .

CERVO, A.; BERVIAN, P. Metodologia científica. São Paulo: Prentice Hall, 2002.

CHAKRABORTY, P.; CHATTERJEE, C. Does environmental regulation indirectly induce upstream innovation? New evidence from India. Research Policy, v. 46, n. 5, p. 939-955, 2017.

CHAN, R. Y. K. et al. Environmental orientation and corporate performance: The mediation mechanism of green supply chain management and moderating effect of competitive intensity. Industrial Marketing Management, v. 41, n. 4, p. 621-630, 2012.

CHARTER, M.; CLARK, T. Key Conclusions from Sustainable Innovation Conferences 2003-2006. Farnham, Surrey, UK: Centre for Sustainable Design, University College for the Creative Arts, 2007.

CHEN, J.; TSOU, H. T.; HUANG, A. Y.-H. Service Delivery Innovation: Antecedents and Impact on Firm Performance. Journal of Service Research, v. 12, n. 1, p. 36-55, 2009.

CHEN, P.-C.; HUNG, S.-W. Collaborative green innovation in emerging countries: a social capital perspective. International Journal of Operations \& Production Management, v. 34, n. 3, p. 347-363, 2014.

CHEN, Y. S.; LAI, S. B.; WEN, C. T. The influence of green innovation performance on corporate advantage in Taiwan. Journal of Business Ethics, v. 67, n. 4, p. 331-339, 2006.

CHENG, C. C. J.; SHIU, E. C. Validation of a proposed instrument for measuring ecoinnovation: An implementation perspective. Technovation, v. 32, n. 6, p. 329-344, 2012.

CHENG, C. C. J.; YANG, C. L.; SHEU, C. The link between eco-innovation and business performance: A Taiwanese industry context. Journal of Cleaner Production, v. 64, p. 81-90, 2014.

CHIEN, M. K.; SHIH, L. H. An empirical study of the implementation of green supply chain management practices in the electrical and electronic industry and their relation to organizational performances performances. International journal of Environmental Science and Technology, v. 4, n. 3, p. 383-394, 2007. 
CHIOU, T. Y. et al. The influence of greening the suppliers and green innovation on environmental performance and competitive advantage in Taiwan. Transportation Research Part E: Logistics and Transportation Review, v. 47, n. 6, p. 822-836, 2011.

CHO, E.; GUPTA, S.; KIM, Y. K. Style consumption: Its drivers and role in sustainable apparel consumption. International Journal of Consumer Studies, v. 39, n. 6, p. 661-669, 2015.

CHOI, S. B. et al. Motivating corporate social responsibility practices under customer pressure among small- and medium-sized suppliers in China: The role of dynamic capabilities. Corporate Social Responsibility and Environmental Management, v. 26, n. 1, p. 213-226, 2019.

CHRISTMANN, P. Effects of "Best Practices" of Environmental Management on Cost Advantage: The Role of Complementary Assets. Academy of Management Journal, v. 43, n. 4, p. 663-680, 2000.

CHRISTMANN, P.; TAYLOR, G. Globalization and the Environment: Determinantes of Firm Self-Regulation in China. Journal of International Business Studies, v. 32, n. 3, p. 439-458, 2001.

CLEFF, T.; RENNINGS, K. Determinants of environmental product and process innovation. European Environment, v. 9, n. 5, p. 191-201, 1999.

CLEMENS, B.; BAKSTRAN, L. A framework of theoretical lenses and strategic purposes to describe relationships among firm environmental strategy, financial performance, and environmental performance. Management Research Review, v. 33, n. 4, p. 393-405, 2010.

CLEMENS, B.; BAMFORD, C. E.; DOUGLAS, T. J. Choosing strategic responses to address emerging environmental regulations: Size, perceived influence and uncertainty. Business Strategy and the Environment, v. 17, n. 8, p. 493-511, 2008.

CLOSS, D. J.; SPEIER, C.; MEACHAM, N. Sustainability to support end-to-end value chains: The role of supply chain management. Journal of the Academy of Marketing Science, v. 39, n. 1, p. 101-116, 2011.

COLLEDANI, M. et al. Technology-based Product-services for Supporting Frugal Innovation. Procedia CIRP, v. 47, p. 126-131, 2016.

COOPER, D. R.; SCHINDLER, P. S. Métodos de Pesquisa em Administração. 12. ed. São Paulo: Bookman, 2016.

CRESWELL, J. W. Projeto de pesquisa: Métodos Qualitativo, Quantitativo e Misto. 2. ed. Porto Alegre: Bookman/Artmed, 2010.

CUNHA, M. P. E. et al. Product innovation in resource-poor environments: Three research streams. Journal of Product Innovation Management, v. 31, n. 2, p. 202-210, 2014. 
DADDI, T. et al. Exploring the link between institutional pressures and environmental management systems effectiveness: An empirical study. Journal of Environmental Management, v. 183, p. 647-656, 2016.

DAI, J.; CANTOR, D. E.; MONTABON, F. L. Examining corporate environmental proactivity and operational performance: A strategy-structure-capabilities-performance perspective within a green context. International Journal of Production Economics, v. 193, p. 272-280, 2017.

DAM, L.; PETKOVA, B. . The impact of environmental supply chain sustainability programs on shareholder wealth. International Journal of Operations \& Production Management, v. 34, n. 5, p. 586-609, 2014.

DAMANPOUR, F.; ARAVIND, D. Organizational Structure and Innovation Revisited: From Organic to Ambidextrous structure. In: Handbook of Organizational Creativity. 1. ed. Norman, OK: Elsevier Inc., 2012. p. 483-513.

DANDONOLI, P. Open innovation as a new paradigm for global collaborations in health. Globalization and Health, v. 9, n. 41, 2013.

DANGELICO, R. M.; PONTRANDOLFO, P. Being "Green and Competitive": The Impact of Environmental Actions and Collaborations on Firm Performance. Business Strategy and the Environment, v. 24, n. 6, p. 413-430, 2015.

DANGELICO, R. M.; PUJARI, D. Mainstreaming green product innovation: Why and how companies integrate environmental sustainability. Journal of Business Ethics, v. 95, n. 3, p. 471-486, 2010.

DE GIOVANNI, P. Do internal and external environmental management contribute to the triple bottom line? International Journal of Operations \& Production Management, v. 32, n. 3, p. 265-290, 2012.

DE MARCHI, V. Environmental innovation and R\&D cooperation: Empirical evidence from Spanish manufacturing firms. Research Policy, v. 41, n. 3, p. 614-623, 2012.

DE OLIVEIRA, C. A.; CARNEIRO, J.; ESTEVES, F. Conceptualizing and measuring the "strategy execution" construct. Journal of Business Research, v. 105, p. 333-344, 2019.

DE OLIVEIRA, U. R. et al. A systematic literature review on green supply chain management: Research implications and future perspectives. Journal of Cleaner Production, v. 187, p. 537-561, 2018.

DEDEHAYIR, O.; MÄKINEN, S. J.; ROLAND ORTT, J. Roles during innovation ecosystem genesis: A literature review. Technological Forecasting and Social Change, v. 136, p. 1829, 2016.

DEIF, A. M. A system model for green manufacturing. Journal of Cleaner Production, v. 19, n. 14, p. 1553-1559, 2011. 
DEL RÍO, P.; PEÑASCO, C.; ROMERO-JORDÁN, D. Distinctive Features of Environmental Innovators: An Econometric Analysis. Business Strategy and the Environment, v. 24, n. 6, p. 361-385, 2015.

DEL RÍO, P.; PEÑASCO, C.; ROMERO-JORDÁN, D. What drives eco-innovators? A critical review of the empirical literature based on econometric methods. Journal of Cleaner Production, v. 112, p. 2158-2170, 2016.

DEL RÍO GONZÁLEZ, P. The empirical analysis of the determinants for environmental technological change: A research agenda. Ecological Economics, v. 68, n. 3, p. 861-878, 2009.

DELLESTRAND, H. Subsidiary embeddedness as a determinant of divisional headquarters involvement in innovation transfer processes. Journal of International Management, v. 17, n. 3, p. 229-242, 2011.

DEMIREL, P.; KESIDOU, E. Stimulating Different Types of Eco-Innovation in the UK: Government Policies and Firm Motivations. Nottingham, UK: Nottingham University Business School, 2010.

DENG, H. et al. Microplastic pollution in water and sediment in a textile industrial area. Environmental Pollution, v. 258, p. 113658, 2020.

DÍAZ-GARCÍA, C.; GONZÁLEZ-MORENO, Á.; SÁEZ-MARTÍNEZ, F. J. Eco-innovation: Insights from a literature review. Innovation: Management, Policy and Practice, v. 17, n. 1, p. 6-23, 2015.

DIMAGGIO, P. J.; POWELL, W. W. The Iron Cage Revisited: Institutional Isomorphism and Collective Rationality in Organizational Fields. American Sociological Review, v. 48, n. 2, p. 147-160, 1983.

DORAN, J.; RYAN, G. Regulation and firm perception, eco-innovation and firm performance. European Journal of Innovation Management, v. 15, n. 4, p. 421-441, 2012.

DORAN, J.; RYAN, G. The Importance of the Diverse Drivers and Types of Environmental Innovation for Firm Performance. Business Strategy and the Environment, v. 25, n. 2, p. 102-119, 2016.

DOSI, G.; NELSON, R. R. Technological Paradigms and Technological Trajectories. Research Policy, v. 1982, p. 147-162, 2016.

DRESSLER, A.; BUCHER, J. Introducing a Sustainability Evaluation Framework based on the Sustainable Development Goals applied to Four Cases of South African Frugal Innovation. Business Strategy \& Development, v. 1, p. 276-285, 2018.

DRIESSEN, P. H.; HILLEBRAND, B. Adoption and Difusion of Green Innovations. In: BARTELS, G. C.; NELISSEN, W. J. A. (ed.), Marketing for Sustainability: Towards Transactional Policy-Making. Amsterdam: IOS Press, 2002. p. 343-355. 
DUBEY, R.; GUNASEKARAN, A.; SAMAR ALI, S. Exploring the relationship between leadership, operational practices, institutional pressures and environmental performance: A framework for green supply chain. International Journal of Production Economics, v. 160, p. 120-132, 2015.

EKINS, P. Eco-innovation for environmental sustainability: Concepts, progress and policies. International Economics and Economic Policy, v. 7, n. 2, p. 267-290, 2010.

EL-KAFAFI, S.; LIDDLE, S. Innovative Sustainable Practices: Are They Commercially Viable? World Journal of Entrepreneurship, Management and Sustainable Development, v. 6, n. 1-2, p. 19-28, 2010.

ELKINGTON, J. Partnerships from Cannibals with Forks: The Triple iottom line of 21st Century Business. Environmental Quality Management, v. 8, n. 1, p. 37-51, 1998.

ERNST, H. et al. The antecedents and consequences of affordable value innovations for emerging markets. Journal of Product Innovation Management, v. 32, n. 1, p. 65-79, 2015.

FALK, J.; RYAN, C. Inventing a sustainable future : Australia and the challenge of ecoinnovation. Futures, v. 39, p. 215-229, 2007.

FAMIYEH, S. et al. Environmental management practices, operational competitiveness and environmental performance. Journal of Manufacturing Technology Management, v. 29, n. 3, p. 588-607, 2018.

FAROOQ, R. A conceptual model of frugal innovation: is environmental munificence a missing link? International Journal of Innovation Science, v. 9, n. 4, p. 320-334, 2017.

FAUL, F. et al. G*Power 3: A flexible statistical power analysis program for the social, behavioral, and biomedical sciences. Behavior Research Methods, v. 39, n. 2, p. 175-191, 2007.

FAVERO, L. P. et al. Análise de dados: modelagem multivariada para tomada de decisões (1. ed.). Rio de Janeiro: Elsevier,2009.

FERNANDO, C. S.; SHARFMAN, M. P.; UYSAL, V. B. Does Greenness Matter? The Effect of Corporate Environmental Performance on Ownership Structure, Analyst Coverage and Firm Value. In: FMA EUROPEAN CONFERENCE, Hamburg, Germany, 2010. Anais [...]. Hamburg, Germany. p. 1-46.

FERRON-VILCHEZ, V.; DE LA TORRE-RUIZ, J. M.; ORTIZ-DE MANDOJANA, N. How Much Would Environmental Issues Cost? The Internalization of Environmental Costs in the European Transport Industry. Environmental Engineering and Management Journal, v. 14, n. 9, p. 2149-2162, 2015.

FLORIDA, R. Lean and Green:The Move to Environmentally Conscious Manufacturing. California Management Review, v. 39, n. 1, p. 80-105, 1996. 
FLYNN, B. B.; HUO, B.; ZHAO, X. The impact of supply chain integration on performance: A contingency and configuration approach. Journal of Operations Management, v. 28, n. 1, p. 58-71, 2010.

FORMENTINI, M.; TATICCHI, P. Corporate sustainability approaches and governance mechanisms in sustainable supply chain management. Journal of Cleaner Production, v. 112, p. 1920-1933, 2016.

FORNELL, C.; LARCKER, D. F. Evaluating Structural Equation Models with Unobservable Variables and Measurement Error. Journal of Marketing Research, v. 18, n. 1, p. 39, 1981.

FOXON, T.; ANDERSEN, M. M. The Greening of Innovation Systems for Eco-Innovation Towards an Evolutionary Climate Mitigation Policy. In: DRUID SUMMER CONFERENCE, Copenhagen, 2009. Anais [...], Copenhagen, Denmark: Copenhagen Business School, 2009.

FRANCESCHINI, S.; FARIA, L. G. D.; JUROWETZKI, R. Unveiling scientific communities about sustainability and innovation. A bibliometric journey around sustainable terms. Journal of Cleaner Production, v. 127, p. 72-83, 2016.

FRANCESCHINI, S.; PANSERA, M. Technological Forecasting \& Social Change Beyond unsustainable eco-innovation: The role of narratives in the evolution of the lighting sector. Technological Forecasting \& Social Change, v. 92, p. 69-83, 2015.

FRONDEL, M.; HORBACH, J.; RENNINGS, K. What triggers environmental management and innovation? Empirical evidence for Germany. Ecological Economics, v. 66, n. 1, p. 153 160, 2008.

FUENFSCHILLING, L.; TRUFFER, B. The structuration of socio-technical regimes Conceptual foundations from institutional theory. Research Policy, v. 43, n. 4, p. 772-791, 2014.

FUSSLER, Claude; JAMES, Peter. Driving eco-innovation: a breakthrough discipline for innovation and sustainability. Financial Times/Prentice Hall, 1996.

GANAPATHY, S. P. et al. Influence of eco-innovation on Indian manufacturing sector sustainable performance. International Journal of Sustainable Development and World Ecology, v. 21, n. 3, p. 198-209, 2014.

GARCÍA-GRANERO, E. M.; PIEDRA-MUÑOZ, L.; GALDEANO-GÓMEZ, E. Ecoinnovation measurement: A review of firm performance indicators. Journal of Cleaner Production, v. 191, p. 304-317, 2018.

GARTNER, E. Industrially interesting approaches to "low-CO2" cements. Cement and Concrete Research, v. 34, n. 9, p. 1489-1498, 2004.

GERYBADZE, A.; REGER, G. Globalisation of R\&D: Recent Changes in the Management of Innovation in Transnational Corporations. Research policy, v. 28, n. 2-3, p. 251-274, 1997. 
GOLD, S.; SEURING, S.; BESKE, P. Sustainable supply chain management and interorganizational resources: A literature review. Corporate Social Responsibility and Environmental Management, v. 17, n. 4, p. 230-245, 2010.

GOLICIC, S. L.; SMITH, C. D. A meta-analysis of environmentally sustainable supply chain management practices and firm performance. Journal of Supply Chain Management, v. 49, n. 2, p. 78-95, 2013.

GOLDSMITH, R. E.; FLYNN REINECKE, L.; CLARK, R. A. Journal of Retailing and Consumer Services The etiology of the frugal consumer. Journal of Retailing and Consumer Services, v. 21, p. 175-184, 2014.

GONZÁLEZ-MORENO, Á.; SÁEZ-MARTÍNEZ, F. J.; DÍAZ-GARCÍA, C. Drivers of ecoinnovation in chemical industry. Environmental Engineering and Management Journal, v. 12, n. 10, p. 2001-2008, 2013.

GOTSCHOL, A.; DE GIOVANNI, P.; VINZI, V. E. Is environmental management an economically sustainable business? Journal of Environmental Management, v. 144, p. 73 82, 2014.

GOVINDARAJAN, V.; KOPALLE, P. K. Disruptiveness of innovations: Measurement and an assessment of reliability and validity. Strategic Management Journal, v. 27, n. 2, p. 189199, 2006.

GOVINDARAJAN, V.; RAMAMURTI, R. Reverse Innovation, Emerging Markets, and Global Strategy. Global Strategy Journal, v. 1, n. 3-4, p. 191-205, 2011.

GOVINDARAJAN, V.; TRIMBLE, C. Reverse innovation: a global growth strategy that could pre-empt disruption at home. Strategy \& Leadership, v. 40, n. 5, p. 5-11, 2014.

GUOYOU, Q. et al. Role of Internalization Process in Defining the Relationship between ISO 14001 Certification and Corporate Environmental Performance. Corporate Social Responsibility and Environmental Management, v. 19, p. 129-140, 2012.

GUPTA, A. K.; WANG, H. Getting China and India right: Strategies for leveraging the world's fastest growing economies for global advantage. 2. ed. Sao Francisco, CA: [s. n.], 2009.

GUPTA, R. et al. Husk Power Systems: Bringing Light to Rural India and Tapping Fortune at the Bottom of the Pyramid. Asian Journal of Management Cases, v. 10, n. 2, p. 129-143, 2013.

HAIR Jr., J. F. et al. Advanced issues in partial least squares structural equation modeling. Los Angeles: Sage Publications, 2017a.

HAIR Jr., J. F. et al. Análise multivariada de dados. São Paulo: Bookman Editora, 2005.

HAIR, Jr., J. F. et al. An updated and expanded assessment of PLS-SEM in information systems research. Industrial Management \& Data Systems, v. 117, n. 3, p. 442-458, 2017 b. 
HAIR, J. F. et al. When to use and how to report the results of PLS-SEM. European Business Review, v. 31, n. 1, p. 2-24, 2019.

HAIR, J. F.; GABRIEL, M. L. D. S.; PATEL, V. K. Modelagem de Equações Estruturais baeada em Covariância (CB-SEM) com o AMOS: Orientações sobre a sua aplicação como uma ferramenta de pesquisa de marketing. REMark - Revista Brasileira de Marketing, v. 13, n. 2, p. 44-55, 2014.

HART, S. L. Beyond Greening: Strategies for a Sustainable World. Harvard Business Review, v. 75, n. 1, p. 66-76, 1996.

HART, S. L.; AHUJA, G.; ARBOR, A. Does it pay to be green? An empirical examination of relationship between emission reduction and firma performance. Business Stratem and the Environment, v. 5, p. 30-37, 1996.

HART, S. L.; CHRISTENSEN, C. M. The Great Leap: Driving Innovation From the Base of the Pyramid. MIT Sloan management review, v. 44, n. 1, p. 51-56, 2002.

HASAN, M. Sustainable Supply Chain Management Practices and Operational Performance. American Journal of Industrial and Business Management, v. 3, n. 1, p. 42-48, 2013.

HASANBEIGI, A.; PRICE, L.; LIN, E. Emerging energy-efficiency and CO 2 emissionreduction technologies for cement and concrete production: A technical review. Renewable and Sustainable Energy Reviews, v. 16, n. 8, p. 6220-6238, 2012.

HAZEN, B. T.; CEGIELSKI, C.; HANNA, J. B. Diffusion of green supply chain management: Examining perceived quality of green reverse logistics. International Journal of Logistics Management, v. 22, n. 3, p. 373-389, 2011.

HE, Q. et al. Systematic impact of institutional pressures on safety climate in the construction industry. Accident Analysis and Prevention, v. 93, p. 230-239, 2016.

HEGENBERG, L.; ARAUJO JUNIOR, A. H.; HEGENBERG. F. E. N. (2012). Métodos de pesquisa: De Sócrates a Marx e Popper. São Paulo: Atlas, 2012.

HEJNY, J. The Trump Administration and environmental policy: Reagan redux? Journal of Environmental Studies and Sciences, v. 8, n. 2, p. 197-211, 2018.

HELLSTRÖM, T. Dimensions of environmentally sustainable innovation: the structure of eco-innovation concepts. Sustainable Development, v. 15, p. 148-159, 2007.

HENRIQUES, I.; SADORSKY, P. The Determinants of an Environmentally Responsive Firm: An Empirical Approuch. Journal of environmental economics and management, $v$. 30, n. 26, p. 381-395, 1996.

HENSELER, J.; SARSTEDT, M. Goodness-of-fit indices for partial least squares path modeling. Computational Statistics, v. 28, n. 2, p. 565-580, 2013.

HENSELER, J.; RINGLE, C. M.; SARSTEDT, M. A new criterion for assessing discriminant validity in variance-based structural equation modeling. Journal of the Academy of Marketing Science, v. 43, n. 1, p. 115-135, 2014. 
HENSELER, J.; RINGLE, C. M.; SINKOVICS, R. R. The use of partial least squares path modeling in international marketing. In: CAVUSGIL, T.; SINKOVICS, R. R.; GHAURI, P. New challenges to international marketing. Binley, United Kingdom: Emerald Group Publishing Limited, 2009. p. 277-319.

HILL, N. A Lei do Triunfo: curso prático em 16 lições.18. ed. Rio de Janeiro: José Olympio, 1997. p. 579.

HININGS, B.; GEGENHUBER, T.; GREENWOOD, R. Digital innovation and transformation: An institutional perspective. Information and Organization, v. 28, n. 1, p. 52-61, 2018.

HOJNIK, J.; RUZZIER, M. What drives eco-innovation? A review of an emerging literature. Environmental Innovation and Societal Transitions, v. 19, p. 31-41, 2016.

HOPPE, T. et al. Local governments supporting local energy initiatives: Lessons from the best practices of Saerbeck (Germany) and Lochem (The Netherlands). Sustainability, v. 7, n. 2, p. 1900-1931, 2015.

HORBACH, J. Determinants of environmental innovation - New evidence from German panel data sources. Research Policy, v. 37, p. 163-173, 2008.

HORBACH, J. Do eco-innovations need specific regional characteristics? An econometric analysis for Germany. Review of Regional Research, v. 34, n. 1, p. 23-38, 2014.

HORBACH, J. Empirical determinants of eco-innovation in European countries using the community innovation survey. Environmental Innovation and Societal Transitions, v. 19, p. 1-14, 2016.

HORBACH, J.; RAMMER, C.; RENNINGS, K. Determinants of eco-innovations by type of environmental impact - The role of regulatory push/pull, technology push and market pull. Ecological Economics, v. 78, p. 112-122, 2012.

HORN, C.; BREM, A. Strategic directions on innovation management - a conceptual framework. Management Research Review, v. 36, n. 10, p. 939-954, 2013.

HOSSAIN, M. Frugal innovation: A review and research agenda. Journal of Cleaner Production, v. 182, p. 926-936, 2018.

HOSSAIN, M. Frugal Innovation: A Systematic Literature Review. SSRN Electronic Journal, 2016. Disponível em: https://papers.ssrn.com/sol3/papers.cfm?abstract_id=2768254. Acesso em: 10 dez. 2020.

HOSSAIN, M. Mapping the frugal innovation phenomenon. Technology in Society, v. 51, p. 199-208, Nov. 2017.

HOSSAIN, M.; SIMULA, H.; HALME, M. Can frugal go global? Diffusion patterns of frugal innovations. Technology in Society, v. 46, p. 132-139, 2016. 
HREBINIAK, L. G. Obstacles to effective strategy implementation. Organizational Dynamics, v. 35, n. 1, p. 12-31, 2006.

HSU, C.-C.; TAN, K.-C.; ZAILANI, S. H. M. Strategic orientations, sustainable supply chain initiatives, and reverse logistics. International Journal of Operations \& Production Management, v. 36, n. 1, p. 86-110, 2016.

HU, Y.; CHENG, H. Water pollution during China's industrial transition. Environmental Development, v. 8, n. 1, p. 57-73, 2013.

HUANG, J. W.; LI, Y. H. Green Innovation and Performance: The View of Organizational Capability and Social Reciprocity. Journal of Business Ethics, v. 145, n. 2, p. 309-324, 2017.

HUANG, X. et al. The relationships between regulatory and customer pressure, green organizational responses, and green innovation performance. Journal of Cleaner Production, v. 112, p. 3423-3433, 2016.

HYMAN, L., LAMB, J.;BULMER, M. The Use of Pre-Existing Survey Questions : Implications for Data Quality. European Conference on Quality in Survey Statistics, 3.2006

HYVÄRINEN, A.; KESKINEN, M.; VARIS, O. Potential and pitfalls of frugal innovation in the water sector: Insights from Tanzania to global value chains. Sustainability, v. 8, n. 9, p. $888,2016$.

INIGO, E. A.; ALBAREDA, L. Technological Forecasting \& Social Change Sustainability oriented innovation dynamics : Levels of dynamic capabilities and their path-dependent and self-reinforcing logics. Technological Forecasting \& Social Change, v. 139, p. 334-351, 2019.

IRANMANESH, M. et al. Impact of Lean Manufacturing Practices on Firms' Sustainable Performance: Lean Culture as a Moderator. Sustainability, v. 11, n. 4, p. 1112, 2019.

JABBOUR, A. B. et al. Mixed methodology to analyze the relationship between maturity of environmental management and the adoption of green supply chain management in Brazil.

Resources, Conservation and Recycling, v. 92, p. 255-267, 2014.

JAFFE, A. B. et al. Environmental Regulation and the Competitiveness What Does the Evidence Tell Us? Journal of Economic Literature, v. 23, p. 132-163, 1995.

JAFFE, A. B.; PALMER, K. Environmental regulation and competitivness: A panel data study. Review of Economics and Statistics, v. 79, n. 4, p. 610-619, 1997.

JAFFE, A. B.; STAVINS, R. N. Dynamic incentives of environmental regulations: The effects of alternative policy instruments on technology diffusion. Journal of Environmental Economics and Management, v. 29, n. 3, p. S43-S63, 1995. 
JANSSON, J. Consumer Eco-Innovation Adoption: Assessing Attitudinal Factors and Perceived Product Characteristics. Business Strategy and the Environment, v. 20, n. 3, p. 192-210, 2011.

JAYAL, A. D. et al. Sustainable manufacturing: Modeling and optimization challenges at the product, process and system levels. CIRP Journal of Manufacturing Science and Technology, v. 2, n. 3, p. 144-152, 2010.

JAYARAM, J.; AVITTATHUR, B. Green supply chains: A perspective from an emerging economy. International Journal of Production Economics, v. 164, p. 234-244, 2015.

JHA, S. K.; KRISHNAN, R. T. Local innovation: The key to globalisation. IIMB Management Review, v. 25, n. 4, p. 249-256, 2013.

JI, G.; GUNASEKARAN, A.; YANG, G. Constructing sustainable supply chain under double environmental medium regulations. International Journal of Production Economics, v. 147, p. 211-219, 2014.

JOHNSON, K. et al. Building capacity and sustainable prevention innovations: A sustainability planning model. Evaluation and Program Planning, v. 27, n. 2, p. 135-149, 2004.

KAHLE, H. N. et al. The democratizing effects of frugal innovation: Implications for inclusive growth and state-building. Journal of Indian Business Research, v. 5, n. 4, p. 220$234,2013$.

KAHLE, H. N.; DUBIEL, A.; ERNST, H. The democratizing effects of frugal innovation. Journal of Indian Business Research, v. 5, n. 4, p. 220-234, 2013.

KAMMERER, D. The effects of customer benefit and regulation on environmental product innovation. Empirical evidence from appliance manufacturers in Germany. Ecological Economics, v. 68, n. 8-9, p. 2285-2295, 2009.

KARAKAYA, E.; HIDALGO, A.; NUUR, C. Diffusion of eco-innovations: A review. Renewable and Sustainable Energy Reviews, v. 33, p. 392-399, 2014.

KEMP, R.; PEARSON, P. Final report MEI project about measuring eco-innovation. UM Merit, v. 32, n. 3, p. 121-124, 2007.

KEMP, R.; PONTOGLIO, S. The innovation effects of environmental policy instruments - A typical case of the blind men and the elephant? Ecological Economics, v. 72, p. 28-36, 2011.

KEOLEIAN, G. A.; MENEREY, D. Sustainable development by design: review of life cycle design and related approaches. Air \& Waste, v. 44, n. 5, p. 645-668, 1994.

KERIN, R. A.; VARADARAJAN, P. R.; PETERSON, R. A. First-MoverAdvantage: A Framework, Synthesis, Conceptual and Research Proposition. Journal of Marketing, v. 56, n. 4, p. 33-52, 1992.

KESIDOU, E.; DEMIREL, P. On the drivers of eco-innovations: Empirical evidence from the UK. Research Policy, v. 41, n. 5, p. 862-870, 2012. 
KHAN, R. How frugal innovation promotes social sustainability. Sustainability (Switzerland), v. 8, n. 10, p. 1034, 2016.

KHANNA, T.; PALEPU, K. G.; BULLOCK, R. J. Vencendo em mercados emergentes Harvard Business Review, v. 88, n. 6, p. 80-85, 2010.

KIEFER, C. P. et al. Diversity of eco-innovations: A quantitative approach. Journal of Cleaner Production, v. 166, p. 1494-1506, 2017.

KLASSEN, R. D.; WHYBARK, D. C. The impact of environmental technologies on manufacturing performance. Academy of Management Journal, v. 42, n. 6, p. 599-615, 1999.

KLEINDORFER, P. R.; SINGHAL, K.; WASSENHOVE, L. N. VAN. Sustainable Operations Management. Production and Operations Management, v. 14, n. 4, p. 482-492, 2005.

KLEINDORFER, P. R.; SINGHAL, K.; WASSENHOVE, L. N. VAN. Sustainable Operations Management. PRODUCTION AND OPERATIONS MANAGEMENT, v. 14, n. 4, p. 482-492, 2005.

KLEWITZ, J.; HANSEN, E. G. Sustainability-oriented innovation of SMEs: A systematic review. Journal of Cleaner Production, v. 65, p. 57-75, 2014.

KLEWITZ, J.; ZEYEN, A.; HANSEN, E. G. Intermediaries driving eco-innovation in SMEs: a qualitative investigation. European Journal of Innovation Management, v. 15, n. 4, p. 442-467, 2012.

KNELLER, R.; MANDERSON, E. Environmental regulations and innovation activity in UK manufacturing industries. Resource and Energy Economics, v. 34, n. 2, p. 211-235, 2012.

KNORRINGA, P. et al. Frugal Innovation and Development: Aides or Adversaries? European Journal of Development Research, v. 28, n. 2, p. 143-153, 2016.

KONAR, S.; COHEN, M. A. Does the market value environmental performance? The Review of Economics and Statistics, v. 83, n. 2, p. 281-289, 2001.

KOTABE, M. Using Euromonitor database in international marketing research. Journal of the Academy of Marketing Science, v. 30, n. 2, p. 172-175, 2002.

KUMAR, H.; BHADURI, S. Jugaad to grassroot innovations: Understanding the landscape of the informal sector innovations in India. African Journal of Science, Technology, Innovation and Development, v. 6, n. 1, p. 13-22, 2014.

KUMAR, S.; TEICHMAN, S.; TIMPERNAGEL, T. A green supply chain is a requirement for profitability. International Journal of Production Research, v. 50, n. 5, p. 1278-1296, 2012.

KUNAPATARAWONG, R.; MARTÍNEZ-ROS, E. Towards green growth: How does green innovation affect employment? Research Policy, v. 45, n. 6, p. 1218-1232, 2016. 
KUO, A. Harnessing frugal innovation to foster clean technologies. Clean Technologies and Environmental Policy, v. 19, n. 4, p. 1109-1120, 2017.

LAI, K. H.; WONG, C. W. Y. Green logistics management and performance: Some empirical evidence from Chinese manufacturing exporters. Omega, v. 40, n. 3, p. 267-282, 2012.

LAI, K.; WONG, C. W. Y. Green logistics management and performance: Some empirical evidence from Chinese manufacturing exporters. Omega, v. 40, n. 3, p. 267-282, 2012.

LAI, K. H.; WONG, C. W. Y.; CHENG, T. C. E. Ecological modernisation of Chinese export manufacturing via green logistics management and its regional implications. Technological Forecasting and Social Change, v. 79, n. 4, p. 766-770, 2012.

LAMBERT, D. M.; COOPER, M. C. Issues in supply chain management. Industrial Marketing Management, v. 29, n. 1, p. 65-83, 2000.

LASTOVICKA, J. L. et al. Lifestyle of the Tight and Frugal: Theory and Measurement. Journal of Consumer Research, v. 26, n. 1, p. 85-98, 1999.

LAWRENCE, T. B. Institutional strategy. Journal of Management, v. 25, n. 2, p. 161-187, 1999.

LAWRENCE, T. B.; SIMON, M. S. Institutional theory. In: DONSBACH, E. W. (ed.), The International Encyclopedia of Communication. 1. ed. [s. 1.]: John Wiley \& Sons, Ltd., 2008. p. 308-321.

LEACH, M. et al. Transforming innovation for sustainability. Ecology and Society, v. 17, n. 2, p. 11, 2012.

LEAL-RODRÍGUEZ, A. L. et al. Green innovation, indeed a cornerstone in linking market requests and business performance. Evidence from the Spanish automotive components industry. Technological Forecasting and Social Change, v. 129, p. 185-193, 2018.

LEE, S. H. M. When are frugal consumers not frugal? The influence of personal networks. Journal of Retailing and Consumer Services, v. 30, p. 1-7, 2016.

LEVÄNEN, J. et al. Implications of frugal innovations on sustainable development: Evaluating water and energy innovations. Sustainability, v. 8, n. 1, p. 1-17, 2016.

LEVÄNEN, J.; LINDEMAN, S. Frugal innovations in circular economy: Exploring possibilities and challenges in emerging markets. THE INTERNATIONAL SOCIETY FOR ECOLOGICAL ECONOMICS CONFERENCE. Transforming the Economy: Sustaining Food, Water, Energy and Justice. Anais [...]. Washington, D.C., USA, 2016.

LI, J.; KOZHIKODE, R. K. Journal of International Management Developing new innovation models: Shifts in the innovation landscapes in emerging economies and implications for global R\&D management. Journal of International Management, v. 15, n. 3, p. 328-339, 2009. 
LI, Y. Environmental innovation practices and performance: Moderating effect of resource commitment. Journal of Cleaner Production, v. 66, p. 450-458, 2014.

LIN, H. et al. Can political capital drive corporate green innovation? Lessons from China. Journal of Cleaner Production, v. 64, p. 63-72, 2014.

LINTON, J. D.; KLASSEN, R.; JAYARAMAN, V. Sustainable supply chains: An introduction. Journal of operations management v. 25, n. 6, p. 1075-1082, 2007.

LISI, W.; ZHU, R.; YUAN, C. Embracing green innovation via green supply chain learning: The moderating role of green technology turbulence. Sustainable Development, v. 28, n. 1, p. 155-168, 2020.

LIU, H. et al. The role of institutional pressures and organizational culture in the firm's intention to adopt internet-enabled supply chain management systems. Journal of Operations Management, v. 28, n. 5, p. 372-384, 2010.

LIU, J. Y.; LOW, S. P.; HE, X. Green practices in the Chinese building industry: drivers and impediments". Journal of Technology Management in China, v. 7, n. 1, p. 50-63, 2014.

M'ZUNGU, S.; MERRILEES, B.; MILLER, D. Strategic hybrid orientation between market orientation and brand orientation: guiding principles. Journal of Strategic Marketing, v. 25, n. 4, p. 275-288, 2017.

MADITATI, D. R. et al. A review of green supply chain management : From bibliometric analysis to a conceptual framework and future research directions. Resources, Conservation \& Recycling, v. 139, p. 150-162, 2018.

MAJUMDAR, S. K.; MARCUS, A. A. Rules versus Discretion: The Productivity Consequences of Flexible Regulation. Academy Management, v. 44, n. 1, p. 170-179, 2001.

MCCLAVE, J. T.; BENSON, P. G.; SINCICH, T.Estatística para administração e economia. 10. ed. São Paulo: Pearson Prentice Hall, 2009.

MCFARLAND, R. G.; BLOODGOOD, J. M.; PAYAN, J. M. Supply chain contagion. Journal of Marketing, v. 72, n. 2, p. 63-79, 2008.

MANOLOVA, T. S.; EUNNI, R. V.; GYOSHEV, B. S. Institutional Environments for Entrepreneurship: Evidence from Emerging Economies in Eastern Europe.

Entrepreneurship Theory and Practice, v. 32, n. 1, p. 203-218, 2008.

MARKARD, J.; RAVEN, R.; TRUFFER, B. Sustainability transitions: An emerging field of research and its prospects. Research Policy, v. 41, n. 6, p. 955-967, 2012.

MARUTHI, G. D.; RASHMI, R. Green Manufacturing: It's Tools and Techniques that can be implemented in Manufacturing Sectors. Materials Today: Proceedings, v. 2, n. 4-5, p. 33503355, 2015. 
MATHIYAZHAGAN, K.; SENGUPTA, S.; MATHIVATHANAN, D. Challenges for implementing green concept in sustainable manufacturing: a systematic review. Opsearch, v. 56, n. 1, p. 32-72, 2019.

MATZLER, K. et al. Unlocking laggard markets: Innovation without high tech. Journal of Business Strategy, v. 35, n. 2, p. 19-25, 2014.

MELNYK, S. A.; SROUFE, R. P.; CALANTONE, R. Assessing the impact of environmental management systems on corporate and environmental performance. Journal of Operations Management, v. 21, n. 3, p. 329-351, 2003.

MEYER, J. W.; ROWAN, B. Institutionalized Organizations: Formal Structure as Myth and Ceremony. American Journal of Sociology, v. 83, n. 2, p. 340-363, 1977.

MILLSAP, R. E. Statistical approaches to measurement invariance. New York, London: Routledge, 2012.

MITEREV, M.; ENGWALL, M.; JERBRANT, A. Mechanisms of Isomorphism in ProjectBased Organizations. Project Management Journal, v. 48, n. 5, p. 9-24, 2017.

MITTAL, V. K.; SANGWAN, K. S. Prioritizing drivers for green manufacturing: Environmental, social and economic perspectives. Procedia CIRP, v. 15, p. 135-140, 2014.

MONECKE, A.; LEISCH, F. Structural Equation Modeling Using Partial Least Squares. Journal of Statistical Software, v. 48, n. 3, p. 1-32, 2012.

MONTABON, F.; SROUFE, R.; NARASIMHAN, R. An examination of corporate reporting, environmental management practices and firm performance. Journal of Operations Management, v. 25, n. 5, p. 998-1014, 2007.

MONTALVO, C. General wisdom concerning the factors affecting the adoption of cleaner technologies: a survey 1990-2007. Journal of Cleaner Production, v. 16, n. 1, p. S7-S13, 2008.

MOORE, J. F. Predators and Prey: A New Ecology of Competition. Harvard Business Review, v. 71, n. 3, p. 75-86, 1993.

MOURTZIS, D. et al. Manufacturing Networks Design through Smart Decision Making towards Frugal Innovation. Procedia CIRP, v. 50, p. 354-359, 2016.

MURPHY, J.; GOULDSON, A. Environmental policy and industrial innovation: Integrating environment and economy through ecological modernisation. Geoforum, v. 31, n. 1, p. 3344, 2000.

NAIR, C. S.; ADAMS, P. Survey Platform: A Factor Influencing Online Survey Delivery and Response Rate. Quality in Higher Education, v. 15, n. 3, p. 291-296, 2009.

NARVER, J. C.; SLATER, S. F. The effect of a market orientation on business profitability. Journal of marketing, v. 54, n. 4, p. 20-35, 1990. 
NELSON, R. R.; WINTER, S. G. Evolutionary Theorizing in Economics. Journal of Economic Perspectives, v. 16, n. 2, p. 23-46, 2002.

NIDUMOLU, R.; PRAHALAD, C. K.; RANGASWAMI, M. R. Why Sustainability Is Now the Key Driver of Innovation. Harvard Business Review, v. 87, n. 9, p. 56-64, 2009.

NOBLE, C. H.; SINHA, R. K.; KUMAR, A. Market orientation and alternative strategic orientations: A longitudinal assessment of performance implications. Journal of Marketing, v. 66, n. 4, p. 25-39, 2002.

NOCERA, D. G. Can we progress from solipsistic science to frugal innovation? Daedalus, v. 141, n. 3, p. 45-52, 2012.

NUMMINEN, S.; LUND, P. D. Frugal energy innovations for developing countries - a framework. Global Challenges, v. 1, n. 1, p. 9-19, 2017.

OGUNMAKINDE, O. E. A review of circular economy development models in China, Germany and Japan. Recycling, v. 4, n. 3, p. 27, 2019.

OH, D. S. et al. Innovation ecosystems: A critical examination. Technovation, v. 54, p. 1-6, 2016.

OJHA, A. K. MNCs in India: Focus on frugal innovation. Journal of Indian Business Research, v. 6, n. 1, p. 4-28, 2014.

OLIVER, C. Strategic Responses to Institutional Processes. Academy of Management Review, v. 16, n. 1, p. 145-179, 1991.

OLTRA, V.; KEMP, R.; VRIES, F. P. DE. Patents as a measure for eco-innovation.

International Journal of Environmental Technology and Management, v. 13, n. 2, p. 130$148,2010$.

OLTRA, V.; SAINT JEAN, M. Sectoral systems of environmental innovation: An application to the French automotive industry. Technological Forecasting and Social Change, v. 76, n. 4, p. 567-583, 2009.

PANSERA, M. Eco-innovation as a Development Tool: Evidence from Latin America and Asia. INTERNATIONAL CONFERENCE ON DEGROWTH: ECOLOGICAL SUSTAINABILITY AND SOCIAL EQUITY, 30, Venice, 2012. Disponível em: https://www.researchgate.net/profile/Mario_Pansera2/publication/320323924_Ecoinnovation_as_a_Development_Tool_Evidence_from_Latin_America_and_Asia/links/59ddec 1f458515f6ef0e3260/Eco-innovation-as-a-Development-Tool-Evidence-from-Latin-Americaand-Asia.pdf. Acesso em: 15 dez. 2017.

PANSERA, M. Innovation system for sustainability in developing countries: the renewable energy sector in Bolivia. International Journal of Innovation and Sustainable Development, v. 7, n. 1, p. 27-45, 2013.

PANSERA, M. Frugal or Fair? The Unfulfilled Promises of Frugal Innovation. Technology Innovation Management Review, v. 8, n. 4, p. 6-14, 2018. 
PANSERA, M.; OWEN, R. Eco-Innovation at the "Bottom of the Pyramid". In:

Collaboration for Sustainability and Innovation: A Role For Sustainability Driven by the Global South? Dordrecht: Springer, 2014. p. 293-313.

PANSERA, M.; OWEN, R. Framing resource-constrained innovation at the 'bottom of the pyramid': Insights from an ethnographic case study in rural Bangladesh. Technological Forecasting \& Social Change, v. 92, p. 300-311, 2015.

PENG, M. W. Institutional Transitions and Strategic Choices: Implications for Corporate Social Responsability in Russia. Academy of Management Review, v. 28, n. 2, p. 1-26, 2003.

PENG, M. W. et al. The Institution-Based View as a Third Leg for a Strategy Tripod. Academy of Management Perspectives, v. 23, n. 3, p. 63-81, 2009.

PERESEINA, V. et al. Challenges and conflicts in sustainable supply chain management: Evidence from the heavy vehicle industry. Supply Chain Forum, v. 15, n. 1, p. 22-32, 2014.

PISONI, A.; MICHELINI, L.; MARTIGNONI, G. Frugal approach to innovation: State of the art and future perspectives. Journal of Cleaner Production, v. 171, p. 107-126, 2018.

PODSAKOFF, P. M. et al. Common Method Biases in Behavioral Research: A Critical Review of the Literature and Recommended Remedies. Journal of Applied Psychology, v. 88, n. 5, p. 879-903, 2003.

PODSAKOFF, P. M.; ORGAN, D. W. Self-Reports in Organizational Research: Problems and Prospects. Journal of Management, v. 12, n. 4, p. 531-544, 1986.

POPP, D. International Innovation and Diffusion of Air Pollution Control Technologies: The Efects of NOX and SO2 regulation in the U.S., Japan and Germany. Journal of Environmental Economics and Management, v. 51, n. 1, p. 46-71, 2006.

PORTER, M. E.; KRAMER, M. R. The Big Idea - Creating Shared Value. How to reinvent capitalism - and unleash a wave of innovation and growth. Harvard Business Review, v. 89, n. 1-2, 2011.

PORTER, M. E.; LINDE, C. V. D. Toward a New Conception of the EnvironmentCompetitiveness Relationship. Journal of Economic Perspectives, v. 9, n. 4, p. 97-118, 1995.

PRABHU, J.; JAIN, S. Innovation and entrepreneurship in India: Understanding Jugaad. Asia Pacific Journal of Management, v. 32, n. 4, p. 843-868, 2015.

PRAHALAD, C. K. Bottom of the Pyramid as a Source of Breakthrough Innovations. Journal of Production Management, v. 29, n. 1, p. 6-12, 2012.

PRAJOGO, D. et al. The relationship between supplier management and firms operational performance: A multi-dimensional perspective. International Journal of Production Economics, v. 136, n. 1, p. 123-130, 2012. 
PRZYCHODZEN, J.; PRZYCHODZEN, W. Relationships between eco-innovation and financial performance - Evidence from publicly traded companies in Poland and Hungary. Journal of Cleaner Production, v. 90, p. 253-263, 2015.

PUJARI, D. Eco-innovation and new product development: Understanding the influences on market performance. Technovation, v. 26, n. 1, p. 76-85, 2006.

QI, G. Y. et al. The drivers for contractors' green innovation: An industry perspective. Journal of Cleaner Production, v. 18, n. 14, p. 1358-1365, 2010.

RADJOU, N.; PRABHU, J. Mobilizing for growth in emerging markets. MIT Sloan Management Review, v. 53, n. 3, p. 81-88, 2012.

RAMANATHAN, R. Understanding Complexity: the Curvilinear Relationship Between Environmental Performance and Firm Performance. Journal of Business Ethics, v. 149, n. 2, p. 383-393, 2018.

RAMUS, C., STEGER, U. The roles of supervisory support behaviors and environmental policy. Academy of Management, v. 43, n. 4, p. 605-626, 2000.

RAO, B. C. Advances in science and technology through frugality. IEEE Engineering Management Review, v. 45, n. 1, p. 32-38, 2017a.

RAO, B. C. How disruptive is frugal? Technology in Society, v. 35, n. 1, p. 65-73, 2013 a.

RAO, B. C. Revisiting classical design in engineering from a perspective of frugality.

Heliyon, v. 3, n. 5, p. e00299, 2017b.

RAO, B. C. Technology in Society How disruptive is frugal? Technology in Society, v. 35, n. 1, p. $65-73,2013 b$.

RAO, P.; HOLT, D. Do green supply chains lead to competitiveness and economic performance? International Journal of Operations \& Production Management, v. 25, n. 9, p. 898-916, 2005.

RAY, S.; RAY, P. K. Technovation Product innovation for the people' s car in an emerging economy. Technovation, v. 31, n. 5-6, p. 216-227, 2011.

REHFELD, K. M.; RENNINGS, K.; ZIEGLER, A. Integrated product policy and environmental product innovations: An empirical analysis. Ecological Economics, v. 61, n. 1, p. 91-100, 2007.

REHMAN, M. A.; SETH, D.; SHRIVASTAVA, R. L. Impact of green manufacturing practices on organisational performance in Indian context: An empirical study. Journal of Cleaner Production, v. 137, p. 427-48, 2016.

REINHARDT, F. L. Environmental Product Differentiation: Implications for Corporate Strategy. California Management Review, v. 40, n. 4, p. 43-73, 1998. 
RENNINGS, K. Redefining innovation - Eco-innovation research and the contribution from ecological economics. Ecological Economics, v. 32, n. 2, p. 319-332, 2000.

RENNINGS, K.; ZWICK, T. Employment Impact of Cleaner Production on the Firm Level: Empirical Evidence from a Survey in Five European Countries. International Journal of Innovation Management, v. 6, n. 3, p. 319, 2002.

RICHTER, N. F. et al. A critical look at the use of SEM in international business research. International Marketing Review, v. 33, n. 3, p. 376-404, 2016.

RINGLE, C. M.; DA SILVA, D.; BIDO, D. D. S. Modelagem de Equações estruturais com Utilização do SMARTPLS. Revista Brasileira de Marketing, v. 13, n. 2, p. 56-73, 2014.

ROBERT, H.; ROBERT, S.; STEVEN, W. Integrating environmental management and supply chain strategies. Business Strategy and the Environment, v. 14, n. 1, p. 1-19, 2005.

RONG, K.; LIU, Z.; SHI, Y. Reshaping the business ecosystem in China: Case studies and implications. Journal of Science and Technology Policy in China, v. 2, n. 2, p. 171-192, 2011.

RONG, K.; SHI, Y. Renew business ecosystem: A comparison study between traditional and Shanzhai network. IEEE INTERNATIONAL CONFERENCE ON INDUSTRIAL

ENGINEERING AND ENGINEERING MANAGEMENT, Macao, China, 2010. Anais [...], Macao, China: IEEE.

ROSCA, E.; ARNOLD, M.; BENDUL, J. C. Business models for sustainable innovation - an empirical analysis of frugal products and services. Journal of Cleaner Production, v. 162, p. S133-S145, 2017.

ROSCA, E.; REEDY, J.; BENDUL, J. C. Does Frugal Innovation Enable Sustainable Development? A Systematic Literature Review. European Journal of Development Research, v. 30, n. 1, p. 136-157, 2018.

ROSCOE, S.; COUSINS, P. D.; LAMMING, R. C. Developing eco-innovations: A threestage typology of supply networks. Journal of Cleaner Production, v. 112, p. 1948-1959, 2016.

ROSSETTO, D. E.; BORINI, F. M. A Proposed Instrument for Measuring Frugal Innovation: The First Stage of Development a New Scale. Academy of Management Proceedings. Anais [...]. Briarcliff Manor, NY, 2017

ROY, M.; KHASTAGIR, D. Exploring role of green management in enhancing organizational efficiency in petro-chemical industry in India. Journal of Cleaner Production, v. 121, p. 109-115, 2016.

RUSINKO, C. Green Manufacturing: An Evaluation of Environmentally Sustainable Manufacturing Practices and Their Impact on Competitive Outcomes. IEEE Transactions on Engineering Management, v. 54, n. 3, p. 445-454, 2007.

RUSSO, M. V; FOUTS, P. A.; RUSSO, M. V. A Resource-Based Perspective on Corporate 
Environmental Performance and Profitability. Academy of Management, v. 40, n. 3, p. 534$559,1997$.

SAMMER, K.; WÜSTENHAGEN, R. The influence of eco-labelling on consumer behaviour - Results of a discrete choice analysis for washing machines. Business Strategy and the Environment, v. 15, n. 3, p. 185-199, 2006.

SANNI, M. Technological Forecasting \& Social Change Drivers of eco-innovation in the manufacturing sector of Nigeria. Technological Forecasting \& Social Change, v. 131, n. October 2017, p. 303-314, 2018.

SANTANGELO, G. D.; MEYER, K. E. Extending the internationalization process model: Increases and decreases of MNE commitment in emerging economies. Journal of International Business Studies, v. 42, n. 7, p. 894-909, 2011.

SANTOS, L. L.; BORINI, F. M.; OLIVEIRA JÚNIOR, M. de M. In search of the frugal innovation strategy. Review of International Business and Strategy, v. 30, n. 2, p. 245-263, 2020.

SARKIS, J.; GONZALEZ-TORRE, P.; ADENSO-DIAZ, B. Stakeholder pressure and the adoption of environmental practices: The mediating effect of training. Journal of Operations Management, v. 28, n. 2, p. 163-176, 2010.

SCHALTEGGER, S.; HANSEN, E. G.; LÜDEKE-FREUND, F. Business Models for Sustainability: Origins, Present Research, and Future Avenues. Organization and Environment, v. 29, n. 1, p. 3-10, 2016.

SCHIEDERIG, T.; TIETZE, F.; HERSTATT, C. Green innovation in technology and innovation management - an exploratory literature review. R\&D Management, v. 42, n. 2, p. 180-192, Mar. 2012.

SCHOT, J.; GEELS, F. W. Strategic niche management and sustainable innovation journeys: theory, findings, research agenda, and policy. Technology Analysis \& Strategic Management, v. 20, n. 5, p. 537-554, 2008.

SEGARRA-OÑA, M.; PEIRÓ-SIGNES, Á.; MONDÉJAR-JIMÉNEZ, J. Twisting the twist: how manufacturing \& knowledge-intensive firms excel over manufacturing \& operational and all service sectors in their eco-innovative orientation. Journal of Cleaner Production, v. 138, p. 19-27, Dec. 2016.

SEGARRA-ONA, M.; PEIRO-SIGNES, A.; PAYA-MARTINEZ, A. Factors Influencing Automobile Firms' Eco-Innovation Orientation. Emj-Engineering Management Journal, v. 26, n. 1, p. 31-38, 2014.

SEMENOVA, N.; HASSEL, L. G. Financial Outcomes of Environmental Risk. Sustainable Development, v. 212, n. 3, p. 195-212, 2008.

SETH, D.; PANIGRAHI, A. Application and evaluation of packaging postponement strategy to boost supply chain responsiveness: A case study. Production Planning and Control, v. 26, n. 13, p. 1069-1089, 2015. 
SETH, D.; TRIPATHI, D. A critical study of TQM and TPM approaches on business performance of Indian manufacturing industry. Total Quality Management and Business Excellence, v. 17, n. 7, p. 811-824, 2006.

SETH, D.; TRIPATHI, D. Relationship between TQM and TPM implementation factors and business performance of manufacturing industry in Indian context. International Journal of Quality and Reliability Management, v. 22, n. 3, p. 256-277, 2005.

SHAN, J.; KHAN, M. A. Implications of reverse innovation for socio-economic sustainability: A case study of Philips China. Sustainability, v. 8, n. 6, p. 530, 2016.

SHARMA, A.; IYER, G. R. Resource-constrained product development: Implications for green marketing and green supply chains. Industrial Marketing Management, v. 41, n. 4, p. 599-608, 2012.

SHARMA, S. Managerial interpretations and organizational context as predictors of corporate choice of environmental strategy. Academy of Management Journal, v. 43, n. 4, p. 681-697, 2000 .

SHARMA, S.; PABLO, A. L.; VREDENBURG, H. Corporate environmental responsiveness strategies: The importance of Issue Interpretation and Organizational Context. The Journal of Applied Behavioral Science, v. 35, n. 1, p. 87-108, 1999.

SHIBIN, K. T. et al. Frugal innovation for supply chain sustainability in SMEs: multi-method research design. Production Planning and Control, v. 29, n. 11, p. 908-927, 2018.

SHRIMALI, G. et al. Improved stoves in India: A study of sustainable business models. Energy Policy, v. 39, n. 12, p. 7543-7556, 2011.

SHRIVASTAVA, P. The Role of Corporations in Achieving Ecological Sustainability. Academy of Management Review, v. 20, n. 4, p. 936-960, 1995.

SHRIVASTAVA, S.; SHRIVASTAVA, R. L. A systematic literature review on green manufacturing concepts in cement industries. International Journal of Quality \& Reliability Management, v. 34, n. 1, p. 68-90, 2017.

SHU, C. et al. How Green Management Influences Product Innovation in China: The Role of Institutional Benefits. Journal of Business Ethics, v. 133, n. 3, p. 471-485, 2016.

SIMULA, H.; HOSSAIN, M.; HALME, M. Frugal and reverse innovations. Current Science, v. 109, n. 9, p. 1567-1572, 2015.

SINGH, R.; GUPTA, V.; MONDAL, A. Jugaad-From "Making Do" and "Quick Fix" to an Innovative, Sustainable and Low-Cost Survival Strategy at the Bottom of the Pyramid. International Journal of Rural Management, v. 8, n. 1-2, p. 87-105, 2012.

SMINK, M. M.; HEKKERT, M. P.; NEGRO, S. O. Keeping sustainable innovation on a leash? Exploring incumbents' institutional strategies. Business Strategy and the Environment, v. 24, n. 2, p. 86-101, 2015. 
SONI, P.; KRISHNAN, R. T. Frugal innovation: Aligning theory, practice, and public policy. Journal of Indian Business Research, v. 6, n. 1, p. 29-47, 2014.

SOSIK, J. J.; KAHAI, S. S.; PIOVOSO, M. J. Silver bullet or voodoo statistics? A primer for using the partial least squares data analytic technique in group and organization research.

Group and Organization Management, v. 34, n. 1, p. 5-36, 2009.

SOUSA, R.; VOSS, C. A. Contingency research in operations management practices.

Journal of Operations Management, v. 26, n. 6, p. 697-713, 2008.

SRIVASTAVA, S. K. Green supply-chain management: A state-of-the-art literature review. International Journal of Management Reviews, v. 9, n. 1, p. 53-80, 2007.

SROUFE, R. Effects of Environmental Management Systems on Environmental Management Practices and Operations. Production and Operations Management, v. 12, n. 3, p. 416-431, 2003.

STAHEL, W. R. The Functional Economy: Cultural and Organizational Change. International Journal of Performability Engineering, v. 1, n. 2, p. 121-130, 2005.

SUCHMAN, M. C. Managing Legitimacy: Strategic and Institutional Approaches. The Academy of Management Review, v. 20, n. 3, p. 571-610, 1995.

SZWILSKI, T. B. Using environmental management systems to systematically improve operational performance and environmental protection. International Journal of Surface Mining, Reclamation and Environment, v. 14, n. 3, p. 183-191, 2000.

TAAL, M. et al. Success from the Bottom Up. Business Horizons, v. 55, n. 3, p. 1-19, 2012.

TAN, C. L. et al. The impact of green supply chain management practices on firm competitiveness. International Journal of Business Innovation and Research, v. 11, n. 4, p. 539-558, 2016.

TESTA, F.; IRALDO, F. Shadows and lights of GSCM (green supply chain management): Determinants and effects of these practices based on a multi-national study. Journal of Cleaner Production, v. 18, n. 10-11, p. 953-962, 2010.

THEYEL, G. Management Practices for Environmental Innovation and Performance. International Journal of Operations \& Production Management, v. 20, n. 2, p. 249-266, 2000 .

THEYEL, G.; HOFMANN, K. H. Environmental practices and innovation performance of US small and medium-sized manufacturers. Journal of Manufacturing Technology Management, v. 26, n. 3, p. 333-348, 2015.

TIWARI, R.; FISCHER, L.; KALOGERAKIS, K. Frugal Innovation in Scholarly and Social Discourse: An Assessment of Trends and Potential Societal Implications. Leipzig: Fraunhofer Moez Leipzig; Hamburg: Hamburg University of Technology in the BMBF ITA. Mar. 2016. (Working Paper of Project Potenziale Frugaler Innovationen). Disponível em: 
https://tubdok.tub.tuhh.de/bitstream/11420/1291/1/Tiwari_et_al_2016_Frugal_Innovation_B MBF_ITA.pdf. Acesso em: 11 dez. 2020.

TIWARI, R.; HERSTATT, C. Assessing India's lead market potential for cost-effective innovations. Journal of Indian Business Research, v. 4, n. 2, p. 97-115, 2012a.

TIWARI, R.; HERSTATT, C. Frugal Innovation: A Global Networks' Perspective. Swiss Journal of Business Research and Practice, v. 66, n. 3, p. 245-274, 2012 b.

TIWARI, R.; HERSTATT, C. Frugal innovations for the "unserved" customer: An assessment of India's attractiveness as a lead Market for cost-effective products. Technology and Innovation Management Working Paper, n. 69, 2012c.

TIWARI, R.; KALOGERAKIS, K. A Bibliometric Analysis of Academic Papers on Frugal Innovation. Center for Frugal Innovation Institute for Technology and Innovation Management, Hamburg University of Technology, Hamburg, Germany, 2016. (Working Paper n. 93). Disponível em:

https://tore.tuhh.de/bitstream/11420/1314/1/Working_Paper_93.pdf. Acesso em: $11 \mathrm{dez}$. 2020.

TIWARI, R.; KALOGERAKIS, K.; HERSTATT, C. Frugal innovation and analogies: some propositions for product development in emerging economies. Center for Frugal Innovation Institute for Technology and Innovation Management, Hamburg University of Technology, Hamburg, Germany, 2014. (Working Paper n. 84). Disponível em: https://tore.tuhh.de/handle/11420/1175. Acesso em: 14 dez. 2020.

TOLBERT, P. S.; ZUCKER, L. G. The Institutionalization of Institutional Theory. In: CLEGG, S.; HARDY, C; NORD, W. (ed.), Handbook of organization studies. London, England: Sage, 1996. pp. 175-190.

TRIEBSWETTER, U.; WACKERBAUER, J. Integrated environmental product innovation in the region of Munich and its impact on company competitiveness. Journal of Cleaner Production, v. 16, n. 14, p. 1484-1493, 2008.

TRIGUERO, A.; MORENO-MONDÉJAR, L.; DAVIA, M. A. Drivers of different types of eco-innovation in European SMEs. Ecological Economics, v. 92, p. 25-33, 2013.

TRIGUERO, A.; MORENO-MONDÉJAR, L.; DAVIA, M. A. Eco-innovation by small and medium-sized firms in Europe: From end-of-pipe to cleaner technologies. Innovation:

Management, Policy and Practice, v. 17, n. 1, p. 24-40, 2015.

TSAI, M. T. et al. The effects assessment of firm environmental strategy and customer environmental conscious on green product development. Environmental Monitoring and Assessment, v. 184, n. 7, p. 4435-4447, 2012.

URPELAINEN, J. Energy poverty and perceptions of solar power in marginalized communities: Survey evidence from Uttar Pradesh, India. Renewable Energy, v. 85, p. 534539, 2016. 
VACHON, S.; KLASSEN, R. D. Green project partnership in the supply chain: The case of the package printing industry. Journal of Cleaner Production, v. 14, n. 6-7, p. 661-671, 2006.

VARGO, S. L.; WIELAND, H.; AKAKA, M. A. Innovation through institutionalization: A service ecosystems perspective. Industrial Marketing Management, v. 44, p. 63-72, 2015.

VERBEKE, A.; BUYSSE, K. Proactive environmental strategies: astakeholder management perspective. Strategic Management Journal, v. 24, n. 5, p. 453-470, 2003.

VIJAYVARGY, L.; THAKKAR, J.; AGARWAL, G. Green supply chain management practices and performance: the role of firm-size for emerging economies. Journal of Manufacturing Technology Management, v. 28, n. 3, p. 299-323, 2017.

VILCHEZ, V. F.; HIZ, D. I. de L. Lessons on Frugal Eco-Innovation: More with less in European Business Context. The Critical State of Corporate Social Responsibility in Europe, v. 12, p. 279-298, 2018.

VON JANDA, S. et al. What frugal products are and why they matter: A cross-national multimethod study. Journal of Cleaner Production, v. 246, p. 118977, 2020.

WAGNER, M. Empirical influence of environmental management on innovation: Evidence from Europe. Ecological Economics, v. 66, n. 2-3, p. 392-402, 2008.

WAGNER, M. On the relationship between environmental management, environmental innovation and patenting: Evidence from German manufacturing firms. Research Policy, v. 36, n. 10, p. 1587-1602, 2007.

WENG, H.-H.; CHEN, J.-S.; CHEN, P.-C. Effects of Green Innovation on Environmental and Corporate Performance: A Stakeholder Perspective. Sustainability, v. 7, n. 5, p. 4997-5026, 2015.

WERTS, Charles E.; LINN, Robert L.; JÖRESKOG, Karl G. Intraclass reliability estimates: Testing structural assumptions. Educational and Psychological measurement, v. 34, n. 1, p. 25-33, 1974.

WESTLAND, J. Christopher. Lower bounds on sample size in structural equation modeling. Electronic commerce research and applications, v. 9, n. 6, p. 476-487, 2010.

WEYRAUCH, T.; HERSTATT, C. What is frugal innovation? Three defining criteria. Journal of Frugal Innovation, v. 2, n. 1, p. 1-17, 2016.

WIJETHILAKE, C.; MUNIR, R.; APPUHAMI, R. Strategic responses to institutional pressures for sustainability: The role of management control systems. Accounting, Auditing and Accountability Journal, v. 30, n. 8, p. 1677-1710, 2017.

WILLIAMSON, P. J. Cost innovation: Preparing for a "value-for-money" revolution. Long Range Planning, v. 43, n. 2-3, p. 343-353, 2010. 
WINTERHALTER, S. et al. Business Models for Frugal Innovation in Emerging Markets: The Case of the Medical Device and Laboratory Equipment Industry. Technovation, v. 66, p. 3-13, 2017.

WOHLFART, L. et al. The two faces of frugal Innovation - Bridging gaps to foster successful innovation strategies. In: THE INTERNATIONAL SOCIETY FOR PROFESSIONAL INNOVATION MANAGEMENT (ISPIM) INNOVATION SYMPOSIUM, Manchester, 2015. Anais [...]. Manchester, England: ISPIM. p. 1-15.

XAVIER, A. F. et al. Systematic literature review of eco-innovation models: Opportunities and recommendations for future research. Journal of Cleaner Production, v. 149, p. 1278$1302,2017$.

XIAO, C. et al. When Does Corporate Sustainability Performance Pay off? The Impact of Country-Level Sustainability Performance. Ecological Economics, v. 146, p. 325-333, 2018.

XIE, Z.; LI, J. Demand Heterogeneity, Learning Diversity and Innovation in an Emerging Economy. Journal of International Management, v. 21, n. 4, p. 277-292, 2015.

YANG, C. H.; TSENG, Y. H.; CHEN, C. P. Environmental regulations, induced R\&D, and productivity: Evidence from Taiwan's manufacturing industries. Resource and Energy Economics, v. 34, n. 4, p. 514-532, 2012.

YANG, M. X. et al. Environmentally sustainable or economically sustainable? The effect of Chinese manufacturing firms' corporate sustainable strategy on their green performances.

Business Strategy and the Environment, v. 28, n. 6, p. 989-997, 2019.

YE, F. et al. The impact of institutional pressures, top managers' posture and reverse logistics on performance - Evidence from China. International Journal of Production Economics, v. 143, n. 1, p. 132-143, 2013.

YIN, H.; SCHMEIDLER, P. J. Why Do Standardized ISO 14001 Environmental Management Systems Lead to Heterogeneous Environmental Outcomes? Business Strategy and the Environment, v. 18, p. 469-486, 2009.

YU LIN, C.; HUI HO, Y. An Empirical Study on Logistics services provider, intention to adopt Green Innovations. Journal of Technology, Management and Innovation, v. 3, n. 1, p. 17-26, 2008.

YU, Y.; HUO, B. The impact of environmental orientation on supplier green management and financial performance: The moderating role of relational capital. Journal of Cleaner Production, v. 211, p. 628-639, 2019.

YUAN, B.; XIANG, Q. Environmental regulation, industrial innovation and green development of Chinese manufacturing: Based on an extended CDM model. Journal of Cleaner Production, v. 176, p. 895-908, 2018.

YUNFENG, Y. F.; LAIKE, Y. K. China's foreign trade and climate change: A case study of CO2 emissions. Energy Policy, v. 38, n. 1, p. 350-356, 2010. 
ZAKARYA, G. Y. et al. Factors Affecting CO2 Emissions in the BRICS Countries: A Panel Data Analysis. Procedia Economics and Finance, v. 26, p. 114-125, 2015.

ZEDTWITZ, M. VON et al. A Typology of Reverse Innovation. Journal of Product Innovation Management, v. 32, n. 1, p. 12-28, 2015.

ZESCHKY, M.; WIDENMAYER, B.; GASSMANN, O. Frugal Innovation in Emerging Markets: The case of Mettler Toledo. Research-Technology Management, v. 54, n. 4, p. 3845, 2011.

ZESCHKY, M.; WINTERHALTER, B.; GASSMANN, O. From Cost to Frugal and Reverse Innovation: Mapping the Field and Implications for Global Competitiveness. ResearchTechnology Management, v. 57, n. 4, p. 20-27, 2014.

ZHAN, Y. et al. Green and lean sustainable development path in China: Guanxi, practices and performance. Resources, Conservation and Recycling, v. 128, p. 240-249, 2018.

ZHANG, F. et al. Toward an systemic navigation framework to integrate sustainable development into company. Journal of Cleaner Production, v. 54, p. 199-214, 2013.

ZHANG, K. M.; WEN, Z. G. Review and challenges of policies of environmental protection and sustainable development in China. Journal of Environmental Management, v. 88, n. 4, p. 1249-1261, 2008.

ZHAO, J. The effect of the ISO-14001 environmental management system on corporate financial performance. International Journal of Business Excellence, v. 1, n. 1-2, p. 210$230,2008$.

ZHU, Q.; SARKIS, J. An inter-sectoral comparison of green supply chain management in China: Drivers and practices. Journal of Cleaner Production, v. 14, n. 5, p. 472-486, 2006.

ZHU, Q.; SARKIS, J. Relationships between operational practices and performance among early adopters of green supply chain management practices in Chinese manufacturing enterprises. Journal of Operations Management, v. 22, n. 3, p. 265-289, 2004.

ZHU, Q.; SARKIS, J.; LAI, K. H. Green supply chain management: pressures, practices and performance within the Chinese automobile industry. Journal of Cleaner Production, v. 15, n. 11-12, p. 1041-1052, 2007a.

ZHU, Q.; SARKIS, J.; LAI, K. H. Initiatives and outcomes of green supply chain management implementation by Chinese manufacturers. Journal of Environmental Management, v. 85, p. 179-189, 2007b.

ZHU, Q.; SARKIS, J.; LAI, K. H. Institutional-based antecedents and performance outcomes of internal and external green supply chain management practices. Journal of Purchasing and Supply Management, v. 19, n. 2, p. 106-117, 2013.

ZHU, W.; HE, Y. Green product design in supply chains under competition. European Journal of Operational Research, v. 258, n. 1, p. 165-180, 2017. 
ZIKMUND, W. G. Princípios da pesquisa de marketing. São Paulo: Pioneira Thomson Learning, 2006. 
APÊNDICE A - QUESTIONÁRIO EM INGLÊS 


\section{QUESTIONÁRIO EM INGLÊS}

QUESTIONNAIRE

Please, rate each of the following from strongly disagree to strongly agree

$\mathbf{1}$ - Considering the position listed below, which position is closest to your current position?

$\square$ Owner, President or Vice-President

Director or C-Level

$\square$ Manager

Coordinator or Consultant

Analyst

Others

$\mathbf{2}-$ My company has assigned great importance to......

\begin{tabular}{|c|c|c|c|c|c|c|}
\hline \multicolumn{3}{|c|}{$\begin{array}{l}\text { Strongly } \\
\text { Disagree }\end{array}$} & \multicolumn{3}{|c|}{$\begin{array}{l}\text { Strongly } \\
\text { Agree }\end{array}$} & \\
\hline & 2 & 3 & 4 & 5 & 6 & 7 \\
\hline & ם & 口 & 口 & ם & 口 & \\
\hline & $\begin{array}{l}\square \\
\square \\
\end{array}$ & & $\begin{array}{l}\square \\
\square\end{array}$ & $\begin{array}{l}\square \\
\square\end{array}$ & & \\
\hline & ם & & 口 & ם & $\square$ & \\
\hline & $\begin{array}{l}\square \\
\square \\
\square \\
\square \\
\square \\
\square \\
\square\end{array}$ & & $\begin{array}{l}\square \\
0 \\
0 \\
\square \\
0 \\
0\end{array}$ & $\begin{array}{l}\square \\
\square \\
\square \\
\square \\
\square \\
\square \\
0\end{array}$ & $\begin{array}{l}\square \\
\square \\
\square \\
\square \\
\square \\
\square\end{array}$ & \\
\hline
\end{tabular}

1 The core functionality of the product rather than additional functionality.

2 ease of product use.

3 the question of the durability of the product (does not spoil easy).

4 efficient and effective solutions to customers' social/environmental needs.

5 solutions that offer "good value" products.

6 significant cost reduction in the operational process.

7 savings of organizational resources in the operational process.

8 rearrangement of organizational resources in the operational process.

9 environmental sustainability in the operational process.

10 partnerships with local companies in the operational process.

3 - Regard the firm where you work...

\begin{tabular}{llllll}
$\begin{array}{l}\text { Strongly } \\
\text { Disagree }\end{array}$ & \multicolumn{3}{c}{$\begin{array}{c}\text { Strongly } \\
\text { Agree }\end{array}$} \\
$\begin{array}{lllllll}1 & 2 & 3 & 4 & 5 & 6\end{array}$
\end{tabular}

1 Our company allocates adequate resources for new green innovation initiatives/activities.

2 There are emphasizes on process innovation that promotes green initiatives.

3 Our top management emphasizes product innovation that promotes green initiatives.

4 Green life-cycle assessment is an important criterion while developing new products.

5 Our company competes on innovative driven goals and green initiatives.

6 Our company aggressively conducts training and education in innovation-based green initiatives.

5 - Compared to our competitors ...

$\begin{array}{ll}\text { Strongly } & \begin{array}{l}\text { Strongly } \\ \text { Disagree }\end{array} \\ \text { Agree }\end{array}$

1 Our operating costs are lower.

2 Our prices of products/services are more competitive.

3 We have better compliance with product / service specifications.

4 We have better product quality/service performance.

5 We have better delivery time.

$6 \quad$ We have better speed of delivery.

7 We have better flexibility of production capacity.

8 We have the best range of products/service.

9 We have better ROI (Return over investment).

10 We have better Sales growth.

11 We have better Market Share growth.

12 We have better Profit Level growth.

$\begin{array}{lllllll}1 & 2 & 3 & 4 & 5 & 6 & 7\end{array}$

$\begin{array}{lllllll}1 & 2 & 3 & 4 & 5 & 6 & 7\end{array}$

$\begin{array}{lllllll}\square & \square & \square & \square & \square & \square & \square \\ \square & \square & \square & \square & \square & \square & \square\end{array}$

$\square \square \square \square \quad \square \quad \square \quad \square$

$\square \quad \square \quad \square \quad \square \quad \square \quad \square \quad \square$

$\begin{array}{lllllll}\square & \square & \square & \square & \square & \square & \square \\ \square & \square & \square & \square & \square & \square & \square\end{array}$

$\square \quad \square \quad \square \quad \square \quad \square \quad \square \quad \square$

$\square \quad \square \quad \square \quad \square \quad \square \quad \square \quad \square$

$\begin{array}{lllllll}\square & \square & \square & \square & \square & \square & \square \\ \square & \square & \square & \square & \square & \square & \square\end{array}$

$\square \quad \square \quad \square \quad \square \quad \square \quad \square \quad \square$

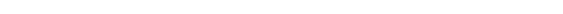


6 - In order to develop innovation activities, my company is under pressure from...

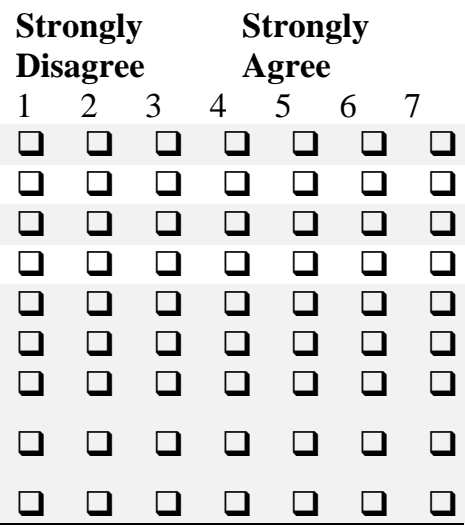

1 Emission standards.

2 Production technology standards.

3 Legal risks.

4 Government supervision.

5 Administrative penalties.

6 Increased awareness of environmental issues among our customers.

7 Customers' preferences for environmentally friendly products.

8 Customers' continuous attention to our firm' environmental behavior.

9 Customers who seek green suppliers.

7 - How many employees work in your company?

Up to 50 employees.

$\square$ From 51 to 250 employees.

From 251 to 500 employees.

From 501 to 1000 employees.

More than 1000 employees. 
APÊNDICE B - QUESTIONÁRIO EM PORTUGUÊS 


\section{QUESTIONÁRIO EM PORTUGUÊS}

\section{Questionário}

Classifique cada uma das seguintes opções de discordo totalmente e concordo totalmente

1 - Considerando os cargos listados abaixo, qual deles mais se aproxima de seu cargo atual?

$\square$ Proprietário, Presidente ou Vice-Presidente

Diretor ou C-Level

$\square$ Gerente

Coordenador ou Consultor

Analista

Outros

2 - Minha empresa atribui grande importância ...

$\begin{array}{ll}\begin{array}{l}\text { Discordo } \\ \text { fortemente }\end{array} & \begin{array}{l}\text { Concordo } \\ \text { fortemente }\end{array} \\ 1 & 2\end{array}$

1 à funcionalidade principal do produto/serviço, em vez da funcionalidade adicional.

2 à facilidade de uso do produto/serviço.

3 à questão da durabilidade do produto (não estraga fácil).

4 a soluções eficientes e eficazes para as necessidades sociais/ambientais dos clientes.

5 às soluções que oferecem produtos/serviços "bons e baratos".

6 à redução significativa de custos no processo operacional.

7 à economia de recursos organizacionais no processo operacional.

8 ao rearranjo de recursos organizacionais no processo operacional.

9 à sustentabilidade ambiental no processo operacional.

10 às parcerias com empresas locais no processo operacional.

3 - Em relação à empresa onde você trabalha...

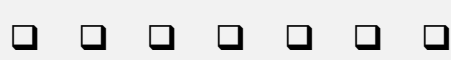

$\begin{array}{lllllll}\square & \square & \square & \square & \square & \square & \square \\ \square & \square & \square & \square & \square & \square & \square\end{array}$

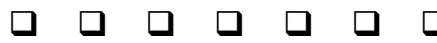

1 são alocados recursos adequados para novas iniciativas de inovação verde.

2 há ênfase na inovação de processos que promovem iniciativas verdes.

3 a gerência enfatiza a inovação de produtos/serviços que promovem iniciativas verdes.

4 a avaliação do ciclo de vida verde é um critério importante no desenvolvimento de novos produtos/serviços.

5 competimos em objetivos inovadores e iniciativas verdes.

6 são realizados, com frequência, treinamentos e educação em iniciativas verdes, baseados em inovação.

4 - Minha empresa...

1 produz produtos com conteúdo reutilizado ou reciclado, como plásticos e vidro.

2 usa avaliação do ciclo de vida para avaliar a poluição ambiental dos produtos.

3 produz produtos isentos de substâncias perigosas, tais como chumbo, mercúrio etc.

4 projeta produtos para garantir que eles tenham conteúdo reciclável ou reutilizável.

5 produz produtos que reduzem o consumo de materiais e energia durante o uso.

6 reduz o consumo de energia durante a fabricação e transporte.

7 aumenta a vida útil do produto, resultando em maior eficiência e produtividade.

$\begin{array}{ll}\text { Discordo } & \text { Concordo } \\ \text { fortemente } & \text { fortemente }\end{array}$
$\begin{array}{lllllll}1 & 2 & 3 & 4 & 5 & 6 & 7\end{array}$

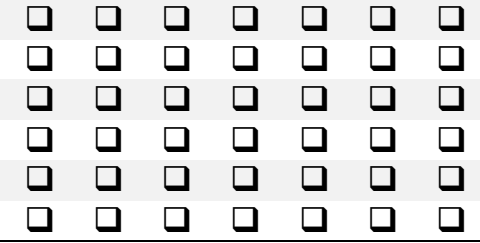

Discordo

Concordo

fortemente fortemente

$\begin{array}{lllllll}1 & 2 & 3 & 4 & 5 & 6 & 7\end{array}$

$\square \square \square \square \square \square \square$

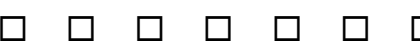

$\square \square \square \square \square \square \square$

$\square \square \square \square \square \square \square$

$\square \square \square \square \square \square \square$

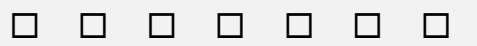

$\square-\square-\square$ 


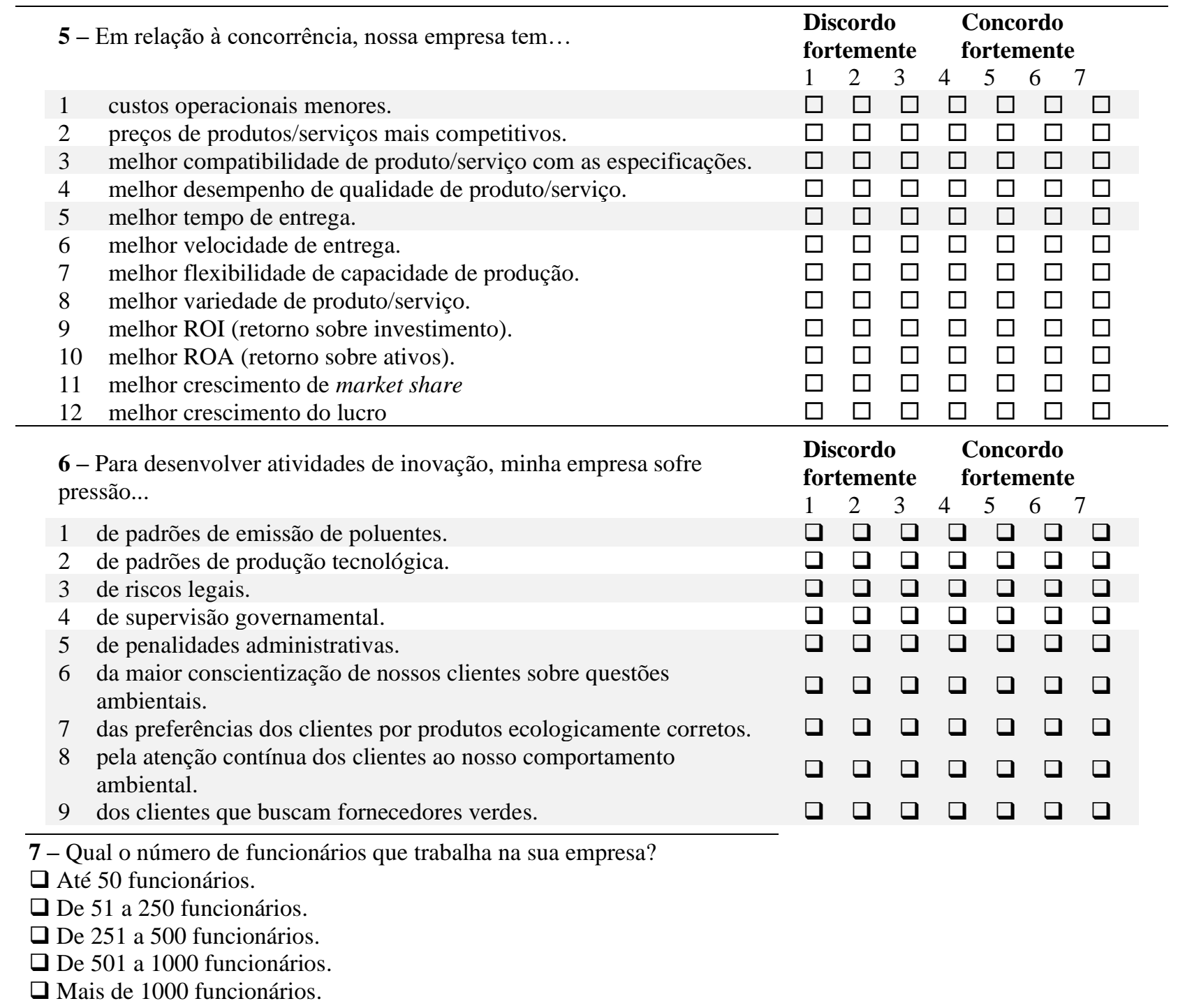


APÊNDICE C - CONCEITOS DE ECOINOVAÇÃO 


\section{CONCEITOS DE ECOINOVAÇÃO}

\begin{tabular}{|c|c|}
\hline Autor(es) & Conceito \\
\hline (FUSSLER; JAMES, 1996) & $\begin{array}{l}\text { Processo de desenvolvimento de novos produtos, processos ou serviços que agregam valor ao cliente e ao negócio, reduzindo o } \\
\text { impacto ambiental. }\end{array}$ \\
\hline (AZZONE; NOCI, 1998) & É um meio de impulsionar a diferenciação de produtos. \\
\hline (ARUNDEL; KEMP, 2009) & $\begin{array}{l}\text { Inovações ambientais são processos, equipamentos, produtos, técnicas e sistemas de gerenciamento novos e modificados, que } \\
\text { evitam ou reduzem os impactos ambientais prejudiciais. }\end{array}$ \\
\hline (RENNINGS, 2000) & $\begin{array}{l}\text { Ecoinovações são processos de inovação em direção ao desenvolvimento sustentável. Inovações ambientais são medidas de atores } \\
\text { relevantes (firmas, particulares), que: (1) desenvolvem novas ideias, comportamentos, produtos e processos, aplicam ou os } \\
\text { apresenta; e (2) contribuem para a redução dos encargos ambientais ou para metas de sustentabilidade ecológica. }\end{array}$ \\
\hline $\begin{array}{l}\text { (BRUNNERMEIER; COHEN, 2003; } \\
\text { CHEN; LAI; WEN, 2006; CHENG; SHIU, } \\
\text { 2012; CHIOU et al., 2011) }\end{array}$ & $\begin{array}{l}\text { Está relacionada a produtos ou processos verdes, abrangendo tecnologias voltadas à(aos): economia de energia, prevenção da } \\
\text { poluição, reciclagem de resíduos, projetos, gestão ambiental corporativa, eliminação do uso/geração de substâncias perigosas. }\end{array}$ \\
\hline (BEISE; RENNINGS, 2005) & $\begin{array}{l}\text { É um meio de melhorar a ecoeficiência em nível nacional, em que as organizações implementam ferramentas para melhorar a } \\
\text { ecoinovação. }\end{array}$ \\
\hline $\begin{array}{l}\text { (CAINELLI; MAZZANTI; ZOBOLI, } \\
\text { 2011; DE MARCHI, 2012; HORBACH, } \\
\text { 2008; REHFELD; RENNINGS; } \\
\text { ZIEGLER, 2007; THEYEL, 2000) }\end{array}$ & $\begin{array}{l}\text { Produção, assimilação e exploração de um produto, processo de produção, serviço ou gestão, ou método de negócios novo para a } \\
\text { organização (desenvolvimento ou adoção), e que resulta, por meio do seu ciclo de vida, na redução do risco ambiental, da poluição } \\
\text { ou de outros impactos negativos de uso de recursos (incluindo de energia), comparado a alternativas relevantes. }\end{array}$ \\
\hline (CHARTER; CLARK, 2007) & $\begin{array}{l}\text { Processo no qual as considerações sustentáveis são integradas nos sistemas da organização, da geração de ideias à P\&D e } \\
\text { comercialização. }\end{array}$ \\
\hline$($ EKINS, 2010) & Subclasse da inovação, que atua entre os aspectos econômicos e ambientais da inovação. \\
\hline $\begin{array}{l}\text { (HORBACH; RAMMER; RENNINGS, } \\
\text { 2012) }\end{array}$ & $\begin{array}{l}\text { São inovações de produtos, processos, marketing e organizacional, que levam a uma redução notável dos encargos ambientais. Os } \\
\text { efeitos da inovação podem ocorrer dentro da organização ou pelo uso pelos clientes. }\end{array}$ \\
\hline $\begin{array}{l}\text { (GARCÍA-GRANERO; PIEDRA- } \\
\text { MUÑOZ; GALDEANO-GÓMEZ, 2018) }\end{array}$ & $\begin{array}{l}\text { Alvo para as organizações se tornarem mais sustentáveis, reduzindo externalidades negativas e atendendo a requisitos ecológicos } \\
\text { dos governos e às exigências dos consumidores. }\end{array}$ \\
\hline $\begin{array}{l}\text { (CARRILLO-HERMOSILLA; } \\
\text { GONZÁLEZ; KÖNNÖLÄ, 2009) }\end{array}$ & $\begin{array}{l}\text { Ecoinovação é um processo de mudança sistêmica, tecnológica e/ou social, que consiste na invenção de uma ideia e sua aplicação } \\
\text { na prática da melhoria ambiental. }\end{array}$ \\
\hline $\begin{array}{l}\text { (SEGARRA-ONA; PEIRO-SIGNES; } \\
\text { PAYA-MARTINEZ, 2014) }\end{array}$ & $\begin{array}{l}\text { Ecoinovação não inclui somente a modificação de padrões de produção e consumo, mas também considera o desenvolvimento de } \\
\text { tecnologias, produtos e serviços para reduzir o impacto no ambiente. }\end{array}$ \\
\hline
\end{tabular}

Fonte: Autora. 
APÊNDICE D - RELAÇÃO DAS PRÁTICAS DE MANUFATURA E DESEMPENHO ORGANIZACIONAL/OPERACIONAL 


\section{RELAÇÃO DAS PRÁTICAS DE MANUFATURA E DESEMPENHO ORGANIZACIONAL/OPERACIONAL}

\begin{tabular}{|c|c|c|c|c|c|}
\hline Artigo & Amostra & País & Metodologia & $\begin{array}{l}\text { Relação } \\
\text { com } \\
\text { desempenho } \\
\text { operacional } \\
\end{array}$ & $\begin{array}{l}\text { Relação com } \\
\text { desempenho } \\
\text { organizacional } \\
\text { e/ou financeiro }\end{array}$ \\
\hline (SROUFE, 2003) & 1,118 respondentes em empresas de manufatura. & EUA & $\begin{array}{l}\text { Modelo de Equações } \\
\text { Estruturais }\end{array}$ & Positiva & Positiva \\
\hline $\begin{array}{l}\text { (MONTABON; } \\
\text { SROUFE; } \\
\text { NARASIMHAN, 2007) }\end{array}$ & $\begin{array}{l}45 \text { relatórios corporativos de desempenho em empresas } \\
\text { com destaque em desempenho ambiental, na visão de } \\
\text { acadêmicos e executivos. }\end{array}$ & $\begin{array}{l}\text { EUA, Reino Unido e } \\
\text { Austrália }\end{array}$ & Modelo de Regressão & Positiva & Negativa \\
\hline $\begin{array}{l}\text { (PRZYCHODZEN; } \\
\text { PRZYCHODZEN, 2015) }\end{array}$ & $\begin{array}{l}439 \text { organizações ( } 426 \text { polonesas e } 13 \text { húngaras) de capital } \\
\text { aberto no Warsaw Stock Exchange (WSE) e no Budapest } \\
\text { Stock Exchange (BSE), entre } 2006 \text { e } 2013 \text {. }\end{array}$ & Polônia e Hungria & Modelo de Regressão & Não testada & Positiva \\
\hline (FAMIYEH et al., 2018) & $\begin{array}{l}164 \text { respondentes de grandes e médias empresas, operando } \\
\text { dentro da área metropolitana da Grande Accra }\end{array}$ & Ghana & $\begin{array}{l}\text { Modelo de Equações } \\
\text { Estruturais }\end{array}$ & Positiva & Não testada \\
\hline $\begin{array}{l}\text { (MELNYK; SROUFE; } \\
\text { CALANTONE, 2003) }\end{array}$ & $\begin{array}{l}1,222 \text { respondentes de empresas de manufatura, que têm } \\
\text { práticas de negócios ambientais. }\end{array}$ & EUA & $\begin{array}{l}\text { Modelo de } \\
\text { Regressão/ANOVA }\end{array}$ & Positiva & Não testada \\
\hline (RAO; HOLT, 2005) & $\begin{array}{l}\text { Gestores de operação de } 52 \text { empresas com certificação } \\
\text { ISO14001. }\end{array}$ & $\begin{array}{l}\text { Países do sul asiático } \\
\text { (Filipinas, Indonésia, } \\
\text { Malásia, Tailândia e } \\
\text { Singapura) }\end{array}$ & Equações Estruturais & Não testada & Negativa \\
\hline $\begin{array}{l}\text { (THEYEL; HOFMANN, } \\
\text { 2015) }\end{array}$ & 295 empresas e sete pequenas e médias empresas. & EUA & $\begin{array}{l}\text { Modelo de Regressão } \\
\text { Múltipla }\end{array}$ & Positiva & Não testada \\
\hline (REINHARDT, 1998) & Empresa: Monsanto. & EUA & Estudo de Caso & Negativa & Não testada \\
\hline (ZHU; SARKIS, 2004) & $\begin{array}{l}186 \text { respondentes de grandes empresas de manufatura e } \\
\text { processamento. }\end{array}$ & China & Modelo de Regressão & $\begin{array}{r}\text { Positiva e } \\
\text { Negativa }\end{array}$ & Não testada \\
\hline
\end{tabular}

Fonte: Autora 
APÊNDICE E - ECOINOVAÇÃO E DIMENSÕES DA INOVAÇÃO FRUGAL 


\section{ECOINOVAÇÃO E DIMENSÕES DA INOVAÇÃO FRUGAL}

\begin{tabular}{|c|c|c|c|c|c|c|}
\hline Artigo & Journal & $\begin{array}{l}\text { Descrição de } \\
\text { ecoinovação }\end{array}$ & Foco Principal & $\begin{array}{l}\text { Tipo de } \\
\text { estudo }\end{array}$ & Amostra/Dados & $\begin{array}{l}\text { Transversalidade com as dimensões da } \\
\text { inovação frugal }\end{array}$ \\
\hline $\begin{array}{l}\text { (RENNINGS, } \\
2000 \text { ) }\end{array}$ & $\begin{array}{l}\text { Ecological } \\
\text { Economics } \\
(\mathrm{FI}=3.895)\end{array}$ & $\begin{array}{l}\text { Processo de desenvolver } \\
\text { novas ideias, } \\
\text { comportamentos, } \\
\text { produtos e processos, } \\
\text { que contribuam para a } \\
\text { redução do impacto de } \\
\text { encargos financeiros ou } \\
\text { metas de sustentabilidade } \\
\text { ecológicas específicas. }\end{array}$ & $\begin{array}{l}\text { Discutir a contribuição } \\
\text { potencial das } \\
\text { abordagens neoclássica } \\
\text { e (co-)evolucionária da } \\
\text { economia ambiental e } \\
\text { da inovação. } \\
\text { Questão central: as } \\
\text { inovações voltadas à } \\
\text { sustentabilidade podem } \\
\text { ser tratadas como } \\
\text { inovações normais, ou } \\
\text { se uma nova teoria e } \\
\text { políticas específicas } \\
\text { são necessárias. }\end{array}$ & $\begin{array}{l}\text { Meta-análise } \\
\text { de } \\
\text { ecoinovação }\end{array}$ & $\begin{array}{l}\text { Literatura de } \\
\text { inovação, economia e } \\
\text { desenvolvimento } \\
\text { sustentável. }\end{array}$ & $\begin{array}{l}\text { Benefícios secundários: redução de custos, } \\
\text { aumento da competitividade, criação de novos } \\
\text { mercados para produtos e processos voltados ao } \\
\text { meio ambiente, e uso desses produtos } \\
\text { (custos/funcionalidade). } \\
\text { O custo ambiental para as organizações é mais } \\
\text { caro, quando ela tem que pagar pelas taxas de } \\
\text { poluição, do que o custo de controlar a poluição e } \\
\text { resíduos (custos). } \\
\text { A política de inovação reduz os custos de } \\
\text { inovação tecnológica, institucional e social, } \\
\text { especialmente nas fases de invenção e de } \\
\text { introdução no mercado (custos). } \\
\text { Rede científica para avaliação do impacto } \\
\text { ambiental, estabelecida em nível nacional, } \\
\text { regional e local é importante para a discussão da } \\
\text { inovação (ecossistema). }\end{array}$ \\
\hline $\begin{array}{l}\text { (THEYEL, } \\
2000)\end{array}$ & $\begin{array}{l}\text { Internation } \\
\text { al Journal } \\
\text { of } \\
\text { Operations } \\
\text { \& } \\
\text { Production } \\
\text { Managemen } \\
\text { t } \\
(\mathrm{FI}=2.955)\end{array}$ & $\begin{array}{l}\text { Processo de desenvolver } \\
\text { novas ideias, } \\
\text { comportamentos, } \\
\text { produtos e processos, } \\
\text { que contribuam para a } \\
\text { redução do impacto de } \\
\text { encargos financeiros ou } \\
\text { metas de sustentabilidade } \\
\text { ecológicas específicas. } \\
\text { (RENNINGS, 2000). }\end{array}$ & $\begin{array}{l}\text { Explora se existem } \\
\text { diferenças distintas na } \\
\text { inovação e no } \\
\text { desempenho ambiental } \\
\text { das empresas químicas } \\
\text { norte-americanas, que } \\
\text { podem ser explicadas } \\
\text { pelas diferenças nas } \\
\text { práticas e } \\
\text { características de } \\
\text { gestão das empresas. }\end{array}$ & $\begin{array}{l}\text { Quantitativo: } \\
\text { modelo de } \\
\text { regressão }\end{array}$ & $\begin{array}{l}\text { Survey e entrevistas } \\
\text { com } 188 \text { empresas } \\
\text { químicas norte- } \\
\text { americanas. }\end{array}$ & $\begin{array}{l}\text { Projetos e gestão dos resíduos: redução dos custos } \\
\text { totais ambientais e inovações ambientais na } \\
\text { organização (custos). } \\
\text { Produtos e processos redesenhados, a partir do } \\
\text { ciclo de vida, para torná-los mais seguros e } \\
\text { compatíveis ambientalmente. O ciclo de vida de } \\
\text { um produto é estudado para fechar loops de } \\
\text { produção, encontrar formas de reciclar resíduos e } \\
\text { produtos, de forma a evitar a poluição } \\
\text { (ecossistema/funcionalidade). }\end{array}$ \\
\hline
\end{tabular}

Fonte: Autora. 


\section{ECOINOVAÇÃO E DIMENSÕES DA INOVAÇÃO FRUGAL}

(continua)

\begin{tabular}{|c|c|c|c|c|c|c|}
\hline Artigo & Journal & Descrição de ecoinovação & Foco Principal & $\begin{array}{l}\text { Tipo de } \\
\text { estudo }\end{array}$ & Amostra/Dados & $\begin{array}{l}\text { Transversalidade com as } \\
\text { dimensões da inovação frugal }\end{array}$ \\
\hline $\begin{array}{l}\text { (BRUNNERMEIER; } \\
\text { COHEN, 2003) }\end{array}$ & $\begin{array}{l}\text { Journal of } \\
\text { Environmental } \\
\text { Economics } \\
\text { and } \\
\text { Management } \\
(\mathrm{FI}=4.175)\end{array}$ & $\begin{array}{l}\text { Resposta às pressões } \\
\text { regulatórias e não- } \\
\text { regulatórias, como } \\
\text { concorrência internacional, e } \\
\text { características industriais e } \\
\text { econômicas sobre as } \\
\text { empresas, para diminuir a } \\
\text { poluição e os custos } \\
\text { resultantes de seus processos } \\
\text { de produção. }\end{array}$ & $\begin{array}{l}\text { Provar novas } \\
\text { evidências dos } \\
\text { fatores } \\
\text { determinantes da } \\
\text { inovação } \\
\text { ambiental. }\end{array}$ & $\begin{array}{l}\text { Quantitativo: } \\
\text { modelo de } \\
\text { regressão }\end{array}$ & $\begin{array}{l}\text { Conjunto de dados, em painel } \\
\text { que abrange } 146 \text { indústrias } \\
\text { manufatureiras dos EUA, de } \\
1983 \text { a } 1992 .\end{array}$ & $\begin{array}{l}\text { Inovação ambiental: resposta ao } \\
\text { aumento nos custos de redução; } \\
\text { não implica necessariamente em } \\
\text { aumento do lucro líquido. É } \\
\text { bem possível que, apesar dessas } \\
\text { inovações, haja altos custos de } \\
\text { oportunidade para desviar } \\
\text { recursos para P\&D ambiental } \\
\text { (custo). }\end{array}$ \\
\hline $\begin{array}{l}\text { (BEISE; } \\
\text { RENNINGS, 2005) }\end{array}$ & $\begin{array}{l}\text { Ecological } \\
\text { Economics } \\
(\mathrm{FI}=3.895)\end{array}$ & $\begin{array}{l}\text { Processo de desenvolver } \\
\text { novas ideias, comportamentos, } \\
\text { produtos e processos, que } \\
\text { contribuam para a redução do } \\
\text { impacto de encargos } \\
\text { financeiros ou metas de } \\
\text { sustentabilidade ecológicas } \\
\text { específicas (RENNINGS, } \\
\text { 2000). }\end{array}$ & $\begin{array}{l}\text { Questão central: } \\
\text { regulamentações } \\
\text { ambientais são } \\
\text { capazes de criar } \\
\text { mercados líderes, } \\
\text { que permitam às } \\
\text { empresas locais } \\
\text { exportar } \\
\text { inovações } \\
\text { ambientais. }\end{array}$ & $\begin{array}{l}\text { Qualitativo: } \\
\text { estudo de } \\
\text { casos }\end{array}$ & $\begin{array}{l}\text { Estudo de casos de tecnologia } \\
\text { de geração de energia eólica, } \\
\text { comparando Dinamarca, } \\
\text { Alemanha, Espanha e Reino } \\
\text { Unido; e estudo de caso da } \\
\text { eficiência de combustível para } \\
\text { carros de passageiros, } \\
\text { comparando Alemanha, } \\
\text { Estados Unidos, Japão, França } \\
\text { e Europa Ocidental. }\end{array}$ & $\begin{array}{l}\text { A trajetória tecnológica da } \\
\text { energia eólica na Dinamarca foi } \\
\text { caracterizada por maior } \\
\text { variedade e flexibilidade, } \\
\text { possibilitando reduções de } \\
\text { custos de cerca de } 50 \% \text { (custos). }\end{array}$ \\
\hline (PUJARI, 2006) & $\begin{array}{l}\text { Technovation } \\
(\mathrm{FI}=5.25)\end{array}$ & $\begin{array}{l}\text { Questões de sustentabilidade } \\
\text { ambiental incluem eficiência } \\
\text { de recursos, redução de } \\
\text { resíduos e emissões que levam } \\
\text { a um melhor desempenho } \\
\text { ambiental e/ou impacto } \\
\text { ambiental reduzido. }\end{array}$ & $\begin{array}{l}\text { Abordar o } \\
\text { desenvolvimento } \\
\text { de novos produtos } \\
\text { ambientais de } \\
\text { forma empírica. }\end{array}$ & $\begin{array}{l}\text { Quantitativo: } \\
\text { modelo de } \\
\text { regressão }\end{array}$ & $\begin{array}{l}68 \text { gerentes ambientais de } \\
\text { desenvolvimento de produtos, } \\
\text { em empresas norte- } \\
\text { americanas. Questões } \\
\text { relacionadas às atividades de } \\
\text { ecoinovação no processo de } \\
\text { desenvolvimento de produtos, } \\
\text { medição do desempenho } \\
\text { ambiental e de mercado de } \\
\text { produtos mais ecológicos. }\end{array}$ & $\begin{array}{l}\text { Benefícios do produto ocorrem } \\
\text { em paralelo à relação custo- } \\
\text { eficácia técnica e económica. } \\
\text { (custos /funcionalidade). } \\
\text { Desenvolvimento de produtos } \\
\text { mais ecológicos tem estreita } \\
\text { colaboração com os } \\
\text { fornecedores, com uso técnicas } \\
\text { de gestão ambiental e seleção de } \\
\text { fornecedores (ecossistema). }\end{array}$ \\
\hline
\end{tabular}




\section{ECOINOVAÇÃO E DIMENSÕES DA INOVAÇÃO FRUGAL}

\begin{tabular}{|c|c|c|c|c|c|c|}
\hline Artigo & Journal & Descrição de ecoinovação & Foco Principal & $\begin{array}{l}\text { Tipo de } \\
\text { estudo }\end{array}$ & Amostra/Dados & $\begin{array}{l}\text { Transversalidade com as } \\
\text { dimensões da inovação frugal }\end{array}$ \\
\hline $\begin{array}{l}\text { (CHEN; LAI; } \\
\text { WEN, 2006) }\end{array}$ & $\begin{array}{l}\text { Journal of } \\
\text { Business } \\
\text { Ethics } \\
(\mathrm{FI}=2.917)\end{array}$ & $\begin{array}{l}\text { Inovação de hardware ou } \\
\text { software, relacionada a produtos } \\
\text { ou processos verdes: inovação em } \\
\text { tecnologias envolvidas na } \\
\text { economia de energia, prevenção } \\
\text { de poluição, reciclagem de } \\
\text { resíduos, projetos de produtos } \\
\text { ecológicos ou gerenciamento } \\
\text { ambiental corporativo. }\end{array}$ & $\begin{array}{l}\text { Encontrar a correta } \\
\text { evolução e posição da } \\
\text { inovação verde em } \\
\text { processos e produtos } \\
\text { para a vantagem } \\
\text { competitiva da } \\
\text { organização. }\end{array}$ & $\begin{array}{l}\text { Quantitativo: } \\
\text { modelo de } \\
\text { regressão }\end{array}$ & $\begin{array}{l}\text { Survey com } 203 \\
\text { organizações taiwanesas } \\
\text { do setor da informação e } \\
\text { eletrônicos. }\end{array}$ & $\begin{array}{l}\text { Quanto mais investimento em } \\
\text { inovações verdes, melhor a vantagem } \\
\text { competitiva, e custo mais baixos, se } \\
\text { comparado aos concorrentes (custos). } \\
\text { Materiais que preservem recursos e } \\
\text { reduzam o consumo de matéria-prima } \\
\text { no desenvolvimento de produtos; e } \\
\text { produtos finais que favoreçam o } \\
\text { reuso, a reciclagem e a decomposição } \\
\text { (ecossistema). }\end{array}$ \\
\hline $\begin{array}{l}\text { (REHFELD; } \\
\text { RENNINGS; } \\
\text { ZIEGLER, } \\
\text { 2007) }\end{array}$ & $\begin{array}{l}\text { Ecological } \\
\text { Economics } \\
(\mathrm{FI}=3.895)\end{array}$ & $\begin{array}{l}\text { Resultado das metas da empresa } \\
\text { (corte de custos ou melhoria da } \\
\text { qualidade), de maneira a } \\
\text { contribuir com benefícios } \\
\text { ambientais, com os negócios, e } \\
\text { com benefícios orientados ao } \\
\text { consumidor (RENNINGS; } \\
\text { ZWICK, 2002). }\end{array}$ & $\begin{array}{l}\text { Examinar } \\
\text { empiricamente a } \\
\text { relação entre medidas } \\
\text { organizacionais } \\
\text { ambientais da Política } \\
\text { Integrada de Produtos } \\
\text { pela Comissão } \\
\text { Europeia e inovações } \\
\text { de produtos } \\
\text { ambientais. }\end{array}$ & $\begin{array}{l}\text { Quantitativo: } \\
\text { análise } \\
\text { econométrica }\end{array}$ & $\begin{array}{l}\text { Survey com } 588 \\
\text { empresas de manufatura } \\
\text { alemãs, sobre quatro } \\
\text { tipos diferentes de } \\
\text { inovação: inovações } \\
\text { convencionais de } \\
\text { produtos e de processos, } \\
\text { inovações ambientais de } \\
\text { produtos, e inovações de } \\
\text { processos ambientais. }\end{array}$ & $\begin{array}{l}\text { Soluções para utilização básica e } \\
\text { opções de reciclagem, redução dos } \\
\text { custos de tratamento de resíduos e } \\
\text { reciclagem, no planejamento e } \\
\text { desenvolvimento do produto (custos). } \\
\text { Altos custos para os clientes têm } \\
\text { efeito na adoção de inovações de } \\
\text { produtos ambientais (custos). } \\
\text { Processos operacionais voltados à } \\
\text { sustentabilidade ambiental } \\
\text { (ecossistema). }\end{array}$ \\
\hline $\begin{array}{l}\text { (WAGNER, } \\
2007)\end{array}$ & $\begin{array}{l}\text { Research } \\
\text { Policy } \\
(\mathrm{FI}=5.425)\end{array}$ & $\begin{array}{l}\text { São medidas de atores relevantes, } \\
\text { que: (1) desenvolvem, aplicam ou } \\
\text { introduzem novas ideias, } \\
\text { comportamentos, produtos e } \\
\text { processos; e (2) contribuem para } \\
\text { uma redução de encargos } \\
\text { ambientais ou para as metas de } \\
\text { sustentabilidade (RENNINGS, } \\
\text { 2000). }\end{array}$ & $\begin{array}{l}\text { Analisar } \\
\text { empiricamente a } \\
\text { relação entre } \\
\text { inovações ambientais, } \\
\text { gestão ambiental e } \\
\text { patenteamento. }\end{array}$ & $\begin{array}{l}\text { Quantitativo: } \\
\text { modelo de } \\
\text { regressão }\end{array}$ & $\begin{array}{l}\text { Survey com } 342 \\
\text { empresas alemãs do setor } \\
\text { de manufatura. }\end{array}$ & $\begin{array}{l}\text { Parceiros de colaboração, envolvidos } \\
\text { direta ou indiretamente com questões } \\
\text { ambientais, como órgãos do governo } \\
\text { e sindicatos, e fornecedores de } \\
\text { matéria-prima e revendedores de } \\
\text { varejo têm relação significativa com } \\
\text { ecoinovações de produtos } \\
\text { (ecossistema). }\end{array}$ \\
\hline
\end{tabular}

Fonte: Elaborado pela autora (2020). 


\section{ECOINOVAÇÃO E DIMENSÕES DA INOVAÇÃO FRUGAL}

\begin{tabular}{|c|c|c|c|c|c|c|}
\hline Artigo & Journal & Descrição de ecoinovação & Foco Principal & $\begin{array}{l}\text { Tipo de } \\
\text { estudo }\end{array}$ & Amostra/Dados & $\begin{array}{l}\text { Transversalidade com as } \\
\text { dimensões da inovação frugal }\end{array}$ \\
\hline $\begin{array}{l}\text { (HELLSTRÖM, } \\
\text { 2007) }\end{array}$ & $\begin{array}{l}\text { Sustainable } \\
\text { Development } \\
(\mathrm{FI}=3.821)\end{array}$ & $\begin{array}{l}\text { Processo de desenvolver } \\
\text { novas ideias, } \\
\text { comportamentos, produtos } \\
\text { e processos, que } \\
\text { contribuam para a redução } \\
\text { do impacto de encargos } \\
\text { financeiros ou metas de } \\
\text { sustentabilidade ecológicas } \\
\text { específicas (RENNINGS, } \\
\text { 2000). }\end{array}$ & $\begin{array}{l}\text { Analisar a inovação } \\
\text { ambientalmente } \\
\text { sustentável, ou a } \\
\text { ecoinovação, sob a } \\
\text { perspectiva das } \\
\text { teorias de inovação, a } \\
\text { fim de estabelecer } \\
\text { estruturas dominantes } \\
\text { e fraquezas atuais, } \\
\text { bem como formas } \\
\text { futuras. }\end{array}$ & $\begin{array}{l}\text { Conceitual: } \\
\text { revisão da } \\
\text { literatura }\end{array}$ & $\begin{array}{l}\text { Investigação das dimensões } \\
\text { inovadoras de } 105 \text { ideias de } \\
\text { inovação "verde". }\end{array}$ & $\begin{array}{l}\text { As dimensões ambientais são } \\
\text { fontes potenciais de inovação de } \\
\text { processos e produtos, quanto aos } \\
\text { aspectos do processo de } \\
\text { fabricação, uso do produto, fim da } \\
\text { vida útil e redesenho de funções. } \\
\text { Essas dimensões respondem a } \\
\text { problemas existentes em } \\
\text { rearranjos, a fim de torná-los mais } \\
\text { ecológicos } \\
\text { (ecossistema/funcionalidade). }\end{array}$ \\
\hline $\begin{array}{l}\text { (TRIEBSWETTER; } \\
\text { WACKERBAUER, } \\
\text { 2008) }\end{array}$ & $\begin{array}{l}\text { Journal of } \\
\text { Cleaner } \\
\text { Production } \\
(\mathrm{FI}=6.395)\end{array}$ & $\begin{array}{l}\text { Mudanças técnico- } \\
\text { econômicas, } \\
\text { organizacionais, sociais e } \\
\text { institucionais, que levam a } \\
\text { uma melhor qualidade do } \\
\text { meio ambiente. } \\
\text { (Klemmer,1999) }\end{array}$ & $\begin{array}{l}\text { Examina o impacto } \\
\text { das inovações } \\
\text { ambientais na } \\
\text { competitividade das } \\
\text { empresas, tanto da } \\
\text { indústria ambiental } \\
\text { quanto dos setores, } \\
\text { relacionados à região } \\
\text { de Munique. }\end{array}$ & Estudo de caso & $\begin{array}{l}\text { Entrevistas com } 14 \text { empresas } \\
\text { de manufatura e serviços, } \\
\text { em Munique (sul da } \\
\text { Alemanha). }\end{array}$ & $\begin{array}{l}\text { Custos e a pressão competitiva, } \\
\text { assim como o avanço tecnológico, } \\
\text { são os maiores estímulos para as } \\
\text { inovações ambientais, assim } \\
\text { como a pressão do mercado e a } \\
\text { pressão do cliente (custos). }\end{array}$ \\
\hline (HORBACH, 2008) & $\begin{array}{l}\text { Research } \\
\text { Policy } \\
(\mathrm{FI}=5.425)\end{array}$ & $\begin{array}{l}\text { Processos, técnicas, } \\
\text { sistemas e produtos novos } \\
\text { ou modificados para evitar } \\
\text { ou reduzir os danos } \\
\text { ambientais (KEMP; } \\
\text { PEARSON, 2007). }\end{array}$ & $\begin{array}{l}\text { Explorar os fatores } \\
\text { determinantes da } \\
\text { inovação ambiental. }\end{array}$ & $\begin{array}{l}\text { Quantitativo: } \\
\text { análise } \\
\text { econométrica }\end{array}$ & $\begin{array}{l}\text { Dados secundários: painel } \\
\text { do Institute for Employment } \\
\text { Research (IAB), e painel de } \\
\text { inovação de Mannheim } \\
\text { (MIP), do Centre for } \\
\text { European Economic } \\
\text { Research (ZEW), para as } \\
\text { empresas alemãs. }\end{array}$ & $\begin{array}{l}\text { Processos operacionais voltados a } \\
\text { soluções de sustentabilidade } \\
\text { ambiental (ecossistema). } \\
\text { Custos e adequação às medidas } \\
\text { regulatórias são determinantes } \\
\text { para inovações ambientais } \\
\text { (custos). }\end{array}$ \\
\hline
\end{tabular}

Fonte: Autora. 
ECOINOVAÇÃO E DIMENSÕES DA INOVAÇÃ̃ FRUGAL

\begin{tabular}{|c|c|c|c|c|c|c|}
\hline Artigo & Journal & Descrição de ecoinovação & Foco Principal & $\begin{array}{l}\text { Tipo de } \\
\text { estudo }\end{array}$ & Amostra/Dados & $\begin{array}{l}\text { Transversalidade com as } \\
\text { dimensões da inovação frugal }\end{array}$ \\
\hline $\begin{array}{l}\text { (WAGNER, } \\
2008)\end{array}$ & $\begin{array}{l}\text { Ecological } \\
\text { Economics } \\
(\mathrm{FI}=3.895)\end{array}$ & $\begin{array}{l}\text { São medidas de atores } \\
\text { relevantes, que: (1) } \\
\text { desenvolvem, aplicam ou } \\
\text { introduzem novas ideias, } \\
\text { comportamentos, produtos e } \\
\text { processos; e (2) contribuem para } \\
\text { a redução de encargos } \\
\text { ambientais ou para as metas de } \\
\text { sustentabilidade (RENNINGS, } \\
2000) \text {. }\end{array}$ & $\begin{array}{l}\text { Analisar a hipótese de que os } \\
\text { sistemas de gestão ambiental e } \\
\text { as atividades gerenciais, para } \\
\text { reduzir os impactos } \\
\text { ambientais negativos, que não } \\
\text { fazem parte do SGA, } \\
\text { influenciam positivamente a } \\
\text { probabilidade de as empresas } \\
\text { realizarem inovações } \\
\text { ambientais. }\end{array}$ & $\begin{array}{l}\text { Quantitativo: } \\
\text { modelo de } \\
\text { regressão }\end{array}$ & $\begin{array}{l}\text { Os dados baseados na } \\
\text { última pesquisa } \\
\text { European Business } \\
\text { Environment } \\
\text { Barometer (EBEB), } \\
\text { em 2001, realizada em: } \\
\text { Bélgica, França, } \\
\text { Alemanha, Hungria, } \\
\text { Holanda, Noruega, } \\
\text { Suécia, Suíça, Reino } \\
\text { Unido. }\end{array}$ & $\begin{array}{l}\text { A existência de atividades, como } \\
\text { sistema de reciclagem, fornece } \\
\text { incentivos à realização de } \\
\text { inovações de produtos ambientais, } \\
\text { que permitem a distribuição do } \\
\text { custo operacional do sistema pela } \\
\text { quantidade maior de produtos } \\
\text { produzidos (custos). }\end{array}$ \\
\hline $\begin{array}{l}\text { (CHEN, } \\
\text { 2008a) }\end{array}$ & $\begin{array}{l}\text { Journal of } \\
\text { Business } \\
\text { Ethics } \\
(\mathrm{FI}=2.917)\end{array}$ & $\begin{array}{l}\text { Inovação de hardware ou } \\
\text { software, relacionada a produtos } \\
\text { ou processos verdes: inovação } \\
\text { em tecnologias envolvidas na } \\
\text { economia de energia, prevenção } \\
\text { de poluição, reciclagem de } \\
\text { resíduos, projetos de produtos } \\
\text { ecológicos ou gerenciamento } \\
\text { ambiental corporativo (CHEN; } \\
\text { LAI; WEN, 2006). }\end{array}$ & $\begin{array}{l}\text { Propor um novo construto - } \\
\text { competência do núcleo verde } \\
\text { - para explorar seus efeitos } \\
\text { positivos na inovação verde e } \\
\text { imagens verdes de empresas. }\end{array}$ & $\begin{array}{l}\text { Quantitativo: } \\
\text { modelo de } \\
\text { regressão }\end{array}$ & $\begin{array}{l}\text { Survey com } 136 \\
\text { empresas taiwanesas de } \\
\text { tecnologia da } \\
\text { informação e } \\
\text { equipamentos } \\
\text { eletrônicos. }\end{array}$ & $\begin{array}{l}\text { As competências essenciais } \\
\text { verdes das empresas, envolvendo } \\
\text { aprendizado coletivo e gestão } \\
\text { ambiental, têm efeitos positivos } \\
\text { no desempenho de inovação de } \\
\text { produtos e processos/imagem } \\
\text { verdes (ecossistema). }\end{array}$ \\
\hline $\begin{array}{l}\text { (FRONDEL; } \\
\text { HORBACH; } \\
\text { RENNINGS, } \\
\text { 2008) }\end{array}$ & $\begin{array}{l}\text { Ecological } \\
\text { Economics } \\
(\mathrm{FI}=3.895)\end{array}$ & $\begin{array}{l}\text { Inovações contidas em } \\
\text { processos, práticas, sistemas e } \\
\text { produtos que beneficiam o meio } \\
\text { ambiente e contribuem para a } \\
\text { sustentabilidade ambiental. }\end{array}$ & $\begin{array}{l}\text { Abordar a simultaneidade } \\
\text { entre a adoção de sistemas de } \\
\text { gestão ambiental e o } \\
\text { comportamento de inovação } \\
\text { ambiental. }\end{array}$ & $\begin{array}{l}\text { Quantitativo: } \\
\text { modelo de } \\
\text { regressão }\end{array}$ & $\begin{array}{l}\text { Empresas alemãs de } \\
\text { manufatura (899), } \\
\text { participantes da OCDE, } \\
\text { sobre ferramentas de } \\
\text { política ambiental, } \\
\text { realizada em 2003, em } \\
\text { sete países, entre os } \\
\text { quais, EUA, Japão e } \\
\text { Alemanha. }\end{array}$ & $\begin{array}{l}\text { As atividades de redução de } \\
\text { impacto ambiental estão } \\
\text { correlacionadas a fortes impactos } \\
\text { ambientais dos processos de } \\
\text { produção de uma instalação: } \\
\text { instalações mais poluidoras são } \\
\text { mais propensas a inovar e a fazer } \\
\text { rearranjos produtivos de redução, } \\
\text { do que as menos poluentes } \\
\text { (ecossistemas). }\end{array}$ \\
\hline
\end{tabular}




\section{ECOINOVAÇÃO E DIMENSÕES DA INOVAÇÃO FRUGAL}

\begin{tabular}{|c|c|c|c|c|c|c|}
\hline Artigo & Journal & $\begin{array}{l}\text { Descrição de } \\
\text { ecoinovação }\end{array}$ & Foco Principal & Tipo de estudo & Amostra/Dados & $\begin{array}{l}\text { Transversalidade com as dimensões da } \\
\text { inovação frugal }\end{array}$ \\
\hline $\begin{array}{l}\text { (ARUNDEL; } \\
\text { KEMP, 2009) }\end{array}$ & $\begin{array}{l}\text { Maastricht: } \\
\text { United Nations } \\
\text { University }\end{array}$ & $\begin{array}{l}\text { Criação ou } \\
\text { implementação de } \\
\text { produtos (bens e } \\
\text { serviços) novos ou } \\
\text { significativamente } \\
\text { melhorados, processos, } \\
\text { métodos de marketing, } \\
\text { estruturas } \\
\text { organizacionais e } \\
\text { arranjos institucionais } \\
\text { que - com ou sem } \\
\text { intenções - leva a } \\
\text { melhorias ambientais, } \\
\text { em comparação a outras } \\
\text { alternativas relevantes } \\
\text { (OECD, 2008). }\end{array}$ & $\begin{array}{l}\text { Oferecer uma } \\
\text { discussão sobre a } \\
\text { ecoinovação e como } \\
\text { mensurá-la. }\end{array}$ & $\begin{array}{l}\text { Conceitual: meta- } \\
\text { análise de } \\
\text { trabalhos de } \\
\text { mensuração da } \\
\text { ecoinovação }\end{array}$ & N/A & $\begin{array}{l}\text { Os benefícios ambientais de uma inovação } \\
\text { podem ser efeito colateral de outros, como } \\
\text { reciclar metais pesados para reduzir custo. } \\
\text { (custos). A implementação de tecnologias } \\
\text { de produção mais limpas é impulsionada } \\
\text { pela aptidão de aumentar a eficiência da } \\
\text { fabricação e reduzir os custos das } \\
\text { operações (custos). As inovações de } \\
\text { processo e a reciclagem foram muitas } \\
\text { vezes introduzidas em resposta à } \\
\text { necessidade de cumprir os regulamentos, } \\
\text { mas também para obter economias de } \\
\text { custos (não relacionadas com o ambiente) } \\
\text { ou para melhorar a imagem ambiental da } \\
\text { empresa (ecossistema/custos). }\end{array}$ \\
\hline $\begin{array}{l}\text { (KAMMERE } \\
\mathrm{R}, 2009)\end{array}$ & $\begin{array}{l}\text { Ecological } \\
\text { Economics } \\
(\mathrm{FI}=3.895)\end{array}$ & $\begin{array}{l}\text { São definidas como } \\
\text { todas as inovações que } \\
\text { têm um efeito benéfico } \\
\text { sobre o ambiente } \\
\text { natural, } \\
\text { independentemente se } \\
\text { esse foi o principal } \\
\text { objetivo da inovação. }\end{array}$ & $\begin{array}{l}\text { Analisar a influência } \\
\text { do benefício e da } \\
\text { regulamentação do } \\
\text { cliente na inovação } \\
\text { ambiental de } \\
\text { produtos, e utilizar o } \\
\text { nível da questão } \\
\text { ambiental para essa } \\
\text { análise. }\end{array}$ & $\begin{array}{l}\text { Quantitativo: } \\
\text { análise } \\
\text { econométrica }\end{array}$ & $\begin{array}{l}\text { Survey com } 92 \\
\text { fabricantes alemãs de } \\
\text { energia elétrica e } \\
\text { aparelhos eletrônicos } \\
\text { (uso doméstico, } \\
\text { tecnologia da } \\
\text { informação e } \\
\text { aplicações médicas). }\end{array}$ & $\begin{array}{l}\text { A redução de custo de energia, por } \\
\text { exemplo, é um dos benefícios para os } \\
\text { clientes de ecoinovação, assim como um } \\
\text { fator-chave para as demandas do mercado } \\
\text { verde (custos). }\end{array}$ \\
\hline $\begin{array}{l}\text { (OLTRA; } \\
\text { SAINT JEAN, } \\
\text { 2009) }\end{array}$ & $\begin{array}{l}\text { Technological } \\
\text { Forecasting \& } \\
\text { Social Change } \\
(\mathrm{FI}=3.129)\end{array}$ & $\begin{array}{l}\text { Inovações que } \\
\text { consistem em processos, } \\
\text { práticas, sistemas e } \\
\text { produtos que beneficiam } \\
\text { o meio ambiente e } \\
\text { contribuem para a } \\
\text { sustentabilidade } \\
\text { ambiental. }\end{array}$ & $\begin{array}{l}\text { Mostrar como uma } \\
\text { abordagem de } \\
\text { sistema setorial pode } \\
\text { contribuir para a } \\
\text { análise dos } \\
\text { determinantes das } \\
\text { inovações ambientais. }\end{array}$ & $\begin{array}{l}\text { Framework } \\
\text { aplicado a estudo } \\
\text { de caso da } \\
\text { indústria } \\
\text { automobilística } \\
\text { francesa. }\end{array}$ & $\begin{array}{l}\text { Indústria automotiva } \\
\text { francesa }\end{array}$ & $\begin{array}{l}\text { As relações entre fornecedores e } \\
\text { organizações na manufatura, na produção } \\
\text { de conhecimento e na tecnologia devem } \\
\text { ser levadas em conta ao analisar as } \\
\text { inovações ambientais desenvolvidas pela } \\
\text { indústria automotiva (ecossistema). }\end{array}$ \\
\hline
\end{tabular}

Fonte: Elaborado pela autora (2020). 


\section{ECOINOVAÇÃO E DIMENSÕES DA INOVAÇÃO FRUGAL}

\begin{tabular}{|c|c|c|c|c|c|c|}
\hline Artigo & Journal & Descrição de ecoinovação & Foco Principal & $\begin{array}{l}\text { Tipo de } \\
\text { estudo }\end{array}$ & Amostra/Dados & $\begin{array}{l}\text { Transversalidade com as dimensões } \\
\text { da inovação frugal }\end{array}$ \\
\hline $\begin{array}{l}\text { (DEMIREL; } \\
\text { KESIDOU, 2010) }\end{array}$ & $\begin{array}{l}\text { Ecological } \\
\text { Economics } \\
(\mathrm{FI}=3.895)\end{array}$ & $\begin{array}{l}\text { Possuem as dimensões } \\
\text { ecológicas, econômicas e } \\
\text { sociais, que demandam } \\
\text { uma abordagem } \\
\text { interdisciplinar de insights } \\
\text { da economia ambiental e } \\
\text { da inovação, diante das } \\
\text { diferentes lentes } \\
\text { metodológicas das escolas } \\
\text { de pensamento neoclássico } \\
\text { e evolucionista } \\
\text { (RENNINGS, 2000). }\end{array}$ & $\begin{array}{l}\text { Demonstrar que } \\
\text { ecoinovações são } \\
\text { motivadas por diferentes } \\
\text { ferramentas de política } \\
\text { externa e fatores internos } \\
\text { específicos da empresa. }\end{array}$ & $\begin{array}{l}\text { Quantitativo: } \\
\text { análise } \\
\text { econométrica }\end{array}$ & $\begin{array}{l}\text { Dados secundários de } \\
289 \text { empresas } \\
\text { britânicas; Inquérito do } \\
\text { Governo sobre as } \\
\text { Despesas de Proteção } \\
\text { Ambiental pela } \\
\text { Indústria, em } 2005 \text { e } \\
2006 .\end{array}$ & $\begin{array}{l}\text { Inovações ambientais de baixo impacto } \\
\text { (tecnologias de controle) aumentam os } \\
\text { custos. Em inovações de mudança } \\
\text { tecnológica, como produção limpa, os } \\
\text { custos de investimento são mais baixos } \\
\text { em longo prazo. E inovações de alto } \\
\text { impacto, resultantes de P\&D } \\
\text { ambiental, possuem alto risco e alto } \\
\text { custo de investimento em longo prazo } \\
\text { (custos). }\end{array}$ \\
\hline $\begin{array}{l}\text { (DANGELICO; } \\
\text { PUJARI, 2010) }\end{array}$ & $\begin{array}{l}\text { Journal of } \\
\text { Business } \\
\text { Ethics } \\
(\mathrm{FI}=2.917)\end{array}$ & $\begin{array}{l}\text { Processo segmentado em } \\
\text { três tipos principais de } \\
\text { foco ambiental - material, } \\
\text { energia e poluição - e } \\
\text { destacados com base no } \\
\text { impacto no meio ambiente, } \\
\text { em diferentes estágios do } \\
\text { ciclo de vida físico do } \\
\text { produto - processo de } \\
\text { fabricação, uso do produto } \\
\text { e descarte. }\end{array}$ & $\begin{array}{l}\text { Propor uma estrutura } \\
\text { conceitual com três } \\
\text { dimensões ambientais da } \\
\text { inovação de produtos } \\
\text { verdes: minimização de } \\
\text { energia, redução de } \\
\text { materiais e prevenção da } \\
\text { poluição nas fases do } \\
\text { ciclo de vida de } \\
\text { produtos. }\end{array}$ & $\begin{array}{l}\text { Qualitativo: } \\
\text { estudo de caso }\end{array}$ & $\begin{array}{l}\text { Estudo de casos } \\
\text { múltiplos de } 12 \\
\text { pequenas e médias } \\
\text { empresas de } \\
\text { manufatura na Itália e } \\
\text { no Canadá. }\end{array}$ & $\begin{array}{l}\text { O ritmo lento de introdução de } \\
\text { produtos verdes em vários setores, } \\
\text { devido aos altos custos de } \\
\text { desenvolvimento e de fabricação, que } \\
\text { tornam seu preço não competitivo, } \\
\text { apesar de possuírem tecnologia } \\
\text { adequada (custos). } \\
\text { Redução e otimização de material na } \\
\text { embalagem, uso de reciclados ou } \\
\text { materiais biodegradáveis } \\
\text { (ecossistema). }\end{array}$ \\
\hline $\begin{array}{l}\text { (CARRILLO- } \\
\text { HERMOSILLA; } \\
\text { DEL RÍO; } \\
\text { KÖNNÖLÄ, } \\
2010)\end{array}$ & $\begin{array}{l}\text { Journal of } \\
\text { Cleaner } \\
\text { Production } \\
(\mathrm{FI}=6.395)\end{array}$ & $\begin{array}{l}\text { Reduzem o impacto } \\
\text { ambiental causado pelo } \\
\text { consumo e produção de } \\
\text { atividades. Principal } \\
\text { motivação pode ou não ser } \\
\text { ambiental. }\end{array}$ & $\begin{array}{l}\text { Desenvolver estrutura } \\
\text { analítica para explorar a } \\
\text { diversidade de } \\
\text { ecoinovações, de acordo } \\
\text { com várias dimensões- } \\
\text { chave (design, usuário, } \\
\text { serviço de produto e } \\
\text { governança). }\end{array}$ & $\begin{array}{l}\text { Qualitativo: } \\
\text { estudo de } \\
\text { casos }\end{array}$ & $\begin{array}{l}\text { Framework, a partir de } \\
\text { estudos de casos no } \\
\text { Japão, USA, Suécia e } \\
\text { Espanha. }\end{array}$ & $\begin{array}{l}\text { Ecoinovações baseadas na adição de } \\
\text { componentes, mas com baixo projeto } \\
\text { de mudança de sistema, podem } \\
\text { otimizar o processo existente, levando } \\
\text { a melhorias de eficiência e reduções de } \\
\text { custos, diminuindo simultaneamente os } \\
\text { impactos nocivos ao meio ambiente } \\
\text { (custos/ecosssitema). }\end{array}$ \\
\hline
\end{tabular}


ECOINOVAÇÃO E DIMENSÕES DA INOVAÇÃ̃ FRUGAL

\begin{tabular}{|c|c|c|c|c|c|c|}
\hline Artigo & Journal & Descrição de ecoinovação & Foco Principal & $\begin{array}{l}\text { Tipo de } \\
\text { estudo }\end{array}$ & Amostra/Dados & $\begin{array}{l}\text { Transversalidade com as } \\
\text { dimensões da inovação frugal }\end{array}$ \\
\hline $\begin{array}{l}\text { (KEMP; } \\
\text { PONTOGLIO, } \\
\text { 2011) }\end{array}$ & $\begin{array}{l}\text { Ecological } \\
\text { Economics } \\
(\mathrm{FI}=3.895)\end{array}$ & $\begin{array}{l}\text { Compreende inovação no controle da } \\
\text { poluição (tecnologia de redução nova, } \\
\text { melhor ou mais barata), produtos } \\
\text { verdes, tecnologias de processo mais } \\
\text { limpas, tecnologia de energia verde e } \\
\text { tecnologias de transporte e redução de } \\
\text { resíduos e técnicas de manuseio. }\end{array}$ & $\begin{array}{l}\text { Examina os efeitos da } \\
\text { inovação de instrumentos } \\
\text { de política ambiental nas } \\
\text { literaturas de modelos } \\
\text { teóricos sobre incentivos } \\
\text { para a ecoinovação, } \\
\text { estudos econométricos } \\
\text { baseados em dados } \\
\text { observados, e análise de } \\
\text { pesquisa com base em } \\
\text { estudos de caso } \\
\text { tecnológicos. }\end{array}$ & $\begin{array}{l}\text { Conceitual: } \\
\text { meta-análise } \\
\text { dos efeitos dos } \\
\text { instrumentos } \\
\text { de política de } \\
\text { inovação } \\
\text { ambiental em } \\
\text { quatro } \\
\text { literaturas. }\end{array}$ & $\begin{array}{l}\text { Meta-análise da } \\
\text { literatura das } \\
\text { pesquisas de modelos } \\
\text { teóricos sobre } \\
\text { incentivos, estudos } \\
\text { econométricos, } \\
\text { estudos de casos, e } \\
\text { survey com } 400 \\
\text { organizações da } \\
\text { OECD. }\end{array}$ & $\begin{array}{l}\text { A redução de custos é mais } \\
\text { importante do que a regulação } \\
\text { para a implementação de uma } \\
\text { produção limpa (custos). }\end{array}$ \\
\hline $\begin{array}{l}\text { (KESIDOU; } \\
\text { DEMIREL, } \\
\text { 2012) }\end{array}$ & $\begin{array}{l}\text { Research } \\
\text { Policy } \\
(\mathrm{FI}=5.425)\end{array}$ & $\begin{array}{l}\text { É a inovação que reflete a ênfase } \\
\text { explícita na redução do impacto } \\
\text { ambiental, seja esse efeito intencional } \\
\text { ou não. Não se limita à inovação em } \\
\text { produtos, processos, métodos de } \\
\text { marketing e métodos organizacionais, } \\
\text { também incluindo inovação nas } \\
\text { estruturas sociais e institucionais } \\
\text { (OCDE, 2009, p. 13). }\end{array}$ & $\begin{array}{l}\text { Reunir pontos de vista } \\
\text { das disciplinas de } \\
\text { economia ambiental e } \\
\text { inovação sobre os fatores } \\
\text { impulsionadores das } \\
\text { ecoinovações. }\end{array}$ & $\begin{array}{l}\text { Quantitativo: } \\
\text { modelo de } \\
\text { regressão }\end{array}$ & $\begin{array}{l}\text { Dados secundários } \\
\text { das } 1566 \text { empresas } \\
\text { britânicas de } \\
\text { manufatura; Inquérito } \\
\text { do Governo sobre as } \\
\text { Despesas de Proteção } \\
\text { Ambiental pela } \\
\text { Indústria, em } 2006 .\end{array}$ & $\begin{array}{l}\text { Desenvolvimento de soluções } \\
\text { ambientais para adequação às } \\
\text { regulamentações, e que reduzam } \\
\text { os custos de produção e/ou } \\
\text { possibilitem a expansão para } \\
\text { mercado de produtos ecológicos } \\
\text { (custos). }\end{array}$ \\
\hline $\begin{array}{l}\text { (HORBACH; } \\
\text { RAMMER; } \\
\text { RENNINGS, } \\
\text { 2012) }\end{array}$ & $\begin{array}{l}\text { Ecological } \\
\text { Economics } \\
(\mathrm{FI}=3.895)\end{array}$ & $\begin{array}{l}\text { Produção, aplicação ou exploração de } \\
\text { serviço, processo de produção, } \\
\text { estrutura organizacional, gestão ou } \\
\text { método de negócio, que é novo para a } \\
\text { empresa/usuário e resulta, ao longo de } \\
\text { seu ciclo de vida, em uma redução do } \\
\text { risco ambiental, poluição e impactos } \\
\text { negativos do uso de recursos, em } \\
\text { comparação com alternativas } \\
\text { relevantes (ARUNDEL; KEMP, 2009). }\end{array}$ & $\begin{array}{l}\text { Testar se diferentes tipos } \\
\text { de ecoinovação (de } \\
\text { acordo com seus } \\
\text { impactos ambientais) são } \\
\text { conduzidos por } \\
\text { diferentes fatores. }\end{array}$ & $\begin{array}{l}\text { Quantitativo: } \\
\text { análise } \\
\text { econométrica }\end{array}$ & $\begin{array}{l}\text { Dados de empresas, } \\
\text { coletados no contexto } \\
\text { do Inquérito } \\
\text { Comunitário à } \\
\text { Inovação (CEI), da } \\
\text { União Europeia, } \\
\text { Comissão de } 2952 \\
\text { empresas, em } 2009 \text {. }\end{array}$ & $\begin{array}{l}\text { Ecoinovações podem ser o } \\
\text { resultado de motivações } \\
\text { econômicas, como aumentar a } \\
\text { participação de mercado ou } \\
\text { reduzir custos de operação } \\
\text { (custos). } \\
\text { As parcerias com fornecedores } \\
\text { locais são significativas para o } \\
\text { processo operacional de } \\
\text { ecoinovações (ecossistema). }\end{array}$ \\
\hline
\end{tabular}

Fonte: Autora. 
APÊNDICE F - INOVAÇÃO FRUGAL E ECOINOVAÇÃO 


\section{INOVAÇÃO FRUGAL E ECOINOVAÇÃO}

\begin{tabular}{|c|c|c|c|c|c|c|}
\hline Artigo & Journal & $\begin{array}{l}\text { Descrição de inovação } \\
\text { frugal }\end{array}$ & Foco Principal & $\begin{array}{l}\text { Tipo de } \\
\text { Estudo }\end{array}$ & Amostra/Dados & $\begin{array}{l}\text { Transversalidade com conceito } \\
\text { de ecoinovação }\end{array}$ \\
\hline (RAO, 2013b) & $\begin{array}{l}\text { Technology in } \\
\text { Society } \\
(\mathrm{FI}=1.670)\end{array}$ & $\begin{array}{l}\text { Baixo preço, design } \\
\text { compacto, uso de matérias- } \\
\text { primas limitadas ou } \\
\text { reutilização de } \\
\text { componentes existentes, } \\
\text { facilidade de uso e uso de } \\
\text { tecnologia de ponta para } \\
\text { reduzir custos. }\end{array}$ & $\begin{array}{l}\text { Revelar as } \\
\text { características das } \\
\text { inovações frugais e sua } \\
\text { disruptividade em } \\
\text { relação a outras } \\
\text { inovações. }\end{array}$ & $\begin{array}{l}\text { Conceitual: } \\
\text { meta-análise } \\
\text { das } \\
\text { características } \\
\text { de inovações } \\
\text { frugais. }\end{array}$ & $\begin{array}{l}\text { Uso de } 28 \text { exemplos de } \\
\text { inovações frugais populares. }\end{array}$ & $\begin{array}{l}\text { Uso mínimo de recursos para } \\
\text { realizar o funcionamento eficiente } \\
\text { dos produtos. } \\
\text { Reutilização de componentes e } \\
\text { designs mais simples, que } \\
\text { resultam em produtos sem } \\
\text { acessórios. } \\
\text { Motivadas pela escassez de } \\
\text { recursos, regulamentos ambientais } \\
\text { mais rigorosos e maior eficiência } \\
\text { energética dos países. }\end{array}$ \\
\hline $\begin{array}{l}\text { (ZESCHKY, } \\
\text { MARCO; } \\
\text { WINTERHAL } \\
\text { TER; } \\
\text { GASSMANN, } \\
\text { 2014) }\end{array}$ & $\begin{array}{l}\text { Research } \\
\text { Technology } \\
\text { Management } \\
(\mathrm{FI}=1.407)\end{array}$ & $\begin{array}{l}\text { Produtos ou serviços para } \\
\text { aplicações muito } \\
\text { específicas, em ambientes } \\
\text { com recursos limitados. } \\
\text { São, muitas vezes, } \\
\text { disruptivas, tanto em } \\
\text { forma quanto em aplicação } \\
\text { e cliente final. }\end{array}$ & $\begin{array}{l}\text { Analisar os diferentes } \\
\text { tipos de inovação com } \\
\text { recursos limitados - } \\
\text { custo, inovação } \\
\text { suficiente, frugal e } \\
\text { reversa - conceitua as } \\
\text { distinções entre eles e } \\
\text { discute as implicações } \\
\text { para a estratégia. }\end{array}$ & $\begin{array}{l}\text { Conceitual: } \\
\text { revisão } \\
\text { sistemática da } \\
\text { literatura. }\end{array}$ & $\begin{array}{l}\text { Utilizados } 13 \text { casos } \\
\text { selecionados, e dentre eles, } \\
\text { foram realizadas entrevistas } \\
\text { com gerentes e coleta de } \\
\text { dados de fontes } \\
\text { reconhecidas. }\end{array}$ & $\begin{array}{l}\text { Novos designs de produtos ou } \\
\text { serviços, visando reduzir o } \\
\text { consumo de matéria-prima. }\end{array}$ \\
\hline $\begin{array}{l}\text { (BREM; } \\
\text { WOLFRAM, } \\
\text { 2014) }\end{array}$ & $\begin{array}{l}\text { Journal of } \\
\text { Innovation and } \\
\text { Entrepreneurship } \\
(\mathrm{FI}=1.374)\end{array}$ & $\begin{array}{l}\text { Baseada no jugaad, que se } \\
\text { concentra no } \\
\text { desenvolvimento, } \\
\text { produção e gerenciamento } \\
\text { de produtos e processos, } \\
\text { que economizam recursos } \\
\text { para as pessoas na base da } \\
\text { pirâmide, alcançando um } \\
\text { nível suficiente de } \\
\text { taxonomia e evitando } \\
\text { custos desnecessários. }\end{array}$ & $\begin{array}{l}\text { Oferecer uma visão } \\
\text { abrangente dos termos } \\
\text { comumente usados: } \\
\text { jugaad, engenharia } \\
\text { frugal, inovação } \\
\text { baseada em restrições, } \\
\text { e inovação frugal, } \\
\text { Gandhian, catalítica, } \\
\text { popular, indigenous e } \\
\text { reversa. }\end{array}$ & $\begin{array}{l}\text { Conceitual: } \\
\text { revisão } \\
\text { sistemática da } \\
\text { literatura }\end{array}$ & $\begin{array}{l}\text { Utilizados } 119 \text { artigos do } \\
\text { Google Scholar e Business } \\
\text { Source Complete (BSC). }\end{array}$ & $\begin{array}{l}\text { Ideia ecológica quanto à } \\
\text { possibilidade de reaproveitamento } \\
\text { de recursos obsoletos e de antigas } \\
\text { tecnologias de outras empresas, } \\
\text { como substituição de recursos } \\
\text { ausentes (próprios), sem custos } \\
\text { adicionais. }\end{array}$ \\
\hline
\end{tabular}




\section{INOVAÇÃO FRUGAL E ECOINOVAÇÃO}

\begin{tabular}{|c|c|c|c|c|c|c|}
\hline Artigo & Journal & Descrição de inovação frugal & Foco Principal & $\begin{array}{l}\text { Tipo de } \\
\text { Estudo }\end{array}$ & Amostra/Dados & $\begin{array}{l}\text { Transversalidade com conceito } \\
\text { de ecoinovação }\end{array}$ \\
\hline $\begin{array}{l}\text { (CUNHA } \text { et al., } \\
\text { 2014) }\end{array}$ & $\begin{array}{l}\text { Journal of } \\
\text { Production } \\
\text { Innovation } \\
\text { Management } \\
(\mathrm{FI}=4.305)\end{array}$ & $\begin{array}{l}\text { Fornecer aos clientes produtos } \\
\text { com funções essenciais. Para } \\
\text { os inovadores frugais, a } \\
\text { escassez é tanto um fato (eles } \\
\text { não podem mudar facilmente a } \\
\text { condição econômica de seus } \\
\text { clientes) quanto uma } \\
\text { oportunidade. }\end{array}$ & $\begin{array}{l}\text { Discutir as variedades de } \\
\text { inovação de produto em } \\
\text { condições de escassez. }\end{array}$ & $\begin{array}{l}\text { Conceitual: } \\
\text { revisão } \\
\text { sistemática } \\
\text { da literatura }\end{array}$ & $\begin{array}{l}53 \text { artigos selecionados da } \\
\text { base de dados EBSCO e } \\
\text { ISI Web of Science. }\end{array}$ & $\begin{array}{l}\text { Criar um futuro, no qual as } \\
\text { empresas enfrentam crescentes } \\
\text { pressões sociais para integrar a } \\
\text { sustentabilidade em suas } \\
\text { operações e aprender a fazer mais } \\
\text { com menos. }\end{array}$ \\
\hline $\begin{array}{l}\text { (AGNIHOTRI, } \\
\text { 2015) }\end{array}$ & $\begin{array}{l}\text { Journal of } \\
\text { Strategic } \\
\text { Marketing }(\mathrm{H}- \\
\text { index }=42)\end{array}$ & $\begin{array}{l}\text { Produtos e serviços } \\
\text { inovadores, desenvolvidos sob } \\
\text { condições de restrições de } \\
\text { recursos. }\end{array}$ & $\begin{array}{l}\text { Descrever quatro tipos de } \\
\text { inovações de baixo custo } \\
\text { em mercados } \\
\text { emergentes: jugaad, } \\
\text { frugal, valor e inovação } \\
\text { reversa, suas } \\
\text { características, } \\
\text { diferenciais e } \\
\text { semelhanças. }\end{array}$ & $\begin{array}{l}\text { Conceitual: } \\
\text { meta-análise }\end{array}$ & $\begin{array}{l}\text { Artigos teóricos de quatro } \\
\text { tipos de inovação de baixo } \\
\text { custo, em mercados } \\
\text { emergentes: jugaad, } \\
\text { frugal, custo e reversa. }\end{array}$ & $\begin{array}{l}\text { Em comparação com os tipos de } \\
\text { inovações radicais e outras, a } \\
\text { inovação de baixo custo é } \\
\text { geralmente mais ecológica e } \\
\text { conservadora de recursos, por ser } \\
\text { de natureza mais simples. }\end{array}$ \\
\hline $\begin{array}{l}\text { (AGARWAL } e t \\
a l ., 2016)\end{array}$ & $\begin{array}{l}\text { IEEE } \\
\text { Transactions on } \\
\text { Engineering } \\
\text { Management } \\
(\mathrm{FI}=1.867)\end{array}$ & $\begin{array}{l}\text { Inovações "boas o suficiente", } \\
\text { com produtos acessíveis, que } \\
\text { atendam às necessidades dos } \\
\text { consumidores com recursos } \\
\text { limitados. }\end{array}$ & $\begin{array}{l}\text { Organizar e sintetizar a } \\
\text { pesquisa sobre } \\
\text { abordagens inovadoras, } \\
\text { originadas em/para } \\
\text { mercados emergentes. }\end{array}$ & $\begin{array}{l}\text { Conceitual: } \\
\text { revisão } \\
\text { sistemática } \\
\text { da literatura }\end{array}$ & $\begin{array}{l}\text { Utilizadas quatro fontes de } \\
\text { base de dados: } \\
\text { EBSCOhost, Science } \\
\text { Direct, Wiley Online } \\
\text { Library, e Google Scholar, } \\
\text { no total de } 3922 \text { artigos. }\end{array}$ & $\begin{array}{l}\text { Acessível, adaptável, custo- } \\
\text { benefício, criativa, fácil de usar, } \\
\text { flexível, alta qualidade, } \\
\text { sofisticada, intuitiva, enxuta, } \\
\text { eficiente, ambiental e verde. }\end{array}$ \\
\hline$(\mathrm{RAO}, 2017 \mathrm{a})$ & $\begin{array}{l}\text { IEEE } \\
\text { Engineering } \\
\text { Management } \\
\text { Rewiew } \\
(\mathrm{FI}=1.46)\end{array}$ & $\begin{array}{l}\text { Baixo custo, envolve design } \\
\text { frugal e engenharia econômica } \\
\text { do produto, e trabalhadores } \\
\text { capazes de compreender e } \\
\text { alavancar a ciência e a } \\
\text { tecnologia para inovações } \\
\text { frugais avançadas. }\end{array}$ & $\begin{array}{l}\text { Propor a Advanced } \\
\text { Frugal Innovation (AFI), } \\
\text { que alavanca } \\
\text { desenvolvimentos em } \\
\text { ciência e tecnologia para } \\
\text { uso frugal no consumo } \\
\text { de recursos. }\end{array}$ & $\begin{array}{l}\text { Conceitual: } \\
\text { revisão } \\
\text { sistemática } \\
\text { da literatura }\end{array}$ & $\begin{array}{l}25 \text { exemplos de inovações } \\
\text { frugais avançadas, na } \\
\text { última década, em setores } \\
\text { que vão de carros para } \\
\text { saúde, armamento e alta } \\
\text { energia física de partículas. }\end{array}$ & $\begin{array}{l}\text { Produtos sofisticados, de baixo } \\
\text { custo, e consumo econômico de } \\
\text { recursos; forças para } \\
\text { desenvolvimento sustentável, por } \\
\text { meio da ciência, tecnologia para } \\
\text { melhoria da sociedade, } \\
\text { preservando os recursos da Terra. }\end{array}$ \\
\hline
\end{tabular}

Fonte: Autora 


\section{INOVAÇÃO FRUGAL E ECOINOVAÇÃO}

\begin{tabular}{|c|c|c|c|c|c|c|}
\hline Artigo & Journal & $\begin{array}{l}\text { Descrição de inovação } \\
\text { frugal }\end{array}$ & Foco Principal & Tipo de Estudo & Amostra/Dados & $\begin{array}{l}\text { Transversalidade } \\
\text { com conceito de } \\
\text { ecoinovação }\end{array}$ \\
\hline $\begin{array}{l}\text { (SHARMA; } \\
\text { IYER, 2012) }\end{array}$ & $\begin{array}{l}\text { Industrial } \\
\text { Marketing } \\
\text { Management } \\
(\mathrm{FI}=3.678)\end{array}$ & $\begin{array}{l}\text { Abordagens inovadoras em } \\
\text { ambientes escassos em } \\
\text { recursos, com produtos de } \\
\text { menor preço, acessíveis a } \\
\text { clientes finais. }\end{array}$ & $\begin{array}{l}\text { Argumentar que abordagens } \\
\text { de desenvolvimento de } \\
\text { produtos com restrição, } \\
\text { observadas em países } \\
\text { emergentes, como China e } \\
\text { Índia, têm o potencial de } \\
\text { mudar os modelos } \\
\text { tradicionais de } \\
\text { desenvolvimento de produtos } \\
\text { verdes. }\end{array}$ & $\begin{array}{l}\text { Conceitual: meta- } \\
\text { análise }\end{array}$ & $\begin{array}{l}22 \text { artigos de } \\
\text { engenharia frugal, } \\
\text { inovação frugal e } \\
\text { restrição de recursos. }\end{array}$ & $\begin{array}{l}\text { A inovação frugal } \\
\text { pode contribuir para o } \\
\text { estabelecimento de } \\
\text { uma cadeia de } \\
\text { fornecimento verde e } \\
\text { o desenvolvimento de } \\
\text { produtos verdes. }\end{array}$ \\
\hline $\begin{array}{l}\text { (LEVÄNEN } e t \\
\text { al., 2016) }\end{array}$ & $\begin{array}{l}\text { Sustainability } \\
(\mathrm{FI}=2.075)\end{array}$ & $\begin{array}{l}\text { São soluções inteligentes e } \\
\text { acessíveis para problemas ou } \\
\text { demanda condicionada por } \\
\text { restrições de recursos. }\end{array}$ & $\begin{array}{l}\text { Avaliar a sustentabilidade de } \\
\text { quatro inovações frugais dos } \\
\text { setores de água e energia, por } \\
\text { meio de indicadores } \\
\text { extraídos dos objetivos de } \\
\text { desenvolvimento sustentável } \\
\text { das Nações Unidas. }\end{array}$ & $\begin{array}{l}\text { Conceitual: revisão } \\
\text { sistemática da } \\
\text { literatura e análise de } \\
\text { casos no setor de água } \\
\text { e energia. }\end{array}$ & $\begin{array}{l}\text { Uso de } 115 \text { artigos, } \\
\text { coletados em bases de } \\
\text { dados (Web of } \\
\text { Science, Scopus, } \\
\text { EBSCO, Google } \\
\text { Scholars e SSRN } \\
\text { (Social Science } \\
\text { Research), } \\
\text { e três livros, aplicando } \\
\text { os nove indicadores } \\
\text { de objetivos de } \\
\text { desenvolvimento } \\
\text { sustentável. }\end{array}$ & $\begin{array}{l}\text { Nos setores de energia } \\
\text { e água, as inovações } \\
\text { frugais podem ser } \\
\text { vistas como mais } \\
\text { sustentáveis do que as } \\
\text { soluções existentes. }\end{array}$ \\
\hline $\begin{array}{l}\text { (PISONI; } \\
\text { MICHELINI; } \\
\text { MARTIGNONI, } \\
\text { 2018) }\end{array}$ & $\begin{array}{l}\text { Journal of } \\
\text { Cleaner } \\
\text { Production } \\
(\mathrm{FI}=6.395)\end{array}$ & $\begin{array}{l}\text { As definições evoluíram de } \\
\text { orientadas por características } \\
\text { dos produtos para orientadas } \\
\text { pelos critérios de redução de } \\
\text { custos, funcionalidade } \\
\text { central, facilidade de uso, e } \\
\text { elevado nível de } \\
\text { performance. }\end{array}$ & $\begin{array}{l}\text { Explorar como o conceito de } \\
\text { inovação frugal se } \\
\text { desenvolveu ao longo dos } \\
\text { anos; analisar as principais } \\
\text { conclusões da literatura } \\
\text { existente, identificar lacunas } \\
\text { e indicar novas direções para } \\
\text { futuras pesquisas. }\end{array}$ & $\begin{array}{l}\text { Conceitual: revisão } \\
\text { sistemática de } \\
\text { literatura }\end{array}$ & $\begin{array}{l}\text { Analisados } 113 \\
\text { artigos, publicados } \\
\text { desde } 1990 .\end{array}$ & $\begin{array}{l}\text { A inovação frugal é } \\
\text { uma contribuição } \\
\text { relevante para a } \\
\text { implementação de } \\
\text { inovações verdes para } \\
\text { mercados } \\
\text { desenvolvidos e em } \\
\text { desenvolvimento. }\end{array}$ \\
\hline
\end{tabular}

Fonte: Autora 


\section{INOVAÇÃO FRUGAL E ECOINOVAÇÃO}

\begin{tabular}{|c|c|c|c|c|c|c|}
\hline Artigo & Journal & Descrição de inovação frugal & Foco Principal & Tipo de Estudo & Amostra/Dados & $\begin{array}{l}\text { Transversalidade com } \\
\text { conceito de ecoinovação }\end{array}$ \\
\hline $\begin{array}{l}\text { (HYVÄRINE } \\
\text { N; } \\
\text { KESKINEN; } \\
\text { VARIS, 2016) }\end{array}$ & $\begin{array}{l}\text { Sustainability } \\
(\mathrm{FI}=2.075)\end{array}$ & $\begin{array}{l}\text { Fornecem produtos e serviços de } \\
\text { qualidade, acessíveis, focados na } \\
\text { simplicidade, bons (suficientes) } \\
\text { para consumidores com recursos } \\
\text { limitados. }\end{array}$ & $\begin{array}{l}\text { Analisar o potencial das } \\
\text { inovações frugais como } \\
\text { um meio para o setor } \\
\text { privado se engajar em } \\
\text { desafios de } \\
\text { desenvolvimento } \\
\text { relacionados à água. }\end{array}$ & $\begin{array}{l}\text { Conceitual: revisão } \\
\text { sistemática de literatura } \\
\text { e estudo de caso. }\end{array}$ & $\begin{array}{l}\text { Caso do } \\
\text { desenvolvimento de } \\
\text { uma inovação de } \\
\text { água frugal - um } \\
\text { novo tipo de filtro de } \\
\text { água - para } \\
\text { consumidores de } \\
\text { baixa renda, na } \\
\text { Tanzânia. }\end{array}$ & $\begin{array}{l}\text { Devido ao seu foco em } \\
\text { soluções acessíveis, } \\
\text { ancoradas na simplicidade, } \\
\text { são um meio com aptidão } \\
\text { para o setor privado, no } \\
\text { engajamento em desafios de } \\
\text { desenvolvimento } \\
\text { relacionados à água. }\end{array}$ \\
\hline $\begin{array}{l}\text { (TIWARI; } \\
\text { HERSTATT, } \\
\text { 2012a) }\end{array}$ & $\begin{array}{l}\text { Technology } \\
\text { and } \\
\text { Innovation } \\
\text { Management } \\
\text { (Working } \\
\text { Paper) }\end{array}$ & $\begin{array}{l}\text { Busca minimizar o uso de } \\
\text { recursos materiais e financeiros } \\
\text { na cadeia de valor completa (para } \\
\text { reduzir o custo, com o fim de } \\
\text { cumprir ou até superar padrões } \\
\text { aceitáveis de qualidade). }\end{array}$ & $\begin{array}{l}\text { Avaliar o potencial da } \\
\text { Índia como um mercado } \\
\text { líder para inovações } \\
\text { frugais econômicas. }\end{array}$ & $\begin{array}{l}\text { Conceitual: revisão } \\
\text { sistemática de literatura } \\
\text { e estudo de caso. }\end{array}$ & $\begin{array}{l}\text { Casos de inovações } \\
\text { frugais na Índia: Tata } \\
\text { Ace, } \\
\text { Tata Swach, Vortex } \\
\text { Gramateller e Godrej } \\
\text { ChotuKool. }\end{array}$ & $\begin{array}{l}\text { Os terminais automatizados } \\
\text { (ATM - Automated Teller } \\
\text { Machines), que funcionam } \\
\text { por meio de energia solar, da } \\
\text { empresa indiana Vortex, são } \\
\text { resultado de solução frugal. }\end{array}$ \\
\hline $\begin{array}{l}\text { (BREM; } \\
\text { IVENS, } \\
\text { 2013a) }\end{array}$ & $\begin{array}{l}\text { Journal of } \\
\text { Technology } \\
\text { Management } \\
\text { for } \\
\text { Growing } \\
\text { Economies }\end{array}$ & $\begin{array}{l}\text { Produtos com vantagens de custo, } \\
\text { em comparação com as soluções } \\
\text { existentes. Normalmente, não } \\
\text { possuem recursos tecnológicos } \\
\text { sofisticados, mas atendem às } \\
\text { necessidades básicas do cliente. }\end{array}$ & $\begin{array}{l}\text { Oferecer uma visão geral } \\
\text { da pesquisa nas áreas de } \\
\text { inovação frugal/reversa e } \\
\text { sustentabilidade; gestão } \\
\text { de sustentabilidade e } \\
\text { construtos de } \\
\text { desempenho. }\end{array}$ & $\begin{array}{l}\text { Conceitual: meta- } \\
\text { análise }\end{array}$ & $\begin{array}{l}\text { Meta-análise; artigos } \\
\text { de inovação reversa e } \\
\text { inovação frugal. }\end{array}$ & $\begin{array}{l}\text { Reduzir a quantidade e o } \\
\text { tipo de recursos necessários } \\
\text { para a produção de uma } \\
\text { oferta de mercado, } \\
\text { melhorando a performance } \\
\text { de sustentabilidade nas } \\
\text { dimensões do Triple- } \\
\text { Bottom-Line. }\end{array}$ \\
\hline (BREM, 2017) & $\begin{array}{l}\text { IEEE } \\
\text { Engineering } \\
\text { Management } \\
\text { Review (FI = } \\
1.46)\end{array}$ & $\begin{array}{l}\text { Além do conceito de inovações de } \\
\text { baixo custo, é focada na utilização } \\
\text { dos recursos e inovações } \\
\text { sustentáveis, com proposições de } \\
\text { maior valor (melhor qualidade, } \\
\text { acessibilidade etc.). }\end{array}$ & $\begin{array}{l}\text { Demonstrar a mudança } \\
\text { contextual na } \\
\text { compreensão e na } \\
\text { exploração da inovação } \\
\text { frugal ao longo dos anos. }\end{array}$ & $\begin{array}{l}\text { Conceitual: meta- } \\
\text { análise }\end{array}$ & $\begin{array}{l}\text { Artigos de inovação } \\
\text { de restrição de } \\
\text { recursos (frugal, } \\
\text { grassroots, reversa, } \\
\text { custos, indigenous e } \\
\text { Ghandian). }\end{array}$ & $\begin{array}{l}\text { Para direções futuras, a } \\
\text { expectativa é que a inovação } \\
\text { frugal tenha uma alta } \\
\text { habilidade para impulsionar } \\
\text { o crescimento sustentável } \\
\text { dos negócios e das nações, } \\
\text { sem danos ao planeta. }\end{array}$ \\
\hline
\end{tabular}

Fonte: Autora. 


\section{INOVAÇÃO FRUGAL E ECOINOVAÇÃO}

\begin{tabular}{|c|c|c|c|c|c|c|}
\hline Artigo & Journal & Descrição de inovação frugal & Foco Principal & $\begin{array}{l}\text { Tipo de } \\
\text { Estudo }\end{array}$ & Amostra/Dados & $\begin{array}{l}\text { Transversalidade com } \\
\text { conceito de ecoinovação }\end{array}$ \\
\hline $\begin{array}{l}\text { (ROSCA; } \\
\text { REEDY; } \\
\text { BENDUL, } \\
2018)\end{array}$ & $\begin{array}{l}\text { The } \\
\text { European } \\
\text { Journal of } \\
\text { Development } \\
\text { Research } \\
(\mathrm{FI}=1.440)\end{array}$ & $\begin{array}{l}\text { Produtos, serviços e sistemas } \\
\text { projetados, que tentam minimizar o } \\
\text { uso de recursos materiais e financeiros } \\
\text { nas várias etapas da cadeia de valor, } \\
\text { para reduzir sua aquisição inicial e os } \\
\text { custos totais do ciclo de vida, exigindo } \\
\text { níveis mais baixos de recursos naturais } \\
\text { e financeiros da sociedade (TIWARI; } \\
\text { HERSTATT, 2012a). }\end{array}$ & $\begin{array}{l}\text { Destacar abordagens e } \\
\text { condições nas quais } \\
\text { inovações frugais podem } \\
\text { conduzir ao } \\
\text { desenvolvimento } \\
\text { sustentável, especialmente } \\
\text { em relação aos diferentes } \\
\text { tipos de atores do setor } \\
\text { privado. }\end{array}$ & $\begin{array}{l}\text { Conceitual: } \\
\text { revisão } \\
\text { sistemática } \\
\text { da literatura }\end{array}$ & $\begin{array}{l}\text { Utilizados } 64 \\
\text { artigos, } \\
\text { publicados entre } \\
2000 \text { e } 2006, \\
\text { sobre inovação } \\
\text { frugal. }\end{array}$ & $\begin{array}{l}\text { Foco no uso frugal de recursos, } \\
\text { inclusão de atores de baixa } \\
\text { renda. Sua natureza de reunir as } \\
\text { partes interessadas oferece } \\
\text { potencial para caminhos de } \\
\text { desenvolvimento sustentável. } \\
\text { Setores de energia e saúde são } \\
\text { chave para as inovações frugais } \\
\text { sustentáveis. }\end{array}$ \\
\hline $\begin{array}{l}\text { (KHAN, } \\
2016)\end{array}$ & $\begin{array}{l}\text { Sustainability } \\
(\mathrm{FI}=2.075)\end{array}$ & $\begin{array}{l}\text { Usa o conceito de simplificação: } \\
\text { menos é mais. São caracterizadas pela } \\
\text { acessibilidade, robustez, facilidade de } \\
\text { uso, escalabilidade e uma proposta de } \\
\text { valor atrativa (TIWARI; HERSTATT, } \\
\text { 2012a). }\end{array}$ & $\begin{array}{l}\text { Encontrar as conexões } \\
\text { entre os dois conceitos de } \\
\text { sustentabilidade social e } \\
\text { inovação frugal, revisando } \\
\text { a literatura existente sobre } \\
\text { ambos os campos. }\end{array}$ & $\begin{array}{l}\text { Conceitual: } \\
\text { revisão } \\
\text { sistemática } \\
\text { da literatura }\end{array}$ & $\begin{array}{l}\text { Utilizadas } 91 \\
\text { publicações da } \\
\text { literatura de } \\
\text { sustentabilidade } \\
\text { social, e } 73 \text { da } \\
\text { literatura de } \\
\text { inovação frugal, } \\
\text { sendo, no total, } \\
164 \text { publicações. }\end{array}$ & $\begin{array}{l}\text { Possibilita a realização de metas } \\
\text { de sustentabilidade social, pois } \\
\text { é um dos principais pilares do } \\
\text { desenvolvimento sustentável } \\
\text { das organizações e de países. } \\
\text { Motivar o uso da eletricidade, } \\
\text { gerada por turbinas de energia } \\
\text { movidas a vento, é uma } \\
\text { mudança comportamental } \\
\text { positiva, que promove o } \\
\text { comportamento ecológico. }\end{array}$ \\
\hline $\begin{array}{l}\text { (BHATTI, } \\
\text { 2012) }\end{array}$ & $\begin{array}{l}\text { Academy of } \\
\text { Management } \\
(\mathrm{FI}=7.417)\end{array}$ & $\begin{array}{l}\text { Busca, além dos custos, criar valor } \\
\text { para os mercados, podendo redefinir } \\
\text { modelos de negócios, reconfigurar } \\
\text { cadeias de valor e redesenhar produtos } \\
\text { para uso dos recursos em diferentes } \\
\text { formas. Cria mercados mais inclusivos } \\
\text { para usuários com restrições de } \\
\text { acessibilidade, de maneira escalonável } \\
\text { e sustentável. }\end{array}$ & $\begin{array}{l}\text { Desenvolver um modelo } \\
\text { teórico de inovação frugal, } \\
\text { para aplicação de teorias } \\
\text { existentes a contextos de } \\
\text { mercados emergentes. }\end{array}$ & $\begin{array}{l}\text { Conceitual: } \\
\text { revisão } \\
\text { sistemática } \\
\text { da literatura }\end{array}$ & N/A & $\begin{array}{l}\text { Frugalidade trata de como algo } \\
\text { é usado para a redução ou a } \\
\text { eliminação de resíduos. }\end{array}$ \\
\hline
\end{tabular}

Fonte: Autora. 
INOVAÇÃO FRUGAL E ECOINOVAÇÃO

\begin{tabular}{|c|c|c|c|c|c|c|}
\hline Artigo & Journal & $\begin{array}{l}\text { Descrição de } \\
\text { inovação frugal }\end{array}$ & Foco Principal & $\begin{array}{l}\text { Tipo de } \\
\text { Estudo }\end{array}$ & Amostra/Dados & $\begin{array}{l}\text { Transversalidade com conceito } \\
\text { de ecoinovação }\end{array}$ \\
\hline $\begin{array}{l}\text { (BHATTI; } \\
\text { VENTRESCA, } \\
\text { 2013) }\end{array}$ & $\begin{array}{l}\text { SSRN - Social } \\
\text { Science } \\
\text { Research } \\
\text { Network } \\
\text { (Working } \\
\text { Paper) }\end{array}$ & $\begin{array}{l}\text { É uma questão de } \\
\text { redesenhar produtos e } \\
\text { processos para cortar } \\
\text { custos } \\
\text { desnecessários. }\end{array}$ & $\begin{array}{l}\text { Mapear o surgimento } \\
\text { do mercado de } \\
\text { inovação frugal, os } \\
\text { direcionadores e a } \\
\text { criação de ecossistema } \\
\text { que envolve diferentes } \\
\text { atores para criar valor } \\
\text { às populações carentes. }\end{array}$ & $\begin{array}{l}\text { Análise } \\
\text { bibliométrica }\end{array}$ & $\begin{array}{l}\text { Busca bibliométrica, no } \\
\text { Google Acadêmico, dos } \\
\text { termos de inovação frugal } \\
\text { ( } 66 \text { artigos), e palavras } \\
\text { complementares. }\end{array}$ & $\begin{array}{l}\text { Está em profundo contraste com } \\
\text { produtos, serviços e processos } \\
\text { tipicamente ineficientes, em } \\
\text { termos de energia, matéria-prima; } \\
\text { e ambientalmente ineficientes, } \\
\text { produzidos frequentemente nas } \\
\text { economias desenvolvidas } \\
\text { avançadas (GUPTA; WANG, } \\
\text { 2009). }\end{array}$ \\
\hline $\begin{array}{l}\text { (WEYRAUCH; } \\
\text { HERSTATT, } \\
\text { 2016) }\end{array}$ & $\begin{array}{l}\text { Journal of } \\
\text { Frugal } \\
\text { Innovation } \\
(\mathrm{FI}=0,832)\end{array}$ & $\begin{array}{l}\text { Atendem } \\
\text { simultaneamente aos } \\
\text { critérios de redução } \\
\text { substancial de custos, } \\
\text { concentração em } \\
\text { funcionalidades } \\
\text { básicas e nível de } \\
\text { desempenho } \\
\text { otimizado. }\end{array}$ & $\begin{array}{l}\text { Estabelecer critérios } \\
\text { para diferenciar a } \\
\text { inovação frugal de } \\
\text { outros tipos de } \\
\text { inovação. }\end{array}$ & $\begin{array}{l}\text { Conceitual: } \\
\text { revisão } \\
\text { sistemática da } \\
\text { literatura e } \\
\text { entrevistas. }\end{array}$ & $\begin{array}{l}\text { Realizada revisão } \\
\text { bibliométrica nas bases } \\
\text { EBSCO e ISI Web } \\
\text { of Science (total de } 62 \\
\text { artigos), e entrevistas com } \\
45 \text { gestores de empresas e } \\
\text { pesquisadores. }\end{array}$ & $\begin{array}{l}\text { Não envolve necessariamente } \\
\text { escalabilidade e sustentabilidade. } \\
\text { Inovações frugais podem } \\
\text { contribuir para a sustentabilidade, } \\
\text { minimizando o uso de recursos. } \\
\text { No entanto, ser sustentável, } \\
\text { muitas vezes, não é o foco } \\
\text { principal. }\end{array}$ \\
\hline $\begin{array}{l}\text { (PRAHALAD, } \\
\text { 2012) }\end{array}$ & $\begin{array}{l}\text { Journal of } \\
\text { Production } \\
\text { Innovation } \\
\text { Management } \\
(\mathrm{FI}=4.305)\end{array}$ & $\begin{array}{l}\text { Atributos das } \\
\text { inovações para a base } \\
\text { da pirâmide: } \\
\text { conscientização, } \\
\text { acessibilidade e } \\
\text { disponibilidade. }\end{array}$ & $\begin{array}{l}\text { Identificar os mercados } \\
\text { da base da pirâmide } \\
\text { (BOP) como uma nova } \\
\text { fonte de inovação } \\
\text { radical. }\end{array}$ & Estudo de caso & $\begin{array}{l}\text { Estudo de caso de fogão de } \\
\text { biomassa, para os mais } \\
\text { pobres, da zona rural da } \\
\text { Índia. }\end{array}$ & $\begin{array}{l}\text { Para a solução do sistema de } \\
\text { cozimento de alimentos na área } \\
\text { rural da Índia, o produto cumpriu } \\
\text { seus compromissos funcionais de } \\
\text { ser livre de fumaça e possuir } \\
\text { eficiência energética. }\end{array}$ \\
\hline $\begin{array}{l}\text { (BOCKEN; } \\
\text { SHORT, 2016) }\end{array}$ & $\begin{array}{l}\text { Environmental } \\
\text { Innovation } \\
\text { and Societal } \\
\text { Transitions } \\
(\mathrm{FI}=7.514)\end{array}$ & $\begin{array}{l}\text { O design e o uso do } \\
\text { produto estão focados } \\
\text { em reduzir o uso de } \\
\text { recursos, } \\
\text { principalmente em } \\
\text { países de baixa renda } \\
\text { ou não } \\
\text { desenvolvidos. }\end{array}$ & $\begin{array}{l}\text { Investigar como as } \\
\text { empresas podem usar a } \\
\text { suficiência como um } \\
\text { direcionador para a } \\
\text { inovação. }\end{array}$ & $\begin{array}{l}\text { Estudos de } \\
\text { caso }\end{array}$ & $\begin{array}{l}\text { Seis estudos de caso: Vitsoe } \\
\text { (móveis), Brunello Cucinelli } \\
\text { (roupas), Patagonia (roupas), } \\
\text { Kyocera (cerâmica), } \\
\text { Riversimple (automotivo), } \\
\text { Reduse (spin-off da } \\
\text { Universidade de } \\
\text { Cambridge). }\end{array}$ & $\begin{array}{l}\text { Atende aos modelos de } \\
\text { suficiência no ciclo de vida dos } \\
\text { produtos, ao beneficiar clientes na } \\
\text { redução de custo na fase de uso, } \\
\text { ou nos modelos de menor lucro, } \\
\text { em empresas sociais. }\end{array}$ \\
\hline
\end{tabular}

Fonte: Autora. 
INOVAÇÃO FRUGAL E ECOINOVAÇÃO

\begin{tabular}{|c|c|c|c|c|c|c|}
\hline Artigo & Journal & $\begin{array}{l}\text { Descrição de inovação } \\
\text { frugal }\end{array}$ & Foco Principal & $\begin{array}{l}\text { Tipo de } \\
\text { Estudo }\end{array}$ & Amostra/Dados & $\begin{array}{l}\text { Transversalidade com conceito } \\
\text { de ecoinovação }\end{array}$ \\
\hline $\begin{array}{l}\text { (COLLEDANI } \\
\text { et al., 2016) }\end{array}$ & $\begin{array}{l}\text { ProcediaCIRP } \\
(\mathrm{SJR}=0.725)\end{array}$ & $\begin{array}{l}\text { Processo de adaptação de } \\
\text { bens e sua produção às } \\
\text { necessidades dos clientes- } \\
\text { alvo. Descobre novos } \\
\text { modelos de negócios, } \\
\text { reconfigura cadeias de } \\
\text { valor e reprojeta produtos, } \\
\text { com base no uso } \\
\text { inteligente de recursos e } \\
\text { alta eficiência industrial. }\end{array}$ & $\begin{array}{l}\text { Formalizar uma estrutura } \\
\text { para apoiar o design de } \\
\text { produtos e serviços, e a } \\
\text { caracterização do modelo } \\
\text { de negócios, no contexto } \\
\text { da inovação frugal. }\end{array}$ & $\begin{array}{l}\text { Conceitual: } \\
\text { framework } \\
\text { de modelo } \\
\text { de negócios }\end{array}$ & $\begin{array}{l}\text { Analisados três } \\
\text { cenários industriais } \\
\text { reais, na aeronáutica, } \\
\text { nos aparelhos } \\
\text { domésticos e na } \\
\text { indústria de } \\
\text { maquinaria, no âmbito } \\
\text { do projeto financiado } \\
\text { europeu H2020 } \\
\text { "ProRegio". }\end{array}$ & $\begin{array}{l}\text { As restrições ambientais/recursos } \\
\text { podem impulsionar a inovação de } \\
\text { produtos e serviços, aumentando } \\
\text { sua acessibilidade e performances } \\
\text { de sustentabilidade, durante o seu } \\
\text { design (RAO, 2013b), de acordo } \\
\text { com o contexto de mercado. }\end{array}$ \\
\hline $\begin{array}{l}\text { (HOSSAIN; } \\
\text { SIMULA; } \\
\text { HALME; } \\
2016)\end{array}$ & $\begin{array}{l}\text { Technology in } \\
\text { Society } \\
(\mathrm{FI}=1.670)\end{array}$ & $\begin{array}{l}\text { Refere-se a inovações em } \\
\text { produtos, serviços ou } \\
\text { combinações acessíveis, } \\
\text { sustentáveis, fáceis de } \\
\text { usar, em ambiente de } \\
\text { escassez de recursos. }\end{array}$ & $\begin{array}{l}\text { Explorar os diferentes } \\
\text { padrões de difusão da } \\
\text { inovação frugal. }\end{array}$ & $\begin{array}{l}\text { Estudo de } \\
\text { casos }\end{array}$ & $\begin{array}{l}\text { Analisados quatro } \\
\text { estudos de casos na } \\
\text { Índia: ChotuKool, Tata } \\
\text { Nano, GE's Ultrasound } \\
\text { Machine, e Vortex } \\
\text { Gramateller. }\end{array}$ & $\begin{array}{l}\text { Para países em desenvolvimento } \\
\text { e desenvolvidos, como solução ao } \\
\text { crescimento populacional, o } \\
\text { aquecimento global e a crescente } \\
\text { demanda por sustentabilidade e } \\
\text { melhor utilização de recursos. }\end{array}$ \\
\hline$(\mathrm{RAO}, 2017 \mathrm{~b})$ & $\begin{array}{l}\text { Heliyon } \\
(\mathrm{SJR}=0.426)\end{array}$ & $\begin{array}{l}\text { Inovações com estrutura } \\
\text { sem frescura; realização } \\
\text { restringida, em parte, por } \\
\text { recursos materiais mais } \\
\text { escassos (THE } \\
\text { ECONOMIST, 2010). }\end{array}$ & $\begin{array}{l}\text { Propor o fator de inovação } \\
\text { frugal, que pode ser usado } \\
\text { em ecodesign e que aborda } \\
\text { os rigores do processo de } \\
\text { design clássico e a } \\
\text { quantificação da economia } \\
\text { em materiais que entram } \\
\text { em um produto. }\end{array}$ & $\begin{array}{l}\text { Conceitual: } \\
\text { revisão } \\
\text { sistemática } \\
\text { de literatura }\end{array}$ & N/A & $\begin{array}{l}\text { O uso de um fator de inovação } \\
\text { frugal das inovações pode mudar } \\
\text { a filosofia de design clássico e } \\
\text { criar produtos que estejam } \\
\text { sincronizados com princípios e } \\
\text { políticas para mitigar os impactos } \\
\text { da mudança climática e da } \\
\text { carência de recursos. }\end{array}$ \\
\hline $\begin{array}{l}\text { (SHAN; } \\
\text { KHAN, 2016) }\end{array}$ & $\begin{array}{l}\text { Sustainability } \\
(\mathrm{FI}=2.075)\end{array}$ & $\begin{array}{l}\text { Reduzir custos ou alcançar } \\
\text { capacidades frugais } \\
\text { (SHARMA; IYER, 2012) } \\
\text { é o primeiro passo para } \\
\text { alcançar a inovação } \\
\text { reversa. }\end{array}$ & $\begin{array}{l}\text { Entender como a inovação } \\
\text { reversa foi difundida com } \\
\text { sucesso nas estratégias de } \\
\text { desenvolvimento de } \\
\text { produto e mercado da } \\
\text { Philips Inc. }\end{array}$ & $\begin{array}{l}\text { Estudo de } \\
\text { caso único }\end{array}$ & $\begin{array}{l}\text { Analisado o caso de } \\
\text { difusão da inovação } \\
\text { reversa da Philips Inc., } \\
\text { na Índia. }\end{array}$ & $\begin{array}{l}\text { Por meio da inovação frugal, } \\
\text { soluções voltadas à } \\
\text { sustentabilidade podem ser } \\
\text { transferidas de mercados } \\
\text { emergentes para mercados } \\
\text { desenvolvidos (inovação reversa). }\end{array}$ \\
\hline
\end{tabular}


APÊNDICE G - SOLUÇÕES ECO INOVADORAS E INOVAÇ̃̃o FRUGAL 


\section{SOLUÇÕES ECO INOVADORAS E INOVAÇÃO FRUGAL}

\begin{tabular}{|c|c|c|c|}
\hline Artigo & País/Empresa & Solução & Características ecofrugais \\
\hline $\begin{array}{l}\text { DRESSLER; BUCHER, } \\
2018\end{array}$ & $\begin{array}{l}\text { África do Sul } \\
\text { Moladi Building } \\
\text { Systems, 5, Star Stoves, } \\
\text { Mellowcabs e SavvyLoo. }\end{array}$ & $\begin{array}{l}\text { Uso de resíduos para geração de } \\
\text { biocombustíveis. } \\
\text { Geração de energia solar }\end{array}$ & $\begin{array}{l}\text { Baixo custo; foco em funcionalidade principal; acessível à } \\
\text { população de baixa renda; uso de quantidade mínima de recursos; } \\
\text { são mais sustentáveis do ponto de vista ecológico, do que como } \\
\text { soluções convencionais disponíveis. }\end{array}$ \\
\hline $\begin{array}{l}\text { BHATTI; VENTRESCA, } \\
\text { 2013; GUPTA } \text { et al., 2013; } \\
\text { PANSERA; OWEN, 2014; } \\
\text { LEVÄNEN } \text { et al., } 2016\end{array}$ & $\begin{array}{l}\text { Índia } \\
\text { Husk Power System } \\
\text { (HPS) }\end{array}$ & $\begin{array}{l}\text { Postes de isolamento de redes de } \\
\text { distribuição (bambu), para levar } \\
\text { eletricidade acessível às aldeias da Índia. } \\
\text { Resíduos de casca de arroz como biomassa } \\
\text { para alimentar o gerador. }\end{array}$ & $\begin{array}{l}\text { Baixo custo de geração, distribuição e instalação; tecnologia } \\
\text { desenvolvida para gaseificação de biorresíduos; qualidade do } \\
\text { serviço oferecido; uso mínimo de recursos; desenvolvimento em } \\
\text { colaboração com parcerias locais. }\end{array}$ \\
\hline $\begin{array}{l}\text { (HOSSAIN, 2017; } \\
\text { LEVÄNEN et al., 2016) }\end{array}$ & $\begin{array}{l}\text { Índia } \\
\text { Selco }\end{array}$ & $\begin{array}{l}\text { Produtos para energia solar de pequeno } \\
\text { porte. }\end{array}$ & $\begin{array}{l}\text { Acessível à baixa renda; uso de baterias de chumbo recicladas; } \\
\text { logística reversa das lâmpadas fluorescentes para reciclagem. }\end{array}$ \\
\hline $\begin{array}{l}\text { (URPELAINEN, 2016) } \\
\text { (KUMAR; BHADURI, } \\
\text { 2014). }\end{array}$ & $\begin{array}{l}\text { Índia } \\
\text { Boond Engineering \& } \\
\text { Development }\end{array}$ & $\begin{array}{l}\text { Produtos de energia renovável. Rede de } \\
\text { cinco a } 50 \text { residências interligadas, que } \\
\text { podem se conectar a um par de lâmpadas } \\
\text { LED, um dispositivo de carregamento de } \\
\text { célula, um ventilador e uma TV. }\end{array}$ & $\begin{array}{l}\text { Acessível à baixa renda; uso fonte de energia sustentável; } \\
\text { simplicidade de uso; reuso de materiais. }\end{array}$ \\
\hline $\begin{array}{l}\text { (HOSSAIN, 2017; } \\
\text { PANSERA; OWEN, 2015). }\end{array}$ & $\begin{array}{l}\text { Índia } \\
\text { Grammen Shakti (GS) }\end{array}$ & $\begin{array}{l}\text { Acesso financeiro da população menos } \\
\text { favorecida. Sistemas solares domésticos, } \\
\text { que usam fontes renováveis. Tecnologia de } \\
\text { microgeradores e biocombustíveis. }\end{array}$ & $\begin{array}{l}\text { Baixo custo, menor consumo de matéria-prima, uso de fontes } \\
\text { sustentáveis de energia, acessibilidade, foco em funcionalidade } \\
\text { principal, simplicidade de uso. }\end{array}$ \\
\hline (PANSERA; OWEN, 2014). & Brasil Indalma & $\begin{array}{l}\text { Turbina para uso como hidrelétricas de } \\
\text { pequeno porte, em comunidades rurais e } \\
\text { fazendas privadas. }\end{array}$ & $\begin{array}{l}\text { Foco na funcionalidade principal, baixo custo, acessível para baixa } \\
\text { renda, simplicidade para construção, operação e manutenção, } \\
\text { alternativa sustentável aos riscos ambientais causados por } \\
\text { barragens. }\end{array}$ \\
\hline (PANSERA; OWEN, 2014) & $\begin{array}{l}\text { China } \\
\text { Hangzhou International } \\
\text { Energy Market (Inem) }\end{array}$ & $\begin{array}{l}\text { Sistemas solares fotovoltaicos por menos } \\
\text { de US 3.000, para reduzir o custo da } \\
\text { energia renovável }\end{array}$ & $\begin{array}{l}\text { Custo mais baixo, comparado a alternativas convencionais; redução } \\
\text { do uso de recursos com energia renovável. }\end{array}$ \\
\hline (LEVÄNEN et al., 2016) & $\begin{array}{l}\text { Índia } \\
\text { Tata Swach }\end{array}$ & $\begin{array}{l}\text { Dispositivo de purificação para uso } \\
\text { doméstico, que não requer eletricidade ou } \\
\text { água corrente. A tecnologia de tratamento } \\
\text { é baseada em cinzas de casca de arroz e } \\
\text { nanotecnologia. }\end{array}$ & $\begin{array}{l}\text { Simplicidade; foco funcionalidade principal; uso de alta tecnologia; } \\
\text { mais eficientes energeticamente do que soluções tradicionais; sem } \\
\text { necessidade de eletricidade ou água corrente; e sem gerar resíduo } \\
\text { de produtos químicos para purificação. }\end{array}$ \\
\hline
\end{tabular}

Fonte: Autora. 


\section{SOLUÇÕES ECO INOVADORAS E INOVAÇÃO FRUGAL}

\begin{tabular}{|c|c|c|c|}
\hline Artigo & País/Empresa & Solução & Características ecofrugais \\
\hline (LEVÄNEN et al., 2016) & $\begin{array}{l}\text { Índia } \\
\text { Unilever's Pureit }\end{array}$ & $\begin{array}{l}\text { Processo de purificação da água em quatro estágios: } \\
\text { malha de microfibra para a remoção de partículas } \\
\text { maiores; filtro de carbono para a remoção de } \\
\text { parasitas; dispensador de cloro "Germkill Kit" para } \\
\text { desinfecção; e polidor de carbono para remover o } \\
\text { excesso de cloro e subprodutos de cloração. }\end{array}$ & $\begin{array}{l}\text { Simplicidade; uso de alta tecnologia; atende às normas } \\
\text { internacionais; mais eficientes energeticamente do que soluções } \\
\text { tradicionais; sem necessidade de eletricidade ou água corrente, e } \\
\text { sem gerar resíduo de produtos químicos para purificação. }\end{array}$ \\
\hline $\begin{array}{l}\text { (TIWARI; HERSTATT, } \\
\text { 2012c) }\end{array}$ & $\begin{array}{l}\text { Suécia } \\
\text { Solvatten }\end{array}$ & $\begin{array}{l}\text { Sistema portátil de tratamento de água e aquecedor } \\
\text { solar de água para uso doméstico, em países em } \\
\text { desenvolvimento. }\end{array}$ & $\begin{array}{l}\text { Facilidade de uso; simplicidade; sem uso de produtos químicos e } \\
\text { baterias; baixo custo; colaboração em ecossistemas locais de } \\
\text { inovação. }\end{array}$ \\
\hline
\end{tabular}

Fonte: Autora 